\title{
Aquisição de Conhecimento como Apoio ao Método de Engenharia Reversa FUSION-RE/I
}

\author{
Andrea Padovan Jubileu \\ Orientadora: Profa. Dra. Rosely Sanches
}

Dissertação apresentada ao Instituto de Ciências Matemáticas e de Computação - ICMC-USP, como parte dos requisitos para obtenção do título de Mestre em Ciências - Área: Ciências de Computação e Matemática Computacional.

São Carlos

Novembro/1999 
Aos meus pais, Geraldo e Matilde, meus irmãos Cassiano e Adriano e minhas avós Natália (in memorian) e Ana. 


\section{Agradecimentos}

A DEUS pela graça da vida, pela graça do aprendizado, enfim, por tudo permitir.

Aos meus queridos pais, Geraldo e Matilde, por tanto amor, dedicaçäo, incentivo, por nunca medirem esforços para me ajudar $\theta$ por acreditarem em mim.

Aos meus immãos Cassiano e Adriano pelo carinho, à minha tia do coraçăo Ivanilde que sempre esteve ao meu lado e a todos os meus familiares.

À minha orientadora, Prof. Dr. Rosely Sanches, contribuinte por grande parte de meu amadurecimento profissional e até mesmo pessoal, pela confiança depositada, pelos valiosos conselhos, pela paciência e pela amizade.

A todos os professores que, de alguma forma, contribuíram para o meu aprendizado. Em especial ao Prof. Maldonado, Prof*. Solange e Prof. Rosângela.

À minha grande amiga Ana Lúcia pelo incentivo ao ingresso no programa de mestrado.

Às minhas companheiras de casa: Evelise (obrigada, também, pelos "reikis"), Ellen (obrigada, também, pela atenção em revisar este trabalho), Sarah (Bisquii), Selma e Paula pela amizade e por todos os momentos inesqueciveis que passamos juntas. Em especial à $D^{a}$ Rosinha e à $D^{a}$ Zita pelas liçōes de vida.

Ao Jama pelo carinho, pelo incentivo, pela paciência, e por compreender as minhas ausências.

À Giselle por nossas proveitosas conversas.

Às minhas amigas MarinGirls: Thelma, Valéria, Lú e Nilda (por adoção) pelo companheirismo. Em especial à Tati.

Ao pessoal do Labes: Auri, Cris, Sandra, Rejane, Janaína, Elisa, Ana Paula, Caldas, Quinaia, Simone, Delamaro, Tchelo, Plínio, Daniela, Vangrei, William, Mayb, Waine, Jusane, André, Rurik, Paulo (Leonardo), Gelza e Willie. Em especial ao Adenilso pelo auxílio em um dos estudos de caso realizado e pelas preciosas dicas, e à Rosana que sempre esteve à disposição para esclarecer minhas dúvidas.

Aos amigos: Marisa, Marilde, Marília, Jaque, Ana Elisa, Ângelo, Valêncio, Roberto, Tavinho, Araxá, Dani Bola, Dani, Júlio. Elder, Boni, Taboca, Pissioli, Mac, Cláudia, Maristela, Kutova, Emesto (Cabelinho), Carlos Eduardo, Aletéia, Alessandra, Omar, Marco, Luls Carlos, Chandler, Paulo, Tanão, Enzo, Larissa, Minam Renata, Mira, em especial ao Matite; aos amigos de Prudente: Emerson, Marega, Ana Claudia, André, Silvio, Shiro, Rogério e Ronaldo, Camiel, Célio, Giovana, Melissa, Aglaê, Cássia e Serginho e às minhas amigas de Venceslau: Adriane, Angélica, Haline, Clerisa, Aline, Cristiane e Cibele.

Às meninas da seção de Pós: Laura, Marília e Beth, e a todos os funcionários do ICMC, em especial à Maria (da Biblioteca), por toda simpatia e atenção dispensados.

A todos que, de alguma forma, estiveram ao meu lado durante o desenvolvimento deste trabalho.

Ao CNPq e a UNIFRAN pelo apoio financeiro. 


\section{Resumo}

Este trabalho apresenta um procedimento de auxilio ao primeiro passo do método de engenharia reversa FUSION-RE/ - obtenção de informações sobre o sistema. Esse procedimento compreende um processo para a criação de uma base de conhecimento (Processo de Aquisição de Conhecimento IPAIA, instanciado para o domínio de engenharia reversa) e diretrizes para a utilização dessa base de conhecimento na construção de visöes funcionais do sistema. 


\begin{abstract}
This work presents a procedure to help the first step of the FUSION-RE/I reverse engineering method - acquisition of system's information. This procedure comprises a process to create a knowledge base (IPAIA Knowledge Acquisition Process applied to reverse engineening domain) and guidelines for using this knowledge base to construct functional visions of the system.
\end{abstract}




\section{SUMÁRIO}

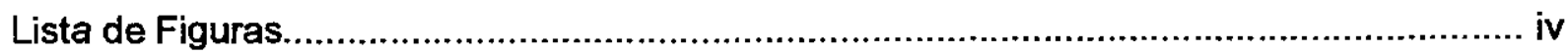

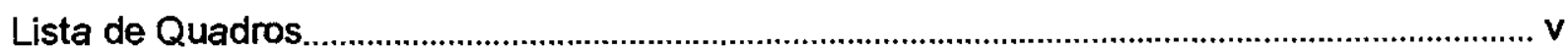

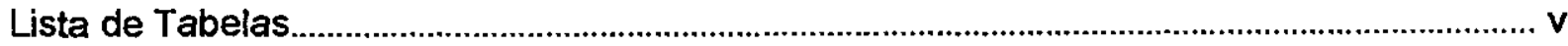

CAPÍTULO 1 - INTRODUÇÃO

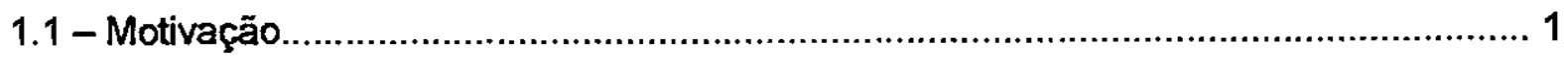

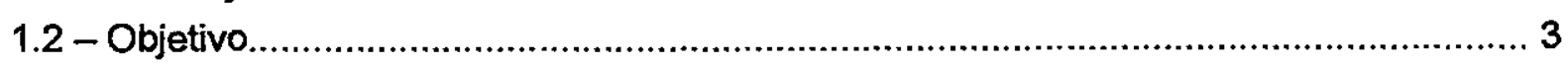

1.3 - Organização do Trabalho.................................................................................... 3

\section{CAPITULO 2 - ENGENHARIA REVERSA}

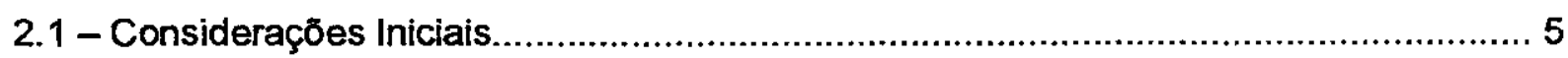

2.2 - Conceitos de Engenharia Reversa................................................................ 5

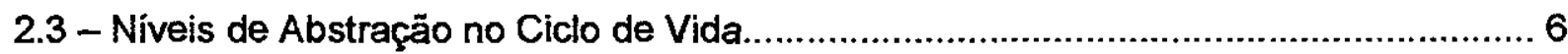

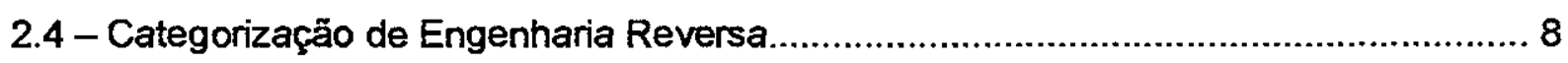

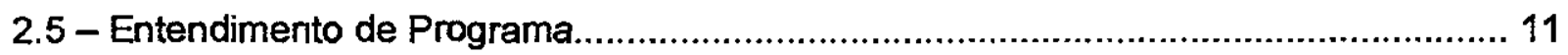

2.5.1 - Método de Engenharia Reversa FUSION-REII........................................ 13

2.5.2 - Modelo de Biggerstaff para o Entendimento de Programa......................... 15

2.5.3 - Modelo de Mayrhauser para o Entendimento de Programa....................... 19

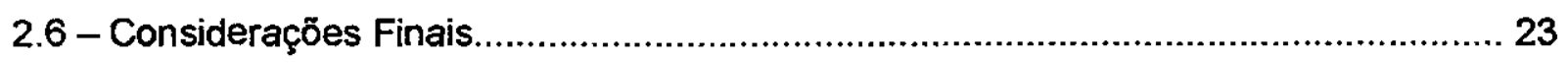

\section{CAPITULO 3 - AQUISIÇÃO DE CONHECIMENTO}

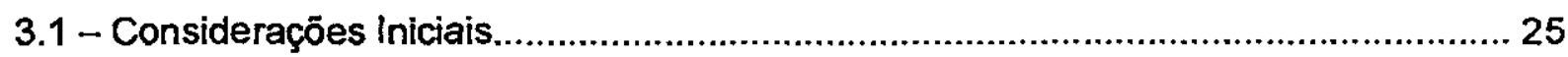

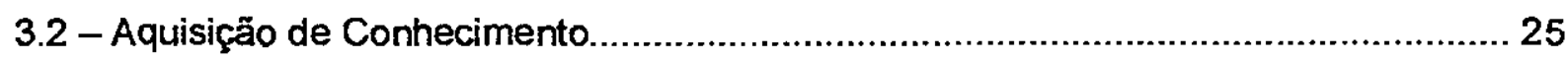

3.3 - Técnicas de Aquisição de Conhecimento ......................................................... 27

3.4 - Formas de Representação do Conhecimento................................................... 34

3.5 - Problemas Típicos Ocorridos Durante a Aquisição de Conhecimento Explicito........ 39

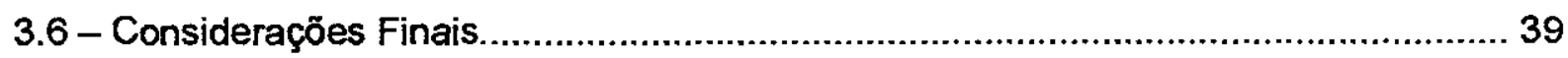

CAPITULO 4 - PROCESSO DE AQUISIÇÃO DE CONHECIMENTO

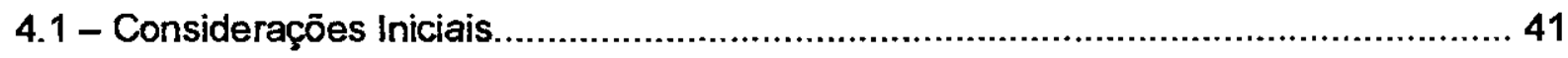

4.2 - Processo de Aquisição de Conhecimento.......................................................... 41

4.3 - Processo IPAIA Instanciado para o Dominio de Engenharia Reversa...................... 46

4.3.1 - Fase 1 - Início do Processo de Aquisição de Conhecimento...................... 47

4.3.2 - Ciclo Brainstorming do Processo IPAIA Instanciado para o Domínio de Engenharia Reversa.

4.3.3 - Ciclo Rastreamento de Processo do Processo IPAIA Instanciado para o Domínio de Engenharia Reversa. 
4.3.4 - Ciclo Entrevista Estruturada do Processo IPAIA Instanciado para o

Domínio de Engenharia Reversa.......................................................... 59

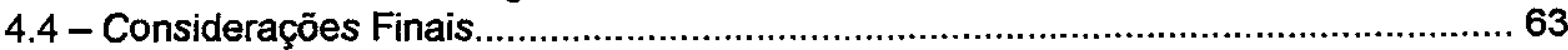

\section{CAPÍTULO 5 - DIRETRIZES PARA A UTILIZAÇÃO DA BASE DE CONHECIMENTO}

5.1 - Consideraçőes Iniciais...................................................................................... 65

5.2 - Diretrizes para a Utilização da Base de Conhecimento na Elaboração dos

Modelos de Análise Fusion........................................................................... 65

5.2.1 - Diretrizes para a Elaboração do Modelo de Ciclo de Vida.......................... 66

5.2.2 - Diretrizes para a Elaboraçáo do Modelo de Operações.............................. 69

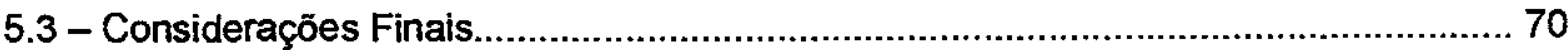

\section{CAPÍTULO 6 - ESTUDOS DE CASO}

6.1 - Considerações Iniciais........................................................................................ 71

6.2 - Primeiro Estudo de Caso - Sistema de Chamadas Técnicas do CISC-USP............. 72

6.2.1 - Fase 1 - Inicio do Processo de Aquisiçáo de Conhecimento...................... 72

6.2.2 - Ciclo Brainstorming do Processo IPAIA Instanciado para o Domínio de Engenharia Reversa.......................................................................... 74

6.2.3 - Ciclo Rastreamento de Processo do Processo IPAIA Instanciado para o Dominio de Engenharia Reversa............................................................ 79

6.2.4 - Ciclo Entrevista Estruturada do Processo IPAIA Instanciado para o Dominio de Engenharia Reversa.

6.3 - Segundo Estudo de Caso - MGASET (Módulo de Geraçäo de Seqüências de Teste) 89

6.3.1 - Fase 1 - Início do Processo de Aquisição de Conhecimento........................ 89

6.3.2 - Ciclo Brainstorming do Processo IPAIA Instanciado para o Domínio de Engenharia Reversa.

6.3.3 - Ciclo Rastreamento de Processo do Processo IPAIA Instanciado para o Dominio de Engenharia Reversa........................................................... 107

6.3.4 - Ciclo Entrevista Estruturada do Processo IPAIA Instanciado para o Domínio de Engenharia Reversa........................................................... 111

6.3.5-Modelo de Ciclo de Vida da Ferramenta MGASET .................................... 113

6.3.6-Modelo de Operaçöes da Ferramenta MGASET ....................................... 116

6.4 - Considerações Finais........................................................................................ 118

\section{CAPITTULO 7 - CONCLUSÕES E TRABALHOS FUTUROS}

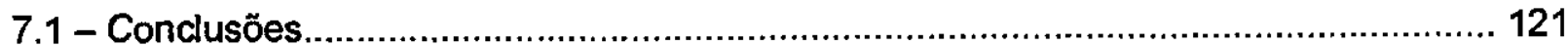

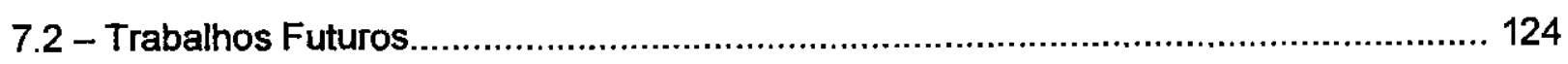




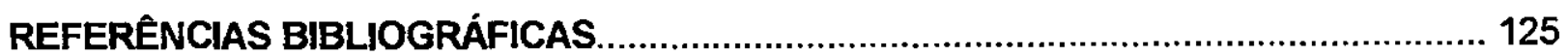

ANEXO A

Malha de Dados Resultante do Exemplo Northwind - Ferramenta Rules Visualizer..

ANEXO B

DAD da Operação "Inserção de Chamadas Técnicas" e

DAD da Operação "Alteração/Exclusão de Chamadas Técnicas. 


\section{Lista de Figuras}

FIGURA 1.1 - ENGENHARLA PROGRESTVAENGENHARLA REVERSA........................................................................

FIGURA I. 2 - PROPOSTA DA UTHZIZAGÄO DE ULA BASE DE CONFECTMENTO NO MÉTODO FUSION-RE/L.............................. 3

FIGURA 2.1 - RELACIONAMENTO ENTRE AS ATTVDADES DE ENGENHARIA PROGRESSIVA E ENGENHARLA REVERSA................. 7

FIGURA 2.2 - NIVETS DE ENTENDIMENTO DO SOFTWARE DE ACORDO COM O CICLO DE VDA......................................... 8

FIGURA 2.3 - CATEGORIAS DA ENGENHARIA REVERSA REIAGONADAS AO CICLO DE VIDA............................................ 10

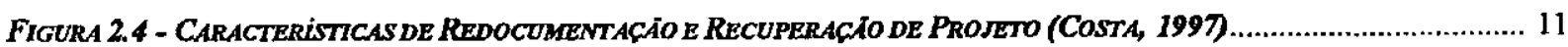

FIGURA 2.5 - SINTESE DO MÉTODO DE ENGENHARIA REVERSA FUSION.REI (COSTA, 1997)........................................... 13

FIGURA 2.6 - PROCESSO BASICO DE RECUPERAGÁO DE PRoJETO (BIGGERSTAFF, 1989)................................................ 16

FIGURA 2.7 - EXTENSÁO DA RECUPERAGÁO DE PROJETO (BIGGERSTAFF, 1989)...................................................... 17

FIGURA 2.8 - PROCESSSO DE RECUPERAGÁO OE PROJETO BASEADO EM MODELO (BJGGERSTAFT, 1989) ................................ 18

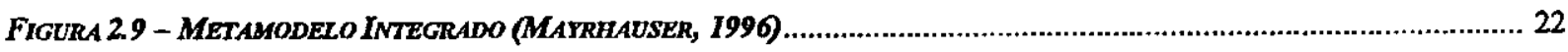

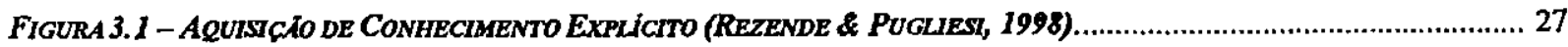

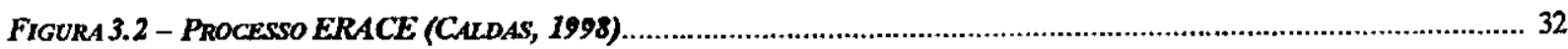

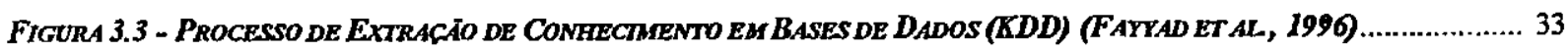

FIGURA 3.4 - REPRESENTAGAO DO CONHECTMENTO EM PRoLog (RICR \& KNIGTH, 1993).............................................. 34

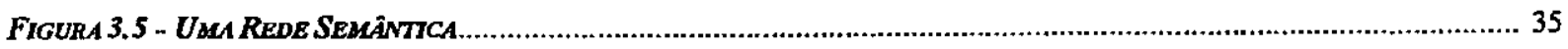

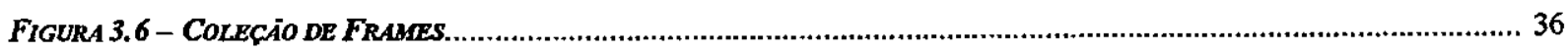

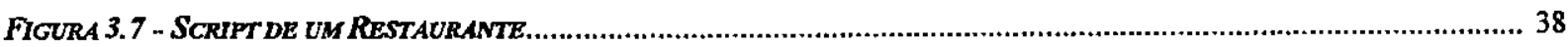

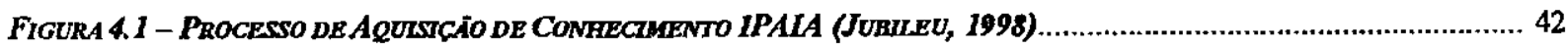

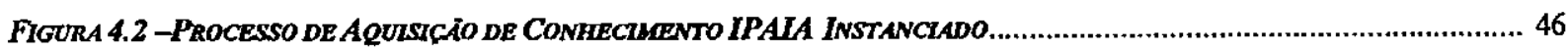

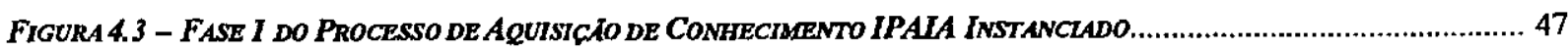

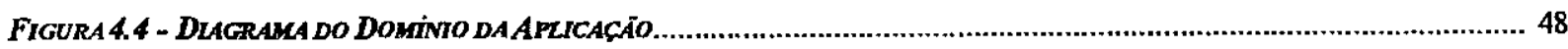

Figura 4.5 - Ciclo Brainstorming do Processo de AQuisigho de Coniectmento iPAIA Instanciado....................... 50

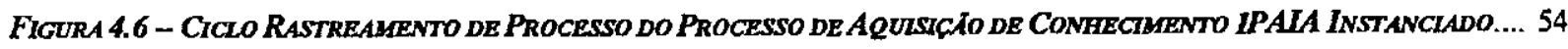

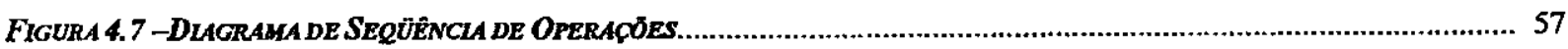

FIGURA 4.8 -DLAGRAMA DE SEQÜÊNCTA DE OPERAÇ̄̃ES (EXRMPLO).................................................................... 59

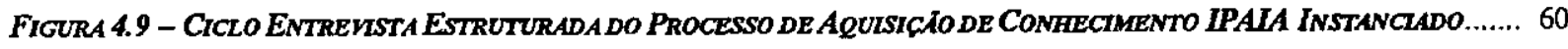

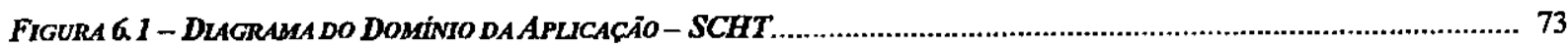

FIGURA 6.2 - DLAGRAMA DE SEQÜÊNCZA DE OPERAĞÖES DO SISTEMA SCHT ............................................................ 85

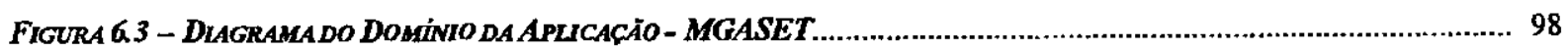

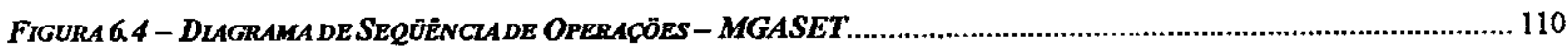

FIGURA 65 - TRANSIGAO DO DLAGRAMA DE OPERAÇOES PARA O MODELO DE CICLO DE VIDA (MGASET)........................... 113

FigURA 6.6 - TRANSIGAO do QUADRo CONSENSUAL ESPECIFICO DO SISTEMA ANALLAADO PARA A EXPRESSÃo DE CICLO DE

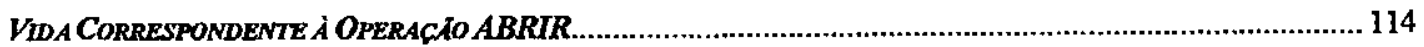

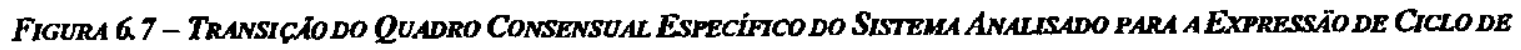

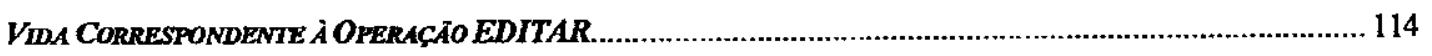

FIGURA 6.8 - TRANSICYCIO DO QUADRO CONSENSUAL ESPECIFICO DO SISTEMAANALISADO PARA A EXPRESSÄO DE CTCLO DE VIDA CORRESPONDENTE A OPERAGAO VERUFICAR AS PROPRIEDADES............................................ 115

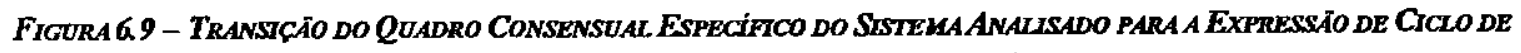
VIDA CORRESPONDENTE À OPERAG̈̈O GERAR SEQÜÊENCIAS BÁSICAS............................................. 115

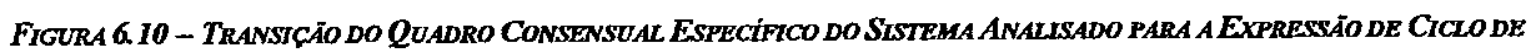

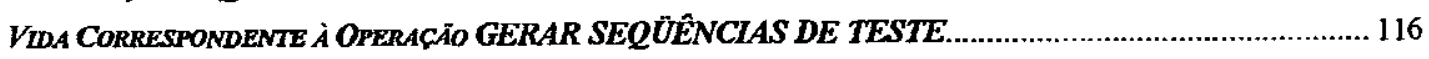

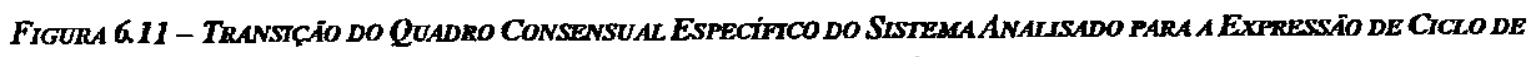
VIDA CORRESPONDENTE À OPERAGÄO EXECUTAR SEQÜ̂ANCLAS DE TESTE ..................................... 116 


\section{Lista de Quadros}

QUADRO 4.1 - QUADRO DE DESCRÇÄO DAS PRINCTPALS FunÇȮES..................................................................48

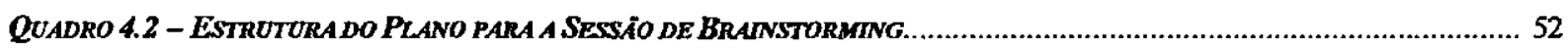

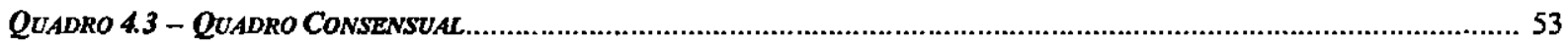

QUADRO 4.4 - ESTRUTURA DO PLANO PARA AS SESSÓES DE RASTREAHENTO DE PROCESSO............................................... 55

QUADRO 4.5 - QUADRO CONSENSUAL ESPECIFCO DO SISTEMA ANALISADO (EXEMPLO)...................................................57

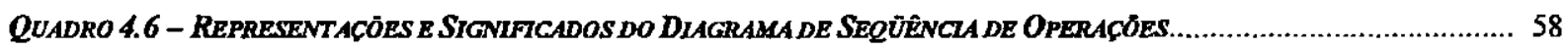

QUADRO 4.7 - ESTRUTURA DO PLANO PARA AS SESSÓES DE ENTRERSTA ESTRUTURADA..................................................... 61

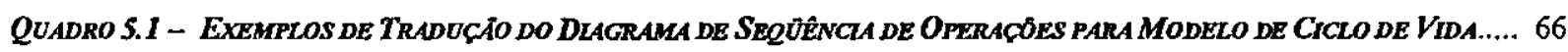

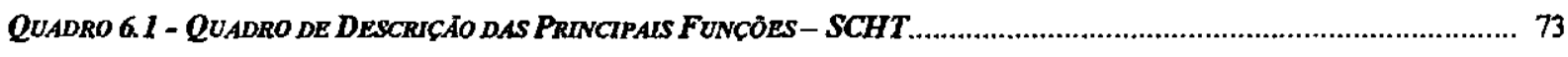

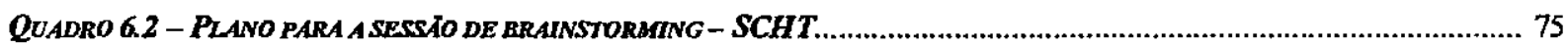

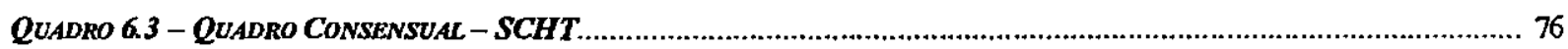

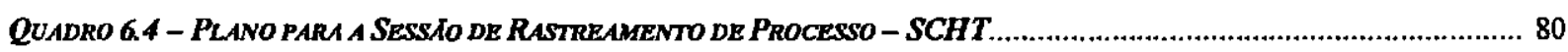

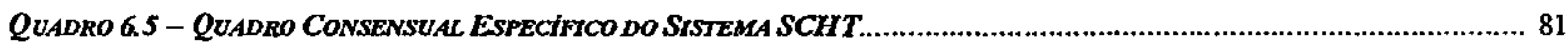

QUADRO 6.6 - PLANO PARA A SESSAO DE ENTREVSTA ESTRUTURADA - SCHT............................................................ 88

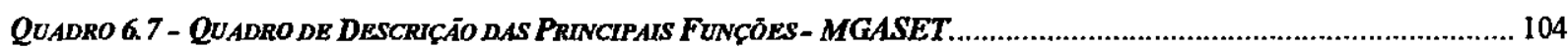

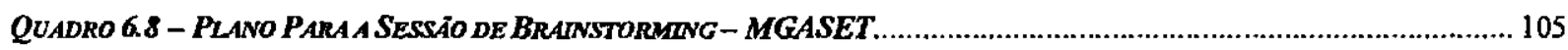

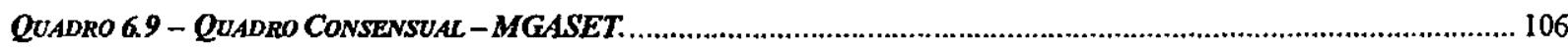

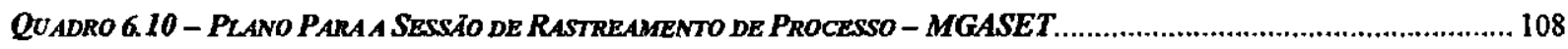

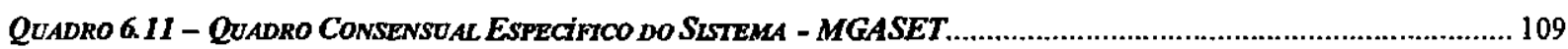

QUADRO 6.12 - PLANO PARA A SESSAOO DE ENTREYSTA ESTRUTURADA - MGASET ................................................ 112

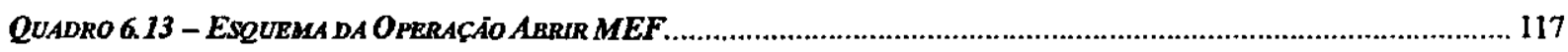

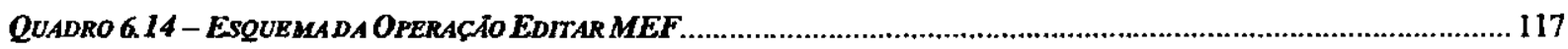

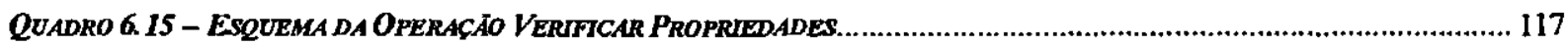

QUADRO 6. 16 - ESQUEMA DA OPERAÇĀO GERAR SEQÜÉNCIAS BASICAS .............................................................118

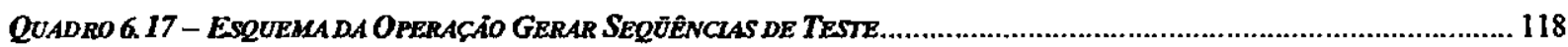

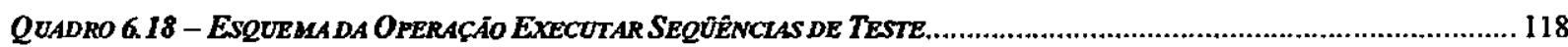

\section{Lista de Tabelas}

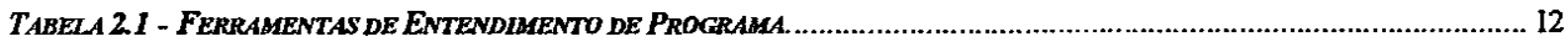

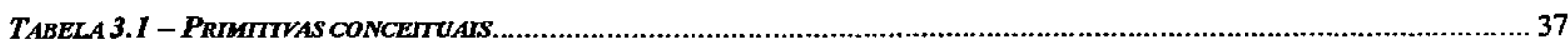

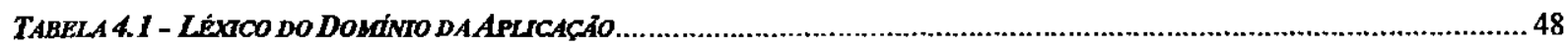

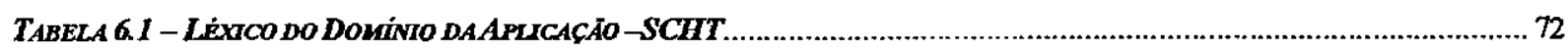

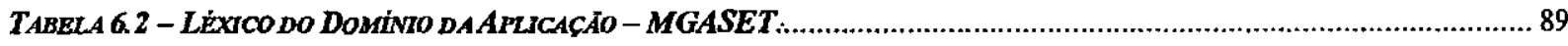




\section{CAPÍTULO 1 - INTRODUÇÃO}

\section{1 - Motivação}

O processo tradicional de engenharia de software - caracterizado pelas atividades progressivas do ciclo de vida, que partem de um alto nivel de abstração para um baixo nivel de abstração - é conhecido como engenharia progresstva (Chikofsky \& Cross II, 1990). O processo inverso à engenharia progressiva - caracterizado pelas atividades retroativas do ciclo de vida - é conhecido como engenharia reversa (Figura 1.1).

Nos últimos anos tem ocorrido um crescente reconhecimento da importância da engenharia reversa, tanto em meio acadêmico quanto em ambientes de produção (Chikofsky \& Cross II, 1990; Benedusi et al., 1992; Waters \& Chikofsky, 1994; Bennet, 1995). Esse reconhecimento tem resultado em diversas pesquisas abordando diferentes métodos, técnicas e ferramentas de engenharia reversa (Biggerstaff, 1989; Harandi \& Ning, 1990; Oman et al., 1990; Bennet, 1991; Penteado et al., 1996; Wong et al., 1995).

Um dos objetivos principais da engenharia reversa é a recuperação de informações para serem utilizadas na fase de manutenção do software. Pode-se observar que a facilidade de manutenção (manutenibilidade) - caracterizada principalmente pelo entendimento do sistema - está fortemente relacionada à disponibilidade de informações sobre o sistema. Essas informações podem ser produzidas pela engenharia reversa facilitando, primeiramente, o entendimento e, posteriormente, a modificação e revalidação do sistema, aumentando 
assim a manutenibilidade do mesmo (Chikofsky \& Cross II, 1990; Benedusi et al., 1992; Waters \& Chikofsky, 1994; Stephen \& Lynn, 1995; Sage, 1995).

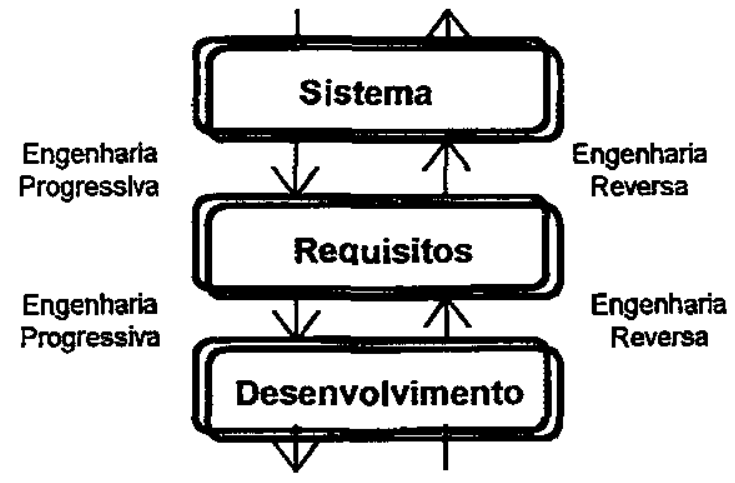

FIGURA 1.1 - ENGENHARIA PROGRESSIVAENGENHARIA REVERSA

Para auxiliar a atividade de manutenção de software, Costa (1997) desenvolveu o método de engenharia reversa FUSION-RE/ que, partindo do código fonte, de aspectos operacionais do sistema e de dados da interface, recupera visões do sistema - visóes funcionais e visões estruturais. As visões funcionais são recuperadas partindo-se de informações apresentadas na interface e de aspectos operacionais; as visões estruturais são recuperadas utilizando as visões funcionais produzidas e o código fonte do sistema. $O$ método FUSION-RE/ é constituído de duas etapas: a primeira etapa tem como objetivo a abstração da funcionalidade do sistema, representada por meio dos modelos de ciclo de vida, de operaçōes e de objetos do sistema, segundo o método Fusion (Coleman et al., 1994); a segunda etapa tem como objetivo a identificação dos procedimentos, que implementam as operaçōes da interface do sistema, representados através dos quadros de chamadas de procedimentos e de operaçóes-procedimentos de implementação.

No primeiro passo do método FUSION-RE/l deve ser reunida toda a documentação envolvendo a informação textual existente sobre o sistema (manuais, livros, artigos, listagem do código fonte, etc.) e a informação técnica relacionada aos conceitos pertinentes (dominio do sistema, aplicação, linguagem de implementação do sistema, da interface, etc.). Muitas vezes, no entanto, informaçōes importantes sobre o sistema não estão documentadas e um modo de recuperá-las é a partir de entrevistas com os idealizadores, os usuários, os projetistas e/ou os desenvolvedores do sistema. Esse passo é considerado muito importante, pois de seus resultados dependem os outros passos do método. Entretanto, no FUSION-RE/I o passo de obtenção de informações não está explicitamente especificado, ou seja, não há uma sistemática para adquirir e representar o conhecimento obtido do sistema. 


\section{2 - Objetivo}

Visto que o primeiro passo do método FUSION-RE/I - obter informações sobre o sistema - é muito importante e não está claramente formalizado, o objetivo deste trabalho é apresentar um procedimento de auxilio para esse passo. $O$ procedimento compreende a criação de uma base de conhecimento, através da qual podem ser produzidas as visões funcionais do sistema, e diretnizes para a utilização dessa base na construção das visões funcionais do sistema (Figura 1.2). Na base de conhecimento são amazenados conhecimentos relacionados ao ambiente e à interface. Esse conhecimento é obtido através do Processo de Aquisição de Conhecimento IPAIA (Jubileu et al., 1998), instanciado para o domínio de engenharia reversa.

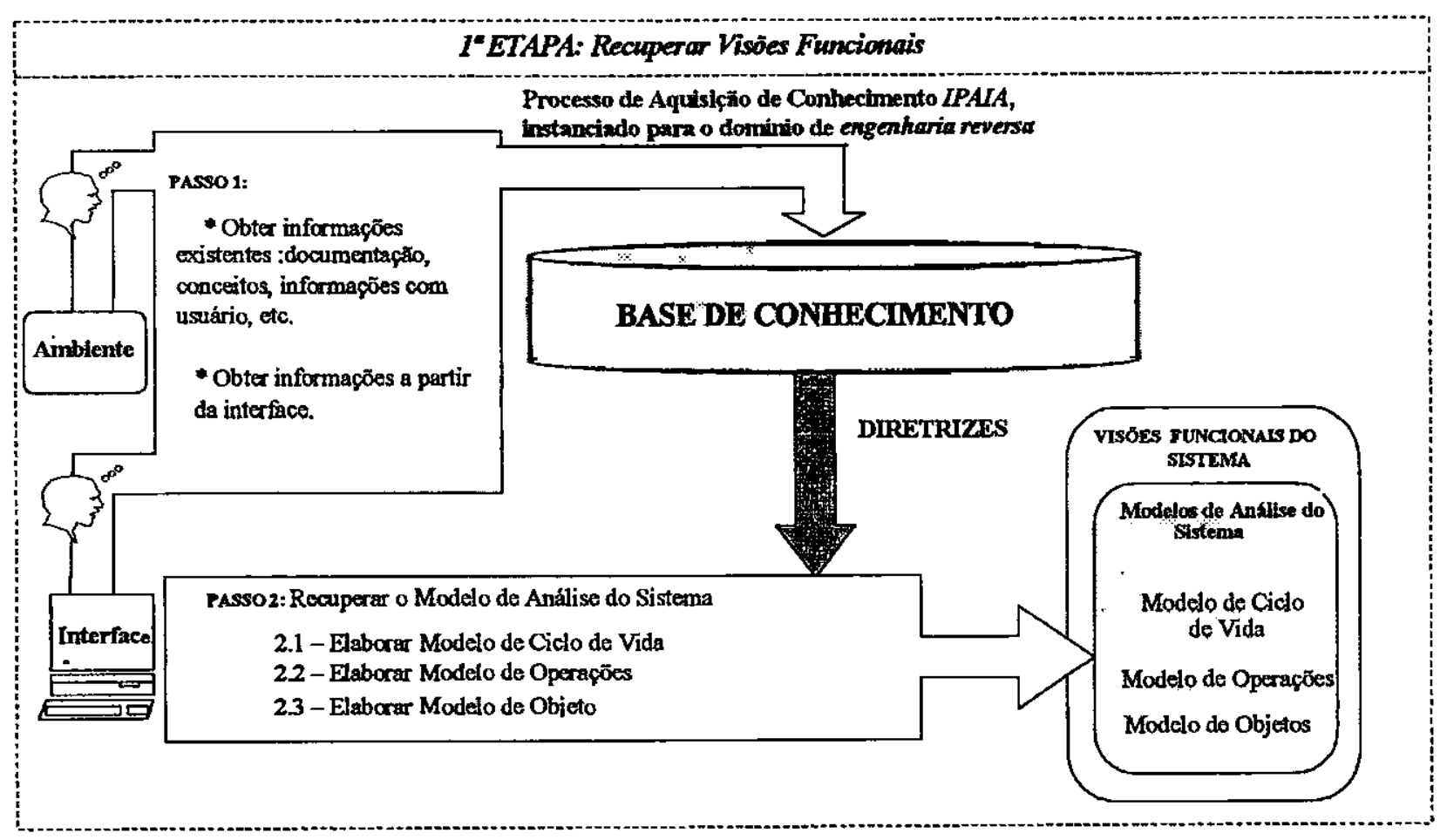

FIGURA 1.2 - PROPOSTA DA UTILIZAÇÃO DE UMA BASE DE CONHECIMENTO NO MÉTODO FUSION-RE/1

\section{3 - Organização do Trabalho}

Este trabalho está organizado em sete capitulos. Neste capítulo foram expostos a motivação e o objetivo deste trabalho. 
Os capítulos 2 e 3 referem-se à revisão bibliográfica. No Capitulo 2 é apresentada uma visão geral de Engenharia Reversa, dando-se ênfase à categoria de engenharia reversa Entendimento de Programa, por ser esta a de maior interesse neste trabalho. Para 0 entendimento de programa é necessário adquirir conhecimento, sendo assim, no Capítulo 3 são apresentados alguns conceitos referentes à Aquisição de Conhecimento, algumas técnicas de aquisição de conhecimento explícito e implícito, bem como algumas estruturas de representaçäo de conhecimento.

Para adquirir conhecimento de uma forma organizada é necessário um planejamento. No caso deste trabalho, esse planejamento envolve um processo denominado Processo de Aquisição de Conhecimento IPAIA, instanciado para o domínio de engenharia reversa, o qual é apresentado no Capítulo 4.

O referido processo tem como resultado uma base de conhecimento através da qual podem ser produzidas as visöes funcionais do sistema. As diretrizes de utilização dessa base na elaboração das visōes são apresentadas no Capítulo 5.

Dois estudos de caso, utilizando o Processo de Aquisição de Conhecimento IPAIA instanciado para o domínio de engenharia reversa, são apresentados no Capítulo 6.

Finalmente, no Capitulo 7 são apresentadas as conclusōes deste trabalho, bem como os trabalhos futuros que possam vir a ser desenvolvidos.

Em anexo são apresentados alguns exemplos das tentativas de se utilizar diagramas abstratos detalhados, como estruturas de representação do conhecimento, e de se utilizar a técrica de data mining para obter, a partir de uma base de dados, indícios para elaborar 0 modelo de objetos do sistema. 


\section{CAPITULO 2 - ENGENHARIA REVERSA}

\section{1 - Considerações Iniciais}

Este capitulo apresenta os niveis de abstração do ciclo de vida de software, uma vez que o processo de engenharia reversa envolve mudanças nesses niveis. Visualizaçöes, que podem ser obtidas do software por meio da engenharia reversa, em diferentes niveis de abstração, e uma categorização de engenharia reversa de acordo com o nivel de entendimento obtido do sistema e o escopo das informações fornecidas, também são abordadas neste capitulo. Dentro da categorização de engenharia reversa é enfatizada a recuperação de projeto (entendimento de programa), por ser a categoria de engenharia reversa de maior interesse neste trabalho.

\section{2 - Conceitos de Engenharia Reversa}

O termo "engenharia reversa" tem sua origem na análise de hardware, onde a prática de extrair projetos de produtos finalizados é comum. A engenharia reversa de hardware é regularmente aplicada para melhorar os produtos da própria empresa e também para analisar os produtos de concorrentes em situações militares ou de segurança nacional (Rekoff, 1985). 
O conceito de engenharia reversa de software é similar. Entretanto, o objetivo da engenharia reversa de hardware é, tradicionalmente, fazer um clone do sistema, enquanto o objetivo da engenharia reversa de software, freqüentemente, é obter um entendimento do sistema em um nível mais alto de abstração (o conceito de abstração é apresentado na seção 2.3) e uma estrutura para auxiliar na manutençăo, expansão ou substituição do sistema (Rekoff, 1985).

Segundo Chikofsky \& Cross II (1990), a aplicação da engenharia reversa não envolve mudanças ou criação de um novo software. Trata-se do processo de exame e compreensão do sistema existente, a fim de recuperar ou recriar o projeto e decifrar os requisitos atualmente implementados, apresentando-os em um grau ou nivel mais alto de abstraçăo.

Para Pressman (1995) a engenharia reversa é o processo de analisar um software num esforço de criar uma representação do mesmo, em um nivel de abstração mais alto que 0 código fonte.

Benedusi et al. (1992) afirmam que a engenharia reversa é uma coleção de teorias, métodos e técricas capazes de dar apoio (1) ao projeto e implementaçăo de um processo para extrair e abstrair informaçōes de software existentes e produzir documentação consistente com o código e (2) à adição de conhecimentos e experiências à documentação, os quais não podem ser automaticamente reconstruídos a partir do código.

Assim, de maneira geral, o objetivo da engenharia reversa é a produção de informações que possam aumentar o conhecimento geral de sistemas de software. Essas informações podem ser utilizadas em atividades como manutenção, reuso, teste e controle de qualidade de software.

Por meio da engenharia reversa, um software pode ser visualizado em diferentes niveis de abstração que serão apresentados na próxima seção.

\section{3 - Niveis de Abstração no Ciclo de Vida}

As fases do ciclo de vida podem ser agrupadas em três atividades fundamentais:

(1) Sistema (engenharia de sistemas): envolve o contexto em que o sistema está operando, ou seja, o porquê do sistema ser desenvolvido;

(2) Requisitos (análise): são estabelecidos os serviços a serem fomecidos pelo sistema e as restriçőes sob as quais ele deve operar, ou seja, o que o sistema deve fazer e sob quais circunstâncias;

(3) Desenvolvimento (projeto, codificação e testes): cria-se um planejamento da solução, ou seja, como o sistema cumprirá o que foi estabelecido na atividade de requisitos e a 
implementação dessa solução, incluindo a codificação, os testes, a depuração e a entrega do sistema. A fase de manutenção é vista como reiteração das atividades prévias.

As atividades consideradas fundamentais no ciclo de vida (Figura 2.1) possuem uma nítida diferença nos niveis de abstração. Cada visualização abstrai características próprias da fase do ciclo de vida correspondente à abstração.

Abstração é a habilidade de se ignorar os aspectos de assuntos não relevantes para o propósito em questão, tornando possivel uma major concentração nos assuntos principais (Oxford, 1986). A abstração relaciona-se com as atividades do ciclo de vida segundo os conceitos de niveis e graus de abstraçăo.

Nivel de Abstração: à medida que se avança nas fases do processo de desenvolvimento de software, tem-se um refinamento do nivel de abstração (Figura 2.1). Assim, nos estágios iniciajs do ciclo de vida, as informaçōes possuem alto nível de abstraçăo são representados poucos detalhes - e nos estágios finais, baixo nível de abstração (Chikofsky \& Cross Il, 1990).

Grau de Abstração: considerando-se o mesmo nível de abstração, as informaçōes apresentadas de forma mais global possuem alto grau de abstração, enquanto as apresentadas de forma mais detalhada, baixo grau de abstração (Figura 2.1) (Chikofsky \& Cross (I, 1990).

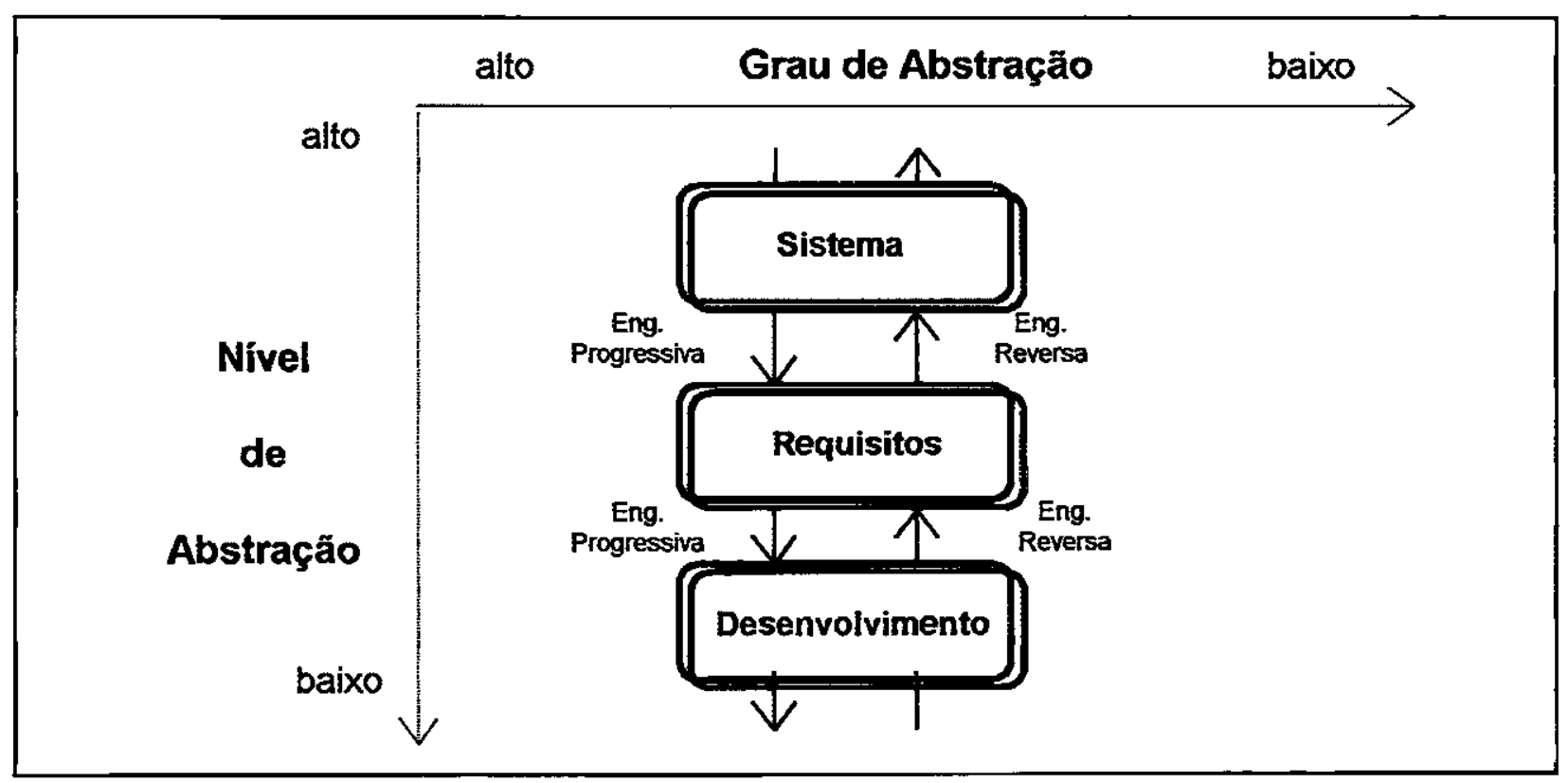

\section{FIGURA 2.1 - RELACIONAMENTO ENTRE AS ATIVIDADES DE ENGENHARIA PROGRESSIVA E ENGENHARIA REVERSA}

A engenharia progressiva é o processo tradicional de engenharia de software e se inicia num alto nivel de abstraçăo que vai diminuindo até chegar na implementação física do 
sistema. Já a engenharia reversa é o processo inverso à engenharia progressiva, caracterizado pelas atividades do ciclo de vida aplicadas em ordem inversa, partindo de um baixo nivel de abstração para um alto nivel de abstração (Figura 2.1) (Chikofsky \& Cross II. 1990).

\section{4 - Categorizaçăo de Engenharia Reversa}

Um software pode ser visualizado obtendo-se diferentes niveis de entendimento (Harandi \& Ning, 1990). Com base nos niveis de abstraçăo, as visões obtidas do software são classificadas em quatro categorias: visão em nivel implementacional, visão em nível estrutural, visão em nivel funcional, visão em nivel de domínio.

A Figura 2.2 mostra a correspondência entre as categorias de visualização do software $e$ as informações produzidas e utilizadas nas diferentes atividades do ciclo de vida do software.

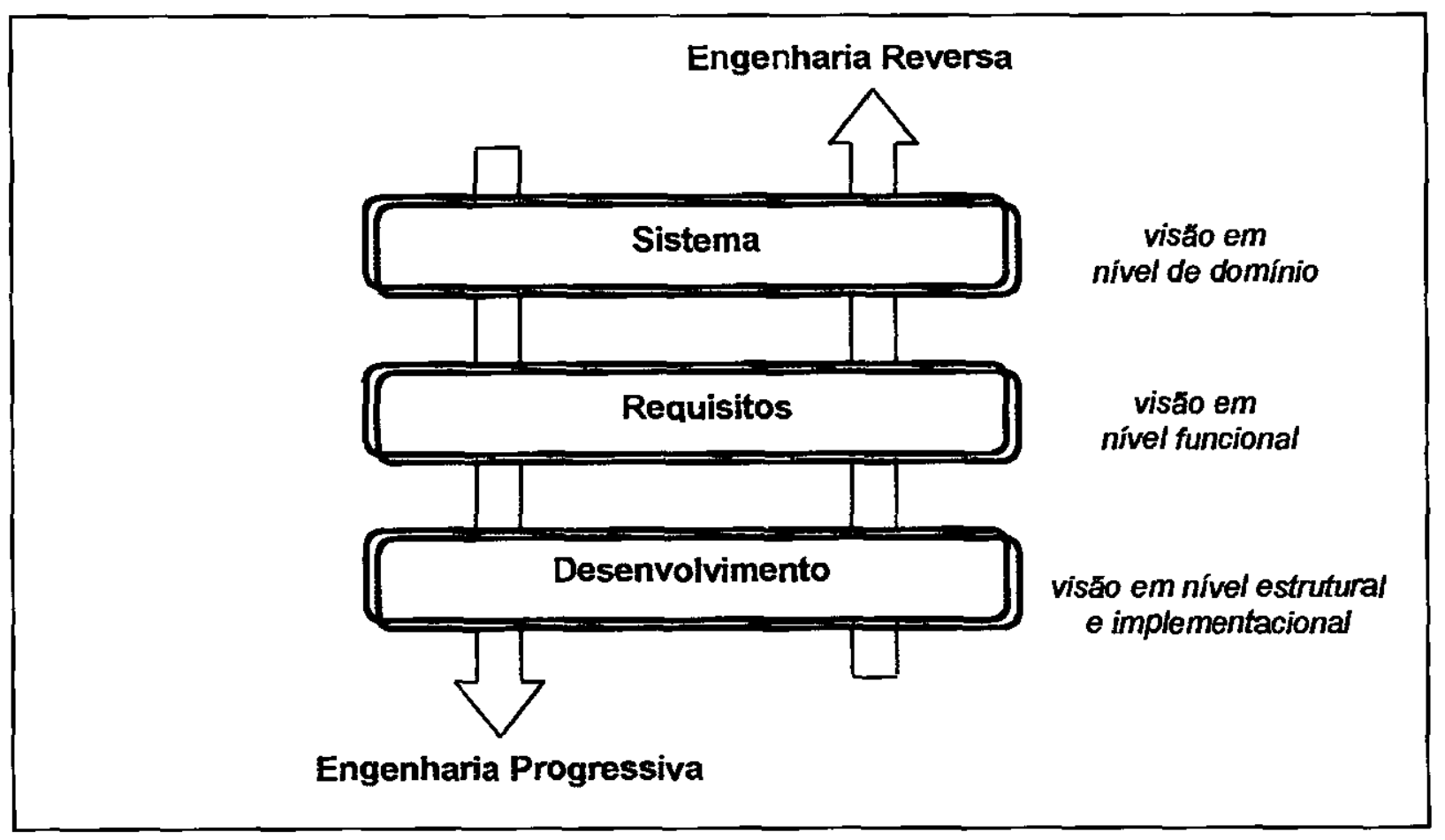

FIGURA 2.2 - NÍVEIS DE ENTENDIMENTO DO SOFTWARE DE ACORDO COM O CICLO DE VIDA

Visão em nivel implementacional: abstrai características da linguagem de programação e especificamente da implementaçăo. Exemplos de visões em nivel implementacional são 
informações a respeito da sintaxe e da semântica da linguagem e informaçōes de implementação.

Visão em nivel estrutural: abstrai detalhes da implementação para revelar sua estrutura a partir de diferentes perspectivas. O resultado é uma representação explicita das dependências entre os componentes do sistema. Exemplos de visões em nivel estrutural são grafos de fluxo de dados, grafos de fluxo de controle (Cleveland, 1989), projeto arquitetural expresso por meio de gráficos de estruturas (chama/chamado por) (Cross II, 1990) ou por meio de uma linguagem de interconexão modular, como NuMIL (Choi \& Scacchi, 1990).

Visão em nivel funcional: abstrai a função de um componente do sistema, isto é, o que - componente faz. Relaciona partes do programa às suas funções a fim de revelar as relaçőes lógicas entre elas. Cada componente dessa visão é uma representação abstrata da classe de funcionalidade equivalente à implementação, mas estruturalmente diferente. Exemplos de visões em nivel funcional podem ser descriçōes da função do sistema, expressos de maneira formal usando linguagens tais como $Z$ e $Z^{++}$(Spivey, 1988; Khabaza, 1989; Bennet, 1991), e diagramas de entidade-relacionamento (Ross, 1988) que mostram os dados e seus relacionamentos.

Visão em nivel de domínio: abstrai o contexto em que o sistema está operando, ou seja, o porquê do sistema ser desenvolvido.

$\dot{E}$ fato que poucas representações restringem-se somente a uma fase do ciclo de vida ou são consideradas como pertencentes a uma categoria de visualização. Um diagrama de fluxo de dados (DeMarco \& Sarson, 1979) pode ser usado para descrever o que o sistema faz ou como o processo interage com outros elementos. Uma linguagem de descrição de programa (PDL) (Caine \& Gordon, 1975) pode ser usada para representar as funções na fase de requisitos ou o projeto procedimental na fase de projeto. Assim, o fato de uma representação extraída ser uma representação de requisitos ou uma representação de projeto depende principalmente do contexto em que tal representação será usada.

Para obter as diversas visōes do software, usualmente é necessário acrescentar às informações contidas no código outras informações provenientes de conhecimento e de experiência humana. Baseado no nivel de entendimento obtido do sistema e no escopo das informações fornecidas há uma categorização das técnicas de engenhana reversa: redocumentação e recuperação de projeto (Chikofsky \& Cross II, 1990). Na Figura 2.3, são apresentadas as categonias de engenharia reversa, relacionadas às fases do ciclo de vida.

Redocumentação: $\dot{E}$ a criaçāo ou revisão de representaçōes semanticamente equivalentes em um mesmo nivel de abstração. O processo de redocumentação cria as representações a partir de informações obtidas apenas da análise do código fonte. Por exemplo: a partir do código fonte, pode-se analisar e extrair a arquitetura do programa, a estrutura de controle, a estrutura de dados, etc. As formas obtidas das representações são 
consideradas visões alternativas, tendo como objetivo melhorar a compreensibilidade do sistema global.

Recuperaçāo de Projeto: Tem como objetivo entender o sistema ao invés de simplesmente fornecer visōes altemativas para auxiliar o usuánio a entendê-lo, distinguindose, porém, da redocumentação. Esse entendimento vai além do escopo do conhecimento em nivel implementacional e estrutural. A ênfase é obter conhecimento em nivel funcional e até mesmo em nivel de domínio (ambiente de operação do sistema).

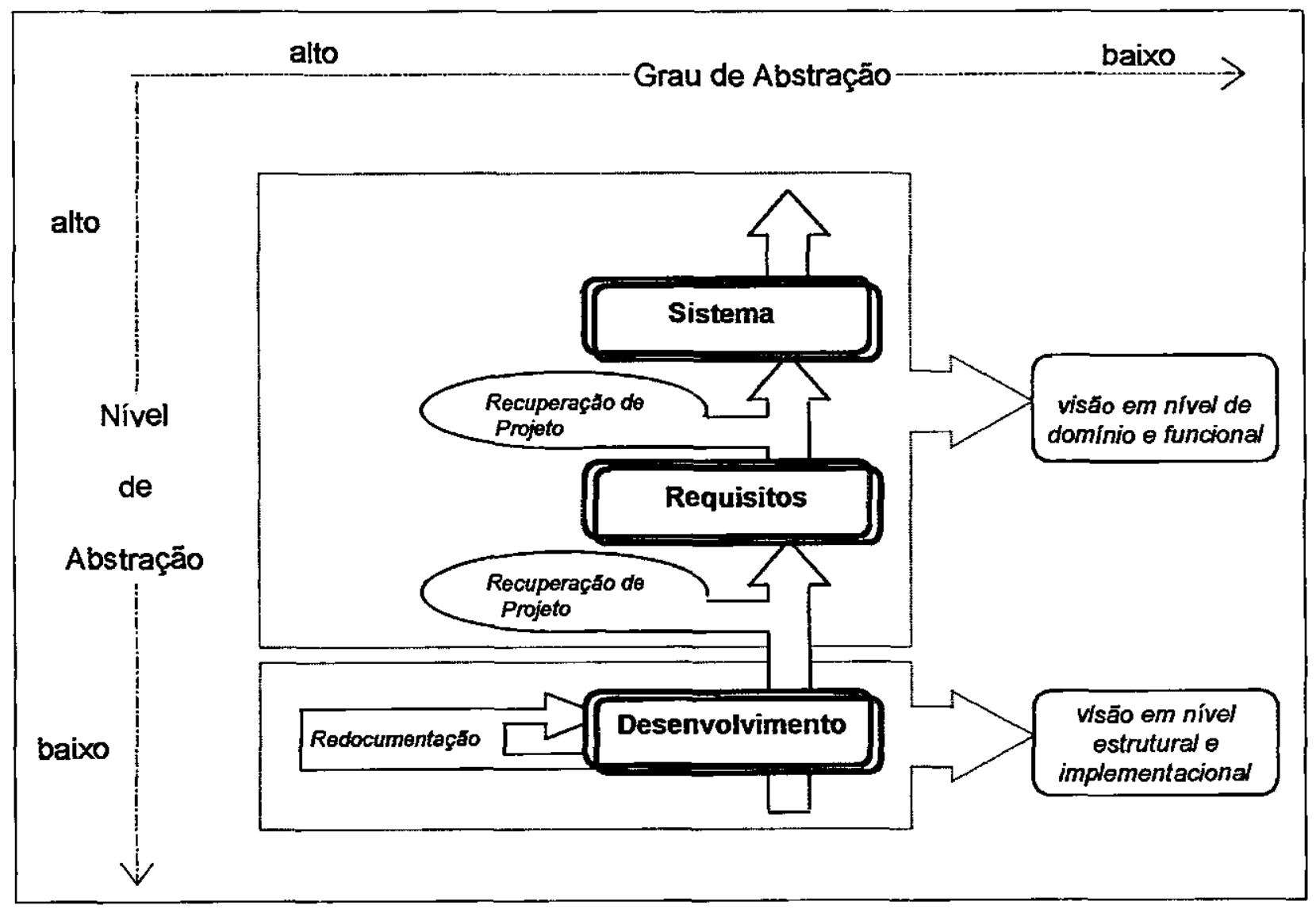

FIGURA 2.3 - CATEGORIAS DA ENGENHARIA REVERSA RELACIONADAS AO CICLO DE VIDA

Na Figura 2.4 são apresentadas as categorias de engenharia reversa, segundo as visōes que podem ser obtidas e o escopo das informaçōes fornecidas, por meio da análise apenas do código fonte ou da análise do código combinada com informações de uma base de conhecimento. 


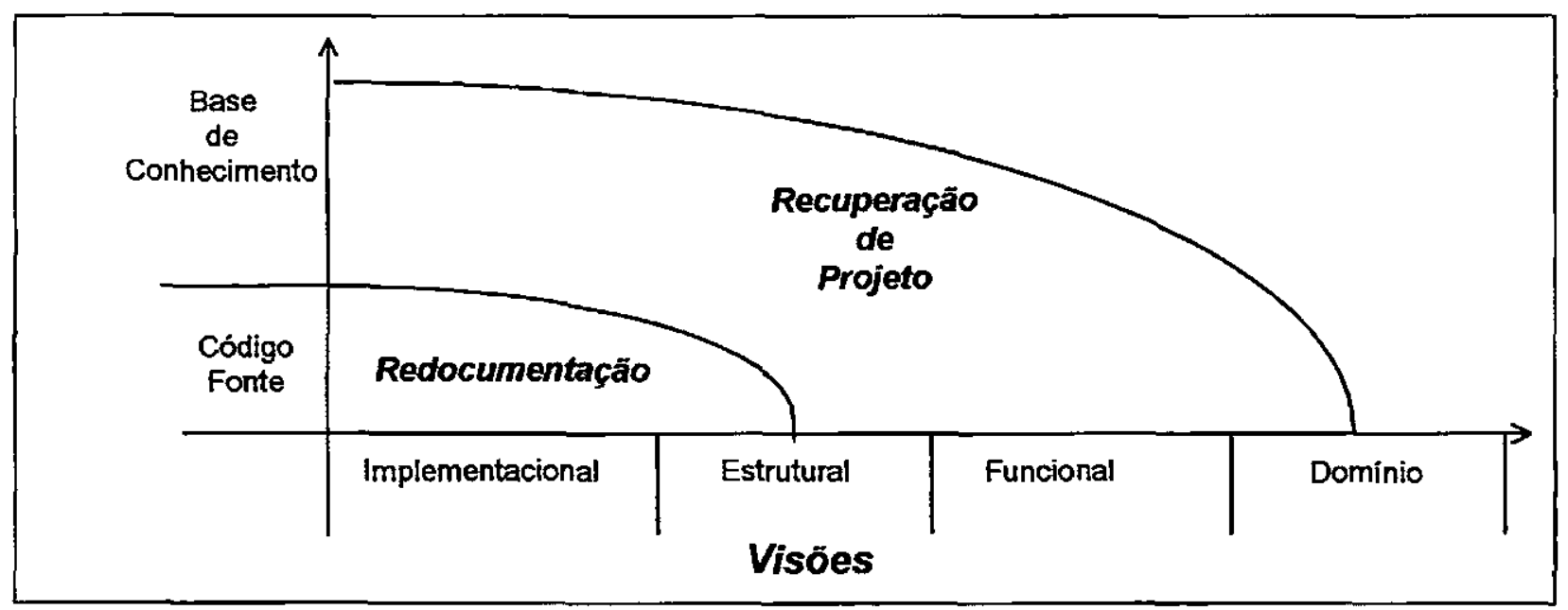

FIGURA 2.4 - CARACTERISTICAS DE REDOCUMENTAÇÃO E RECUPERAÇÃO DE PROJETO (COSTA, 1997)

\section{5 - Entendimento de Programa}

A categoria de engenharia reversa - recuperação de projeto - é também denominada entendimento de programa. Um completo entendimento de programa busca reconstruir não somente a função do sistema, mas também o processo pelo qual o sistema foi desenvolvido (processo de projeto).

O entendimento de programa recria abstraçőes de projeto do sistema por meio da combinaçăo de informações obtidas do código, documentação existente de projeto, experiência pessoal, e conhecimento geral sobre o problema e domínio de aplicação. Abstraçöes de projeto são estruturas generalizadas que contém menos detalhes do que as encontradas no código fonte. Essas abstraçöes incluem representações da engenharia de software convencional tais como especificações formais, estrutura modular, abstraçōes de dados, fluxo de dados e linguagem de descrição de programa (PDL). Também incluem conhecimento informal sobre o domínio do problema, da aplicação e do mundo real de um modo geral. Sintetizando, o entendimento de programa reproduz todas as informaçöes necessárias para entender completamente o que o sistema faz, como faz e porquê faz.

Existem algumas ferramentas que têm sido utilizadas para auxiliar essa categoria de engenharia reversa, as quais pesquisam o código fonte com o intuito de encontrar padröes e estruturas de interesse. Uma relação de algumas dessas ferramentas é apresentada na Tabela 2.1. 
TABELA 2.1 - FERRAMENTAS DE ENTENDIMENTO DE PROGRAMA

\begin{tabular}{|c|c|c|}
\hline Nome da Ferramenta & Estratégia de Entendimento & Referência \\
\hline $\begin{array}{c}\text { DESIRE } \\
\text { DESign Information } \\
\text { Recovery Environment } \\
\text { Protótipo }\end{array}$ & $\begin{array}{l}\text { Utiliza abstrações conceituais (informações formais } \\
\text { e informais) para localizar padrões na } \\
\text { implementação de sistemas escritos em C. }\end{array}$ & (Biggerstaff, 1989) \\
\hline $\begin{array}{l}\text { PROUST } \\
\text { Protótipo }\end{array}$ & $\begin{array}{l}\text { Utiliza a técnica Intention-Based Analysis. São } \\
\text { geradas hipóteses sobre as intençöes dos } \\
\text { programadores (como os programadores escrevem } \\
\text { programas), combinadas ao código fonte para } \\
\text { detectar possiveis ocorrências de erros. }\end{array}$ & (Johnson, 1990) \\
\hline $\begin{array}{l}\text { PAT } \\
\text { Program Analysis Tool }\end{array}$ & $\begin{array}{l}\text { Utiliza uma estrutura orientada a objetos para } \\
\text { representar conceitos de programação e um } \\
\text { mecanismo de aprendizado baseado em } \\
\text { heurísticas para derivar os conceitos funcionais em } \\
\text { alto nivel a partir do código. }\end{array}$ & (Harandi \& Ning, 1990) \\
\hline $\begin{array}{l}\text { LAURA } \\
\text { Protótipo }\end{array}$ & $\begin{array}{l}\text { Utiliza a técnica Intention-Based Analysis. } \\
\text { Compara um programa "correto" com o programa } \\
\text { objeto, ambos traduzidos em grafo de fluxos } \\
\text { normallzados. }\end{array}$ & (Seviora, 1987) \\
\hline REDO & $\begin{array}{c}\text { Utiliza a reestruturaçáo, incluindo estruturas de } \\
\text { dados, variáveis locais e estruturas de controle, a } \\
\text { redocumentaçáo a partir do código, e uma } \\
\text { inguagem intermediária (UNIFORM) antes de } \\
\text { atingir uma linguagem de especificação formal ( } \mathrm{Z} \text { e } \\
\text { Z++). } \\
\text { As informaçōes extraídas são armazenadas em um } \\
\text { banco de dados. }\end{array}$ & $\begin{array}{l}\text { (Khabaza, 1989), } \\
\text { (Bennet, 1991), } \\
\text { (Jonathan et al., 1993) }\end{array}$ \\
\hline Protótipo & $\begin{array}{c}\text { Utiliza a técnica Intention-Based Analysis. } \\
\text { Compara a solução ideal com um programa objeto } \\
\text { por meio de algoritmos hipotéticos. }\end{array}$ & (Ourston, 1989) \\
\hline
\end{tabular}

Vários modelos, estratégias, abordagens e paradigmas são propostos para auxiliar no entendimento de programa (Benedusi et al., 1992; Biggerstaff, 1989; Biggerstaff et al., 1994; Harandi \& Ning, 1990; Littman et al., 1987; Letovsky, 1987; Mayrhauser, 1995; Mayrhauser, 
1996; Oman et al., 1990; Johnson, 1990; Robson et al., 1991). Dentre eles foram selecionados os modelos de Biggerstaff (1989) e de Mayrhauser (1996) devido à idéia de correspondência existente entre os componentes de projeto a serem recuperados e os tipos de conhecimento necessários para apoiar a etapa de recuperação de visões funcionais do método FUSION-RE/I (Costa, 1997).

\subsection{1 - Método de Engenharia Reversa FUSION-RE/I}

Esse método é constituido de duas etapas: na primeira, parte-se de considerações lógicas, obtidas por meio de aspectos operacionais e visões de dados disponiveis via interface, para a recuperação de visões funcionais do sistema; na segunda etapa, parte-se de consideraçōes físicas, obtidas por mejo do código fonte, e das visões funcionais para a recuperação de visões estruturais do sistema. A Figura 2.5 visualiza uma sintese do método de engenharia reversa FUSION-RE/I.

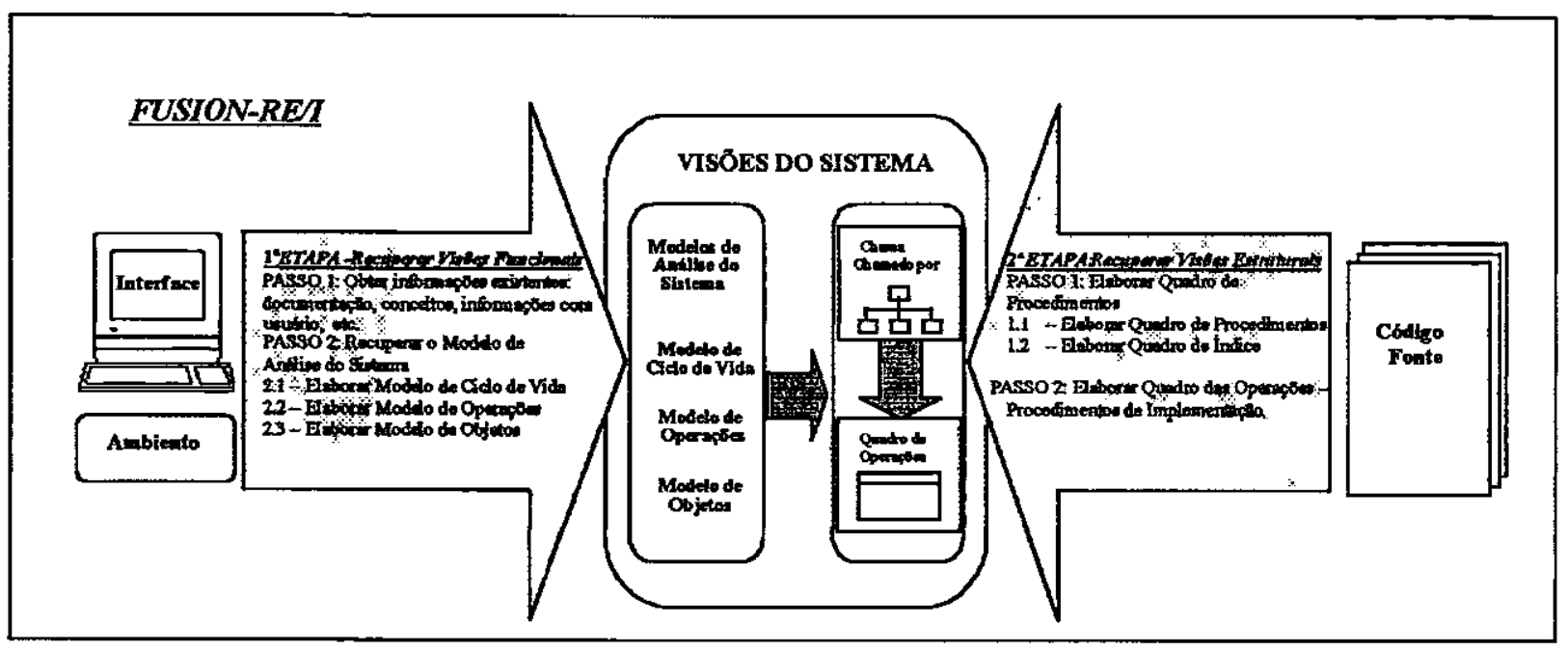

FIGURA 2.5 - SÍNTESE DO MÉTODO DE ENGENHARIA REVERSA FUSION-RE/ (COSTA, 1997)

Conforme ilustrado, a etapa de recuperação de visőes funcionais é subdividida em dois passos: o primeiro envolve a reunião de todas as informaçōes existentes sobre o sistema em estudo. Nesse passo deve-se:

- reunir toda a documentação envolvendo a informação textual existente sobre o sistema (manuais, livros, artigos, listagem do código fonte, etc.) e a informação técnica relacionada aos conceitos pertinentes (dominio do sistema, aplicação, linguagem de implementação do sistema, da interface, método Fusion, etc.);

- identificar os usuários do sistema, pois informaçōes importantes podem não estar documentadas e um modo de recuperá-las é a partir do conhecimento dos 
desenvolvedores e usuários. Esses conhecedores do sistema também são requeridos para auxiliar na validação dos modelos obtidos no processo de aplicação do método FUSIONREת;

- analisar os dados a fim de identificar informações relacionadas aos requisitos do sistema, ao projeto arquitetural, de dados e procedimental, ao ambiente onde o sistema é executado, à linguagem de implementaçâo do sistema, à organização dos arquivos no disco, etc.

O segundo passo da etapa recuperação de visóes funcionais do método FUSION-RE/I envolve recuperar informações da fase de análise do sistema em estudo. Para representar essas informaçóes são utilizados os modelos da fase de análise do método Fusion (Coleman et al.,1994) de desenvolvimento de software orientado a objeto. A fase de análise do Fusion gera dois modelos: 1) o modelo de objetos, que descreve a estrutura do sistema e 2) 0 modelo de interface, que descreve o comportamento do sistema. O modelo de interface é composto de dois modelos que capturam diferentes aspectos do comportamento: o modelo de ciclo de vida, o qual caracteriza seqüências permitidas de operaçōes e eventos do sistema, e o modelo de operações, o qual caracteriza o efeito de cada operação do sistema em termos de mudanças de estado e eventos gerados. Esse passo consiste em:

- elaborar o modelo de clclo de vida do sistema. Para tanto é necessário um bom conhecimento do dominio e da aplicação do sistema submetido à engenharia reversa, incluindo estudo da documentação existente e entrevistas com os usuánios do sistema. A partir disso, e principalmente do uso do sistema, é possivel definir as seqüências de operaçóøs permitidas $\theta$ os eventos de entrada $\theta$ de saída que o sistema aceita;

- elaborar o modelo de operações do sistema, partindo-se do modelo de ciclo de vida, obtido anteriormente. O modelo de ciclo de vida apresenta uma visão geral da funcionalidade das operaçōes do sistema, as quais, para elaboração do modelo de operaçס̄es, devem ser melhor estudadas, por meio do uso intensivo do sistema, de modo que possam ser especificadas detalhadamente;

- desenvolver o modelo de objetos do sistema definindo, primeiramente, assuntos com os quais a funcionalidade do sistema se relaciona. $O$ objetivo da definição de assuntos é identificar os diferentes n/veis de abstraçăo da funcionalidade do sistema e os possivels agrupamentos de operaçōes de um mesmo assunto. Seguindo a nomenclatura do método FUSION-RE (Penteado, 1996), esses assuntos são denominados temas.

Quanto à etapa de recuperação de visōes estruturais do método FUSION-RE/l os passos a serem desenvolvidos são subdivididos em: 1) elaborar o quadro de procedimentos e 2) elaborar o quadro das operações/procedimentos de implementação. O primeiro passo da etapa de recuperação das visões estruturais envolve entender a implementação do sistema, por meio da identificação dos procedimentos de implementação, da funcionalidade de cada 
procedimento identificado e a seqüência de chamadas desses procedimentos. A apresentação dos procedimentos de cada arquivo do sistema é realizada por meio de um conjunto de quadros de chamadas o qual vem acompanhado por um índice geral dos procedimentos do sistema. Esse passo, então, envolve:

- elaborar o quadro de chamadas de procedimentos. Esse subpasso é semelhante ao primeiro passo do método FUSION-RE (Penteado, 1996), no qual a arquitetura do sistema é revitalizada. Para cada arquivo do sistema deve ser elaborado um quadro de chamadas dos procedimentos de implementação. Nesse quadro de chamadas devem ser apresentados todos os procedimentos contidos no arquivo, fazendo-se referência aos procedimentos utilizados (CHAMA) e utilizadores (CHAMADO POR);

- elaborar o quadro índice de procedimentos. Para isso utilizam-se os quadros de chamadas de procedimentos de todos os arquivos. Esses quadros săo reunidos, retirando-se deles, 0 cabeçalho e a coluna contendo a "Descrição" e os procedimentos CHAMA e CHAMADO POR.

O segundo passo da etapa recuperar visões estruturais do método FUSION-RE/I, envolve identificar, entre todos os procedimentos considerados no quadro de chamadas, aqueles que implementam as operações da interface do sistema (identificadas na primeira etapa), e alocá-los, de acordo com sua funcionalidade, a interface ou a um dos temas do sistema (identificados na primeira etapa). Nesse passo, um quadro de operações/procedimentos de implementação deve ser elaborado. Nesse quadro, as duas primeiras colunas săo referentes às opçōes e operações da interface do sistema. A terceira coluna refere-se aos procedimentos que impiementam as opções e as operações do sistema. As demais colunas são utilizadas para indicar a funcionalidade de cada procedimento, associando-os à interface ou a algum dos temas do sistema (identificados na etapa anterior).

\subsection{2 - Modelo de Biggerstaff para o Entendimento de Programa}

Para Biggerstaff (1989), o entendimento de programa é denominado recuperação de projeto e tem como objetivo o desenvolvimento de estruturas que auxiliem 0 entendimento de programas ou sistemas.

O processo de recuperação de projeto consiste em três etapas:

- apoiar o entendimento de programa para manutenção: Examinam-se, primeiramente, as estruturas organizacionais em grande escala, tais como estruturas de sub-sistemas, estruturas modulares e estruturas de dados importantes. Seguindo, recuperam-se várias estruturas úteis de projeto as quais podem ser expressas em formas abstratas, tais como diagramas informais, conceitos e relações informais, refinamento de módulos, fluxo de 
dados e fluxo de controle. Finalmente, faz-se o mapeamento entre as vánias abstraçōes e os segmentos de código que as implementam. A Figura 2.6 ilustra os passos do processo de recuperação de projeto que auxiliam no entendimento de programas escritos em $\mathrm{C}$.

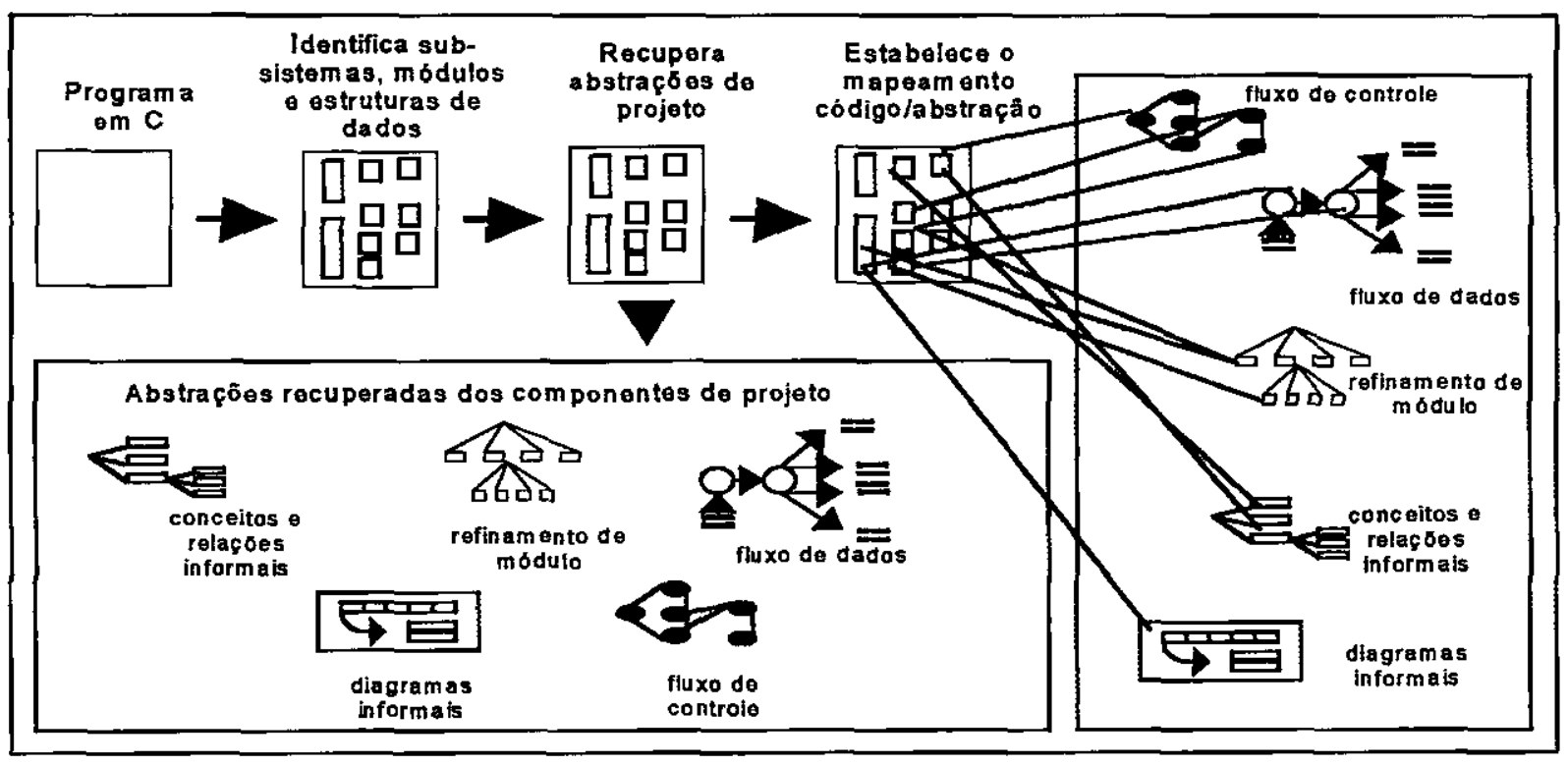

FIGURA 2.6 - PROCESSO BÁSICO DE RECUPERAÇÄO DE PROJETO (BIGGERSTAFF, 1989)

- apoiar a bibljoteca de reuso: Nessa etapa é necessário uma exterisão do processo básico de recuperaçăo de projeto visualizado na Figura 2.6. Essa extensão refere-se à generalização dos componentes de projeto a fim de aumentar sua reusabilidade, ou seja, fazer com que os componentes tomem-se aplicáveis em um amplo espectro de aplicações. Por último, integram-se as novas abstraçōes em uma biblioteca de reuso e o conhecimento recuperado em uma base de conhecimento (Figura 2.7).

O conhecimento armazenado na base de conhecimento refere-se a módulos, itens de dados chaves, artefatos de projeto da engenharia de software e abstraçőes informais de projeto.

- módulos: são identificados utilizando-se uma combinação de experiência e intuição humana e algum conhecimento de padrōes convencionais da organização em aplicações semelhantes ao tipo considerado. Para identificar módulos em grande escala associa-se as estruturas a conceitos semânticos informais. Isto é, produz-se abstraçōes de linguagem natural que representam o conceito essencial de módulo.

- itens de dados chaves: é necessário saber quais são os itens de dados importantes, quais são os conceitos abstratos informais relacionados a esses itens e quais são suas relações com os módulos identificados.

- artefatos de projeto da engenharia de software: existem diferentes artefatos de projeto da engenharia de software dependendo do modelo de processo adotado pela 
organização. Por exemplo, linguagem de descrição de programa (PDL), fluxo de dados, estrutura modular, dicionário de dados, etc.

- abstrações informais de projeto: são necessánias outras estruturas de informação para - conjunto de abstraçōes ser realmente efetivo, muitas das quais não são bem definidas e formais como os artefatos de projeto da engenharia de software. Assim, é necessário recuperar uma ampla variedade de artefatos de projeto que contenham uma mistura de informações informais e formais.

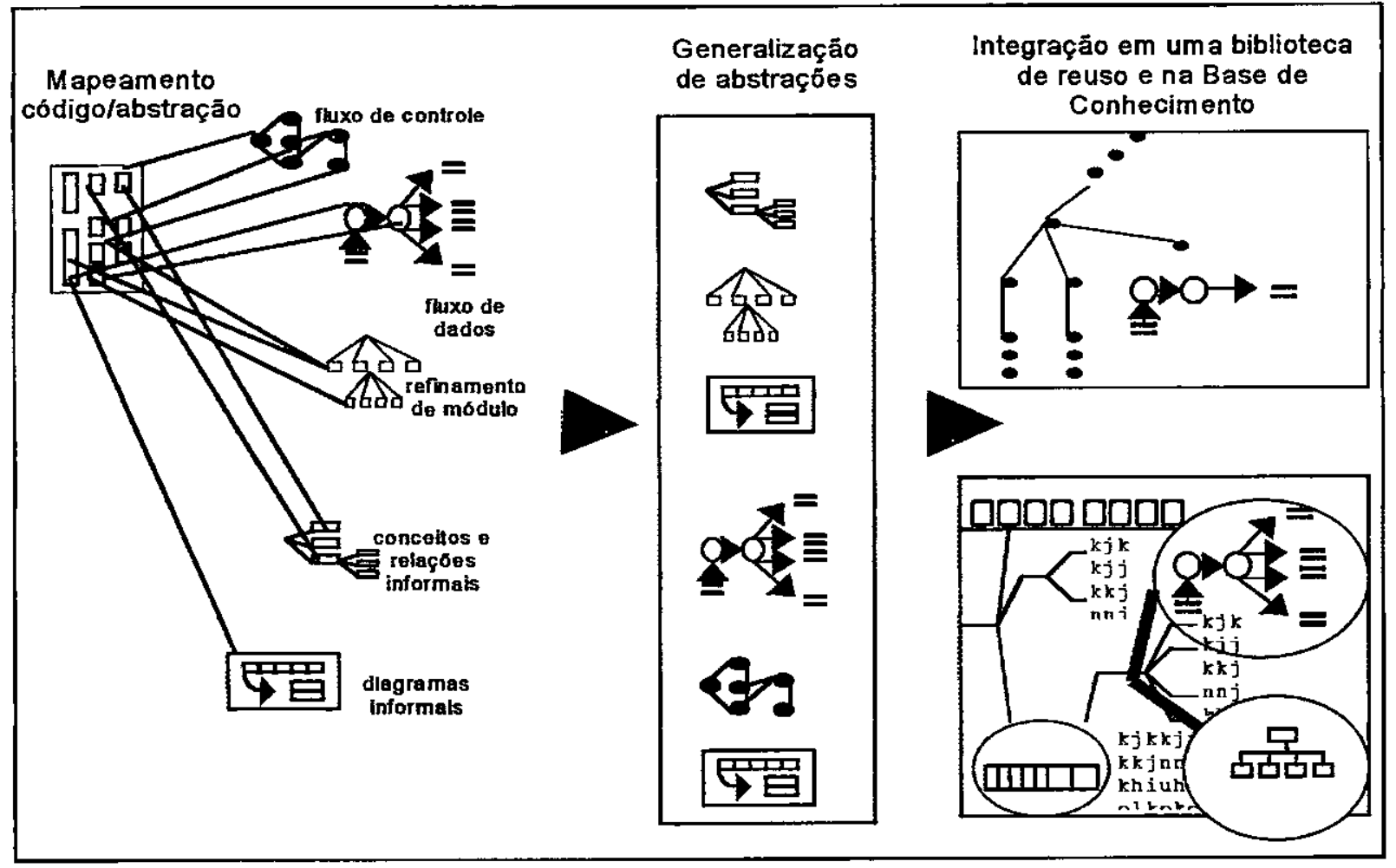

FIGURA 2.7 - EXTENSÃO DA RECUPERAÇĀO DE PROJETO (BIGGERSTAFF, 1989)

A recuperação dos conceitos informais e a determinação de suas realizações - dentro de um programa especifico e em um certo contexto - é chamada problema de assimilação de conceito. O sistema de recuperação de projeto chamado DESIRE, considerado um assistente de entendimento de programa, apresenta algumas estratégias, por meio de cenánios exemplos, e algumas classes de ferramentas que suportam o problema de assimilação de conceito (Biggerstaff et al., 1994).

A não utilização da informação informal pode acarretar na obscuridade das interpretações das funçōes. Algumas pesquisas mostram a importância da informação informal para o entendimento do programa. 
Schneiderman apud Robson ${ }^{\imath}$ investigou o efeito de usar identificadores significativos a fim de compreender o programa. Concluiu que, em termos do modelo sintático/semântico, o efeito de nomes de variáveis significativas simplifica a conversão da representação sintática para a semântica.

Segundo Miara et al. apud Robson ${ }^{2}$, programas com linhas de comando escritas com deslocamentos ("identados") são facilmente compreendidos. Concluiu que, uma "identaçäo" exagerada pode diminuir a taxa de compreensão e que uma "identação" ideal seria de dois a quatro espaços para cada novo bloco.

Woodfield et al. apud Robson ${ }^{3}$ investigaram o efeito dos comentários para a compreensão do programa. A conclusão foi que comentánios auxiliam o entendimento de programa, embora em programas com boa "identação" e identificadores significativos o uso dos comentários não faça uma diferença significativa.

- aplicar os resultados da Recuperação de Projeto: Nessa etapa a base de conhecimento é utilizada para recuperar o projeto. A Figura 2.8 evidencia que os componentes abstratos de projeto armazenados na base de conhecimento tornam-se o ponto inicial para a descoberta de candidatos às realizaçōes concretas em um novo código de sistema.

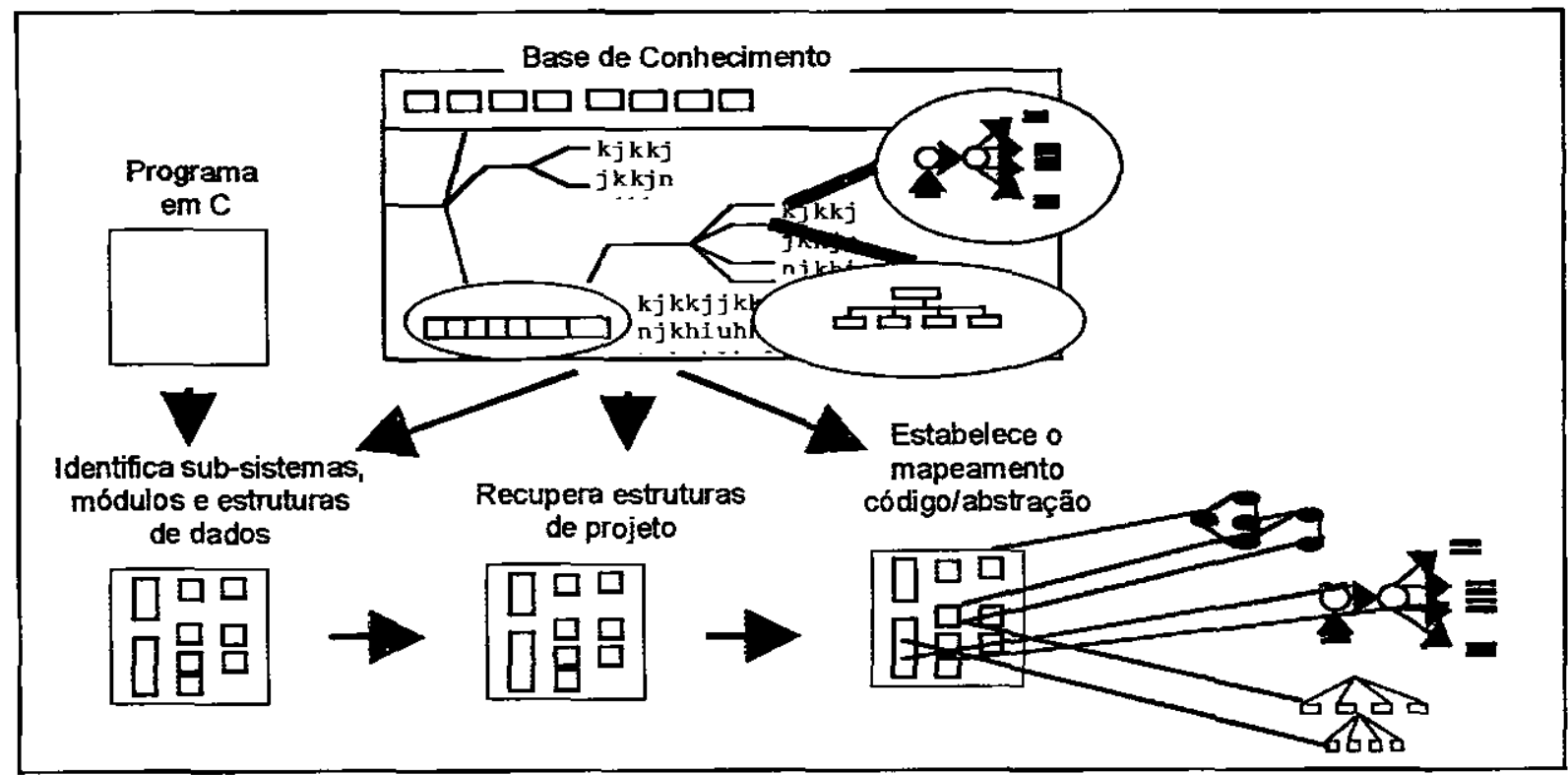

FIGURA 2.8 - PROCESSO DE RECUPERAÇAO DE PROJETO BASEADO EM MODELO (BIGGERSTAFF, 1989)

\footnotetext{
${ }^{1}$ SHNEIDERMAN, B. Software Psychology, Winthrop, 1980. Apud Robson, D. J. (Robsan et al., 1991).

${ }^{2}$ MIARA, R J. A al. Program identtation and comprethensibility, Comm. of the ACM, 26(11), 861-867, 1983. Apud Robscon, D.J. (Robson et ol., 1991).

${ }^{3}$ WOODFIELD, S. N. at al. The effect of modularization and commentes an program comprehension, Proc. $5^{\text {th }}$ Int. Conf. on Software Engineering, 215-223, 1981. Apud Robscn, D. J. at al. (Robson et al, 1991).
} 


\subsection{3 - Modelo de Mayrhauser para o Entendimento de Programa}

Para Mayrhauser $(1995,1996)$ o processo de entendimento de programa conduz à criação de um modelo mental do software considerado. Para a criação desse modelo utiliza-se tanto conhecimento geral, independentemente da aplicação especifica do software que está se tentando entender, quanto conhecimento especifico, que representa o nivel de compreensäo da aplicação do software.

O processo de entendimento combina o conhecimento existente com o novo conhecimento até que se entenda o código. O conjunto de combinações é o modelo mental. O conhecimento existente está relacionado à linguagem de programação e ao ambiente de computação, principios de programação, algoritmos e abordagens de possiveis soluçöes. Assim, se o programador já trabalhou com o código anteriormente, o conhecimento existente faz parte do modelo mental do software. O novo conhecimento relaciona-se, principalmente, ao produto de software e é obtido por mejo do processo de entendimento do código fonte. Esse conhecimento relaciona-se à funcionalidade, à arquitetura do software, aos algoritmos e objetos implementados, aos controles, ao fluxo de dados, etc.

O modelo mental é uma representação interna do software considerado. Esse modelo contém elementos estáticos como estruturas texto, chunks, planos, hipóteses, sinais e regras de raciocínio, e elementos dinâmicos como estratégias.

- estruturas texto: incluem o texto do programa e sua estrutura. As unidades de conhecimento do tipo estrutura texto incluem construções de controle - iteração, seqüências e construçōes condicionais; definições de variáveis; hierarquia de chamada de módulos e definições de parâmetros de módulos. As microestruturas do texto do programa contêm comandos reais de programa e seus relacionamentos. Por exemplo, um comando begin inicia um bloco de código, enquanto um subseqüente comando if indica uma estrutura de controle condicional com um propósito particular. Seu relacionamento é que o if faz parte do bloco inicializado pelo begin.

- chunks: são estruturas de conhecimento contendo vários niveis de abstração de estruturas texto. Chunks de estruturas texto são chamados macroestruturas e são identificados por um nome. Correspondem à organização do fluxo de controle do texto do programa. Por exemplo, a microestrutura para um sort inclui todos os comandos, enquanto a macroestrutura é uma abstração do bloco de código e inclui somente o nome sort. Chunks de nivel mais baixo podem formar chunks de nivel mais alto, os quais incluem muitos nomes e os relacionamentos do fluxo de controle entre eles.

- planos: são elementos do conhecimento para desenvolver e validar suposiçöes, interpretaçöes e inferencias. Esses planos incluem o conhecimento de causa a respeito do fluxo de informaçöes e refacionamentos entre as partes do programa. Os planos de programação são conceitos de programação de baixo, intermediário e alto nivel. Exemplos 
de conceitos de nivel intermediário são algoritmos de busca e estrutura de dados (como árvores). Os planos de domínio incorporam todo conhecimento sobre a área do problema exceto o código e algonitmo de baixo nível. Planos de domínio aplicam-se a objetos no mundo real e são considerados muito importantes para o entendimento da funcionalidade do programa. Por exemplo, os planos para desenvolver um software para projetar automóveis devem incluir esquemas relacionados à aparência e função de um carro genénico. Planos de domínio também fazem referência ao ambiente que envolve a aplicação do software, à arquitetura do domínio específico e às soluções alternativas.

- hipóteses: são suposições definidas como resultado das atividades de compreensão. As três principais hipóteses existentes para Letovsky apud Mayhauser ${ }^{4}$ são: porquê (o propósito de uma função ou escolha de projeto), como (o método para atingir o objetivo do programa) e qual (classificação, por exemplo, uma vanável ou função). As hipóteses orientam a direção de futuras investigações. Gerar hipóteses sobre o código e investigar se estas devem ser aceitas ou rejeitadas é uma importante caracteństica de entendimento de código.

- sinais: são indícios que levam ao conhecimento e podem ser texto ou um componente de outro conhecimento. Por exemplo, um comando swap dentro de um laço ou procedimento pode ser um sinal de uma função de classificação. Sinais são úteis na obtenção de um entendimento de alto nivel.

- regras de raciocínio: são convençöes na programação, tais como padrões de codificação, implementaçöes de algonitmos, uso esperado de certas estruturas de dados, etc. Essas regras estabelecem as suposições do programador através das quais são recuperados os planos de programação.

Referindo-se a um elemento dinâmico do modelo mental, uma estratégia é uma abordagem global de alto nivel para o entendimento, ou melhor, é um estilo ou método para o entendimento. A estratégia orienta uma seqüência de ações seguindo um plano para alcançar uma meta. Por exemplo, se a meta é entender um bloco de código, a estratégia pode ser ler e entender cada linha de código sistematicamente enquanto constrói-se uma representação mental em niveis de abstração mais altos. Estratégias ovientam dois mecanismos de entendimento que produzem informação: o chunking e cross-referencing.

- Chunking cria novas estruturas de abstração em um nivel mais alto a partir de chunks de estruturas de nivel mais baixo. Conforme as estruturas são reconhecidas, os nomes substituem os detalhes dos chunks de nivel mais baixo. Dessa maneira, estruturas de nivel mais baixo podem ser "montadas" em estruturas maiores em um nivel mais alto de abstração.

\footnotetext{
${ }^{4}$ LETOVSKY, S. Cognitive Processes in Program Comprchension, Proc. First Workshop Empirical Studies of Programmers, Ablex Publishing Norwood, N. J., pgs. 58-79, 1986. Apud Maychauser A. (Maymausser, 1995).
} 
- Cross-referencing relaciona diferentes níveis de abstração, tais como uma visão de fluxo de controle e uma visão funcional por meio do mapeamento de partes de programa com as descriçōes funcionais. Cross-referencing é essencial para a construção de uma representação mental por meio dos niveis de abstração.

O modelo de compreensão de código de Mayrhauser denominado metamodelo integrado, combina o modelo de compreensão de Soloway apud Maymauser ${ }^{5}$ (entendimento top-down ou modelo de domínio) com os modelos de Pennington apud Mayrhauser ${ }^{6}$ (entendimento bottom-up).

O metamodelo integrado de Mayrhauser (1995, 1996) (Figura 2.9) tem quatro componentes principais: o modelo top-down, o modelo de situação, o modelo de programa e a base de conhecimento. Os três primeiros refletem o processo de compreensão; o quarto é necessário para a construção dos anteriores. O modelo top-down, o modelo de situaçáo e o modelo de programa correspondem às representações mentais e estratégias usadas para construí-los em diferentes niveis de abstração. Para a construção dessas representações mentais é necessária a base de conhecimento, na qual são armazenadas as novas informaçס̃es para uso futuro. Assim, o metamodelo integrado caracteriza-se pela construção do modelo de programa, modelo de situaçăo, modelo top-down e do conhecimento para a construção da representação mental do código.

$\mathrm{Na}$ Figura 2.9, os retângulos grandes mostram cada processo de compreensão e o triângulo representa o conhecimento usado em cada processo. Cada processo inicia com a documentação existente e prossegue mapeando-se 0 conhecimento acumulado aos documentos. Os modelos de programa e de situaçăo têm componentes de memória de curto prazo e são diferenciados pelo nivel de abstraçăo. O modelo de programa contém microestruturas (comandos de código e seus relacionamentos) e macroestruturas (elementos abstraídos de microestruturas). A memória de curto prazo do modeio de situação contém mapeamentos para o modelo de programa e para o modelo top-down dos quais, a partir das informações destes, constrói-se planos de mais alto nivel. Chunking generaliza abstraçס̋es de baixo nivel para descriçס̃es de mais alto nivel ou em um nome. Cada processo do modeio de situação e do modelo de programa tem um componente chunking. Chunking causa o armazenamento de descrições em alto nivel na memória de longo prazo.

\footnotetext{
s SOLOWAY, E; ADELSON, B; EHRLICH, K. Knowledge and Processes in the Comprehension of Computer Programs, in The Nature of Expertise, M. Chi, R. Glauser, and M. Farr, eds., Lawrence Eribaum Associates, Hillsdale, N.J., 1988, pp. 129-152. Apud MAYRHAUSER, A. V. (Maynhauser, 1996).

PENNINGTON, N. Stimulus Structures and Mental Representations in Expert Comprehension of Computer Programs. Cognitive Psychology, vol. 19, 1987, pp. 295.341. Apud MAYRHAUSER, A. V. (Mayrhauser, 1996).
} 


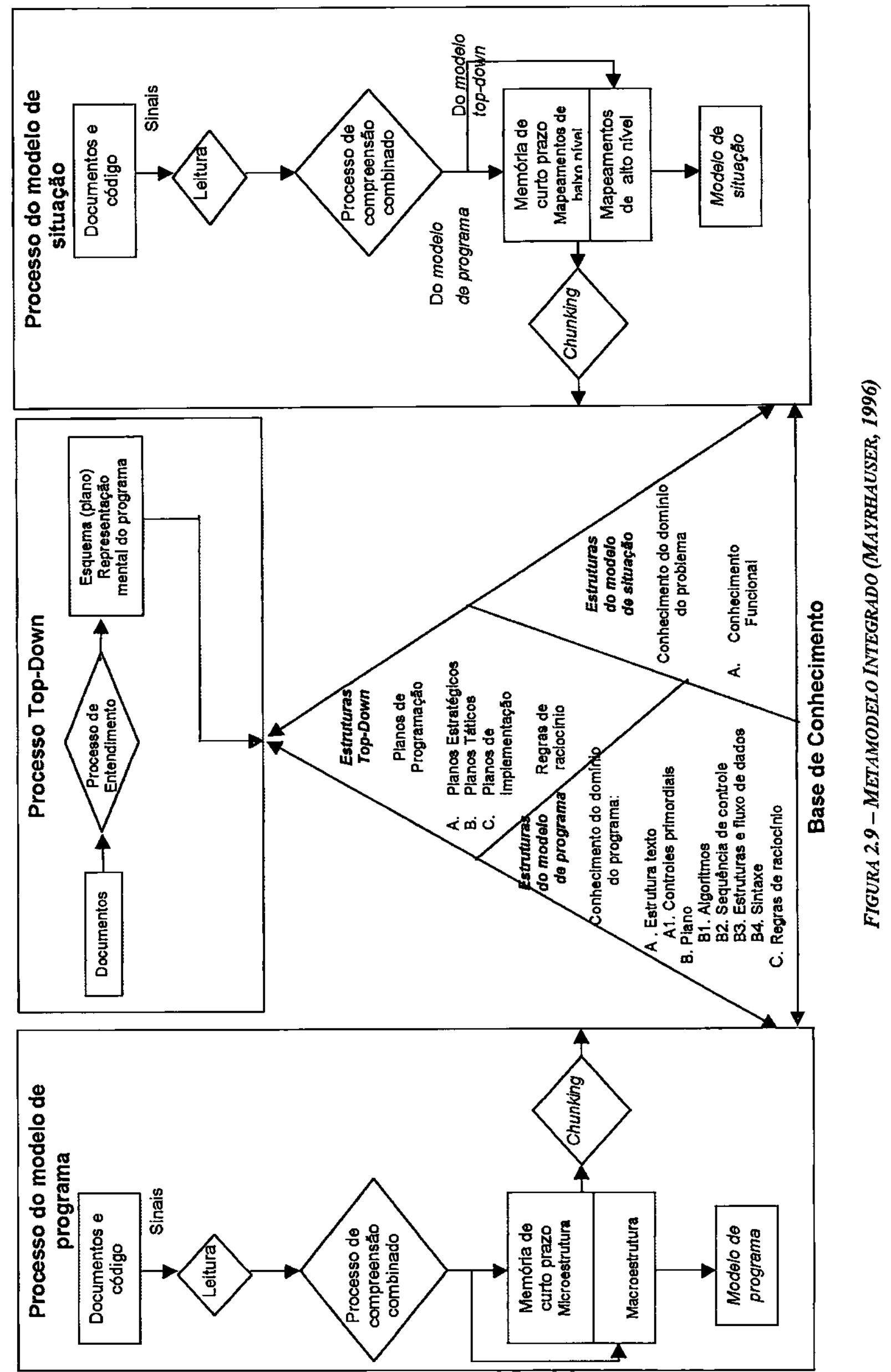


As estruturas de conhecimento construídas por algum dos três modelos são disponiveis para os outros dois. Cada componente de modelo tem seu tipo de conhecimento. As estruturas de conhecimento do modelo top-down contêm planos de programação (conceitos de programação). As estruturas do modelo de situação incorporam conhecimento do mundo real e conhecimento funcional (planos de dominio). As estruturas do modelo de programa consistem de construçōes e sintaxe da linguagem de programação. O metamodelo integrado permite a ativação e potenciais trocas entre qualquer um dos três componentes em qualquer momento do processo de compreensão. Essas potenciais trocas estāo representadas na Figura 2.9, por intermédio de flechas ao longo da base de conhecimento.

\section{6 - Consideraçōes Finais}

Neste capitulo foram apresentados alguns dos principais conceitos relacionados à engenharia reversa, com ênfase aqueles referentes ao entendimento de programa. Para tanto, é necessário adquirir conhecimento sobre o sistema.

O próximo capítulo abordará conceitos referentes ao contexto de aquisição de conhecimento, algumas técnicas de aquisição de conhecimento explicito e implicito e algumas estruturas de representação de conhecimento. 



\section{CAPÍTULO 3 - AQUISIÇÃO DE CONHECIMENTO}

\section{1 - Considerações Iniciais}

Como este trabalho envoive o uso da aquisição de conhecimento, neste capítulo são abordados alguns conceitos referentes ao contexto de aquisição de conhecimento, algumas técnicas de aquisição de conhecimento explicito e implícito e algumas formas de representação de conhecimento.

\section{2 - Aquisiçăo de Conhecimento}

A expressão "aquisiçäo de conhecimento" corresponde a todos os mecanismos para adquirir conhecimento a ser utilizado na modelagem de um domínio de conhecimento. Pode-se dizer também, que a aquisição de conhecimento é o processo que visa obter toda a informação necessária para a construçăo de uma base de conhecimento para sistemas inteligentes (Rezende \& Pugliesi, 1998).

Em (Goonatilake \& Khebbal, 1995) a aquisição de conhecimento é descrita como um processo envolvendo a extração, interpretação e representação do conhecimento de um dado 
dominio, e é considerada como sendo o estágio mais difícil e precáno no desenvolvimento de sistemas inteligentes.

A aquisição de conhecimento é o elemento mais crítico no desenvolvimento de sistemas especialistas ${ }^{1}$. É necessáno algum modo de organizar as diretrizes para formalizar a aquisição de conhecimento. Uma forma para tal formalização é por intermédio de um processo.

Um processo de aquisição de conhecimento envolve a extração, interpretação e representação do conhecimento de um dado dominio. Neste contexto, alguns papéis importantes são desempenhados como o do engenheiro de conhecimento, o do especialista do dominio e do usuário final.

O engenheiro de conhecimento é o profissional responsável pela elaboração de um plano para aquisição de conhecimento explícito e pela aquisição de conhecimento propriamente dita. Sua tarefa primordial é extrair o conhecimento do(s) especialista(s) do domínio, ou de outra fonte - usuários finais, relatórios, livros, manuais e dados entre outros interpretá-lo e representá-lo em uma base de conhecimento.

O especialista do domínio é o profissional selecionado devido à sua especialidade em um determinado dominio e sua habilidade em transpor seu conhecimento. $\mathrm{Na}$ extração de conhecimento, os especialistas do domínio se destacam devido às suas experiências no domínio do problema e ao alto grau de conhecimento. Eles são, muitas vezes, as únicas fontes de informação que as companhias especializadas preservam. Em outras situações, os especialistas do dominio podem ser chamados para oferecer especialidade, que pode ser combinada e compartilhada entre trabalhadores menos especializados.

Os usuários finais têm, de forma geral, uma boa visão do dominio em questão e podem fornecer informaçōes de teor valioso durante as investigaçōes iniciais.

O processo de aquisição de conhecimento pode ser realizado de forma manual, conhecido como aquisição de conhecimento explícito, elicitação ou eliciação de conhecimento, ou automática, conhecido como aquisiçăo de conhecimento implícito.

A abordagem de aquisição de conhecimento explícito teve origem na integração das ciências humanas, tais como a psicologia e sociologia, nas quais estuda-se o comportamento humano e técnicas de relacionamento interpessoal, com as técnicas de inteligência artificial, tais como representação de conhecimento e construção da base de conhecimento, que visam estruturar o conhecimento humano em uma forma a ser interpretada e consultada pela máquina (Figura 3.1).

\footnotetext{
${ }^{1}$ Sistemas Especialistas são programas que resolvem problemas em um certo dominio de conhecimento mediante um processo de raciocinio baseado nesse conhecimento especifico.
} 


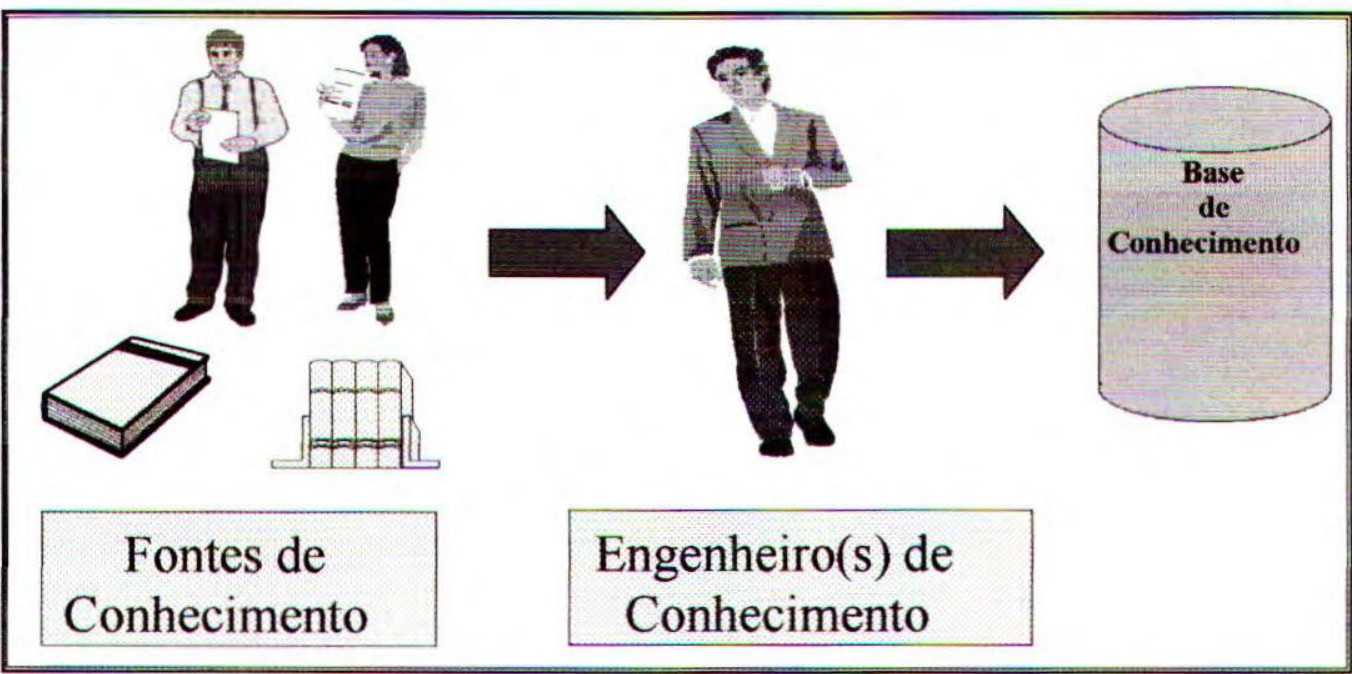

FIGURA 3.1 - AQUISIÇÃO DE CONHECIMENTO EXPLÍCITO (REZENDE \& PUGLIESI, 1998)

\section{3 - Técnicas de Aquisição de Conhecimento}

Existem técnicas apropriadas tanto para a aquisição de conhecimento explícito quanto para a aquisição de conhecimento implícito. Técnicas como entrevista, análise de protocolos, rastreamento de processo, brainstorming, repertório grid, estudo de casos, introspecção e cenários são exemplos para a aquisição de conhecimento explícito (McGraw \& Briggs, 1989; Cooke, 1994; Tuthill, 1990). Já data mining (Fayyad et al., 1996) é um exemplo para a aquisição de conhecimento implícito.

Entrevista é a técnica mais comum utilizada por engenheiros de conhecimento para elicitação - a partir de especialistas - do conhecimento do domínio em questão. Utilizada nos estágios iniciais da aquisição de conhecimento, permite que o engenheiro de conhecimento compreenda, rapidamente, os conceitos e vocabulário do domínio.

Em geral, a entrevista nem sempre é a melhor escolha de técnica e é muitas vezes aplicada incorretamente. Os engenheiros de conhecimento não especializados podem entender a entrevista como a única técnica de elicitação e podem ter uma idéia inapropriada do seu propósito e estrutura.

Durante a entrevista (1) o engenheiro de conhecimento deve deixar claro o propósito do envolvimento dos entrevistados na sessão; (2) as informações podem ser registradas como notas, em áudio-tape ou vídeo-tape; (3) situações, instâncias e problemas específicos são bem mais fáceis de serem conduzidos; (4) o especialista do domínio não deve ser forçado a produzir informações de maneira determinada pelo engenheiro de conhecimento na qual ele 
não entende o método - é melhor usar uma representação natural e depois transportar as informações para uma representação devida; (5) o engenheiro de conhecimento deve tentar năo interromper o raciocinio do especialista do domínio, mesmo que esse repita as informações várias vezes, e deve prestar muita atenção e ouvir cuidadosamente não só os fatos, teorias e heurísticas importantes, mas o caminho pelo qual o especialista do dominio manipula o conhecimento (Kidd, 1987).

Há vários caminhos para se conduzir uma sessão de entrevista. Os engenheiros de conhecimento necessitam estar cientes das várias técnicas de questionamento, muitas das quais têm sua base na psicologia, e usar as que são mais apropriadas para uma determinada situação. A utilização do método depende muito do problema, do tipo de conhecimento a ser elicitado e das personalidades envolvidas.

As entrevistas podem ser do tipo:

- desestruturada: é apropriada quando o engenheiro de conhecimento precisa explorar um problema em questão durante, principalmente, as fases iniciais. Raramente produz descrições completas $e$ bem organizadas do processo cognitivo. Trata-se de uma entrevista mais informal;

- estruturada: é apropriada quando o engenheiro de conhecimento deseja informações específicas do conteúdo ou o esclarecimento de uma questão. Este tipo de entrevista é orientada a objetivos e os resultados são mais úteis para a base de conhecimento.

Muitos projetos iniciam com a entrevista desestruturada onde o engenheiro de conhecimento toma-se familiar com a terminologia geral e com os problemas. De qualquer maneira, isso tende a consumir tempo e dificulta a análise, por isso, é usual mover-se para a entrevista estruturada ou a um outro método.

Alguns métodos de entrevista são (Kidd, 1987):

- casos interessantes: pede-se ao especialista para descrever casos dificeis ou interessantes que se recorde, e sua experiência naquele tempo. Casos difíceis e interessantes são mais memoráveis e estimulantes, assim a probabilidade de omitir detalhes essenciais toma-se bem menor comparada a casos fáceis;

- características $\theta$ decisões: enquanto os especialistas não estão aptos a formular regras e heuristicas, podem fomecer listas de caracteristicas e possiveis decisōes;

- distinção de objetivos: é dado um objetivo específico para o especialista e este deve especificar o conjunto de evidências que são necessárias e suficientes para distinguir este objetivo de outras altemativas. Se isso é feito até o objetivo final, para cada objetivo intermediário, pode ser construído um modelo estruturado desse conhecimento. Este método provoca discussões a respeito da natureza precisa e razöes para os objetivos; 
- dividindo o domínio: os especialistas começam descrevendo as características, que são agrupadas sucessivamente até que se alcance o objetivo final;

- análise de decisão: métodos de análise de decisão são aplicados em muitas áreas de gerenciamento e negócios. O método genérico é: (1) listar todas as decisões possíveis; (2) para cada decisão, listar as possíveis conseqüências; (3) para cada conseqüencia, avaliar o valor e a probabilidade de ocorrência; (4) calcular o valor esperado de cada conseqüência multiplicando o valor pela probabilidade; (5) calcular o valor esperado de uma decisão como o total de todos os valores esperados dessas conseqüências e (6) selecionar a decisão que maximiza o valor esperado. Um problema desse método é a confiança nas estimativas de valores e probabilidades.

Brainstorming é uma técnica designada a estimular e encorajar pensamentos e gerar idéias criativas em grupo em um menor espaço de tempo possivel. Originou-se da preocupação dos altos executivos de negócios para com os gerentes subordinados a eles, que os imitavam em sua prudência e sabedoria. Embora essa seja uma tática politicamente segura, exclui as idéias dos gerentes, que podem ser úteis.

É usada em sessões de aquisição de conhecimento envolvendo equipes com vários especialistas, cujo objetivo é gerar, e não necessariamente validar, um conjunto de soluções. A partir daí, nas sessões subseqüentes podem ser utilizadas outras técnicas para validar, avaliar e priorizar as soluções a fim de alcançar as tomadas de decisões. Essa técnica, também, é utilizada para auxiliar os especialistas do domínio e os engenheiros de conhecimento a se libertarem de soluções óbvias ou convencionais de problemas complexos.

Rastreamento de Processo é um conjunto de técnicas que permite ao engenheiro de conhecimento determinar uma série de pensamentos dos especialistas do domínio, enquanto estes terminam uma tarefa ou chegam a uma conclusão. Os engenheiros de conhecimento investigam as informaçōes que o(s) especialista(s) usa(m) para tomar uma decisão e como foi o processo que os especialistas usaram para chegar até ela.

A sessão pode ser baseada em duas técnicas básicas:

- Venbalização Concomente: o especialista "pensa alto" como resolve o problema, ou seja, produz um relatório verbal das açōes, consideraçōes, pontos de decisão $\theta$ estratégias enquanto está realizando alguma tarefa.

- Venalização Retrospectiva: o engenheiro de conhecimento registra, em fitas ou manualmente, o procedimento do especialista na resolução do problema a fím de, posteriormente, revisarem juntos a sessão para produzir o protocolo. 
Análise de Protocolos requer que o engenheiro de conhecimento determine uma das várias técnicas para analisar os protocolos e os relatórios verbais que foram gerados pelo especialista do domínio no final de uma sessão. Deve ser antecedido por uma sessão de entrevistas ou de rastreamento de processo.

A análise de protocolos é utilizada para estudar como as pessoas resolvem problemas e para identificar operaçöes especificas usadas para se mover de um estado de conhecimento para outro.

Quando se tem o resultado de uma sessão de aquisição de conhecimento registrado em fitas ou manualmente, o engenheiro de conhecimento deve traduzir esse conhecimento em protocolos para analisá-lo posteriormente. Estas informações podem ser obtidas tanto por sinais verbais quanto não verbais.

Repertório Grid è uma técnica para elicitar e analisar um modelo do domínio do especialista. A teoria desta análise estabelece que cada pessoa age como um "cientista" que classifica e organiza o seu mundo. Os individuos, baseados nestas classificações, são habilitados para construir teorias de como funciona um certo dominio e para agir no domínio baseado em suas teorias. Uma vez que as classificaçōes foram identificadas e construidas isoladamente, um repertório grid pode ser desenvolvido para representar a compreensão do especialista de uma entidade especifica (um problema, um conceito), ou melhor, para representar os conceitos básicos do domínio.

Para desenvolver uma "grid", o engenheiro de conhecimento precisa elicitar, primeiramente, um conjunto de construtores (como, características bipolares). Depois, o engenheiro de conhecimento precisa estimular o especialista do domínio a produzir um conjunto de exemplos, chamados elementos. Logo após, o engenheiro de conhecimento solicita que o especialista classifique cada elemento de acordo com os construtores.

Depois da classificação de cada elemento, os resultados podem ser analisados por uma variedade de técnicas, incluindo análise de fator $e$ análise de cluster. $O$ objetivo da análise é medir similaridades e diferenças entre os objetos e representar isso graficamente por meio de uma "grid".

Essa técrica è mais utilizada nas fases finais de aquisição de conhecimento. É apropriada quando há vários conceitos relacionados, normalmente identificados por novatos.

Estudo de Casos é uma técnica na qual elicita-se o conhecimento do analista por intermédio de casos já documentados. É utilizada para elicitar conhecimentos específicos, sendo que os casos devem cobrir vánas possibilidades dentro do domínio. 
O próprio especialista escolhe um ou mais casos resolvidos por ele para descrever ao engenheiro de conhecimento. São expostos os passos desenvolvidos e as considerações levadas em conta para resoluçăo do problema.

Mesmo havendo material suficiente dentro do domínio para o desenvolvimento do estudo, o conhecimento obtido provavelmente será insuficiente. Daí, a utilização de entrevistas e análise de protocolos para auxiliar. $O$ sucesso do método depende, proporcionalmente, do caso selecionado a ser explanado.

Introspecção é útil para a obtenção de uma estratégia global de resolução. $O$ especialista verbaliza sensaçōes, memórias, sentimentos e imagens percebidas enquanto resolve um problema.

As desvantagens da introspeç̧ão são: (1) o conhecimento talvez não reflita o processo de tomada de decisão usado pelo especialista, pois informaçöes ficam no subconsciente; (2) a análise do raciocínio pode fazer com que o especialista se concentre em detalhes insignificantes e (3) o sucesso do método depende do caso.

As formas mais comuns de introspecção são casos passados (descrição retrospectiva), hipotéticos (simulação de um cenário) ou difíceis (episódio crítico).

Cenários modelam uma fração do mundo real com a intenção de modelar um sistema; evoluem durante o ciclo de vida do software e auxiliam na definição de requisitos funcionais e não-funcionais. Segundo Loma Zorman, "cenários são descriçōes de situaçőes" (Leite, 1997). Em geral, cenários podem ser vistos como descrições que ajudam a definir um sistema e suas características, a partir das necessidades do usuánio, auxiliando assim, na fase de especificação de requisitos. Essa técrica consiste em representar cenas extraídas do cotidiano, do dominio do problema, que são identificadas por estímulos e respostas do sistema, sempre com base na visão de quem gerou o estímulo.

Cada cenário pode descrever uma ou mais cenas associadas com o uso hipotético do sistema. Cada uma dessas cenas deve revelar procedimentos sobre como utilizar recursos do domínio, manipular a entrada de dados e obter informação do sistema.

Cenários podem ser representados de diferentes formas. Essas variam desde bastante informais (narrativa simples) até totalmente formais (gramáticas regulares), passando por representações semi-formais em forma de tabelas ou diagramas. Dentre algumas formas de representação dos cenários encontram-se os casos de uso propostos por Jacobson (Leite, 1997).

Algumas heurísticas para a produção de cenánios: (1) identificação dos atores, (2) elaboração da lista de cenários candidatos, (3) descrição dos cenários candidatos a partir dos atores principais, (4) ampliação da lista de candidatos, (5) descrição dos cenários a partir dos 
atores secundários e (6) análise dos cenários que engloba verificação - descoberta de subcenánios, revisão das restriçōes e das exceçöes - e validação - reuniāo e entrevista com os clientes, protótipos.

Como exemplo de um método que utiliza cenários tem-se o chamado ERACE Engenharia de Requisitos Apoiada por Cenários - (Caldas, 1998), que propōe a elicitação e modelagem de requisitos por intermédio de cenánios. Essa proposta é baseada na fusão dos pontos críticos das fases de engenharia de requisitos dos principais métodos que utilizam a técnica de construção de cenários, tais como OOSE, OBA, FASA, UORE e UML.

O processo utilizado para descrever as atividades do método ERACE, mostrado na Figura 3.2 é composto de duas fases: especificação das interações e modelagem dos cenários. Na primeira fase são construídas especificaçōes das interaçōes que ocorrem no sistema em um diagrama de interação das cenas de uso (DIC) que contém informações sobre os atores e as cenas de uso. A construção desse diagrama é baseada nas informações derivadas de um documento inicial de requisitos de software que deve conter todos os requisitos funcionais e de qualidade do software, as capacidades do produto, os recursos disponiveis, os beneficios e os critérios de aceitação. Nessa fase todas as informações contidas no DIC devem ser armazenadas num glossánio. Na segunda fase são descritas e formalizadas as operaçōes existentes em cada cena de uso e são criados os diagramas abstratos detalhados (DADs) das cenas. Nessa fase, utiliza-se o DIC como entrada.

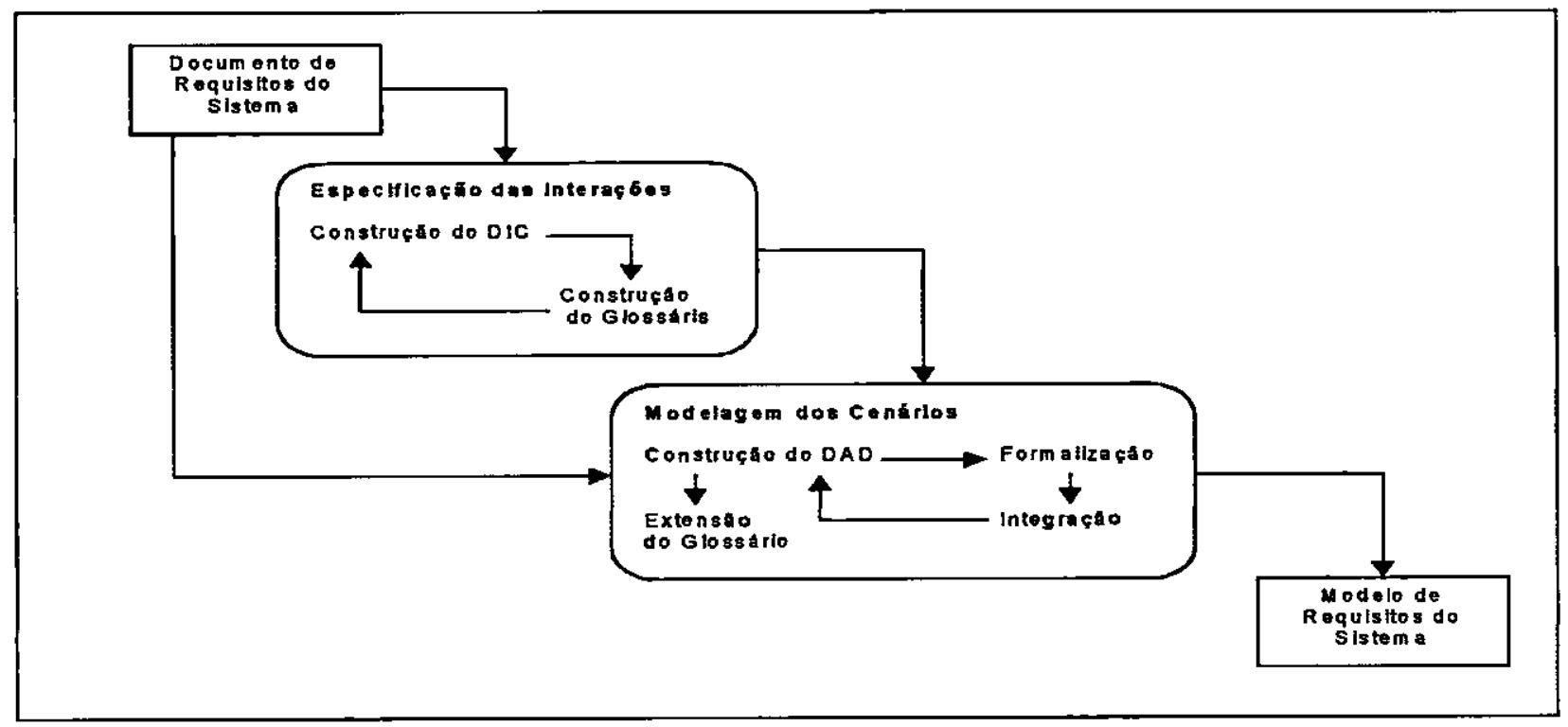

FIGURA 3.2-PROCESSO ERACE (CALDAS, 1998) 
Data Mining é considerada a parte central de um processo de extração de conhecimento em bases de dados (Knowledge Discovery in Databases - KDD). Data Mining envolve a aplicação de algoritmos de busca para encontrar padroes nos dados analisados. O processo KDD abrange: seleção do dado, pré-processamento, transformação, Data Mining e interpretação/avaliação dos resultados (Figura 3.3).

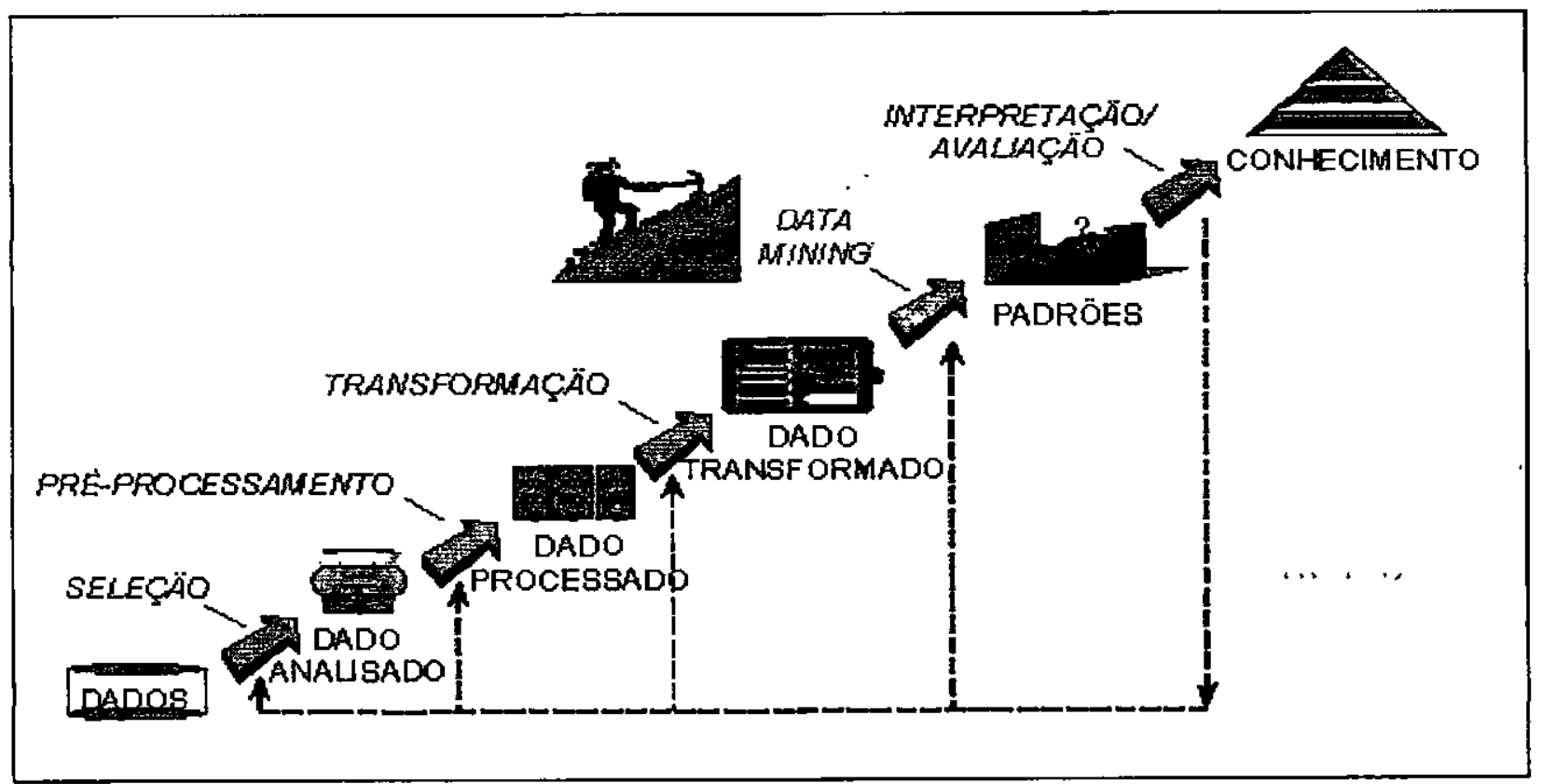

FIGURA 3.3 - PROCESSO DE EXTRAÇĀO DE CONHECIMENTO EM BASES DE DADOS (KDD)

(FAYYAD ET AL, 1996)

- Seleção: seleciona ou segmenta os dados de acordo com alguns critérios, podendo ser determinados subconjuntos de dados;

- Pré-processamento: certas informaçōes desnecessárias podem ser removidas e o dado pode ser re-configurado a fim de assegurar o formato de consistência (o dado pode ter sido gerado por diversas fontes);

- Transformação: envolve não somente transferir dados de um formato para outro, mas também agregar esses dados a outras informaçōes quando necessário;

- Data Mining: refere-se à extração de padröes interessantes embutidos em bases de dados. Esses padrōes podem ser descobertos por meio de regras que descrevem propriedades dos dados, padrōes que ocorrem com freqüência, classificação de objetos, etc.

O processo data mining necessita de algoritmos eficientes, rápidos e eficazes para montar modelos, ou determinar padröes, dos dados observados. Os modelos montados desempenham o papel de todo o conhecimento inferido; 
- Interpretação e Avaliação: a partir dos padröes extraídos do sistema, têm-se os conhecimentos que podem ser usados para suporte e tomada de decisões humanas.

As técnicas de aquisição de conhecimento são utilizadas para adquirir conhecimento. Entretanto, esse conhecimento precisa ser representado de alguma forma dentro da base de conhecimento para posterior utilização. Dentre as formas de representação de conhecimento podem ser citadas regras de produção, redes semânticas, frames, scripts, entre outras, abordadas na próxima seçäo.

\section{4 - Formas de Representação do Conhecimento}

Depois de adquirido o conhecimento é necessário representá-lo em algum tipo de estrutura como regras, redes semânticas, frames e scripts (Rich \& Knigth, 1993). Se for utilizado um conjunto de regras para representar o conhecimento, uma forma de raciocinar é utilizando o chamado raciocinio forward chaning e backward chaning. A Figura 3.4 mostra um exemplo de uma base de conhecimento representada em Prolog ${ }^{2}$. Há dois tipos de declaraçöes: fatos que só contêm constantes (ou seja, nenhuma variável) e representam declaraçöes sobre objetos especificos e regras que contêm variáveis e representam declaraçōes sobre classes de objetos. As regras são bastante utilizadas para modelar o conhecimento de sistemas especialistas.

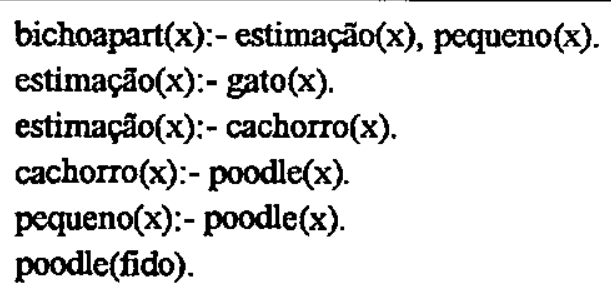

FIGURA 3.4 - REPRESENTAÇĀO DO CONHECIMENTO EM PROLOG (RICH \& KNIGTH, 1993)

Outra forma de representar o conhecimento em uma base de conhecimento é utilizando rede semântica. Nesta, o conhecimento é representado como um conjunto de nós conectados entre si por intermédio de um conjunto de arcos marcados, que representam relações entre os nós. Os nós podem ser de dois tipos: (1) individuais, que representam descrições ou afirmaçōes referentes a uma instância individual de um objeto; (2) genéricos, os quais referem-se a uma classe ou categoria de objetos. As classes estão previamente ordenadas em uma taxonomia e existem arcos que representam relaçőes binánias especiais, tais como isa (is a) e ako (a kind of). $O$ primeiro tipo de arco liga um nó individual a um nó genénico e expressa que um indivíduo é de uma certa classe. O segundo liga dois nós genéricos entre si

\footnotetext{
${ }^{2}$ Prolog: é uma linguagem de programaçăo baseada na lógica matemática e tem muito dos aspectos de linguagens de especificação
} 
e expressa que uma classe é uma subclasse de outra classe. Um exemplo de um fragmento de uma rede semântica é mostrado na Figura 3.5. Nessa figura, o nó Pessoa herda todas as propriedades do nó Mamifero, que por sua vez herda todas as propriedades do nó Animal. Vale ressaltar que, nos casos onde é admitida a existência de exceções, esta inferência nem sempre é valida, pois existem propriedades que são afirmadas sobre uma classe que săo corretas para todos os membros da classe, enquanto que outras propriedades são inerentes à própria classe. Para deduzir eventuais sentidos entre as classes Pessoa e Animal, ativam-se as conexōes desde Pessoa e, pode-se inferir - assumindo a transitividade da relação ako que Pessoa é uma espécie de Animal. Assim, o que permite realizar inferências, como a descrita anteriormente, é a organização hierárquica induzida pelos arcos isa e ako.

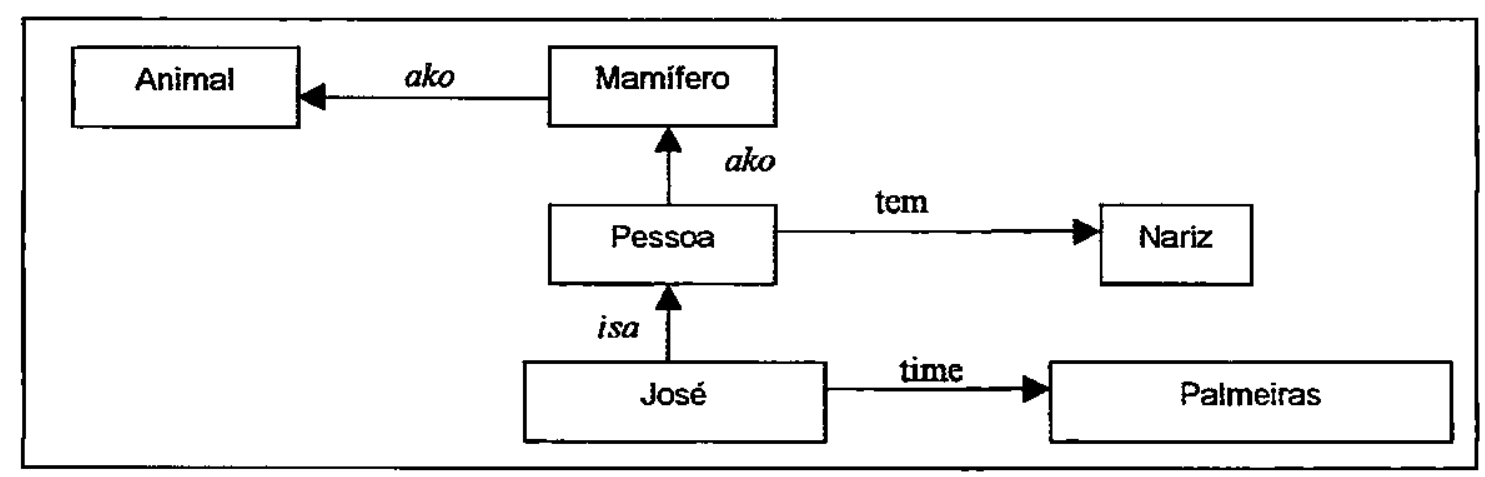

FIGURA 3.5 - UMA REDE SEMÂNTTCA

O frame também é uma forma de representação de conhecimento e permite realizar descriçöes de objetos complexos. Uma de suas principais características é a herança de propriedades, onde uma classe mais especializada pode herdar todas as propriedades da classe mais geral, fornecendo facilidades de representação.

Um frame é uma coleção de atributos chamados de escaninhos (slots) e valores a eles associados (e possivelmente restriçōes a esses valores) que descrevem alguma entidade. Os sistemas de frames são criados a partir de coleçōes de frames que são conectados entre si devido ao fato de que o valor de um atributo de um frame pode ser um outro frame (hierarquia). Cada frame representa uma classe (um conjunto) ou uma instância (um elemento de uma classe). A Figura 3.6 mostra uma coleção de frames.

Na Figura 3.6, os frames Pessoa, Adulto-Masculino e Jogador de Baseball são classes. Já o frame José é uma instância. A relação é-um é uma relaçăo de subconjunto, como exemplo, o conjunto de adultos do sexo masculino é um subconjunto do conjunto de pessoas. A relaçäo instância corresponde à relaçăo elemento-de, como exemplo, José é um elemento do conjunto de jogadores de baseball. 


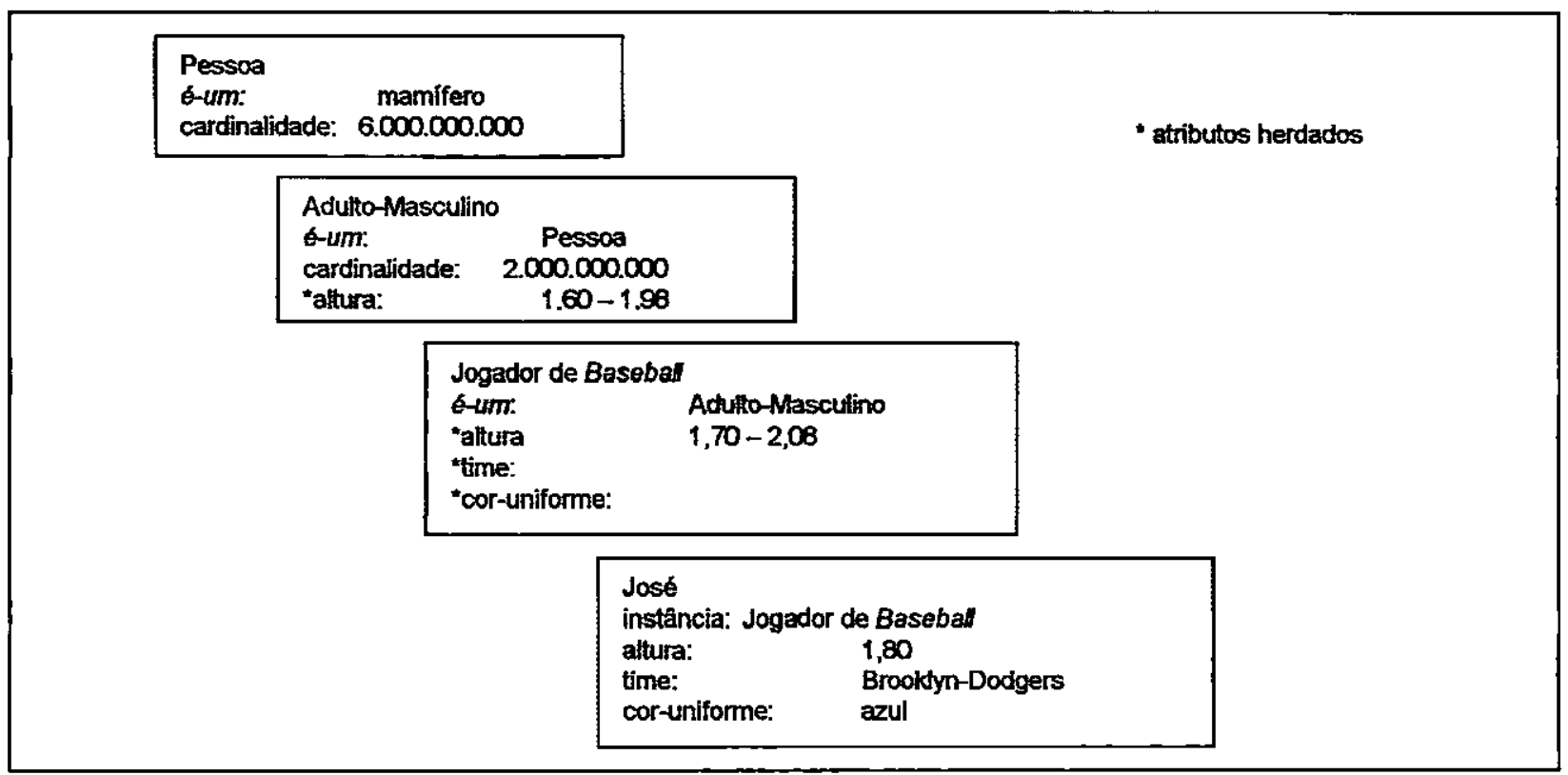

FIGURA 3.6 - COLECGÃO DE FRAMES

Os frames contrastam com as redes semánticas as quais são geralmente usadas para representar conhecimento geral. Frames säo muito usados para representar conhecimento causal devido às suas informaçōes serem organizadas por causa e efeito. Isso devido à combinação de frames de situação que contêm conhecimento sobre o que é esperado de uma dada situação, com frames de ação que contêm slots que especificam açōes a serem realizadas em uma dada situação (Giarratano,1994).

Os scripts, mais uma forma de representação de conhecimento, correspondem a uma seqüência de frames ordenada pelo tempo. O script é uma estrutura que descreve uma seqüência estereotipada de eventos em um determinado contexto. Consiste em um conjunto de escaninhos (s/ots) aos quais podem estar associadas informaçōes sobre os tipos de valores que eles podem conter e também um valor default a ser usado caso nenhuma outra informação esteja disponível. Os scripts são estruturas menos genéricas que os frames, mas são bastante eficazes para representar os tipos de conhecimento especificos para os quais foram projetados.

Os scripts săo úteis, pois no mundo real existem padröes para a ocorrência de certos eventos. Esses padrōes surgem devido às relaçōes causais entre eventos, isto é, agentes executam uma ação para poderem depois executar uma outra. Os eventos descritos em um script formam uma cadeja causal gigante a qual inicia-se por um conjunto de condiçöes de entrada que permitem a ocorrência dos primeiros eventos do script e termina com um conjunto de resultados que podem permitir a ocorrência de eventos posteriores ou de seqüencias de eventos (possivelmente descritos por outros scripts). Os componentes importantes de um script são: 
- Condições de entrada: condições que precisam, em geral, ser satisfeitas antes da ocorrência dos eventos descritos no script,

- Resultado: condições que, em geral, serăo verdadeiras após a ocorrência dos eventos descritos no script,

- Acessórios: slots que representam objetos envolvidos nos eventos descritos no script. A presença desses objetos pode ser inferida mesmo que eles năo sejam mencionados explicitamente;

- Papéis: aberturas que representam pessoas envolvidas nos eventos descritos no script. A presença destas pessoas também pode ser inferida mesmo que elas não sejam mencionadas explicitamente. Se individuos específicos forem mencionados, eles poderäo ser inseridos nos slots apropriados;

- Trilha: variação especifica de um padrão mais genérico representado por esse script em particular. Trilhas diferentes do mesmo script terão em comum muitos, mas não todos os componentes;

- Cenas: seqũências de eventos que ocorrem. Os eventos são representados no formalismo de dependência conceitual. A dependência conceitual é uma teoria sobre como representar o tipo de conhecimento sobre eventos que normalmente está contido em frases de linguagem natural. A representação em dependência conceitual de uma expressão é constituida por primitivas conceituais que podem ser combinadas para formar os significados de palavras em qualquer linguagem particular. Algumas primitivas conceituais utilizadas são mostradas na Tabela 3.1.

\section{TABELA 3.1 - PRIMITIVAS CONCEITUAIS}

\begin{tabular}{|l|l|}
\hline Primitivas & Descrição \\
\hline ATRANS & Transferência de uma relação abstrata (dar) \\
\hline PTRANS & Transferência de local fisico de um objeto (ir) \\
\hline PROPLE & Aplicação de força fisica a um objeto (empurrar) \\
\hline MOVE & Movimento de uma parte do corpo de alguém (chutar) \\
\hline GRASP & Domínio de um objeto por um ator (agarrar) \\
\hline INGEST & Ingestão de um objeto por um animal (comer) \\
\hline EXPEL & Expulsão de algo do corpo de um animal (chorar) \\
\hline MTRANS & Transferência de informação mental (dizer) \\
\hline MBULLD & Elaboração de novas informações a partir de informaçães antigas (decidir) \\
\hline SPEAK & Produção de sons (dizer) \\
\hline ATTEND & Focagem de um órgão dos sentidos em um estímulo (ouvir) \\
\hline
\end{tabular}

A Figura 3.7 mostra um exemplo de um script de um restaurante. 


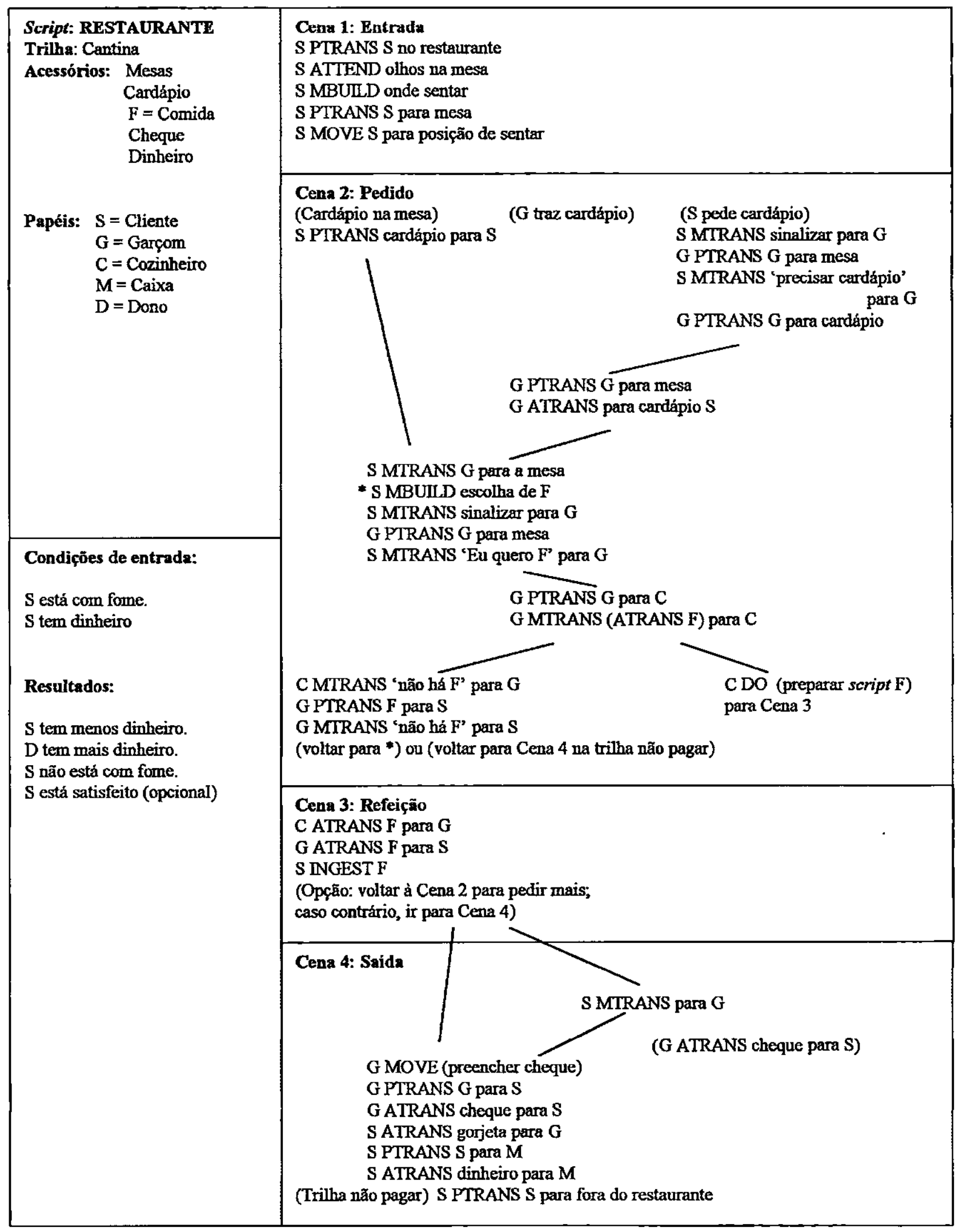

FIGURA 3.7 - SCRIPT DE UM RESTAURANTE 


\section{5 - Problemas Típicos Ocorridos Durante a Aquisição de Conhecimento Explícito}

O problema em potencial que o ocorre durante a aquisição de conhecimento explícito, freqüentemente, é a comunicaçăo entre o engenheiro de conhecimento e o especialista do domínio. Mas, esta năo é a única razão para a falha na captura de conhecimento (Herbane, 1997).

O especialista do domínio precisa ter mais que simples dados ou informaçōes sobre o domínio do problema. Ele tem a obrigação de ser distinguido dos outros devido à posse de um alto grau e conhecimento especialista. O especialista do domínio pode nem sempre estar disposto a transmitir conhecimento para o entrevistador por uma vaniedade de razōes, assim como tem medo do sistema tomar seu lugar quando construido. Outra insegurança pode ser causada quando o especialista não tem certeza sobre a informação que ele está divulgando.

O engenheiro de conhecimento precisa ter um entendimento dos conceitos para construir o sistema inteligente que seja correto e que reflita o conhecimento adquindo. É também obrigado a assegurar que o nível correto de detalhes está sendo extraído do especialista. A imparcialidade deve ser mantida pelo engenheiro de conhecimento ao elicitar as informações objetivas.

Um fator freqũentemente inspecionado por engenheiros de conhecimento é o fato que eles podem ter problemas ao obter acesso ao especialista porque este tende a ser muito ocupado. De qualquer maneira, se o engenheiro de conhecimento superar este problema, pode haver o problema da necessidade de mais tempo para elicitar a informação relevante, que o especialista está disposto dar.

Outros problemas ocorridos durante a aquisição de conhecimento explícito: falta de compromisso, negativismo e apatia, conflitos entre expectativas e realidades, discordância entre vários especialistas, conhecimento irrelevante, incorreto, incompleto ou inconsistente.

\section{6 - Considerações Finais}

Neste capitulo foram apresentados alguns conceitos relacionados a aquisição de conhecimento, enfatizadas algumas técnicas de aquisição de conhecimento explicito e implícito que podem ser utilizadas durante o processo de aquisição de conhecimento e descritas algumas formas de representação do conhecimento.

No próximo capitulo serão apresentados o Processo de Aquisição de Conhecimento IPAIA e sua instância para o domínio de engenharia reversa. 


\section{CAPÍTULO 4 - PROCESSO DE AQUISIÇÃO DE CONHECIMENTO}

\section{1 - Consideraçöes Iniciais}

Este capitulo apresenta o Processo de Aquisição de Conhecimento IPAIA (Jubileu, 1998) elaborado a partir de aspectos de processos existentes na literatura (McGraw \& Briggs, 1989; Scott et. al, 1991; Tuthill, 1990). O IPAIA tem âmbito geral, podendo ser utilizado em qualquer domínio de conhecimento. Neste capítulo também é apresentada uma instância do Processo de Aquisição de Conhecimento IPAIA para o domínio de engenharia reversa. Essa instância tem a finalidade de auxiliar no passo de obtenção de informações do método FUSION-RE/I (Costa, 1997), da qual deve-se extrair conhecimentos a respeito do domínio da aplicação e da interface, para facilitar a elaboração dos modelos de análise Fusion.

\section{2 - Processo de Aquisiçăo de Conhecimento}

A extração, interpretação e representação do conhecimento de um dado domínio podem ser realizadas utilizando-se um processo de aquisição de conhecimento. Para o desenvolvimento deste trabalho, elaborou-se o Processo de Aquisição de Conhecimento IPAIA (acrônimo para as iniciais das fases propostas) (Figura 4.1) - baseado em aspectos de processos de aquisição de conhecimento existentes, procurando incluir os melhores aspectos de cada um. 
Com o objetivo de refinar cada vez mais o conhecimento, a estrutura do Processo de Aquisição de Conhecimento IPAIA foi baseada na idéia de melhoramento contínuo do processo do Modelo IDEAL (Gremba \& Myers, 1998).

O Processo de Aquisição de Conhecimento IPAIA apresenta orientações que proporcionam uma abordagem de aquisição de conhecimento explicito, de uma maneira organizada. Esse processo pode ser direcionado tanto para grandes quanto para pequenos programas de aquisição de conhecimento e contém cinco fases: (1) Início do Processo de Aquisição de Conhecimento, (2) Preparação da Sessão de Aquisição de Conhecimento, (3) Aquisição do Conhecimento, (4) Implementação do Conhecimento e (5) Avaliação do Conhecimento. A fase 1 é realizada apenas uma vez enquanto as fases $2,3,4$ e 5 compöem uma etapa contínua de melhoramento do conhecimento, como mostrado na Figura 4.1.

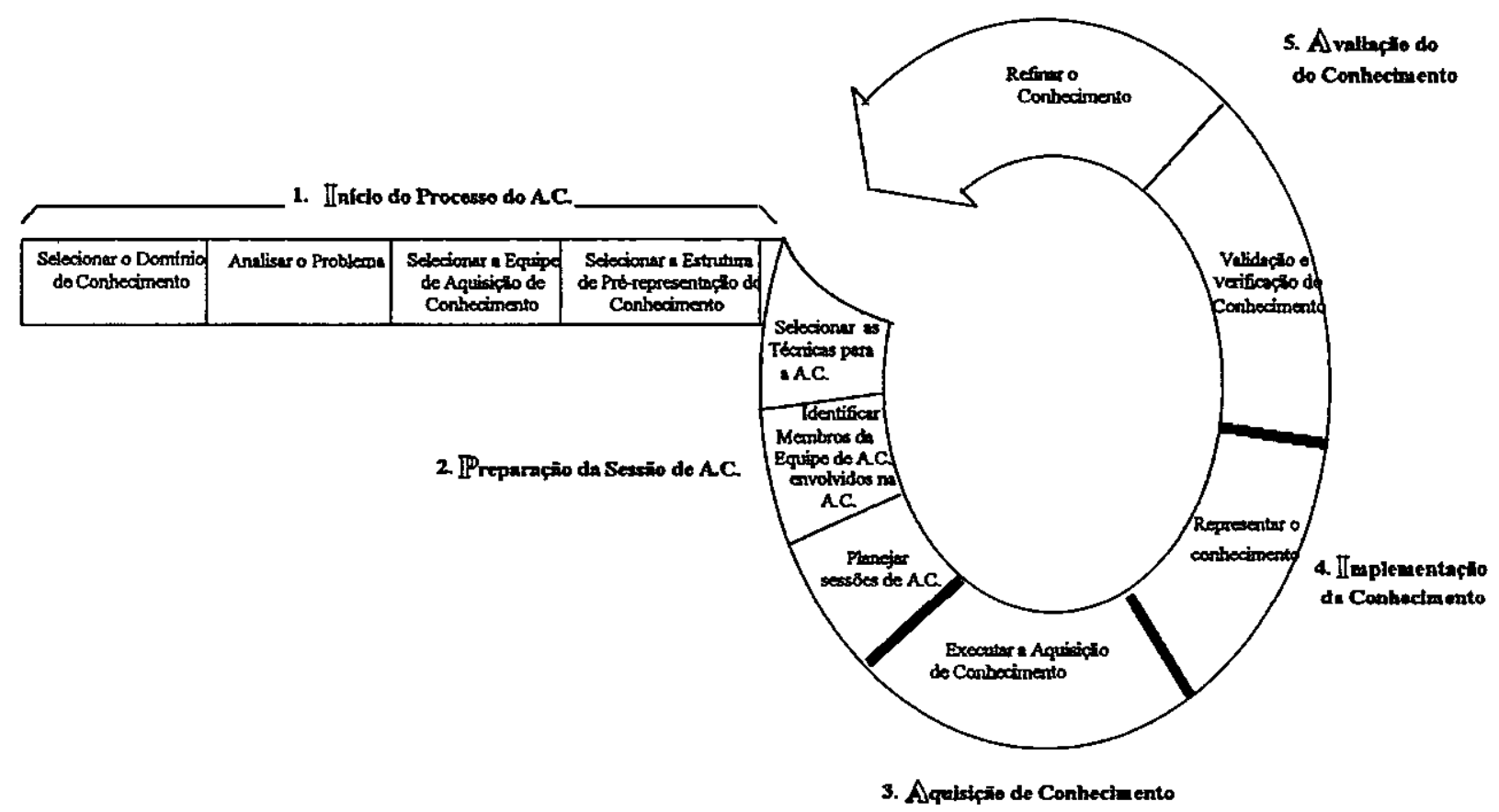

FIGURA 4.1 - PROCESSO DE AQUISICSAOO DE CONHECIMENTO IPAIA (JUBLEU, 1998)

Fase 1 - Início do Processo de Aquisição de Conhecimento: nessa fase são realizadas atividades que proporcionam maior compreensão do dominio de conhecimento para aqueles que irăo interagir com o processo de aquisiçăo de conhecimento. Essas atividades săo descritas a seguir.

- Selecionar o Dominio de Conhecimento: a seleção de um domínio apropriado é crucial para o êxito no desenvolvimento de um sistema baseado em computador. Os limites da tarefa devem ser claramente dellneados; 
- Analisar o Problema: os termos chaves são importantes para se obter uma terminologia única entre os membros da equipe de aquisição de conhecimento; devem ser identificadas todas as referências que o processo de aquisição de conhecimento fizer a padröes, procedimentos, terminologias ou outros documentos; os conceitos iniciais referentes ao domínio de conhecimento devem ser especificados; um mapa mental do domínio de conhecimento deve identificar relaçöes entre os conceitos e identificar as principais funções, permitindo assim, uma maior familiarização com o dominio do conhecimento; uma análise funcional pode ser realizada com o propósito de refletir a principal funcionalidade que o usuário deseja do sistema. A análise funcional é uma técnica que o engenheiro de conhecimento pode usar para estruturar os requisitos do sistema e delinear a sua funcionalidade. $\mathrm{Na}$ análise funcional devem ser identificados módulos distintos, entradas e saídas atuais. A énfase nessa tarefa é traduzir os requisitos para um diagrama funcional inicial e descrever o relacionamento básico entre as funções. Usando diagramas de fluxo funcional, o engenheiro de conhecimento pode descrever sistemas maiores, subsistemas, requisitos de sistemas e interaçöes entre os componentes do sistema;

- Selecionar a Equipe de Aquisição de Conhecimento: uma caracteristica fundamental para a formaçäo da equipe de aquisição de conhecimento é uma boa interação, indispensável entre os componentes de qualquer grupo de trabalho, principalmente na situação aqui tratada, envolvendo um processo dependente da motivação de todos os participantes. Uma equipe de aquisição de conhecimento normalmente é composta pelos seguintes membros: gerente, engenheiro de conhecimento, anotador/assistente, observador e psicólogo;

- Selecionar a Estrutura de Pré-Representação do Conhecimento: a estrutura intema que representará o conhecimento deve ser selecionada de acordo com a necessidade da aplicação e/ou definiçōes do projeto do sistema baseado em computador. Dentre essas estruturas estão regras de produção, redes semánticas, frames e scripts.

Fase 2 - Preparação da Sessão de Aquisição de Conhecimento: nessa fase são realizadas atividades de organização da sessão de aquisição de conhecimento, descritas a seguir.

- Selecionar as Técnicas para a Aquisição de Conhecimento: muitas variáveis influenciam a seleção de técnicas de aquisição de conhecimento e o grau de estruturação com o qual elas são aplicadas. Entre essas variáveis estão: tamanho e meta do programa de aquisição de conhecimento, disponibilidade de especialista(s) do domínio, número de membros e experiência da equipe de aquisição de conhecimento e tipo de conhecimento.

- Tamanho e Meta do Programa de Aquisição de Conhecimento: programas de grande escala têm maior necessidade de estruturas e técnicas pré-determinadas do que programas menores. Por exemplo, numa fase inicial de aquisiçäo de conhecimento pode-se utilizar as técnicas de entrevista e análise de protocolos. Já nas sessões de 
feedback e refinamento, pode ser utilizado o rastreamento de processo seguido pela entrevista estruturada. Nas sessões aprofundadas de aquisição de conhecimento podem ser utilizadas entrevista estruturada, simulações e protótipos de desenvolvimento. A meta do programa de aquisição de conhecimento e a funcionalidade do sistema baseado em conhecimento têm impacto sobre o tipo de técnicas de aquisição de conhecimento que serão selecionadas;

- Disponibilidade de Especialista(s) do Domínio: as técnicas também são selecionadas de acordo com o tempo que um especialista dispõe para um programa de aquisição de conhecimento. Isso não desconsidera o fato de que em alguns casos, a técnica mais apropriada necessite de um tempo maior que aquele que o especialista tem disponivel. Nesses casos deve haver uma negociação. Deve-se considerar, também, o fato de que o tempo disponibilizado a um programa de aquisição de conhecimento depende da complexidade do domínio do conhecimento em questão;

- Número de Membros e Experiência da Equipe de Aquisição de Conhecimento: além do número de membros disponíveis da equipe de aquisição de conhecimento e da experiência dos mesmos com aquisição de conhecimento, um outro aspecto considerado no esforço dessa aquisição é o grau de compatibilidade entre as técnicas de aquisição de conhecimento e a experiência ou capacidade atual do engenheiro de conhecimento com as mesmas;

- Tipo de Conhecimento: é importante caracterizar e combinar os tipos de conhecimento com as técnicas apropriadas de aquisição de conhecimento. Os tipos de conhecimento são declarativo, procedural, semântico e episódico. No conhecimento declarativo identificam-se heurísticas gerais expressas de forma verbal, que são avaliáveis num nível consciente "sabendo que" geralmente em memória de curto prazo. No conhecimento procedural identificam-se tarefas/procedimentos de rotina. Esse conhecimento inclui a habilidade de um indivíduo de "como" realizar algo, envolve uma resposta automática para um estímulo e pode ser de natureza reacionária. No conhecimento semântico identificam-se principais conceitos, ou seja, o vocabulário, procedimentos de decisão e heurísticas avaliáveis num nível inconsciente. Este conhecimento é de grande importância ao(s) Engenheiro(s) de Conhecimento, reflete a estrutura de aprendizado, organização e representação, e representa um conhecimento de memória de longo prazo. No conhecimento episódico identificam-se heuristicas de resolução de problemas análogos. Esse conhecimento reside em memória de longo prazo e contém informações sobre "episódios" ou itens temporariamente datados e relações temporais entre estes itens';

- Identificar Membros da Equipe de Aquisição de Conhecimento Envolvidos na Aquisição de Conhecimento: inclui indicar quem deve acompanhar as atividades. Cada uma das tarefas de 
aquisição de conhecimento deve ter um membro responsável. É recomendável que se registrem os atributos necessários e desejáveis para quem ocupa cada cargo;

- Planejar Sessões de Aquisição de Conhecimento: essa tarefa tem por finalidade criar, efetivamente, um instrumento de auxilio à aquisição de conhecimento e planejar como as sessões de aquisição de conhecimento serão conduzidas.

Fase 3 - Aquisição do Conhecimento: essa fase tem como objetivo adquirir os conhecimentos que serão armazenados na base de conhecimento, ou seja, é a fase de execução do planejamento realizado na etapa anterior.

Fase 4 - Implementação do Conhecimento: nessa fase o conhecimento adquirido deve ser representado formalmente. Para isso é utilizada a estrutura de representação do conhecimento, selecionada na Fase 1 do Processo de Aquisição de Conhecimento IPAIA.

Fase 5 - Avaliação do Conhecimento: nessa fase realiza-se a verificação e validação do conhecimento que será refinado posteriormente, averiguando se o conhecimento existente é suficiente e correto. O conhecimento é considerado suficiente de acordo com o objetivo da aquisição de conhecimento. Martin (McGraw \& Briggs, 1989) descreve verificação como "construir o produto corretamente" e validação como "construir o produto certo". As atividades de verificação e validação constituem parte dos componentes que asseguram a garantia de qualidade e confiabilidade do conhecimento adquirido. Teste é uma das atividades que pode ser utilizada na verificação e validação de produtos. Os testes para localizar potenciais problemas na aquisição de conhecimento podem ser estáticos e dinâmicos. A forma mais comum de teste estático refere-se à checagem, por parte dos especialistas do domínio, da consistência e completitude do conhecimento conceitual do domínio adquirido, e teste dinâmico refere-se à identificação de valores criticos e casos a serem executados (Andert, 1999).

Um aspecto crucial para a verificação da base de conhecimento é determinar se a transformação do conhecimento é exata, considerando a sua forma original, passando por uma ou mais representações intermediárias, até a sua representação final (computável). Porém, ainda não existe uma técnica amplamente aceita para garantir a corretitude dessa transformação. Algumas técnicas utilizadas incluem inspeções/walkthroughs com outros Engenheiros de Conhecimento. As técnicas de verificação e validação são usadas para identificar redundâncias, contradições, ciclos (por exemplo, o conhecimento $X$ infere no $Y$ que por sua vez infere no $X$ novamente) que geralmente indicam falhas na base de conhecimento e conclusões inalcançáveis que ocupam espaço desnecessário na mesma, e indicam 
problemas na lógica. Essas redundâncias, contradições, ciclos e conclusões inalcançáveis devem ser removidos para tornar a base de conhecimento mais eficiente.

\section{3 - Processo IPAIA Instanciado para o Dominio de Engenharia Reversa}

O processo para aquisição de conhecimento explícito - IPAIA (Jubileu et al., 1998) tem âmbito geral, podendo ser utilizado em qualquer domínio de conhecimento. Para o domínio de engenharia reversa, esse processo foi instanciado (Figura 4.2) com a finalidade de auxiliar o passo de obtenção de informaçōes do método FUSION-RE/l - método de engenharia reversa baseado no Fusion e na interface.

O processo IPAIA, como dito na seção anterior, contém cinco fases: (1) Início do Processo de Aquisição de Conhecimento, (2) Preparação da Sessão de Aquisição de Conhecimento, (3) Aquisição de Conhecimento, (4) Implementação do Conhecimento e (5) Avaliação do Conhecimento. Na instância do processo para o domínio de engenharia reversa acrescentou-se uma iteração entre as fases 4 e 5 para que o conhecimento avaliado fique representado em uma forma sintática e semanticamente melhor (Figura 4.2).

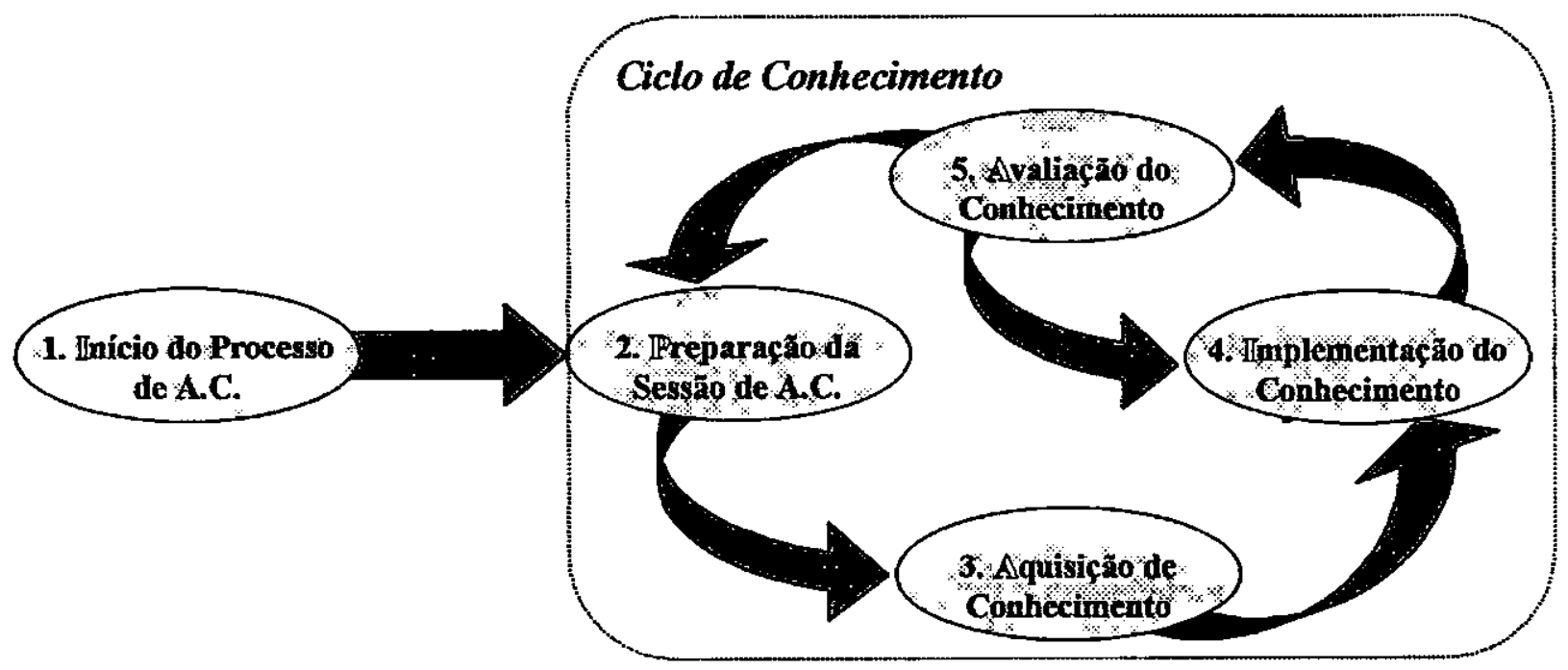

FTGURA 4.2 PROCESSO DE AQUISIÇÃO DE CONHECIMENTO IPAIA INSTANCIADO

A primeira fase é realizada apenas uma vez, ao contránio das quatro fases seguintes, que compöem o Ciclo de Conhecimento, o qual pode se repetir enquanto o conhecimento necessário para eiaborar os modeios de análise Fusion ainda não for suficiente.

O Ciclo de Conhecimento é especializado em três tipos de ciclos de aquisiçăo de conhecimento: Ciclo Brainstorming, Ciclo Rastreamento de Processo e Ciclo Entrevista 
Estruturada. Os tipos de ciclos são correspondentes às técnicas utilizadas para a aquisição de conhecimento. Os ciclos brainstorming são realizados até que se obtenha o conhecimento do domínio da aplicação. Os ciclos rastreamento de processo ocorrem quantas vezes forem necessánas para se obter conhecimento a respeito do sistema submetido à engenharia reversa. Finalmente, os ciclos entrevista estruturada são utilizados para se obter conhecimento mais detahado a fim de esclarecer dúvidas, caso existam, a respeito do conhecimento adquirido e de completar elou confirmar o conhecimento.

\subsection{1 - Fase 1 - Início do Processo de Aquisição de Conhecimento}

Na fase inicial do processo de aquisição de conhecimento (Figura 4.3) deve-se fornecer uma base sólida para o sucesso da aquisição de conhecimento. As atividades dessa fase, descritas a seguir, såo consideradas críticas, pois nas fases subsequentes podem ser desperdiçados muito tempo, esforços e recursos caso essa fase seja concluída de maneira incompleta.

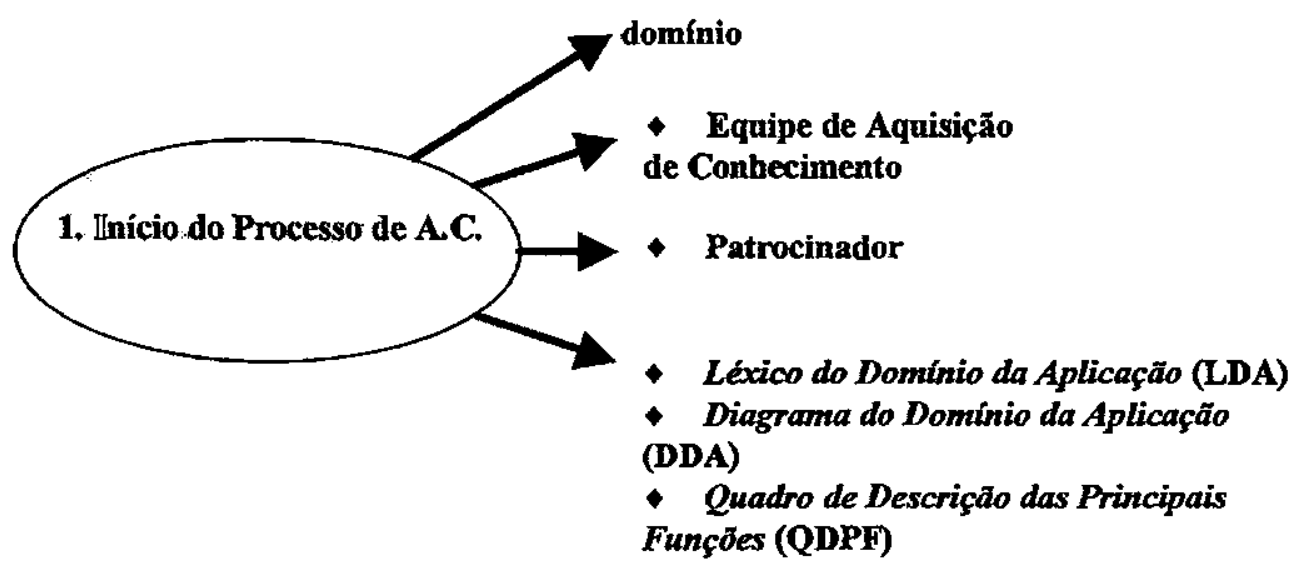

FIGURA 4.3 - FASE 1 DO PROCESSO DE AQUISIÇÃO DE CONHECIMENTO IPALA INSTANCIADO

Atividade 1.1 - Selecionar a área de aplicação do sistema a ser submetido à engenharia reversa, estabelecendo-se os limites do domínio de conhecimento;

Atividade 1.2 - Definir o patrocinador que deve ajudar a manter o compromisso nos momentos de dificuldades e garantir os recursos essenciais utilizados durante a aquisiçâo de conhecimento;

Atividade 1.3 - Adquirir uma visão geral do dominio de conhecimento. Para tanto, são descritos os termos chaves utilizados nesse dominio, obtendo-se uma terminologia única; são também identificadas as relações existentes entre os termos, além de serem identificadas as princlpais funções do sistema referentes ao dominio de conhecimento. Essa visão geral pode ser obtida a partir de 
alguma documentação, caso exista, ou de alguém familiarizado com o dominio da aplicação (usuário). Os termos chaves e seus relacionamentos são representados utilizando-se duas estruturas: Léxico do Domínio da Aplicação LDA (Tabela 4.1) e o Diagrama do Dominio da Aplicação - DDA (Figura 4.4) (Turine \& Masiero, 1996). No LDA são definidos os temos chaves do domínio da aplicaçăo (na coluna "Definiçăo" os termos que săo descritos devem ser sublinhados). No DDA são representados os relacionamentos existentes entre esses termos (as setas representam os relacionamentos entre os termos).

As principais funçōes referentes ao dominio de conhecimento são representadas, em forma textual, num quadro onde são definidos o nome e o objetivo das funçōes (Quadro 4.1).

TABELA 4.1 - LÉXICO DO DOMÍNIO DA APLICAÇĂO

\begin{tabular}{|l|l|l|}
\hline Termo & Definição & Sinônimos \\
\hline <nome do termo1> & <descrição do termo1> & <sinônimos do termo1> \\
\hline <nome do termo2> & <descrição do termo2> & <sinônimos do termo2> \\
\hline
\end{tabular}

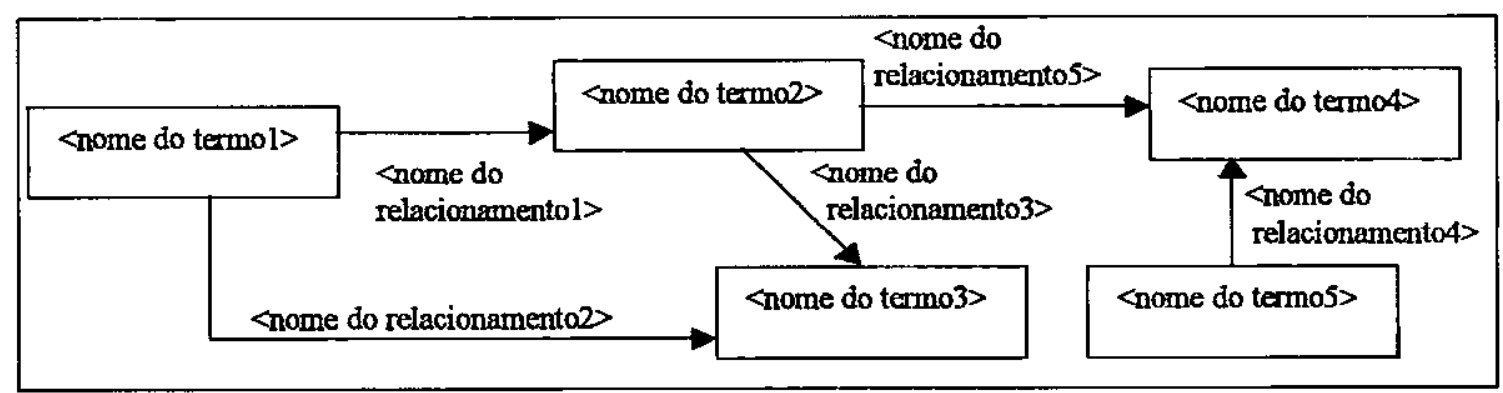

FIGURA 4.4 - DLAGRAMA DO DOMÍNIO DA APLICAÇÄO

QUADRO 4.1 - QUADRO DE DESCRIÇĀO DAS PRINCIPAIS FUNÇÕES

\begin{tabular}{|l|l|}
\hline Função & Objetivo \\
\hline <nome da função 1> & <descrição do objetivo da função 1> \\
\hline <nome da função 2> & <descrição do objetivo da função 2> \\
\hline
\end{tabular}

Atividade 1.4 - Selecionar os membros que participarão das sessōes de aquisição de conhecimento. Dentre esses membros estão o engenheiro de conhecimento, os anotadores/assistentes, os possiveis especialistas do domínio e os 
usuánios. O engenheiro de conhecimento deve ser alguém que saiba usar as formas de representação do conhecimento (diagramas, quadros) para elaborar os modelos de análise do método Fusion. Além disso, o engenheiro de conhecimento deve ser capaz de selecionar os especialistas de domínio considerando não apenas o potencial dos mesmos a respeito do domínio da aplicação, mas também as suas caracteristicas de relacionamento interpessoal. Esse último quesito é importante, pois é sabido que existem alguns problemas sociais que poderão ocorrer durante a sessão de aquisição de conhecimento (Wilson, 1999), além dos problemas tradicionais da aquisição de conhecimento (Herbane, 1997).

Além do engenheiro de conhecimento, participarão da sessão de aquisição de conhecimento, quando necessário, membros com função de anotador e/ou assistente;

Atividade 1.5 - Estimular os possíveis participantes das sessōes de aquisição de conhecimento realizando uma palestra inicial que deve focalizar o que é aquisição de conhecimento, sua importância para a organização, os principais conceitos relacionados à aquisição de conhecimento, como especialistas do domínio, engenheiro de conhecimento, entre outros.

Ao contrário dessa primeira fase, que ocorre apenas uma vez, o Ciclo de Conhecimento (composto pelas fases Preparação da Sessão de Aquisição de Conhecimento, Aquisição de Conhecimento, Implementação do Conhecimento e Avaliação do Conhecimento) repete-se quantas vezes forem necessárias até que se obteriha conhecimento considerado suficiente para a elaboração dos modelos de análise Fusion.

\subsection{2 -Ciclo Brainstorming do Processo IPAIA Instanciado para o Domínio de Engenharia Reversa}

Esse ciclo trata do contato entre o engenheiro de conhecimento e os especialistas do domínio. É de extrema importância, principalmente se na primeira fase do processo IPAIA instanciado, o engenheiro de conhecimento não obteve conhecimento suficiente para elaborar - Léxico do Domínio de Aplicaçăo (LDA), o Diagrama do Domínio de Aplicação (DDA) e o Quadro de Descrição das Principais Funçōes (QDPF), apresentados na Fase 1. Sendo assim, esse ciclo será útil para completar e/ou confirmar o LDA, DDA e QDPF com as informações fornecidas pelos especialistas do domínio durante a sessão de aquisição de conhecimento, $e$ para elaborar o chamado Quadro Consensual onde são descritas as operações que um 
sistema inserido nesse domínio deveria ter e seus respectivos itens de entrada e saída. Além disso, no Quadro Consensual, pode-se descrever comentários, entre chaves, a respeito de operações, itens de entrada e saída que não foram implementados no sistema, mas foram previstos para a implementação de uma versão futura desse sistema.

Para a aquisição de conhecimento é utilizada a técnica brainstoming, pois deseja-se obter conhecimento de âmbito geral a partir de diversos especialistas do domínio, já que um especialista pode ter especialidade somente em um pequeno subconjunto de tarefas que o sistema deveria ter, năo cobrindo as outras áreas de funcionalidade do sistema.

A Figura 4.5 sintetiza os passos do ciclo brainstoming para a aquisição de conhecimento, os quais são descritos, detalhadamente, a seguir.

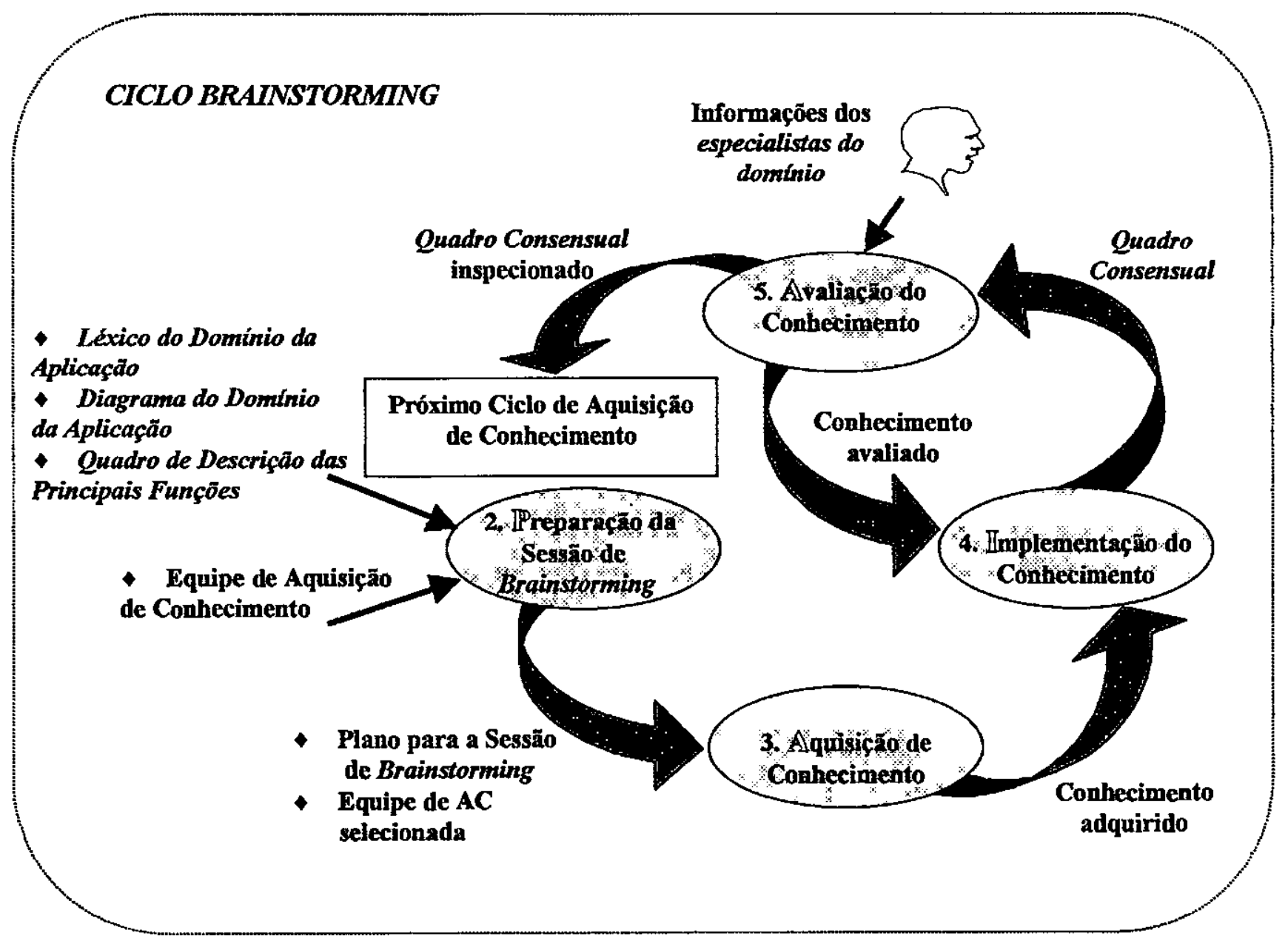

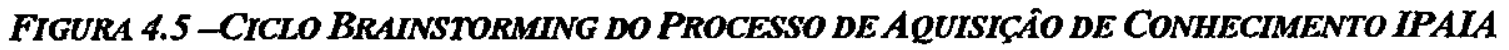
INSTANCLADO

CICLO BRAINSTORMING - Preparação da Sessão de Brainstorming: nessa fase são selecionados os membros que participarão da sessão de brainstoming e é elaborado um plano para auxiliar o engenheiro de conhecimento a conduzir a sessão de brainstoming. 
Atividade 2.1 - Selecionar os membros que participarão da sessão de brainstorming: o engenheiro de conhecimento, os especialistas do domínio e os possiveis anotadores/assistentes.

O engenheiro de conhecimento deverá selecionar dentre os possiveis especialistas do dominio, selecionados na Fase1 do processo, aqueles que realmente participarão da sessão. Essa seleção deve levar em consideração alguns problemas que normalmente ocorrem quando uma sessão de brainstorming é conduzida, além dos problemas referentes à aquisição de conhecimento propriamente dita. Esses problemas são sociais, tais como um grupo de pessoas que não contradizem seus superiores, pessoas que não dão sua opinião por temer "olhares negativos" de outros, pessoas com personalidade autoritária que dominam o grupo, etc. Por isso, devem ser escolhidos os especialistas do domínio considerados indivíduos democráticos direcionados aos objetivos do grupo (Wilson, 1999).

Também poderão fazer parte dos membros que participarão da sessão dois anotadores/assistentes que anotarão tudo o que está ocorrendo durante a sessão.

Atividade 2.2 - Elaborar um plano para orientação durante a sessäo de brainstorming. No Quadro 4.2 é apresentada a estrutura do plano para conduzir essa sessão. $O$ plano é composto por uma introdução na qual é relatado o seu objetivo, por descriçōes referentes ao gerenciamento (local, data e horário da sessão, nome dos membros participantes da sessão, tempo de duração), pela definição das tarefas a serem executadas, por um cronograma e por descriçōes de recursos a serem utilizados para a execução do plano. Esse plano deve ser entregue, com pelo menos dois dias de antecedência, para todos os participantes da sessão.

CICLO BRAINSTORMING - Aquisição do Conhecimento: nessa fase o plano para a sessão de brainstorming, elaborado anteriormente, é colocado em prática para se adquirir conhecimento de âmbito geral a respeito do domínio da aplicação. $O$ engenheiro de conhecimento deve exercer a função de moderador durante a aquisição de conhecimento: deve ponderar as discussões, não deixar ninguém interromper quando um dos especialistas do domínio estiver com a palavra, deve limitar o tempo para que cada um exponha suas informaçöes. Deve, também, esclarecer algumas regras de brainstorming aos Especialistas de Domínio: esses não devem se preocupar como o modo de se expressar (escolher palavras), não devem limitar suas informações mesmo que achem que estas sejam redundantes (não se pode descartar a possibilidade de que, em meio a palavras, haja alguma informação importante que ainda não foi dita), não devem criticar, validar ou julgar as informações 
fornecidas por qualquer um dos especialistas do domínio (Bouchard, 1999), (Kci, 1999), (Osborne, 1999);

\section{QUADRO 4.2 - ESTRUTURA DO PLANO PARA A SESSATO DE BRANSTORAING}

\section{PLANO PARA A SESSÃO DE BRATNSTORMING}

1 Introduçäo: o objetivo deste pläno é or rentar o engenheiro de conhecimento a conduzir uma sessão de brainstorming,

2 Gerenciamento: nesse i tem develn ser idéntificados o local; a däta e horário onde occorrená a sessão, o nome do engentieiro de conhecimento e dos anotadores/assistentes, o tehno de duração da sessão, o nome dos especialistos do dominio e a meta dầ sessão.

Local da Sessâo <local fisico onde ocorrerá a sessãol

Data da Sessão: $\mathrm{rdd} / \mathrm{mm} / \mathrm{ar}$ "Horário: $\langle$ hh:mm

Engenheiro de Conhecimento: (nomes

Anotadores/Assistentes: snomes.

Tempo Total: <duração da sessẫo de aquisişaro de conhecimentos:

Especiálistas do Dominio/Fonte de Conhecimento snome do(s) especialista(s)

Meta da Sessão: obtên conkecimento de âmbito geral sobre o dominio da aplicaçăo, incluindo as principais funcionalidades que um sistema desse tipo deveria ter, a fin de completar e/ou confirmar o Léxico do Domínio do Aplicação (LDA), o Diograma do Domínio da Aplicaşáo (DDA) e o Quadro de Descrição das Principais Funçóes (QDPF), e elaborar o Quadro Consensual:

3 Tarefas:

3.10 engenheiro de conhecimento deve deixar claro o motivọ da participação de cada especialista do domínio, motivando-os e deixando-os à vontade para que a sessäo thanscorra de forma efetiva. Além disso, deve deixar claro o seu papel durante a sessấo $e$ o papel dós anotadores/assistentes que devem Tegistrar as informaçós nelatadas tấo logo apresentadas;

Caso, na fase 1 do processo de Aguisicão de Conhecimento IPAIA, tenhia sido obtida informação suficiente para elaborar $O$ LOA, DDA $C$ QOPF, deve se ufilizar $0^{\circ}$ brainstorming estruturado. Caso contrário, Utilizar o braîstorming desestruturado seguido do estruturado (Vagiz, 1999).

Brainstorming Desestritturedo.

Os especialistas do dominio devem expor suas informacoóes teferentes as funciónalidades que o sistema deveria ter, do modo como elas vêm a mente. Is so sígnifica que náo há momento determinado para cada ún se manifestar. Esse metodo necessita do popel de moderador por parte do engenheiro de conhecimento para que esse reforce as"regras\% quando necessório, e todos os membros tenham oportunidade de falar:

Brainstorming Estreturado:

3.2 Levantar uma das funcionalidades considerando o Quadro de Des crição das Priñicipais Funçães,

3.3 Solicitar que cada especialista exponnha seü conhecinento a respeito da funçäo levantada, enfatizando os itens de entrada necessários para d execução dessa função e os itens de saida, não esquecendo de comentar sobre funcionalidades, itens de entrada e saída que näo foram implementados no sistema, mas foram previstos para a implementacõo de una ver sáo futura desse sistema:

3.4 Repetir as tarefas 3.2 e 3.3 afe que todas as funcionalidades identificadós tenham sido discutidas;

3.5 Verificar se existe alguma funcão que foi obtida dunante a brainstorming desestruturado (se este foi realizado) que ainda näo tenha sido de finda no Quodro de Descrigáo das Principais Fünçóes,

3.6 Repetir a tarefo 3.3 para as novas funçöes identificadas, se existirem;

37 Depois que cada especialista expos seu conhecimetito; aqueles que quíserem complementar algo. poderã̃o fazê-lo.

4 Crónögrama é inportante a élaboraçäo de ún cronograma para nelhor utilizar o tempo de modồ a hãos atrapalhar ó cotidiano dos especialistas do dominio. Deve servestipulado um tempo máximo para que cadoatividade;

5 Recursos: preparar o local selecionado dispondo as codeiras de forma circular, para que todos se vejam. Distribuir papel e caneta a todos os membros da sessão pard anotacões. se no local houver uma mesa onde todos possam se posicionar em forma circular, 6timo; caso não haja mesá, serãa necessárias pranchetas que servinão de apolo para escrever: 
CICLO DE BRAINSTORMING - Implementação do Conhecimento: nessa fase o engenheiro de conhecimento deve transcrever as anotaçōes realizadas pelos anotadores/assistentes ou por ele próprio. Caso o Léxico do Dominio da Aplicação (LDA), o Dlagrama do Dominio da Aplicação (DDA) e o Quadro de Descriçōes das Principais Funções (QDPF) estejam completos, as informaçōes desses devem ser confirmadas. Caso contrário, o LDA, DDA e QDPF devem ser complementados. A seguir, deve ser elaborado um Quadro Consensual (Quadro 4.3) composto pelas operaçōes que o sistema deveria ter e pelos seus respectivos itens de entrada e de saída. Esse quadro não contém informaçőes redundantes e informaçōes semelhantes estão agrupadas.

QUADRO 4.3 - QUADRO CONSENSUAL

\begin{tabular}{|l|l|l|}
\hline Operações & tens de Entrada & Itens de Saída \\
\hline <operação 1> & <itens de entrada p/ op 1> & <itens de saida da op 1> \\
\hline <operação 2> & <itens de entrada p/ op 2> & <itens de saída da op 2> \\
\hline
\end{tabular}

CICLO BRAINSTORMING - Avaliação do Conhecimento: nessa fase o conhecimento adquirido deve ser verificado e validado. A venificação do conhecimento refere-se à confiabilidade de representação, ou seja, é necessário averiguar se o conhecimento adquirido está representado corretamente (sintática e semanticamente) no Quadro Consensual. A validação refere-se à confiabilidade conceitual e é realizada por meio de uma inspeção (Andert, 1999). Essa inspeção é realizada junto aos especialistas do domínio a fim de checar a consistência e completitude do conhecimento conceitual do domínio adquirido.

Se o conhecimento adquirido referente ao domínio da aplicação năo estiver completo, executa-se um outro ciclo brainstorming, caso contrário, armazena-se o LDA, DDA, QDPF e o Quadro Consensual na base de conhecimento e inicia-se o ciclo rastreamento de processo.

\subsection{3 - Ciclo Rastreamento de Processo do Processo IPAIA Instanciado para o Domínio de Engenharia Reversa}

O conhecimento obtido na sessão de brainstorming pode estar além do que o sistema a ser analisado realmente faz - já que se trata do conhecimento do domínio. No ciclo rastreamento de processo será obtido conhecimento específico sobre o sistema analisado.

Nesse ciclo o engenheiro de conhecimento adquire conhecimento de usuários do sistema observando os procedimentos de uso do sistema analisado, a fim de elaborar o Quadro Consensual Especifico do Sistema Analisado e o Diagrama de Seqüéncia de 
Operações. Para adquirir o conhecimento, é utilizada a técnica de rastreamento de processo (McGraw \& Briggs, 1989), na qual o usuário "pensa alto" durante a utilização do sistema, em um caso hipotético ou real, enquanto o engenheiro de conhecimento registra o que está acontecendo.

A Figura 4.6 mostra os passos seguidos durante o ciclo rastreamento de processo para a aquisição de conhecimento, os quais são descritos, detalhadamente, a seguir.

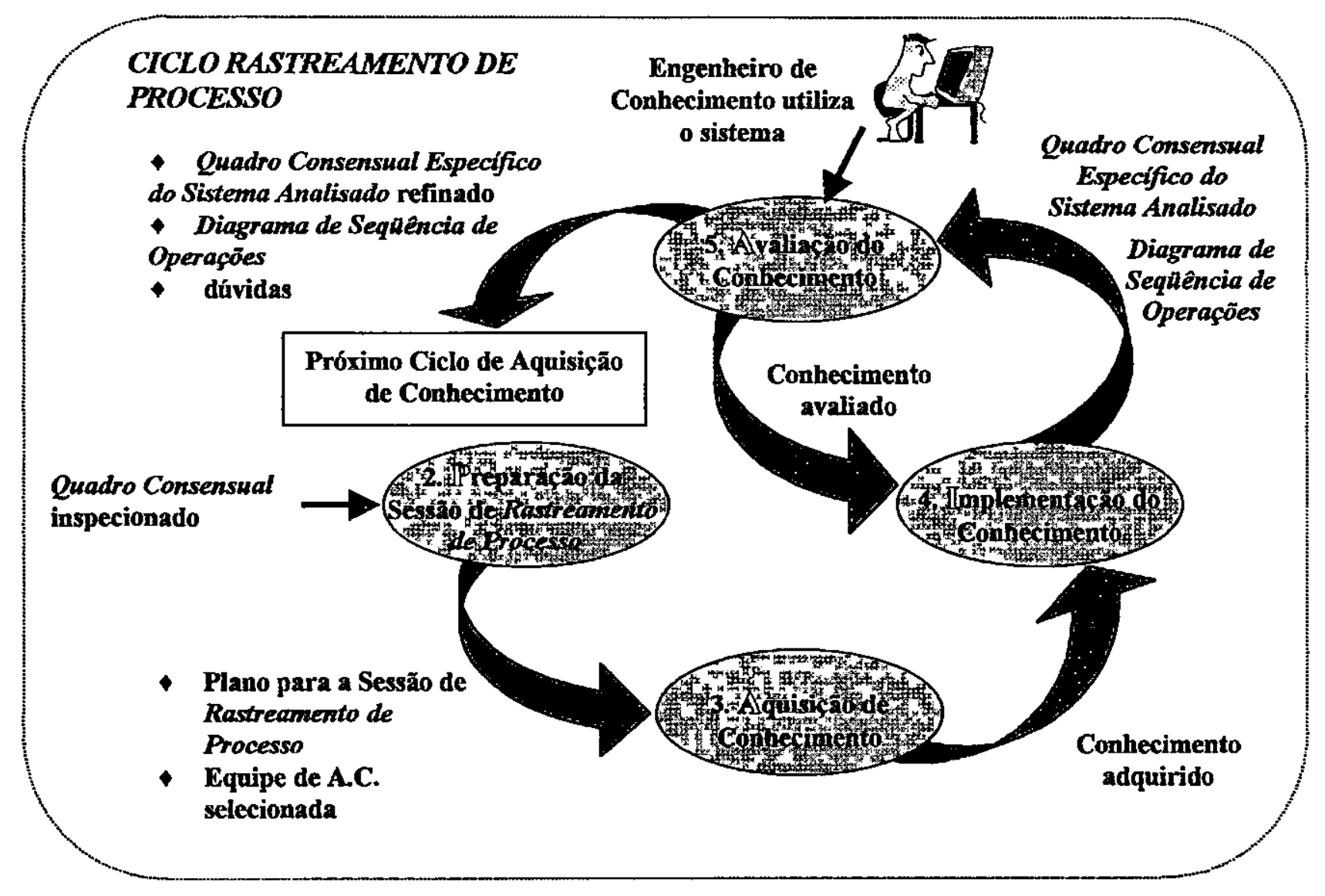

FIGURA 4.6 - CICLO RASTREAMENTO DE PROCESSO DO PROCESSO DE AQUISIÇÃO DE CONHECIMENTO IPALA INSTANCLADO

CICLO RASTREAMENTO DE PROCESSO - Preparação da Sessão de Rastreamento de Processo: nessa fase são selecionados alguns usuários do sistema para deles ser adquirido conhecimento e é elaborado um plano de apoio para a sessão de rastreamento de processo.

Atividade 2.1 - Selecionar os membros que participarão da sessão de rastreamento de processo: o engenheiro de conhecimento e os usuários do sistema.

Atividade 2.2 - Elaborar um plano para servir de orientação durante a sessão de rastreamento de processo. O Quadro 4.4 apresenta a estrutura desse plano. 
QUADRO 4.4 - ESTRUTURA DO PLANO PARA AS SESSÕES DE RASTREAMENTO DE PROCESSO

\section{PLANO PARA AS SESSÕES DE RASTREAMENTO DE PROCEESSO}

1 Introduçäo: a objetivo deste plano é orientar a engenheiro de conhecimento a conduzir uma sessão de mastreamento de processso:

2 Gerenciamento: devem ser identificados o local, a data, o horário e o tempo de duração de cada sessão, o nome do engenheiro de conhecimento e dos usuários, e a meta da sessão.

Engenheiro de Conhecimento: unomes

Meta da Sessäo: obter conhecimento a respeito das funcionalidades do sistema, dos itens de entrada $e$ saída de cada operaçã̃o, da sequiência das operações e da sequiência dos itens de cada operação. observando o uso desse sistema por cada um dos usuários, em um caso hipotético ou real, para elaborar o Quadro Consensual Específico do Sistema Analisado e o Diagrama de Seqüênciä de Operaçäes.

\begin{tabular}{|c|c|c|c|c|}
\hline 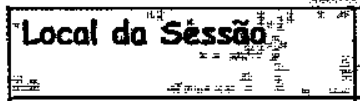 & $\begin{array}{l}\text { Deta } \\
\text { Session. }\end{array}$ & 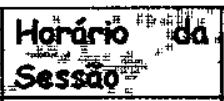 & $\begin{array}{l}\text { Tempo } \\
\text { Total }\end{array}$ & W \\
\hline $\begin{array}{l}\text { ¿local física ondê } \\
\text { ocorrená a sessão? }\end{array}$ & $<d d / m m / a a>$ & shh:mms & $\begin{array}{l}\text { <duração da } \\
\text { sessăo> }\end{array}$ & ¿nome do usuánio do sisfemas \\
\hline & & & & \\
\hline & & & & \\
\hline & & & & \\
\hline
\end{tabular}

3 Tarefas:

3.10 engenheiro de conhecimento deve dizer ao usuário que o observará enquanto utiliza o sistema. Também, deve dẹixar claro o propósito da sessão expondo a importância do conhecimento a ser adquirido no mothento da utilização do sistema por parte do usuário;

3.2 Durante a ütilização do sistema em um caso hipotético ou real, o usuário deve "pensar alto", ou seja, relatar verbalmente todos os passos tomados. É importante que o usuário fale pausadamente cada passo tomado, como se estivesse explicando o sistema a um novo usuário.

3.3 O engentieiro de conhecimento, por sua vez, deve observar e registrar todos os passos do procedimento do usuário ao utilizar o sistema, considerando principolmente:

- As operăções efetuadas pelo usuário e a descrição informal de cada uma delas:

- As pré-condiçốes para que cada operação possa ser executada:

- Os itens de entrada para a execução de cada operação, identificando entre esses itens de entrada quais são as campos chaves (parâmetros da operação, aqueles os quais outros campos dependem):

- Os itens de saída decorrentes da execução de cada operação;

- A sequiencia de ocorrência das operações;

- A sequiéncia de ocorrência dos itens de entrada e saida em cada operação:

- As opçốes dos menus do sistema;

4 Cronograma: deve ser estipulado um tempo máximo para o uso hipotético do sistema:

5 Recursos: no local onde ocorrená a sessäo deve haver um micro com o software instalado e com todos os periféricos necessários para a simulação de um caso hipotético ou real. É importante que o usuário não seja interrompido, para que não haja bloqueios na sua lógica de raciocínio. 
CICLO RASTREAMENTO DE PROCESSO - Aquisição do Conhecimento: nessa fase o plano para a sessão de rastreamento de-processo, elaborado anteriormente, é colocado em prática para se adquirir conhecimento especifico referente às operaçōes do sistema, seus respectivos itens de entrada e de saida, a seqüência de operaçōes e a seqüência de ocorrência dos itens de entrada e saida em cada operação. Durante essa fase, o engenheiro de conhecimento somente observará o usuário no uso do sistema, evitando interrompê-lo para questionamentos. Esse plano será aplicado, individualmente, a todos os usuários selecionados.

CICLO RASTREAMENTO dE PROCESSO - Implementação do Conhecimento: nessa fase o engenheiro de conhecimento deve transcrever, num quadro semelhante ao Quadro Consensual, chamado Quadro Consensual Especifico do Sistema Analisado, o que registrou durante a sessão, organizando esse conhecimento de forma a excluir as redundåncias. Isso deve ser feito para cada sessão aplicada a cada usuário selecionado e por fim, a partir desses quadros consensuais, deve ser elaborado um único Quadro Consensual Específico do Sistema Analisado.

Na primeira coluna do Quadro Consensual Especifico do Sistema Analisado colocam-se as operaçōes e uma breve descrição informal de cada uma delas escrita entre parênteses. $\mathrm{Na}$ segunda coluna colocam-se os itens de entrada; nessa coluna os itens de entrada são apresentados em ordem de ocorrência. Se existirem opçōes relacionadas a um único item de entrada (múltipla escolha), essas opções devem ser representadas entre parênteses logo a seguir do item de entrada. Os campos chaves de cada operação devem ser sublinhados na coluna "Itens de Entrada". Na terceira coluna colocam-se os itens de saida que também devem ser ordenados de acordo com a ocorrência. Para representar a seqüencia dos possiveis itens de saída em relação aos itens de entrada, na coluna "Itens de Entrada" deverá ser inserido um número correspondente ao item de saída na coluna "Itens de Saida". Se o item de saída for uma mensagem deve ser antecedido pela sigla "msg". Quando uma mensagem tiver uma característica de ocorrência alternativa, ou seja, ocorre somente em determinadas situações, há duas alternativas: se há inibição da ocorrência de outro(s) item (itens) de saida, devido à ocorrência dessa mensagem, então (1) na coluna "Itens de Saída" deve aparecer a mensagem separada desse(s) item (itens) de saída por intermédio de um ponto e virgula (;) ou então (2) essa mensagem deve ser acompanhada da palavra "opcional" entre parêrnteses. Na quarta coluna colocam-se as pré-condições necessárias para que a operação possa ser executada. Qualquer comentário inserido nesse quadro deve ser representado entre chaves \{\}. Um exemplo é mostrado no Quadro 4.5. 
QUADRO 4.5 - QUADRO CONSENSUAL ESPECÍFICO DO SISTEMA ANALISADO (EXEMPLO)

\begin{tabular}{|c|c|c|c|}
\hline Operaçōes & Itens de Entrada & Itens de Saída & Préé-Condições \\
\hline $\begin{array}{l}\text { Inserir cliente } \\
\text { (Cadastra dados do } \\
\text { cliente) }\end{array}$ & $\begin{array}{l}\text { CIC, 1, nome do cliente, } \\
\text { endereco, telefone, RG, } \\
\text { data de nascimento, } 2\end{array}$ & $\begin{array}{ll}\text { 1. } & \text { msg "Cliente já está } \\
\text { cadastrado." (opcional) } \\
\text { 2. } & \text { msg "Deseja incluir cliente?" }\end{array}$ & \\
\hline $\begin{array}{l}\text { Alterar cliente } \\
\text { (Altera os dados } \\
\text { referentes a um cliente) }\end{array}$ & $\begin{array}{l}\text { CIC, I, nome do cliente, } \\
\text { endereco, telefone, RG, } \\
\text { data de nascimento, } 2\end{array}$ & $\begin{array}{|ll|}\text { 1. } & \text { msg "Cliente não cadastrado"; } \\
\text { nome do cliente, endereço, } \\
\text { telefone, RG, data de, } \\
\text { nascimento } & \\
\text { 2. } & \begin{array}{l}\text { msg "Deseja alterar o } \\
\text { cliente?" }\end{array} \\
\end{array}$ & \\
\hline $\begin{array}{l}\text { Excluir cliente } \\
\text { (Apaga os dados } \\
\text { referentes a um cliente) }\end{array}$ & $\mathrm{CIC}, 1$ & $\begin{array}{l}\text { 1. msg "Deseja excluir o } \\
\text { cliente?" }\end{array}$ & $\begin{array}{l}\text { Cliente deve estar } \\
\text { cadastrado }\end{array}$ \\
\hline
\end{tabular}

A seqüência das operaçōes será representada num diagrama denominado Diagrama de Seqüência de Operaçöes (Figura 4.7). As opções dos menus do sistema serão representadas como operaçóes dos primeiros niveis do Diagrama de Seqüencia de Operaçöes. Os círculos representam as operaçöes e as setas orientadas representam a seqüência de ocorrência entre as operaçס̃es. Quando as operações estão delimitadas por um quadro pontilhado, isso significa que elas podem ocorrer iterativamente. A numeraçäo das operações é um auxilio para identificar quando uma operação de nivel superior possui um nível inferior. Por exemplo, a <op4> é desmembrada em <op4.1>, <op4.2> e <op4.3>. Quando de uma operação despontam várias setas, isso significa que a ocorrência das operaçöes apontadas por essas setas é alternativa, mas essas operações só podem ocorrer se precedidas pela execução da operação de onde despontou a seta. Quando de uma operação desponta somente uma seta, isso significa obrigatoriedade na seqüência de operaçöes. Quando as operaçōes estão interligadas por uma seta bidirecional, isso significa que essas operações podem ocorrer em paralelo.

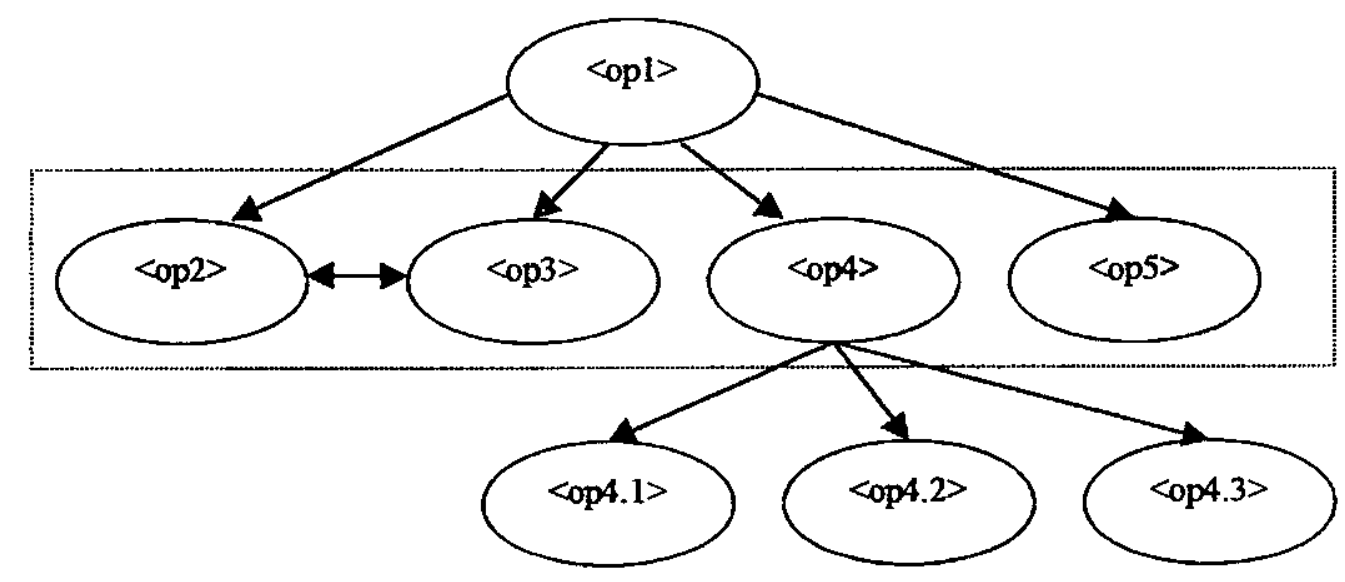

FIGURA 4.7-DIAGRAMA DE SEQÜÊNCIA DE OPERAÇÕES 
No Quadro 4.6 são apresentadas as representaçōes utilizadas para elaborar o Diagrama de Seqüência e seus respectivos significados.

QUADRO 4.6 - REPRESENTAÇÕES E SIGNIFICADOS DO DLAGRAMA DE SEQÜENCIA DE OPERAÇÖES

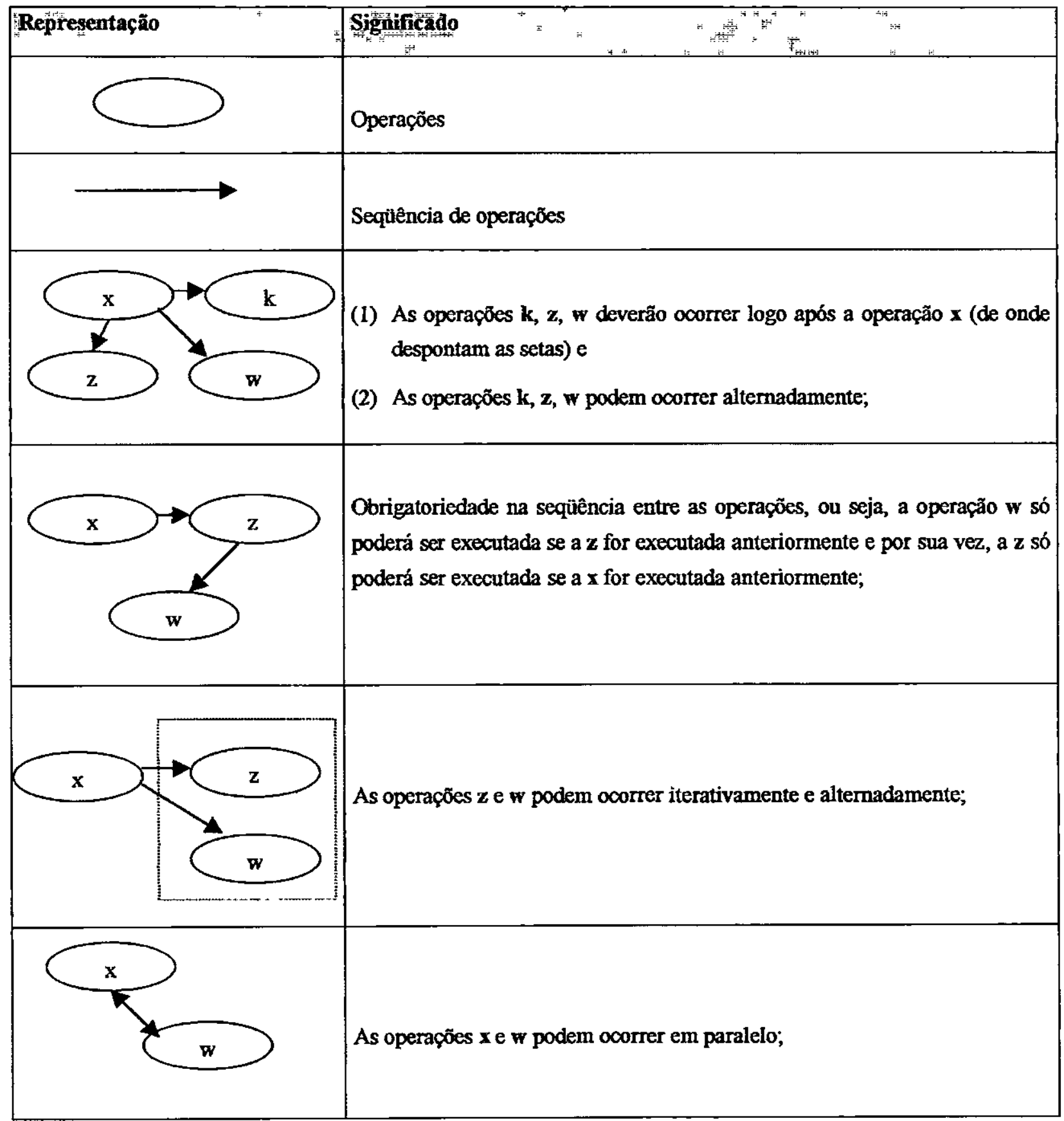

Um exemplo do uso do Diagrama de Seqüência de Operaçōes é mostrado na Figura 4.8. Esse exemplo refere-se a um subsistema que trata do cadastro de produtos, consultas e relatórios desses produtos. A opção cadastrar_produtos engloba inserir produtos, alterar_produtos ou excluir_produtos. 


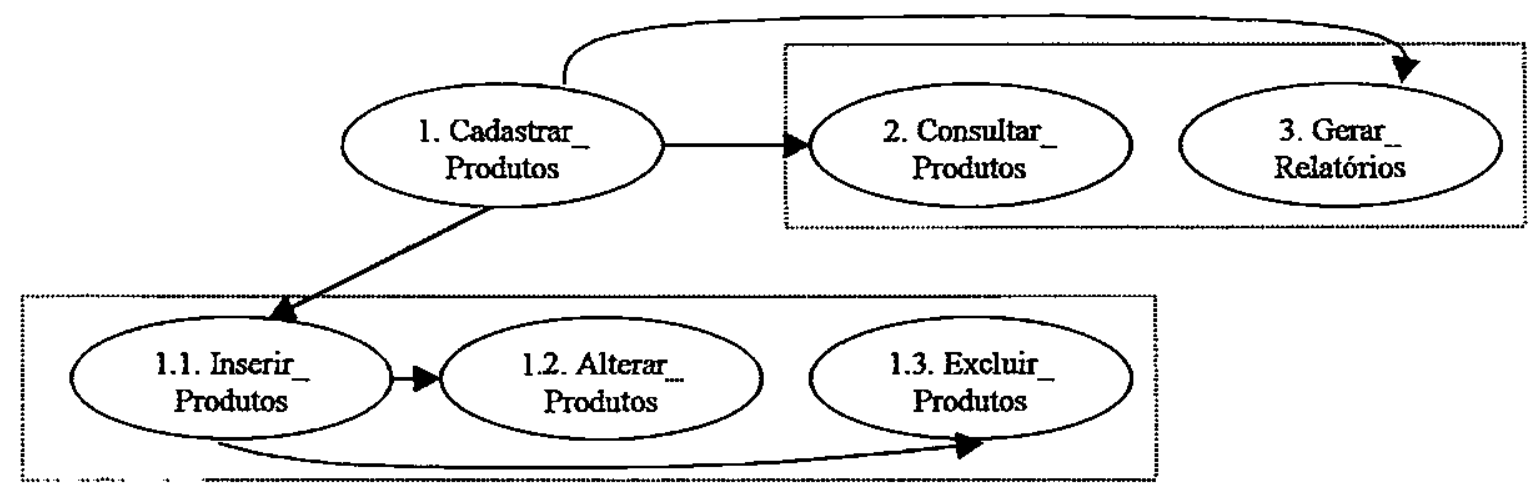

FYGURA 4.8-DIAGRAMA DE SEQŪÊNCZA DE OPERAÇÕES (EXEMPLO)

CICLO RASTREAMENTO DE PROCESSO - Avaliação do Conhecimento: nessa fase o conhecimento adquirido deve ser verificado e validado. Para isso, o engenheiro de conhecimento deve averiguar o fator confiabilidade de representação (a corretitude sintática e semântica tanto do Quadro Consensual Especifico do Sistema Analisado, quanto do Diagrama de Sequêencia de Operaçōes) e o fator confiabilidade conceitual. Para averiguar a confiabilidade conceitual o engenheiro de conhecimento pode utilizar o sistema com a finalidade de conferir a consistência e completitude do conteúdo representado no Quadro Consensual Especifico do Sistema Analisado e no Diagrama de Seqüencia de Operaçöes.

Se o conhecimento obtido não estiver completo, executa-se um outro ciclo rastreamento de processo; caso contrário, inicia-se o ciclo entrevista estruturada.

\subsection{4 - Ciclo Entrevista Estruturada do Processo IPAIA Instanciado para o Domínio de Engenharia Reversa}

Nesse ciclo as dúvidas anotadas pelo engenheiro de conhecimento devem ser esclarecidas. Uma das formas de se identificar essas dúvidas é comparando o Quadro Consensual com o Quadro Consensual Específico do Sistema Analisado. As operações e os itens de entrada e de saída do Quadro Consensual que não estão implementados no sistema, mas foram previstos para uma versão futura desse sistema possuem um comentánio anotado durante $o$ (s) ciclo(s) brainstorming e não precisam ser questionados. Com isso, otimiza-se o tempo e o esforço que poderia ser gasto no(s) ciclo(s) entrevista estruturada, uma vez que, a ausência desse tipo de comentário levaria à possíveis dúvidas a serem questionadas.

No ciclo de entrevista estruturada o engenheiro de conhecimento fará contato com todos os usuários que participaram das sessões de rastreamento de processo, pois é necessário obter conhecimento mais detalhado a respeito das operaçōes do sistema, 
principalmente, da seqũência das operações e dos itens de entrada e saída de cada operação a fim de esclarecer as dúvidas em relaçăo ao conhecimento já adquirido; para isso, é utilizada a técnica de entrevista estruturada. Algumas questões podem surgir a partir da análise das diferenças entre 0 Quadro Consensual e 0 Quadro Consensual Especifico do Sistema Analisado (QCESA) e a partir dos comentánios existentes no QCESA. Em suma, as questões que fazem parte da entrevista estáo direcionadas ao esclarecimento das possiveis dúvidas existentes e à venficação da completitude do conhecimento.

A Figura 4.9 mostra os passos que devem ser seguidos durante o ciclo entrevista estruturada, os quais são descritos, detalhadamente, a seguir.

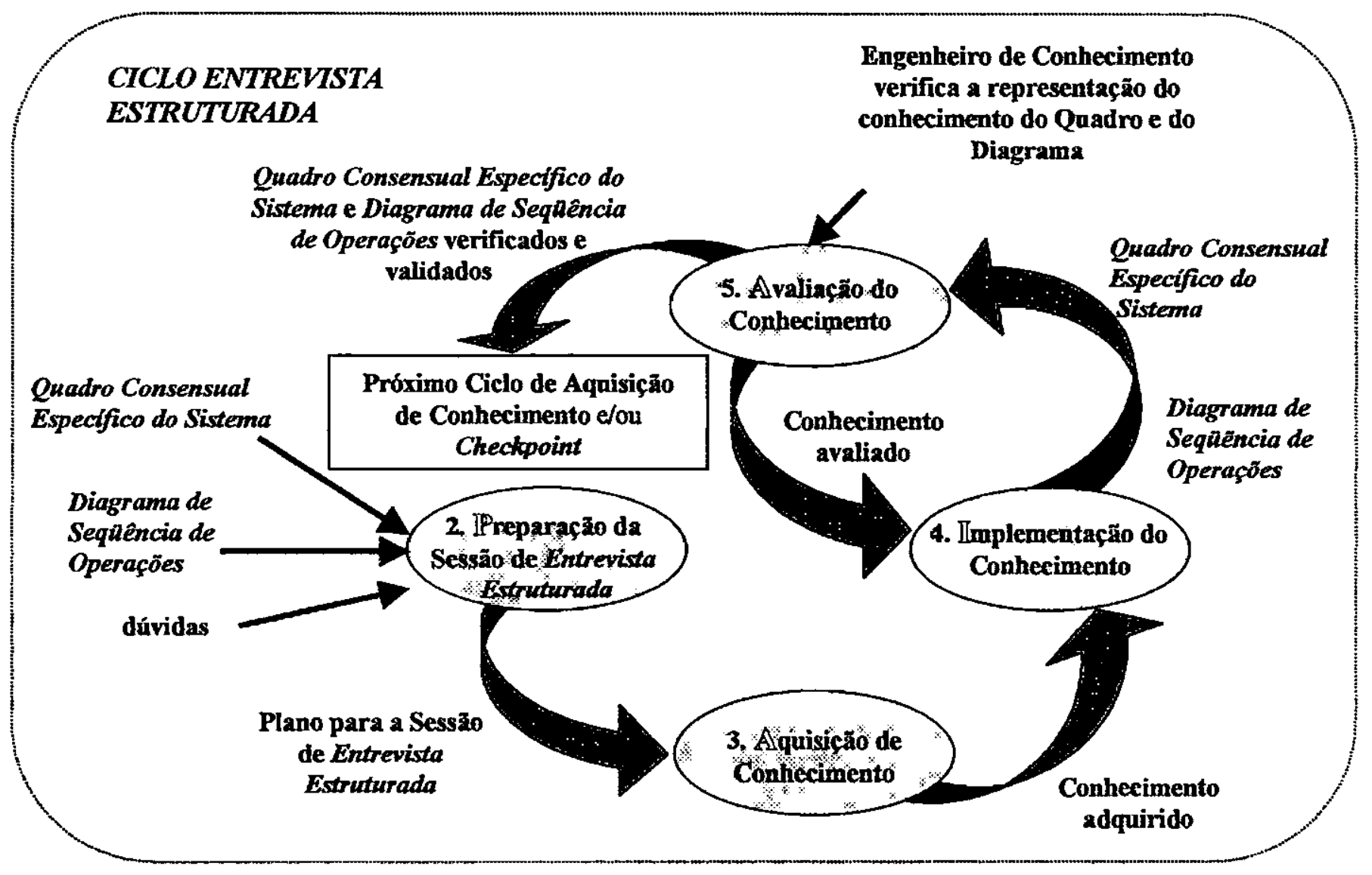

FIGURA 4.9 - CICLO ENTREVISTA ESTRUTURADA DO PROCESSO DE AQUISIÇÄO DE CONHECIMENTO IPAIA INSTANCIADO

CICLO ENTREVISTA ESTRUTURADA - Preparação da Sessão de Entrevista Estruturada: nessa fase são selecionados os membros que participarão da sessão e é elaborado um plano para auxillar o engenheiro de conhecimento a conduzir a sessão de entrevista estruturada.

Atividade 2.1 - Selecionar os membros que participarão da sessão de entrevista desestruturada: 0 engenheiro de conhecimento que fará o papel de entrevistador e anotador, e os usuários participantes da sessão de rastreamento de processo que serão entrevistados um por vez; 
Atividade 2.2 - Elaborar um plano para orientar a condução da sessão de entrevista estruturada. O Quadro 4.7 mostra a estrutura do plano para conduzir essa sessão. O usuário pode utilizar o sistema ao ser entrevistado para ter maior segurança ao responder o que Ihe for questionado sobre o sistema.

\section{QUADRO 4.7 - ESTRUTURA DO PLANO PARA AS SESSŌES DE ENTREVTSTA ESTRUTURADA}

\section{PLANO PARA AS SESSÖES DE ENTREVISTA ESTRUTURADA}

1 Introdução: o objetivo deste plano é orientar o engenheiro de conhecimento a condużir uma sessão de entrevista estruturada.

2 Gerenciamento: devem ser identificados o local, a data, horário e o tempo de duraçäo de cada sessão, o nome dó engenheiro de conhecimento es nomes dos entrevistados.

Engenheiro de Conhecimento: snomes

Meta da Sessõo: questionar sobre a sequiência das operações, sobre a sequência dos itens de entrada e saída de cada operaçáo, entre outros detalhes sobre as funcionalidades do sistema a firn de elíminar as dúvidas existentes e completar e/ou confirmar a conhecimento adquirido.

\begin{tabular}{|c|c|c|c|c|}
\hline 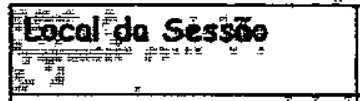 & $\begin{array}{l}\text { Data da } \\
\text { Sessaio }\end{array}$ & 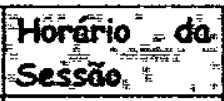 & $\begin{array}{l}\text { Tempon } \\
\text { Tota! } \\
\text { Total } \\
\end{array}$ & 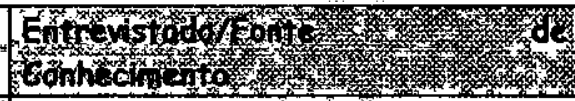 \\
\hline $\begin{array}{l}\text { local físico ondé } \\
\text { ocorreró a sessãos }\end{array}$ & $<d d / m m / a a s$ & sth:mm & $\begin{array}{l}\text { eduraçāo da } \\
\text { entrevistas }\end{array}$ & anome do entrevistados: \\
\hline & & & & \\
\hline & & & & \\
\hline & & & & \\
\hline
\end{tabular}

3 Tarefas:

3.1 Deve ser exposta, a cada entrevistado, a importância de suas informações.

3.2 Deve ser questionado o porquê das diferenças entre o Quadro Consensual a o Quadro Consensual Especifico do Sistema Analisado (QCESA). Elas ocorrem: (1) devido ao esquecimento de alguma funcionalidade ou (2) devido ao fato da funcionalidade estar embutida em alguma funç̃o maior ou ainda (3) devido ao fato do sistema não estar completo?

3.3 Baseado ho QCESA o engenheiro de conhecimento vai questionando o usuário e verificando se o conhecimento existente no QCESA está reaimente correto. Entre as questốes incluern-se:

- Quais são as operações disponiveis nơ sistema? E qual é a sequência de execução dessas operaç̧ôes?

- Quais são os itens de entrada de cada uma das operações apontadas anteriormente, e quais são os respectivos itens de saída (possiveis respostas do sistema aos itens de entrada)?

- Quais sáo os campos chaves de cada operação?

- Qual a sequência de ocorrência dos itens de entrada e saída em cada operação?

- Questionar a respeito de operações que pertencem ao QCESA e que não foram comentadas durante c entrevista pelo usuário.

Conforme o entrevistado vai respondendo, algumas questões relacionadas ds diferenças existentes entre o Quadro Consensuale o QCESA e aos comentários existentes no QCESA poderão ser eliminadas e outras poderão surgir.

4 Cronograma: deve ser estipulado um tempo para cada entrevistado responder as quiestões.

5 Recursos: o local selecionado para a entrevista deve ser isolado de quaisquer outras pessoas que não façam parte da sessão, paŕa que não haja interferência na lógica de raciocínio do usuário. $O$ usuário pode sentir mais firmeza em suas respostas se estiver utilizando o sistema, sendo assim, é importante ter todo o equipamento disponivel. 
CICLO ENTREVISTA ESTRUTURADA - Aquisição do Conhecimento: nessa fase o plano para a sessäo de entrevista estruturada, elaborado na etapa anterior, é colocado em prática a fim de se conhecer mais detalhes sobre as operaçóes do sistema (sequência de operações, itens de entrada e saída, seqüência dos itens de entrada e saída em cada operação) para serem esclarecidas as dúvidas existentes relacionadas ao conhecimento já adquirido e completado elou confirmado o conhecimento já adquirido.

CICLO ENTREVISTA ESTRUTURADA - Implementaçäo do Conhecimento: nessa fase o conhecimento adquirido é representado no Quadro Consensual Específico do Sistema Analisado e no Diagrama de Seqüéncia de Operações com o objetivo de complementá-los.

CICLO ENTREVISTA ESTRUTURADA - Avaliação do Conhecimento: nessa fase o conhecimento é verificado tanto no Quadro Consensual Específico do Sistema Analisado quarto no Diagrama de Seqüéncia de Operações pelo engenheiro de conhecimento. Isso é realizado checando a corretitude sintática e semântica da representação do conhecimento.

Se as dúvidas ainda não foram esclarecidas e/ou as informações não foram confirmadas e/ou não estão completas, inicia-se um outro ciclo entrevista estruturada.

Quando finalizado o ciclo entrevista estruturada, armazena-se o Quadro Consensual Especifico do Sistema Analisado e o Diagrama de Seqūência de Operações na base de conhecimento. Nesse ponto ocorre um momento de questionamento sobre a continuidade do processo de engenharia reversa no sistema - checkpoint.

CHECKPOINT: ponto no qual o patrocinador decide pela continuidade, ou não, da engenhara reversa do sistema. Como subsidio para essa decisão o engenheiro de conhecimento fornece ao patrocinador o Quadro Consensual (armazena conhecimento referente às características que um sistema em tal dominio deveria possuir) e o Quadro Consensual Especifico do Sisterma Analisado (armazena conhecimento referente às características que o sistema possui) evidenciando as diferenças entre esses quadros. Nesse momento, o patrocinador tem condiçőes de averiguar como utilizar, efetivamente, o conhecimento armazenado na base:

- aplicando as diretrizes e utilizando os modelos funcionais produzidos, mesmo que parcialmente;

- descartando a aplicação das diretrizes numa situação onde decide-se pela reconstrução do sistema. Nesse caso, pode-se aproveitar o Quadro Consensual para a criaçäo do documento de requisitos (porto de partida para a construção de um novo sistema). 


\section{4 - Considerações Finais}

Neste capitulo foram apresentadas as fases do Processo de Aquisição de Conhecimento IPAIA que pode ser utilizado em qualquer dominio de conhecimento.

Também foi apresentada uma instância do processo IPAIA para o domínio de engenharia reversa, incluindo as técnicas de aquisição de conhecimento utilizadas e os planos para as sessões de aquisição de conhecimento, entre outros elementos pertinentes ao processo.

As diretrizes para a utilização do conhecimento, armazenado na base, na elaboração dos modelos funcionais serão apresentadas no próximo capitulo. 



\section{CAPÍTULO 5 - DIRETRIZES PARA A UTILIZAÇÃO DA BASE DE CONHECIMENTO}

\section{1 - Considerações Iniciais}

Neste capitulo são apresentadas as diretrizes que auxiliam a utilizar o conhecimento, amazenado na base de conhecimento, na elaboração dos modelos de análise Fusion.

\section{2- Diretrizes para a Utilização da Base de Conhecimento na Elaboração dos Modelos de Análise Fusion}

Os conhecimentos adquiridos durante a aplicação do Processo de Aquisição de Conhecimento IPAIA, instanciado para o domínio de engenhana reversa, alimentam uma base de conhecimento, sendo que esses conhecimentos estão representados nos chamados Quadro Consensual Especifico do Sistema Analisado e Diagrama de Seqüencia de Operaçōes.

A proposta deste trabalho foi a de utilizar uma base de conhecimento para auxiliar na construção dos modelos de análise Fusion: modelo de ciclo de vida, modelo de operações e modelo de objetos. Percebeu-se, porém, que para construir o modelo de objetos é necessário também informações retiradas do código fonte, ou seja, năo é possível recuperar o modelo de objetos de um sistema apenas a partir da interface e de informações do dominio. Nesse caso, 
o modelo recuperado seria o ideal e não o real - podendo ser útil numa possivel reengenharia do sistema ou na reconstrução de um novo sistema. Sendo assim, foram somente criadas diretrizes para a utilização da base de conhecimento na elaboração do modelo de ciclo de vida e do modelo de operaçőes.

\subsection{1 - Diretrizes para a Elaboração do Modelo de Ciclo de Vida}

A partir do Diagrama de Seqüência de Operaçöes são obtidos os conhecimentos que auxiliarão a elaboração do primeiro nivel (o principal) do modelo de ciclo de vida e dos demais niveis, até ser atingido o nivel anterior ao nivel de detalhamento das operaçбes. O Quadro 5.1 mostra alguns exemplos de como interpretar as possiveis representaçōes do Diagrama de Seqüência de Operações para elaborar o modelo de ciclo de vida Fusion.

QUADRO 5.1 - EXEMPLOS DE TRADUÇÃO DO DLAGRAMA DE SEQÜENCIA DE OPERAÇÖES PARA MODELO DE CICLO DE VIDA

\begin{tabular}{|c|c|c|c|}
\hline & 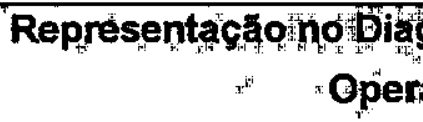 & 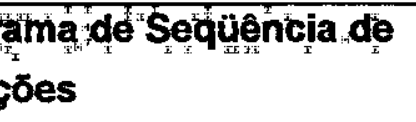 & , Modelo de Cicióade Vyida \\
\hline 1 & (n) & & $\begin{array}{l}\text { Lifecycle SCC = Cadastrar_Cliente . } \\
\text { Consultar_Cliente }\end{array}$ \\
\hline 2 & $\begin{array}{c}\text { Cadastrar } \\
\text { Cliente }\end{array}$ & Gerar_- & $\begin{array}{l}\text { Lifecycle SCC = Cadastrar_Cliente } . \\
\text { (Consultar_Ciiente | Gerar_Relatórios) }\end{array}$ \\
\hline 3 & $\begin{array}{l}\text { Cadastrar } \\
\text { Cliente }\end{array}$ & $\begin{array}{l}\text { Gerar } \\
\text { Relatórios }\end{array}$ & $\begin{array}{l}\text { Lifecycle SCC = Cadastrar_Cliente } \\
\text { Consultar_Cliente } \| \text { Gerar_Relatórios }\end{array}$ \\
\hline
\end{tabular}


QUADRO 5.1 - EXEMPLOS DE TRADUÇÃO DO DLAGRAMA DE SEQÜÊNCLA DE OPERAÇÕES PARA MODELO DE CICLO DE VIDA (CONT.)

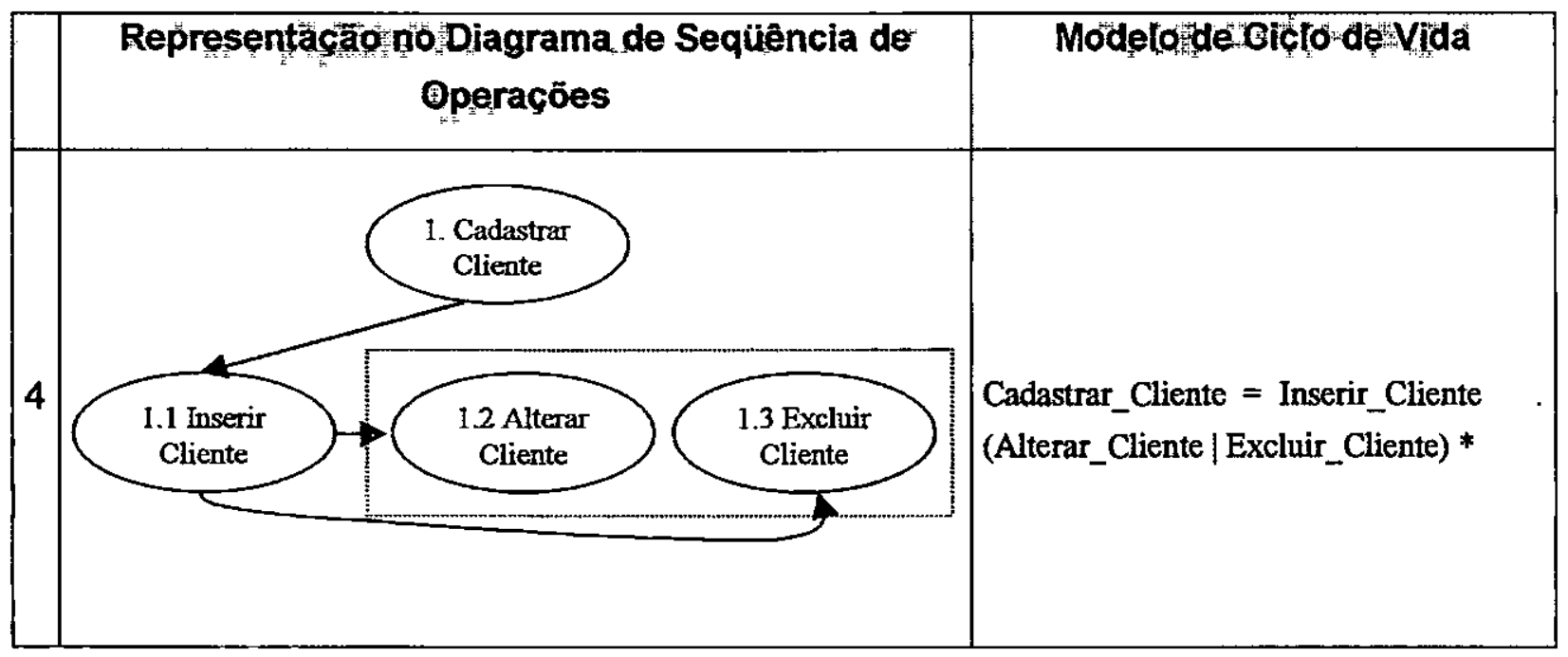

No exemplo 1, da operação cadastrar_cliente parte somente uma seta demonstrando que há obrigatoriedade na seqüência dessa operação. No exemplo 2, da operaçäo cadastrar_cliente partem duas setas representando que as operaçóes consultar_cliente e gerar_relatónios poderäo ocorrer depois da operaçäo cadastrar_cliente e de forma alternada. O fato de existir uma seta bidirecional entre as operaçöes consultar_cliente e gerar_relatórios (exemplo 3) simboliza a possibilidade de paralelismo entre essas operaçōes, ou seja, elas podem ocorrer de forma independente e em qualquer ordem - pode estar sendo realizada uma consulta de cliente em um terminal e sendo gerados relatórios em outro terminal. Quando há a presença da seta bidirecional no diagrama é anulada a propriedade referente à alternância das operaçöes apontadas por setas vindas da mesma operação. No exemplo 3 , da operaçäo cadastrar_cliente partem duas setas que deveriam indicar alternância entre as operaçōes consultar_cliente e gerar_relatórios, mas devido à existência da seta bidirecional essa propriedade é anulada. No exemplo 4, o fato das operaçöes estarem numeradas representa o desmembramento da operação em um nivel inferior, nesse caso, cadastrar_cliente é desmembrada em inserir_cliente, alterar_cliente e excluir_cliente. Da operação inserir_cliente partem duas setas representando altemância entre as operaçōes alterar_cliente e excluir_cliente. $O$ fato das operações estarem contornadas por um retângulo pontilhado representa possibilidade de Iteração entre elas.

Para elaborar as expressōes das operaçöes do nivel mais inferior do Diagrama de Seqüência de Operações - onde são descritos seus elementos (itens de entrada), as possiveis respostas do sistema a esses elementos (itens de saída) e as pré-condições existentes para que a operaçăo possa ser executada - serăo utilizados os conhecimentos representados no Quadro Consensual Especifico do Sistema Analisado; 
1. Os itens de entrada da operaçäo já estão em ordem de ocorrência, sendo assim, devese somente transpô-los para a expressão do ciclo de vida utilizando a devida notação. Se houver opções entre parênteses relacionadas a um único item de entrada essas serăo representadas no ciclo de vida como opcionais;

2. Quando na seqüência dos itens de entrada existir um número significa que, logo após um determinado evento de entrada, há uma resposta do sistema; olhar para a coluna Itens de Saida e associar esse número ao respectivo evento de saída;

3. Se no mesmo item de saida existir uma mensagem separada por um ponto e vírgula (;) de outros itens de saída significa que, após a ocorrência de determinado item de entrada pode haver ocorrência ou da mensagem ou dos outros itens de saída;

4. Se no item de saída a mensagem estiver acompanhada pela palavra "opcional" entre parênteses, isso significa que essa ocorrência é alternativa;

Por exemplo:

\begin{tabular}{|c|c|c|c|}
\hline Opéraçōes: & Itenis de:Entrada & Ttèns dë Sàida & Pré-Condiçōes \\
\hline $\begin{array}{l}\text { Inserir cliente } \\
\text { (Cadastra dados do } \\
\text { cliente) }\end{array}$ & $\begin{array}{l}\text { ClC, } 1 \text {, nome do cliente, } \\
\text { endereço, telefone, RG, } \\
\text { data de nascimento, } 2\end{array}$ & $\begin{array}{l}\text { 1. msg "Cliente já está } \\
\text { cadastrado." (opcional) } \\
\text { 2. msg "Deseja incluir } \\
\text { cliente?" }\end{array}$ & $\begin{array}{l}\text { Cliente näo deve estar } \\
\text { cadastrado }\end{array}$ \\
\hline $\begin{array}{l}\text { Alterar cliente } \\
\text { (Altera os dados } \\
\text { referentes a um cliente) }\end{array}$ & $\begin{array}{l}\text { CIC, 1, nome do cliente, } \\
\text { endereco, telefone, RG, } \\
\text { data de nascimento, } 2\end{array}$ & $\begin{array}{l}\text { msg "Cliente nåo } \\
\text { cadastrado"; nome do } \\
\text { cliente, endereco, telefone, } \\
\text { RG, data de nascimento } \\
\text { 2. msg "Deseja alterar o } \\
\text { cliente?" }\end{array}$ & \\
\hline $\begin{array}{l}\text { Excluir cliente } \\
\text { (Apaga os dados } \\
\text { referentes a um cliente) }\end{array}$ & CIC, 1,2 & $\begin{array}{ll}\text { 1. } & \text { msg "Cliente } \\
\text { cadastrado." (opcional) } \\
\text { 2. msg "Deseja excluir o } \\
\text { cliente?" }\end{array}$ & $\begin{array}{l}\text { Cliente deve estar } \\
\text { cadastrado }\end{array}$ \\
\hline $\begin{array}{l}\text { Verificar caracteristicas } \\
\text { do cliente }\end{array}$ & $\begin{array}{l}\text { CIC, 1, características (bom } \\
\text { cliente, assíduo de alguma } \\
\text { filial), } 2\end{array}$ & $\begin{array}{ll}\text { 1. } & \text { msg "Cliente não } \\
\text { cadastrado" (opcional) } & \text { nasteristicas } \\
\text { 2. } & \text { caracter }\end{array}$ & \\
\hline
\end{tabular}

Inserir_cliente $=\mathrm{CIC} .\left[\right.$ [ $m s g \_C l i e n t e j$ já_cadastrado]. nome_do_cliente. endereço .

telefone . data_de_nascimento. \#msg_Deseja_incluir_cliente

Alterar_cliente = CIC . (\#msg_Cliente_não_cadastrado [ (\#nome_do_cliente . \#endereco . \#telefone .

\#RG. \#data_de_nascimento)) . nome_do_cliente. enderego . telefone .

data_de_nascimento. \#msg_Deseja_alterar cliente

Excluir_cliente = CIC . [\#msg_Cliente_não_cadastrado] . \#msg_Deseja_excluir_cliente

Verificar_características_cliente $=$ CIC . [\#msg_Cliente_não_cadastrado] . [bom_cliente] . [assiduo_filial] . 


\subsection{2 - Diretrizes para a Elaboração do Modelo de Operaçóes}

A partir do Quadro Consensual Especifico do Sistema Analisado săo obtidos os conhecimentos utilizados para elaborar os esquemas do modelo de operações.

1. As cláusulas "Operação" e "Descrição" são retiradas da primeira coluna do quadro. "Operação" refere-se ao identificador único da operação e "Descrição" refere-se à descrição informal e concisa da operação que se encontra entre parênteses;

2. A cláusula "Lê" é retirada da coluna Itens de Entrada do quadro. Refere-se aos itens que podem ser acessados pela operação, mas não alterados por ela. Os itens de entrada considerados campos chaves (parâmetros da operação) encontram-se grifados no Quadro. Esses parâmetros são os precedidos pela palavra reservada supplied no modelo de operações;

3. A cláusula "Altera" também é retirada da coluna Itens de Entrada do quadro. É referente aos itens que podem ser acessados e alterados pela operação. Os parâmetros da operação - campos grifados no quadro - não fazem parte dessa cláusula. Para identificar os registros que estão sendo criados ou modificados em bases de dados, deve-se utilizar o procedimento indicado por Quinaia (1998), onde deve-se visualizar o diretório que contém os arquivos de dados através do comando DIR, com as opções $/ O D$, que permitem ordenar os arquivos por data/hora de atualização. Esse procedimento deve ser executado antes de se executar determinada operação (mostrando o estado atual dos arquivos de dados) e depois dessa operação ser executada (notificando quais arquivos foram criados e/ou modificados). Quando é identificada a criação de um arquivo ou registro, utiliza-se a palavra reservada new precedendo o item referente a essa criação;

4. A cláusula "Envia" é retirada da coluna itens de Saida do quadro. Essa cláusula faz referência aos itens que a operaçăo deve enviar ao ser executada;

5. A cláusula "Assume" é retirada da coluna Pré-Condiçóes do Quadro. Essa cláusula é referente às condições que devem ser satisfeitas para que a operação possa ser executada;

6. A cláusula "Resultado" é obtida por meio da análise das outras cláusulas do esquema (Descrição, Lê, Altera, Envia e Assume), isso significa que não è possivel traduzi-la diretamente para o modelo de operações, é necessánio inferência humana. Essa cláusula é referente a um algoritmo que descreve as pós-condiçőes relacionadas ao estado do sistema após ser executada a operação. 


\section{3 - Considerações Finais}

Neste capitulo foram apresentadas as diretrizes para auxiliar a utilização do conhecimento (armazenado na base de conhecimento) na elaboração do modelo de ciclo de vida e modelo de operaçóes Fusion.

Os resultados da aplicação do Processo de Aquisição de Conhecimento IPAIA, instanciado para o domínio de engenharia reversa, e das diretrizes são apresentados em dois estudos de caso, no capítulo a seguir. 


\section{CAPÍTULO 6 - ESTUDOS DE CASO}

\section{1 - Considerações Iniciais}

Neste capitulo são apresentados dois estudos de caso do Processo de Aquisição de Conhecimento IPAIA, instanciado para o domínio de engenharia reversa. O primeiro estudo de caso foi realizado com o intuito de melhorar o processo, já o segundo caso foi realizado com o intuito de avaliar o processo como um todo, ou seja, averiguar se a proposta do processo foi satisfatória (se com o conhecimento armazenado na base de conhecimento consegue-se construir os modelos de ciclo de vida e de operações Fusion).

O primeiro estudo de caso refere-se a um Sistema de Chamadas Técnicas, utilizado no CISC (Centro de Informática de São Carlos) - USP, que tem por objetivo controlar a transposição de verbas entre os departamentos das unidades da USP em troca de prestação de serviços.

O segundo estudo de caso refere-se a uma ferramenta de Geração de Seqüencia de Teste para sistemas baseados na técnica de Máquina de Estados Finito, denominada MGASET (Nakazato, 1995). 


\section{2 - Primeiro Estudo de Caso - Sistema de Chamadas Técnicas do CISC-USP}

Nesse estudo de caso foram obtidos apenas os diagramas da base de conhecimento, visto que o objetivo do estudo foi o de testar o Processo de Aquisiçäo de Conhecimento IPAIA instanciado.

\subsection{1 - Fase 1 - Inicio do Processo de Aquisiçáo de Conhecimento}

A área de aplicação do sistema refere-se às chamadas técnicas solicitadas, principalmente, pelos departamentos das unidades USP. A visão geral do dominio de conhecimento foi obtida a partir de um usuánio familiarizado com esse domínio e de um documento chamado ficha de chamada técnica. Essa visão geral é resultado da definição de termos chaves contidos nesse dominio (Tabela 6.1), seus relacionamentos (Figura 6.1) e principais funçōes (Quadro 6.1).

TABELA 6.1 - LÉXICO DO DOMÍNIO DA APLICACÃO $S C H T$

\begin{tabular}{|c|c|c|}
\hline Termo & Définição & Sinônimos \\
\hline Atendente & $\begin{array}{l}\text { Técnico responsável pelo atendimento da } \\
\text { chamada técnica. }\end{array}$ & Técnico \\
\hline Centro de Custo & $\begin{array}{l}\text { Órgão responsável por pagar a chamada de } \\
\text { serviço (ChT). O senviço pode estar em } \\
\text { garantia ou podem existir contratos com } \\
\text { empresas (é cobrado das empresas e não da } \\
\text { unidade). }\end{array}$ & \\
\hline Chamada Técnica & $\begin{array}{l}\hat{E} \text { um pedido para reparo ou instalação de } \\
\text { algum equipamento que seja patrimônio de } \\
\text { departamentos das unidades USP. }\end{array}$ & ChT \\
\hline Defeito & $\begin{array}{l}\text { Descrição do(s) defeito(s) que o equipamento } \\
\text { apresenta. }\end{array}$ & \\
\hline Departamento & $\begin{array}{l}\text { Departamento ou Seção da unidade USP que } \\
\text { solicita a chamada técrica. }\end{array}$ & Seção, Depto \\
\hline Equipamento & $\begin{array}{l}\text { Pode ser classificado como I (impressora) ou } \\
M \text { (micro incluindo teclados, monitor, CPU, } \\
\text { etc...) }\end{array}$ & Eqpto \\
\hline Peças & $\begin{array}{l}\text { Peças do equipamento que precisam ser } \\
\text { trocadas. }\end{array}$ & \\
\hline Unidade & $\begin{array}{l}\text { Unidade da USP em que o departamento } \\
\text { solicitante da chamada técnica pertence. }\end{array}$ & \\
\hline Usuário & Funcionário que solicita a chamada técnica. & Funcionário \\
\hline Visita & $\begin{array}{l}\text { E o número da visita que o técnico fez; pode } \\
\text { ser } 1 \text { ( } 1^{a} \text { visita) ou } 2 \text { ( } 2^{a} \text { visita). }\end{array}$ & \\
\hline
\end{tabular}


FIGURA 6.1-DLAGRAMA DO DOMÍNIO DA APLCAÇÃO - SCHT

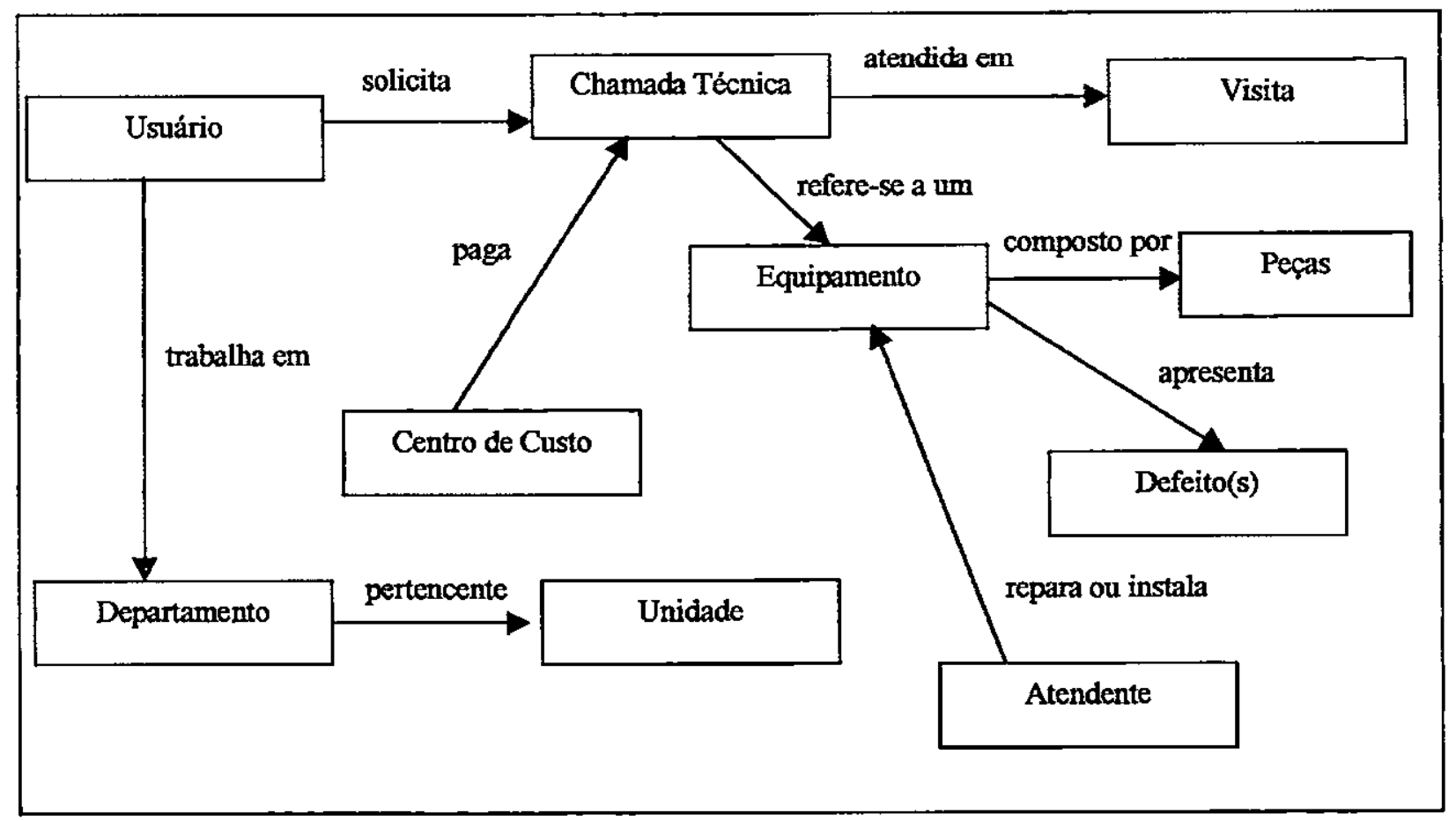

QUADRO 6.1 - QUADRO DE DESCRIÇÃO DAS PRINCIPAIS FUNÇŌES - SCHT

\begin{tabular}{|c|c|}
\hline Função & Objetivo \\
\hline $\begin{array}{l}\text { Manutenção de } \\
\text { chamadas técnicas }\end{array}$ & $\begin{array}{l}\text { Inserção, Alteração e Exclusão de chamadas técnicas solicitadas } \\
\text { pelos departamentos das unidades USP. }\end{array}$ \\
\hline $\begin{array}{ll}\text { Manutenção } & \text { de } \\
\text { deptos/seções } & \end{array}$ & $\begin{array}{l}\text { Inserção, Alteração e Exclusão de departamentos/seçöes das } \\
\text { unidades USP. }\end{array}$ \\
\hline $\begin{array}{l}\text { Manutenção } \\
\text { funcionários } \\
\text { (usuários) }\end{array}$ & $\begin{array}{l}\text { Inserção, Alteração e Exclusão de funcionários dos departamentos da } \\
\text { USP. }\end{array}$ \\
\hline $\begin{array}{l}\text { Manutenção } \\
\text { peças }\end{array}$ & $\begin{array}{l}\text { Inserção, Alteração e Exclusão de peças componentes de um micro ou } \\
\text { impressora (equipamento). }\end{array}$ \\
\hline $\begin{array}{l}\text { Manutenção } \\
\text { técnicos }\end{array}$ & Inserção, Alteração e Exclusão de técnicos. \\
\hline $\begin{array}{l}\text { Manutenção } \\
\text { unidades }\end{array}$ & $\begin{array}{l}\text { Inserção, Alteração e Exclusão de unidades da USP e seus } \\
\text { respectivos departamentos. }\end{array}$ \\
\hline Relatórios & $\begin{array}{l}\text { Relatórios referentes ao custo, para os Centros de Custo, dos serviços } \\
\text { prestados; referentes às horas trabalhadas de cada técnico; referentes } \\
\text { às chamadas técnicas atendidas; referentes às peças disponiveis, } \\
\text { etc... }\end{array}$ \\
\hline
\end{tabular}


Foram selecionados dois membros para participarem das sessöes de aquisição de conhecimento. Esses membros fizeram tanto o papel de especialista do domínio quanto o de usuários do sistema.

\subsection{2 - Cic/o Brainstorming do Processo IPAIA Instanciado para o Dominio de Engenharia Reversa}

Nesse ciclo foi obtido conhecimento de âmbito geral sobre o domínio da aplicação, a partir de especialistas do domínio, incluindo as principais funcionalidades que um sistema insenido no contexto de controle de chamadas técnicas deveria ter.

CTCO BRAINSTORMING - Preparação da Sessão de Brainstorming: nessa fase foram selecionados os dois membros da equipe de aquisição de conhecimento para participarem da sessão de brainstoming; também foi elaborado um plano para auxiliar na condução da sessão de brainstoming. Esse plano foi entregue a cada um dos participantes, com uma semana de artecedência da sessäo, para que esses pudessem se preparar melhor (Quadro 6.2).

Durante essa fase, percebeu-se a necessidade de um estímulo maior para os participantes das sessöes; assim, surgiu a idéia de incluir uma outra atividade na Fase 1 do processo: a de estimular os possiveis participantes das sessőes de aquisição de conhecimento realizando uma palestra inicial que focalize o que é aquisiçăo de conhecimento, sua importância para a organização, os principais conceitos relacionados à aquisição de conhecimento como especialistas do domínio, engenheiro de conhecimento, etc. Notou-se, também, a importância de um patrocinador, pessoa que deve ajudar a manter o compromisso nos momentos de dificuldades e deve garantir os recursos essenciais utilizados durante a aquisição de conhecimento.

CICOO BRAINSTORMING - Aquisição de Conhecimento: nessa fase o plano elaborado anteriormente foi colocado em prática. O engenheiro de conhecimento fez o papel de moderador na sessão quando foi aplicado o brainstoming desestruturado, de modo que quando um estivesse se pronunciando e outro se lembrasse de algo para complementar, existisse ponderação e bom senso para dar a palavra a outro. 
QUADRO 6.2 - PLANO PARA A SESSÃO DE BRAINSTORMING - SCHT

\section{PLANO PARA A SESSÃO DE BRAINSTORMING}

1 Introdução: o objetivo deste plano é orientar na condução da sessão de brainstorming. (técnica utilizada para adquirir informações de um grupo de pessoas sobre determinado assunto).

\section{Gerenciamento}

Local da Sessão: Sala de Reuniões do CISC

Data da Sessão: 02/07/1999 Horário: 08:30 hs

Engenheiro de Conhecimento: Andrea Padovan Jubileu

Anotadore(s)/Assistente(s): não será utilizado

Tempo Total da Sessão de Aquisição de Conhecimento: 30 minutos

Especialistas do Domínio/Fonte de Conhecimento: Antonio Carlos O. S. Aragão

Josemari Bettoni Golveia Silva

Meta da Sessão: obter informações gerais sobre os termos (e os relacionamentos entre esses termos) do domínio da aplicação, e sobre as principais funcionalidades que um sistema de chamadas técnicas deveria ter.

\section{Tarefas:}

3.1 Iniciação: $O$ motivo pelo qual faremos essa sessão de brainstorming é enfocado na obtenção de informações a respeito de Chamadas Técnicas, sendo assim, é de suma importância a sua participação. As informações obtidas servirão de base para a elaboração de representações do conhecimento que farão parte da documentação do sistema que está sendo analisado (SCHT).

3.2 Haverá um tempo disponivel para que cada participante exponha o que conhece a respeito dos termos, relacionamentos entre esses termos e funcionalidades relacionados a um sistema de chamadas técnicas, além de comentários a respeito de funcionalidades que não foram implementadas no sistema, mas foram previstas para a implementação de uma versão futura do SCHT. Se no momento da exposição você se lembrar de algo a respeito do que está sendo relatado, anote e após o término do pronunciamento a respeito dessa funcionalidade, você poderá fazer um adendo ao que foi relatado.

3.3 A seguir, cada uma das funcionalidades que o sistema deveria ter será levantada e cada um dos participantes da sessão terá um tempo para comentar a respeito dessa funcionalidade, expondo quais seriam os itens de entrada necessários para a sua execução e quais seriam os itens de saída.

3.4 Depois que cada especialista expôs seu conhecimento, aqueles que quiserem complementar algo poderão fazê-lo.

\section{Cronograma:}

\begin{tabular}{|c|c|c|c|c|c|c|}
\hline Tarefas & 5 minutos & 10 minutos & 15 minutos & 20 minutos & 25 minutos & 30 minutos \\
\hline 3.1 & - & & & & & \\
\hline \multicolumn{7}{|l|}{3.2} \\
\hline 3.3 & & & & & & \\
\hline & & & & & & \\
\hline
\end{tabular}

5 Recursos: no local onde ocorrerá a sessão, as cadeiras deverão estar dispostas em forma circular, para que todos se vejam, e cada participante terá papel e caneta para anotações. 
CICLO BRAINSTORMING - Implementação do Conhecimento: nessa fase foram transcritas as anotaçōes feitas pelo engenheiro de conhecimento. O Léxico do Domínio da Aplicação, o Diagrama do Dominio da Aplicaçăo e o Quadro de Descriçöes das Principais Funções foram confirmados. Foi elaborado um Quadro Consensual composto pelas operaçöes que o sistema deveria ter e pelos respectivos itens de entrada e de saida dessas operaçōes (Quadro 6.3).

\section{QUADRO 6.3 - QUADRO CONSENSUAL-SCHT}

\begin{tabular}{|c|c|c|}
\hline Operaçōes & Itens de Entrada & Itens de Saida \\
\hline $\begin{array}{l}\text { Inserção das } \\
\text { Chamadas } \\
\text { Técricas }\end{array}$ & $\begin{array}{l}\text { Nr da chamada técnica, nr da } \\
\text { visita, unidade, depto/seção, nr } \\
\text { do património, nr do usuário, } \\
\text { defeito data da chamada, } \\
\text { horário da chamada, centro de } \\
\text { custo (unidade ou empresa) }\end{array}$ & $\begin{array}{l}\text { Msg "Cht já cadastrada" } \\
\text { Msg "Unidade não cadastrada" } \\
\text { Msg "Este depto/seção não pertence } \\
\text { a tal unidade" } \\
\text { Msg "Este eqpto não está } \\
\text { cadastrado" } \\
\text { Classe do equipamento (M ou l), } \\
\text { local, descrição_eqpto, modelo, nr da } \\
\text { série, estação } \\
\text { Nome do usuário } \\
\text { Nome da empresa ou descrição da } \\
\text { unidade } \\
\text { Msg "Empresa não cadastrada" } \\
\text { Msg "Deseja cadastrar?" } \\
\text { Estrutura de orçamento impressa } \\
\text { para ser preenchida e entregue ao } \\
\text { usuário }\end{array}$ \\
\hline $\begin{array}{l}\text { Baixa de Chamada } \\
\text { Técrica }\end{array}$ & $\begin{array}{l}\text { Nr da chamada técnica, nr da } \\
\text { visita, nr_atendente, tempo de } \\
\text { atendimento, tempo de } \\
\text { locomoçäo, tempo de reparo, } \\
\text { tempo de laboratório, situaçäo } \\
\text { (PEN ou OK), código peça e } \\
\text { componentes trocados }\end{array}$ & $\begin{array}{l}\text { Unidade, depto/seção, nr do } \\
\text { património, descrição_eqpto, classe } \\
\text { do eqpto, local, nr série, modelo, } \\
\text { estaçäo, nr do usuário, nome do } \\
\text { usuário, defeito, data da chamada, } \\
\text { horário da chamada, centro de custo } \\
\text { Msg "Atendente näo cadastrado" } \\
\text { Nome atendente (nome técrico) } \\
\text { Msg "Peça näo cadastrada" } \\
\text { Descriçăo da peça } \\
\text { Msg "Dar baixa nessa Cht?" }\end{array}$ \\
\hline
\end{tabular}


QUADRO 6.3 - QUADRO CONSENSUAL - SCHT (CONT.)

\begin{tabular}{|c|c|c|}
\hline Operaçōes & Itens de Entrada & Itens de Saida \\
\hline $\begin{array}{l}\text { Alteração das } \\
\text { Chamadas } \\
\text { Técnicas }\end{array}$ & $\begin{array}{l}\text { Nr da chamada técnica, } \mathrm{nr} \text { da } \\
\text { visita, unidade, depto/seção, nr } \\
\text { do patrimônio, nr do usuário, } \\
\text { defeito, data da chamada, } \\
\text { horáno da chamada, centro de } \\
\text { custo (unidade ou empresa) }\end{array}$ & $\begin{array}{l}\text { Msg "Esta Cht não pode ser alterada. } \\
\text { Já foi dado baixa" } \\
\text { Unidade, depto/seção, nr do } \\
\text { patrimônio, classe do equipamento } \\
\text { (M ou D, local, descrição_eqpto, } \\
\text { modelo, nr da série, estação, nr do } \\
\text { usuário, nome do usuário, defeito, } \\
\text { data da chamada, horário da } \\
\text { chamada, centro de custo } \\
\text { Msg "Unidade não cadastrada" } \\
\text { Msg "Este depto/seção não pertence } \\
\text { a tal unidade" } \\
\text { Msg "Este eqpto não está } \\
\text { cadastrado" } \\
\text { Classe do equipamento (M ou I), } \\
\text { local, descrição_eqpto, modelo, nr da } \\
\text { série, estação } \\
\text { Nome do usuário } \\
\text { Nome da empresa ou descrição da } \\
\text { unidade } \\
\text { Msg "Empresa não cadastrada" } \\
\text { Msg "Confirma Alteração da Cht?" }\end{array}$ \\
\hline $\begin{array}{l}\text { Exclusão de } \\
\text { Chamadas } \\
\text { Técnicas }\end{array}$ & $\begin{array}{l}\mathrm{Nr} \text { da chamada técnica, nr da } \\
\text { visita }\end{array}$ & $\begin{array}{l}\text { Unidade, depto/seção, nr do } \\
\text { património, classe do equipamento } \\
\text { (M ou D), local, descrição_eqpto, } \\
\text { modelo, nr da série, estação, nr do } \\
\text { usuáno, nome do usuáno, defeito, } \\
\text { data da chamada, horário da } \\
\text { chamada, centro de custo, } \\
\text { nr_atendente, nome atendente, } \\
\text { tempo de atendimento, tempo de } \\
\text { locomoção, tempo de reparo, tempo } \\
\text { de laboratório, situação (PEN ou } \\
\text { OK), código peça, descriçăo peças } \\
\text { Msg "Esta Cht não pode ser } \\
\text { excluida" } \\
\text { Msg "Confirma exclusão?" }\end{array}$ \\
\hline $\begin{array}{l}\text { Inserção de } \\
\text { técnicos } \\
\text { (atendente) }\end{array}$ & $\begin{array}{l}\mathrm{Nr} \text { do técriico, nome, nível } \\
\text { técnico }\end{array}$ & Msg "Confirma cadastro?" \\
\hline $\begin{array}{l}\text { Alteração de } \\
\text { técnicos } \\
\text { (atendente) }\end{array}$ & $\begin{array}{l}\text { Nr do técnico } \\
\text { Nome, nível técnico }\end{array}$ & $\begin{array}{l}\text { Nome, nível técnico } \\
\text { Msg "Confirma Alteração?" }\end{array}$ \\
\hline $\begin{array}{l}\text { Exclusão de } \\
\text { técnicos } \\
\text { (atendente) }\end{array}$ & $\mathrm{Nr}$ do técnico & $\begin{array}{l}\text { Nome, nivel técnico } \\
\text { Msg "Este técnico não pode ser } \\
\text { excluido" } \\
\text { Msg "Confirma Exclusão?" }\end{array}$ \\
\hline
\end{tabular}


QUADRO 6.3 - QUADRO CONSENSUAL-SCHT (CONT.)

\begin{tabular}{|c|c|c|}
\hline Operaçoes: & Itens de Entrads & 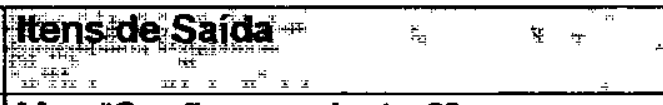 \\
\hline $\begin{array}{l}\text { Inserção de } \\
\text { funcionários } \\
\text { (usuários) }\end{array}$ & $\begin{array}{l}\text { Nr do funcionário, nome, telefone } \\
\text { para contato }\end{array}$ & Msg "Confirma cadastro?" \\
\hline $\begin{array}{l}\text { Alteração de } \\
\text { funcionánios } \\
\text { (usuários) }\end{array}$ & $\begin{array}{l}\text { Nr do funcionário } \\
\text { Nome, telefone para contato }\end{array}$ & $\begin{array}{l}\text { Nome, telefone para contato } \\
\text { Msg "Confirma Alteração?" }\end{array}$ \\
\hline $\begin{array}{l}\text { Exclusão de } \\
\text { funcionários } \\
\text { (usuários) }\end{array}$ & Nr do funcionário & $\begin{array}{l}\text { Nome, telefone para contato } \\
\text { Msg "Este funcionário não pode ser } \\
\text { excluido" } \\
\text { Msg "Confirma Exclusäo?" }\end{array}$ \\
\hline Inclusão de peças & $\begin{array}{l}\text { Código da peça, descriçăo, } \\
\text { quantidade em estoque }\end{array}$ & Msg "Confirma cadastro?" \\
\hline Alteraçāo de peças & $\begin{array}{l}\text { Código da peça } \\
\text { Descriçäo, quantidade em } \\
\text { estoque }\end{array}$ & $\begin{array}{l}\text { Descriçāo, quantidade em estoque } \\
\text { Msg "Confirma Alteração?" }\end{array}$ \\
\hline Exclusão de peças & Código da peça & $\begin{array}{l}\text { Descrição, quantidade em estoque } \\
\text { Msg "Esta peça não pode ser } \\
\text { excluida" } \\
\text { Msg "Confirma Exclusão?" }\end{array}$ \\
\hline Inclusão de eqptos & $\begin{array}{l}\text { Nr do patrimônio, classe do } \\
\text { equipamento ( } M \text { ou } D \text {, local, } \\
\text { descrição_eqpo, modelo, nr da } \\
\text { séne, estaçäo }\end{array}$ & Msg "Confima cadastro?" \\
\hline Alteração de eqptos & $\begin{array}{l}\text { Nr do património } \\
\text { Classe do equipamento ( } M \text { ou } 1), \\
\text { local, descriçäo_eqpto, modelo, } \\
\text { nr da série, estaçäo }\end{array}$ & $\begin{array}{l}\text { Classe do equipamento (M ou } \mathrm{D} \text {, } \\
\text { local, descriçáo_eqpto, modelo, nr da } \\
\text { séne, estação } \\
\text { Msg “Confirma Alteraçäo?” }\end{array}$ \\
\hline Exclusão de eqptos & Nr do patrimônio & $\begin{array}{l}\text { Classe do equipamento (M ou l), } \\
\text { local, descrição_eqpto, modelo, nr da } \\
\text { séne, estaçăo } \\
\text { Msg "Este qpto nāo pode ser } \\
\text { excluido" } \\
\text { Msg "Confirma Exclusāo?" }\end{array}$ \\
\hline $\begin{array}{l}\text { Inclusão de } \\
\text { empresas }\end{array}$ & Código da empresa, descrição & Msg "Confirma cadastro?" \\
\hline $\begin{array}{l}\text { Alteraçăo de } \\
\text { empresas }\end{array}$ & $\begin{array}{l}\text { Código da empresa } \\
\text { Descrição }\end{array}$ & $\begin{array}{l}\text { Descrição } \\
\text { Msg “Confima Alteração?” }\end{array}$ \\
\hline
\end{tabular}


QUADRO 6.3 - QUADRO CONSENSUAL - SCHT (CONT.)

\begin{tabular}{|c|c|c|}
\hline Operaçōes & Htens de Entrada & Itens de Saída \\
\hline $\begin{array}{l}\text { Exclusão de } \\
\text { empresas }\end{array}$ & Código da empresa & $\begin{array}{l}\text { Descrição } \\
\text { Msg "Esta empresa não pode ser } \\
\text { excluida" } \\
\text { Msg "Confirma Exciusão?" }\end{array}$ \\
\hline $\begin{array}{l}\text { Inclusāo de } \\
\text { unidades }\end{array}$ & $\begin{array}{l}\text { Unidade, descrição, } \\
\text { departamentos/seçōes }\end{array}$ & Msg "Confirma cadastro?" \\
\hline $\begin{array}{l}\text { Alteração de } \\
\text { unidades }\end{array}$ & $\begin{array}{l}\text { Unidade } \\
\text { Descrição, } \\
\text { departamentos/seções }\end{array}$ & $\begin{array}{l}\text { Descrição, departamentos/seçōes } \\
\text { Msg "Confirma Alteraçāo?" }\end{array}$ \\
\hline $\begin{array}{l}\text { Exclusão de } \\
\text { unidades }\end{array}$ & Unidade & $\begin{array}{l}\text { Descrição } \\
\text { Msg "Esta empresa năo pode ser } \\
\text { excluida" } \\
\text { Msg "Confirma Exclusão?" }\end{array}$ \\
\hline Relatórios & $\begin{array}{l}\text { Em alguns relatórios somente } \\
\text { periodo, em outros periodos e o } \\
\text { valor da hora, o centro de custo, } \\
\text { em outros ainda, não há itens de } \\
\text { entrada, ou seja, os itens de } \\
\text { entrada dependem do tipo de } \\
\text { relatório solicitado }\end{array}$ & $\begin{array}{l}\text { Dados cadastrados referentes às } \\
\text { chamadas técnicas, às unidades, às } \\
\text { empresas, às peças, aos técnicos, } \\
\text { aos funcionários e e aos } \\
\text { equipamentos. }\end{array}$ \\
\hline
\end{tabular}

CICLO BRAINSTORMING - Avaliação do Conhecimento: nessa fase o conhecimento adquirido foi validado junto aos especialistas do dominio participantes da sessāo de brainstorming. Para isso, foi realizada uma inspeção onde foi averiguada tanto a consistência quanto a completitude do conhecimento conceitual do dominio adquirido. Depois de realizada a inspeção notou-se que não haveria necessidade de ser realizado outro ciclo brainstorming; desse modo, o seguinte ciclo (ciclo rastreamento de processo) foi realizado visando a obtenção do conhecimento especifico do Sistema de Chamadas Técnicas.

\subsection{3 -Ciclo Rastreamento de Processo do Processo IPAIA Instanciado para o Dominio de Engenharia Reversa}

Nesse ciclo o conhecimento foi obtido de um usuário do sistema por meio da observação. $O$ engenheiro do conhecimento acompanhou os procedimentos tomados pelo usuário ao utilizar o sistema a fim de se obter conhecimento, especificamente, a respeito do sistema de chamadas técnicas. 
CICLO RASTREAMENTO DE PROCESSO - Preparação da Sessão de Rastreamento de

Processo: nessa fase foi selecionado um usuário do sistema para dele adquirir conhecimento, e foi elaborado um plano para conduzir a sessão de rastreamento de processo (Quadro 6.4), 0 qual foi entregue ao usuário com dois dias de antecedência.

QUADRO 6.4-PLANO PARA A SESSÄO DE RASTREAMENTO DE PROCESSO-SCHT

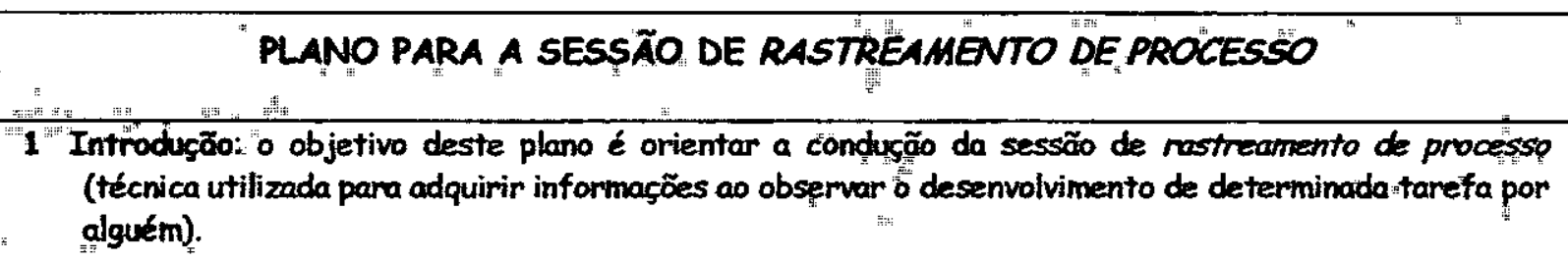

\section{Gerenciamento}

Engenheiro de Connecinento: Andrea Padovan Jubileu

Meta da Sessão: öbter informações a respeito das funcionalidades do Sistema de Chamadas Técnicas (SEHT), observando.o uso do sistema pelo usuário em um casa hipotético ou real.

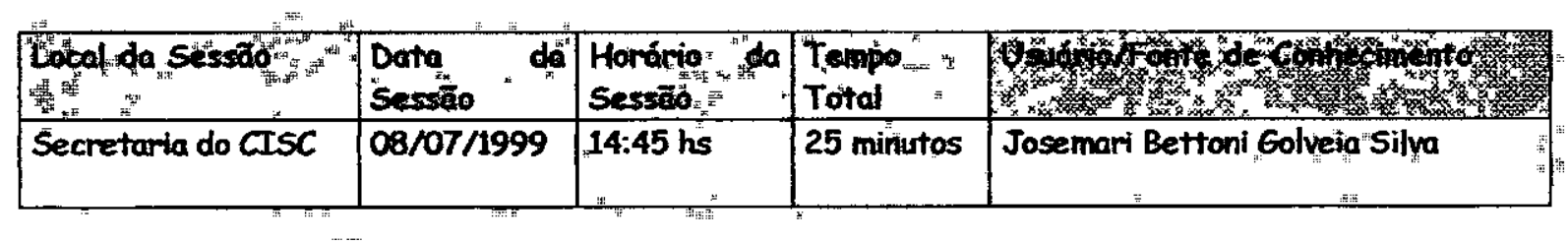

3 Tarefas:

3.1 Iniciação: : O motivo pelo qual faremos essa sessão de rastreamento de processo é enfocado na obtenção de informações a respeito do Sistema de Chamadas Técnicas (SCHT). Enquanto você estiver utilizando o sistema, em um cáso hipotético ou real, sená observado.

3.2. Haverd um tempo disponivel para que você ưtilizé o sistema simulando un caso hipotético ou em un caso real', mảsé de fundamentâl importância que vocé "pense alto" durante a utilizaçäo do sistema, ou seja, relate verbalmente "todos: os passos tomados. Lembre-se que deve utilizar o sistema imăginando que está ensinando a algum novo usuário a utilizá-lo, falando pausadamente cada passo tomado;

3.3 0 engenheiro de conhecimento, "por sua vez, observará e registrará todos os passos do seu prö́cedimento ao" utilizar o sistema, ñão interferindo. A atenção do engenheiro de conhecimęnto estará voltada principalmente:

- Nas operaçóes efetuadas e na descrição informal de cada una delas:

- Nas pré-coñdiçóes para que cada opêração possa ser executada:

- Nos itens de entrada para a execução de cada operaçäo, identificando entre esses ittens de entrada quais são os campos chaves (parâmętros da operação, aqueles os quais outrós campos dependem):

- Nós itens de saída decorrentes da execução de cada operaçäo:

- Na sequiência dé ocorrência das operações:

- Na sequiêricia de ocorrência dos itents de entrada e saida em cada operagãá:

- Nas opcó́es dos menus do sistema:

4 Cronograma:

\begin{tabular}{|c|c|c|c|c|c|}
\hline Tarefas & 5 minutos & 10 minutos & 15 mimitos & 20 minutos & 25 minutos \\
\hline \multicolumn{6}{|l|}{3.1} \\
\hline \multicolumn{6}{|l|}{3.2} \\
\hline 3.3 & & 8 & & & \\
\hline & & & & & \\
\hline
\end{tabular}

5 Recursos: no local onde ocorrerá a sessão deve haver um micro com o software instalädo e com todos os periféricośs necessários para a simulação de um caso hipotético ou real. É importante que você não seja interrompido por eventuais motivos, para que não haja bloqueios na lógica de seu raciocínio: 
CICLO RASTREAMENTO DE PROCESSO - Aquisiçăo do Conhecimento: nessa fase o plano elaborado anteriormente foi colocado em prática a fim de adquir conhecimento específico referente às operações do sistema, seus respectivos itens de entrada e de saída, a seqüência de execução das operaçōes e a seqüência dos itens de cada operação. O papel do engenheiro de conhecimento, nessa fase, fol o de somente observar os procedimentos do usuánio enquanto este utilizava o sistema.

CICLO RASTREAMENTO DE PROCESSO - Implementação do Conhecimento: nessa fase o que foi registrado durante a sessão foi transcrito no Quadro Consensual Especifico do Sistema Analisado (Quadro 6.5) e no Diagrama de Seqüência de Operaçöes (Figura 6.2).

QUADRO 6.5 - QUADRO CONSENSUAL ESPECIFTCO DO SISTEMA SCHT

\begin{tabular}{|c|c|c|c|}
\hline Operaçōes & Ifens de Entrada & Itens de Saída & Pré-Condições \\
\hline $\begin{array}{l}\text { Inserção/Alteração } \\
\text { das Chamadas } \\
\text { Técnicas }\end{array}$ & \begin{tabular}{|l|} 
Nr da chamada técnica, \\
nr da visita, classe do \\
equipamento, unidade, \\
depto/seção, centro de \\
custo, nome do usuánio, \\
telefone, nr do usuário, \\
equipamento, data da \\
solicitação, nr do \\
patrimônio, horário da \\
solicitação, data de \\
encerramento, tempo de \\
atendimento, tempo de \\
locomoção, tempo de \\
reparo, tempo de \\
laboratóno, nível do \\
técnico, situaçăo, valor \\
das peças, defeito, 1
\end{tabular} & $\begin{array}{l}\text { 1. msg "...Posicione } \\
\text { papel... impressora ok- } \\
\text { ENTER. Tecle ESC p/ } \\
\text { retomar" (possibilidade } \\
\text { de impressão de uma } \\
\text { estrutura de orçarnento } \\
\text { para ser preenchida e } \\
\text { entregue ao usuánio) }\end{array}$ & \\
\hline $\begin{array}{l}\text { Exclusão das } \\
\text { Chamadas Técnicas } \\
\text { por periodo }\end{array}$ & $\begin{array}{l}\text { Periodo (data inicial, } \\
\text { data final), } 1\end{array}$ & 1. msg "Aguarde..." & \\
\hline $\begin{array}{l}\text { Exclusão de uma } \\
\text { Chamada Técnica }\end{array}$ & $\begin{array}{l}\text { Nr da chamada técnica, } \\
\text { Or da visita, 1, ESC, } 2\end{array}$ & 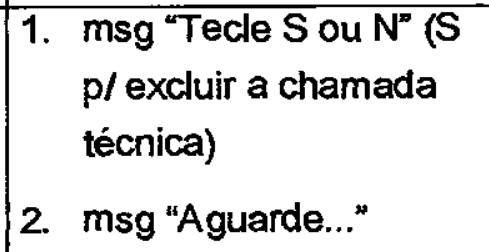 & \\
\hline
\end{tabular}


QUADRO 6.5 - QUADRO CONSENSUAL ESPECIFICO DO SISTEMA SCHT (CONT.)

\begin{tabular}{|c|c|c|c|}
\hline Operaçöes & ttèns de Entrada & Itenș de Saida & Pré-Condiçōes \\
\hline $\begin{array}{l}\text { Relação de Visitas } \\
\text { Solucionadas }\end{array}$ & $\begin{array}{l}\text { Periodo (data inicial, } \\
\text { data final) }\end{array}$ & $\begin{array}{l}\text { Nr da chamada técnica, } \mathrm{nr} \\
\text { da visita, data da } \\
\text { solicitaçäo, unidade, } \\
\text { departamento, telefone, } \\
\text { usuário, técnico, } \\
\text { equipamento, data de } \\
\text { encerramento }\end{array}$ & \\
\hline $\begin{array}{l}\text { Relação de Visitas } \\
\text { Pendentes }\end{array}$ & $\begin{array}{l}\text { Periodo (data inicial, } \\
\text { data final) }\end{array}$ & $\begin{array}{l}\text { Nr da chamada técnica, } \mathrm{nr} \\
\text { da visita, data da } \\
\text { solicitaçäo, unidade, } \\
\text { departamento, telefone, } \\
\text { usuário, técnico, } \\
\text { equipamento, data de } \\
\text { encerramento }\end{array}$ & \\
\hline $\begin{array}{l}\text { Relação de Todas as } \\
\text { Visitas }\end{array}$ & $\begin{array}{l}\text { Periodo (data inicial, } \\
\text { data final) }\end{array}$ & $\begin{array}{l}\text { Nr da chamada técnica, nr } \\
\text { da visita, data da } \\
\text { solicitação, unidade, } \\
\text { departamento, telefone, } \\
\text { usuário, técnico, } \\
\text { equipamento, situação e } \\
\text { data de encerramento }\end{array}$ & \\
\hline $\begin{array}{l}\text { Movimentaçäo de } \\
\text { Chamadas Técnicas }\end{array}$ & $\begin{array}{l}\text { Periodo, valor da hora, } \\
\text { centro de custo } \\
\text { desejado (se o centro } \\
\text { de custo não for } \\
\text { preenchido, serāo } \\
\text { impressas as chamadas } \\
\text { técnicas por centro de } \\
\text { custo existente no } \\
\text { cadastro) }\end{array}$ & $\begin{array}{l}\text { Nr da chamada técnica, nr } \\
\text { da visita, data de } \\
\text { solicitaçăo, equipamento, } \\
\text { nr do patrimônio, defeito, } \\
\text { departamento, nr do } \\
\text { funcionário, valor da mäo } \\
\text { de obra e valor das peças } \\
\text { trocadas }\end{array}$ & \\
\hline
\end{tabular}


QUADRO 6.5 - QUADRO CONSENSUAL ESPECIFICO DO SISTEMA SCHT (CONT.)

\begin{tabular}{|c|c|c|c|}
\hline Operaçōes & Itens de Entrada & Itens de Saida & Pré-Condiçōes \\
\hline $\begin{array}{l}\text { Relaçäo dos } \\
\text { Atendimentos nas } \\
\text { Unidades }\end{array}$ & Periodo & $\begin{array}{l}\text { Unidade, nr de chamadas } \\
\text { técnica, } \mathrm{nr} \text { de visitas, } \mathrm{nr} \text { de } \\
\text { visitas solucionadas, } \mathrm{nr} \text { de } \\
\text { visitas pendentes, total do } \\
\text { tempo de locomoção por } \\
\text { unidade, total do tempo de } \\
\text { atendimento por unidade, } \\
\text { total do tempo de reparo } \\
\text { por unidade e somatória do } \\
\text { tempo de atendimento e de } \\
\text { reparo por unidade }\end{array}$ & \\
\hline $\begin{array}{l}\text { Impressão da } \\
\text { Estrutura de } \\
\text { Orçamento }\end{array}$ & & $\begin{array}{l}\text { Documento com campos a } \\
\text { serem preenchidos: } \mathrm{nr} \text { da } \\
\text { chamada técnica, nr da } \\
\text { visita, unidade, } \\
\text { departamento, usuário, } \\
\text { equipamento, data de } \\
\text { chamada, defeito, peças e } \\
\text { componentes a serem } \\
\text { trocados, valor das peças e } \\
\text { componentes, valor do } \\
\text { tempo de reparo, valor das } \\
\text { visitas, valor do orçamento, } \\
\text { nome do usuário, centro de } \\
\text { custo, data, assinatura }\end{array}$ & ' \\
\hline $\begin{array}{l}\text { Autorizaçäo do } \\
\text { Orçamento }\end{array}$ & $\begin{array}{l}\text { Nr da chamada técnica, } \\
\text { nr da visita, nome do } \\
\text { usuário, valor do } \\
\text { orcamento e data da } \\
\text { autorizacão }\end{array}$ & $\begin{array}{l}\text { Documento que inclui: } \\
\text { nome do usuário, centro de } \\
\text { custo, unidade, } \\
\text { departamento, } \\
\text { equipamento, nr do } \\
\text { patrimônio, data da } \\
\text { chamada }\end{array}$ & \\
\hline
\end{tabular}


QUADRO 6.5 - QUADRO CONSENSUAL ESPECIFICO DO STSTEMA SCHT (CONT.)

\begin{tabular}{|c|c|c|c|}
\hline Operaçöes & Itens de Entrada & ftens de Saida & Pré-Condiçöes \\
\hline $\begin{array}{l}\text { Relação do Tempo } \\
\text { Gasto por Nível } \\
\text { Técnico por Unidade }\end{array}$ & Período & $\begin{array}{l}\text { Unidade, nível técnico, } \mathrm{nr} \\
\text { de visitas, tempo de } \\
\text { locomoção, tempo de } \\
\text { reparo, tempo de } \\
\text { laboratório, tempo de } \\
\text { atendimento, somatória do } \\
\text { tempo gasto (por unidade); } \\
\text { somatónia de visitas, } \\
\text { somatória do tempo de } \\
\text { locomoçäo, somatória do } \\
\text { tempo de reparo, } \\
\text { somatória do tempo de } \\
\text { laboratório, somatória do } \\
\text { tempo de atendimento e } \\
\text { somatóna dos totais de } \\
\text { tempo gasto }\end{array}$ & \\
\hline $\begin{array}{l}\text { Relação de Horas } \\
\text { Trabalhadas pelos } \\
\text { Técnicos }\end{array}$ & $\begin{array}{l}\text { Período, dias úteis no } \\
\text { período }\end{array}$ & $\begin{array}{l}\text { Dias úteis no período, } \\
\text { horas faturadas no } \\
\text { periodo, horas isentas no } \\
\text { periodo, horas de } \\
\text { deslocamento no campus } \\
\text { de Saao Carlos, horas de } \\
\text { desiocamento para } \\
\text { Pirassununga, horas de } \\
\text { deslocamento para } \\
\text { Araraquara e horas } \\
\text { ociosas }\end{array}$ & \\
\hline $\begin{array}{l}\text { Relatório CCI Parcial } \\
\text { (para Impressoras e } \\
\text { para } \\
\text { Microcomputadores } \\
\text { em separado) }\end{array}$ & Periodo e valor da hora & $\begin{array}{l}\text { Centro de custo atendido, } \\
\text { nr de atendimentos } \\
\text { completos, tempo total de } \\
\text { atendimento em minutos e } \\
\text { em horas, nr de chamadas } \\
\text { em aberto, valor total de } \\
\text { peças trocadas, valor total } \\
\text { de mão de obra, total geral } \\
\text { e custo médio. (por centro } \\
\text { de custo atendido) }\end{array}$ & \\
\hline
\end{tabular}


QUADRO 6.5 - QUADRO CONSENSUAL ESPECIFICO DO STSTEMA SCHT (CONT.)

\begin{tabular}{|c|c|c|c|}
\hline Operaçöes & Itens de Entrada & Itens de Saída & Pré-Condições \\
\hline $\begin{array}{l}\text { Relatório CCI Total } \\
\text { (considerando tanto } \\
\text { impressoras quanto } \\
\text { microcomputadores) }\end{array}$ & Período e valor da hora & $\begin{array}{l}\text { Centro de custo atendido, } \\
\mathrm{nr} \text { de atendimentos } \\
\text { completos, tempo total de } \\
\text { atendimento em minutos e } \\
\text { em horas, nr de chamadas } \\
\text { em aberto, valor total de } \\
\text { peças trocadas, valor total } \\
\text { de mäo de obra, total geral } \\
\text { e custo médio. }\end{array}$ & \\
\hline Backup & drive & $\begin{array}{l}\text { Os dados da base de } \\
\text { dados são copiados para o } \\
\text { disquete }\end{array}$ & \\
\hline
\end{tabular}

A Figura 6.2 mostra o Diagrama de Seqũência de Operações do Sistema de Chamadas Técnicas. Nesse diagrama o hexágono representa um conector (necessário quando o número de operaçōes em um mesmo nivel é muito grande); para referenciar cada conector utilizam-se as siglas iniciais da operação.

FIGURA 6.2 -- DIAGRAMA DE SEQÜÊNCIA DE OPERAÇÕES DO SISTEMA SCHT

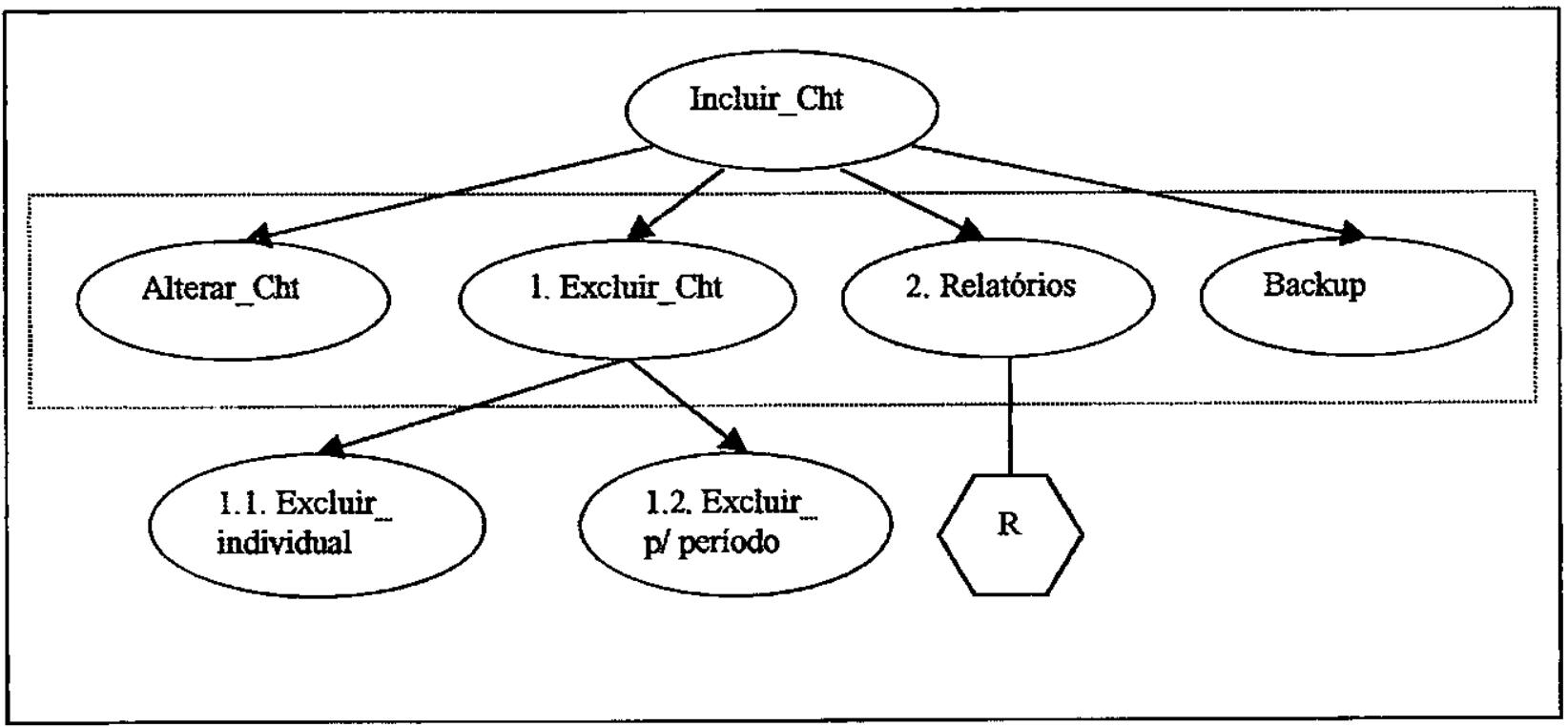


FIGURA 6.2 - DIAGRAMA DE SEQÜÊNCIA DE OPERAÇÕES DO SISTEMA SCHT (CONT.)

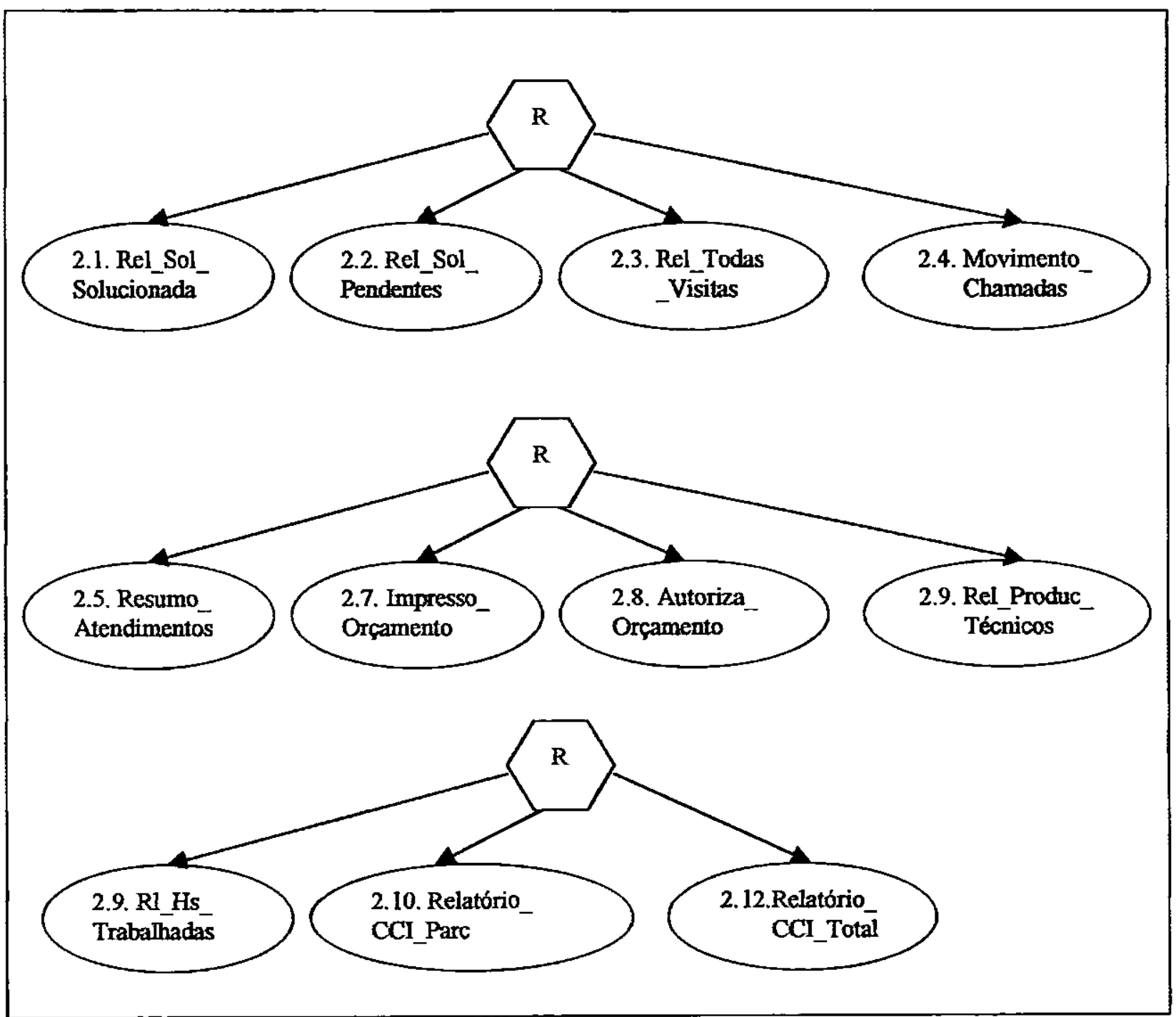

CICLO RASTREAMENTO DE PROCESSO - Avaliação do Conhecimento: nessa fase o conhecimento adquirido foi verificado pelo engenheiro de conhecimento quanto à corretitude sintática e semântica do Quadro Consensual Especifico do Sistema Analisado (QCESA) e do Diagrama de Sequêência de Operaçöes (DSO). Foi também validado por meio da utilização do sistema pelo engenheiro de conhecimento que averiguou se o QCESA e o DSO estavam realmente consistentes. Devido à simplicidade do sistema, com somente um ciclo rastreamento de processo foi possivel adquirir o conhecimento necessário. As dúvidas em relação ao Quadro Consensual e o Quadro Consensual Especifico do Sistema Analisado foram anotadas para serem questionadas na próxima sessão de aquisição de conhecimento. 
6.2.4 -Ciclo Entrevista Estruturada do Processo IPAIA Instanciado para o Domínio de Engenharia Reversa

Nesse ciclo o conhecimento foi obtido do mesmo usuário participarte da sessão anterior com o intuito de obter conhecimento mais detalhado a respeito das operações do sistema, principalmente, da seqüêricia das operações e dos itens de entrada e saida de cada operação, a fim de esclarecer as dúvidas em relação ao conhecimento já adquirido.

CICLO ENTREVISTA ESTRUTURAOA - Preparaçäo da Sessäo de Entrevista Estruturada: nessa fase o usuário participante da sessão de rastreamento de processo foi o selecionado para ser entrevistado, o engenheiro de conhecimento fez o papel de entrevistador e anotador, e foi elaborado um plano (Quadro 6.6) para conduzir a sessão de entrevista estruturada.

CICLO ENTREVISTA ESTRUTURADA - Aquisiçäo de Conhecimento: nessa fase o plano elaborado anteriormente foi colocado em prática a fim de conhecer mais detalhes sobre as operações do sistema como seqüências de operações, itens de entrada e saída, seqüência dos itens de entrada e saída em cada operação e, também, para esclarecer as dúvidas existertes relacionadas ao conhecimento já adquirido.

CICLO ENTREYISTA ESTRUTURADA - Implementação do Conhecimento: não foi necessário complementar o Quadro Consensual Específico do Sistema Analisado (Quadro 6.4); na realidade, esse ciclo foi útil para confirmar o conhecimento já adquirido.

CTCLO ENTREVISTA ESTRUTURADA - Avaliação do Conhecimento: nessa fase o conhecimento representado deveria ser verificado tarito no Quadro Consensual Especifico do Sistema Analisado quarto no Diagrama de Seqüência de Operações. Como não houve necessidade de complementar o quadro, não foi necessário realizar a avaliação do conhecimento existente nesse quadro durarite esse ciclo. 


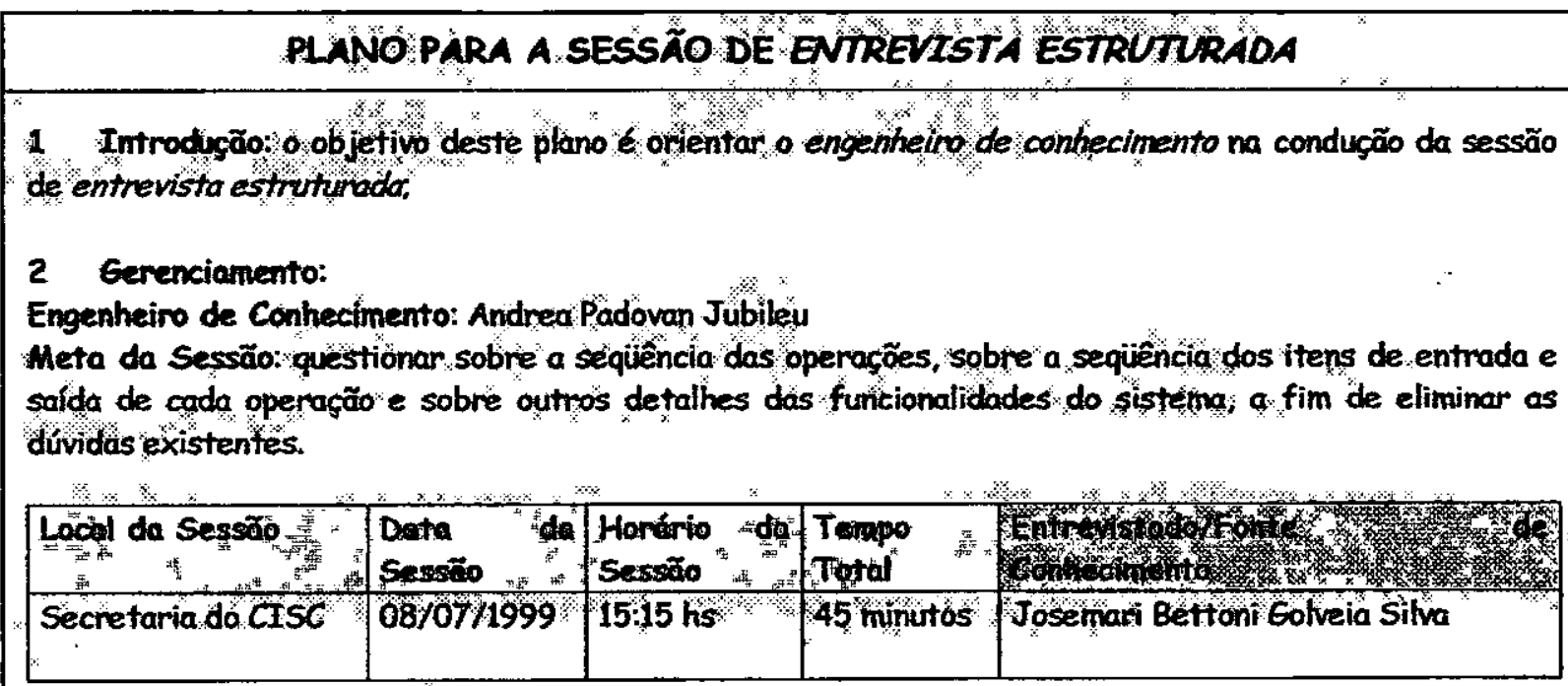

3 Tarefas:

3.1 Injciaçäo: O mótivo pelo qual essa sessä́ de entrevista estruturoda será realizáa é enfocado na öbtenção de informaçóes do Sistena de Chanadas Técnicas a fin de esclarecer as dívidás em relação a conhecinento, ja obtido, e obter inforthacóes mais detalhados das funcö́es do sistetha:

3.2 Das questöes a seguir deseja-se saber a raz̈̈o de, aparentemente, al guns itens näo existinem no sistema. As possiveis razzôes podem ser: (1) devido ao esquecínento de alguma funcionalidade ou (2) devido ao fato da funcionalídade estar enibutida en alguma funçáo maior ou ainda (3) devido ao fato do sistema não estar completo?

Questöes:

- Não há uma operagäo pona ser realizadà a baixa de chamados técnicoss?

- Não há codastro de técnicos, de funcionórios (usuorios), de pegas; de equipamentos, de empresas (centro de custo - contrato) e de unidódes do USP? Como isso é controlado na inserção de chominadas técricass?

3.3 As questốes a seguir serão feitas a efeito de confirtior elou colroletur o conhecimento já existente a respeito dás operaçáes do sistema de chamadas técnicas:

- Quais säo as operaçōes disponiveis no sistema de chamädös fécnicas? E qual é a sequiência de execusä́o dessas operaçëes?

- Quais sắo os itens de entrada de cada una das operaçóes apontadas anferiormente, e quais são os respectivos itens de saida (possiveis respostos do sistema cos itens de entrada)?

- Quais são bs campos chaves de cada operacáo?

- Qual a sequéncia de ocortrencia dos itens de entradá e saida en cada operagäo?

- Seräo questionadas outhos dúvidas particulanes, cosó necessário:

\section{Cronograma:}

\begin{tabular}{|l|c|c|c|c|c|c|c|c|c|}
\hline Tarefas & $\begin{array}{c}5 \\
\text { minutos }\end{array}$ & $\begin{array}{c}10 \\
\text { minutos }\end{array}$ & $\begin{array}{c}15 \\
\text { minutos }\end{array}$ & $\begin{array}{c}20 \\
\text { minutos }\end{array}$ & $\begin{array}{c}25 \\
\text { minutos }\end{array}$ & $\begin{array}{c}30 \\
\text { minutos }\end{array}$ & $\begin{array}{c}35 \\
\text { minutos }\end{array}$ & $\begin{array}{c}40 \\
\text { minutos }\end{array}$ & $\begin{array}{c}45 \\
\text { minutos }\end{array}$ \\
\hline 3.1 & & & & & & & & & \\
\hline 3.2 & & & & & & & & & \\
\hline 3.3. & & & & & & & & & \\
\hline
\end{tabular}

5 Recursos: o local selecionado para a éntrevista deve ser isolado de quaisquer outras pessoas que não

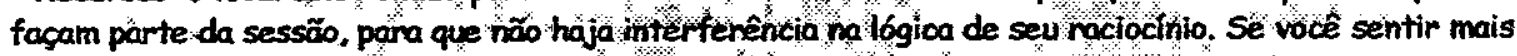
firmeza em suas respostas utilizando o sistema, faca-o dessa forma. Sendo ossim, importante ter todo o equipariento disponivel. 


\section{3 - Segundo Estudo de Caso - MGASET (Módulo de Geração de Seqüências de Teste)}

Com o objetivo de avaliar o Processo de Aquisição de Conhecimento IPAIA, instanciado para o domínio de engenharia reversa, utilizou-se como estudo de caso a ferramenta MGASET, sobre a qual foram aplicadas as fases do processo IPAIA. Como resultado desse estudo de caso foram obtidos os diagramas que faräo parte da base de conhecimento para auxiliar a primeira fase do método de engenharia reversa FUSION-REl, e os modelos de ciclo de vida e de operação Fusion, elaborados a partir das diretrizes desenvolvidas.

\subsection{1 - Fase 1 - Inicio do Processo de Aquisição de Conhecimento}

A ferramenta MGASET situa-se no contexto de especificação e validação de sistemas baseadas na técnica Máquina de Estados Finito (MEF). O patrocinador é o Prof. Dr. José Carlos Maldonado. A visão geral do domínio de conhecimento foi obtida a partir de documentaçöes existentes - relatórios técnicos (Nakazato, 1994a; Nakazato, 1994b; Nakazato, 1994c) e de alguns comentánios de usuánios. Essa visão geral é resultado da definição de termos chaves contidos nesse dominio (Tabela 6.2), seus relacionamentos (Figura 6.3) $\theta$ principais funçōes (Quadro 6.7).

TABELA 6.2 - LÉXICO DO DOMÍNO DAAPLCACCĀO - MGASET

\begin{tabular}{|c|c|c|}
\hline Termo & Dëfiniçäo & Sinônimos \\
\hline $\begin{array}{l}\text { Alcançabilidade } \\
\text { do Estado Inicial }\end{array}$ & $\begin{array}{l}\text { Propniedade da MEF que verifica se para cada estado existe } \\
\text { um caminho entre ele e o estado inicial; }\end{array}$ & \\
\hline $\begin{array}{l}\text { Árvore de } \\
\text { distinçäo }\end{array}$ & $\begin{array}{l}\text { É uma árvore sucessora onde um nó no k-ésimo nivel torna- } \\
\text { se terminal quando: (1) o grupo A associado ao nó apresenta } \\
\text { uma incerteza múltipla; }(2) \text { o grupo A associado ao nó já } \\
\text { ocorreu na árvore de distincão num nível anterior a K ou no } \\
\text { próprio nivel } k ;(3) \text { o grupo A associado ao nó é um grupo A } \\
\text { simples; }\end{array}$ & \\
\hline $\begin{array}{l}\text { Árvore de } \\
\text { sincronização }\end{array}$ & $\begin{array}{l}\text { E uma árvore sucessora construida ignorando-se as saídas e } \\
\text { associando cada nó no j-ésimo nível com a incerteza que } \\
\text { corresponde aos estados finais que resultam da aplicação dos } \\
\text { j-primeiros simbolos de entrada. Um nó no j-ésimo nível da } \\
\text { árvore de sincronizaçäo torna-se terminal quando este nó já } \\
\text { ocorreu anteriormente na árvore de sincronizaçäo num nível } \\
\text { anterior, }\end{array}$ & \\
\hline Árvore de Teste & $\begin{array}{l}\text { É formada por todos os caminhos parciais de uma MEF. Um } \\
\text { caminho parcial é uma seqüência de estados que começa no } \\
\text { estado inicial e termina quando é atingido um estado terminal } \\
\text { ou quando alcança-se um estado que já faz parte desse } \\
\text { caminho; }\end{array}$ & \\
\hline
\end{tabular}


TABELA 6.2 - LÉXICO DO DOMINIO DA APLICACÃO- MGASET (CONT.)

\begin{tabular}{|c|c|c|}
\hline Termo & Definicta & Sinônimos \\
\hline $\begin{array}{l}\text { Árvore } \\
\text { sucessora }\end{array}$ & $\begin{array}{l}\text { É uma estrutura definida para uma } \mathrm{MEF} \text { M e um conjunto } \\
\text { admissivel } \mathrm{A}(\mathrm{M}) \text {. Essa estrutura é composta de ramos } \\
\text { arranjados em niveis sucessivos onde o primeiro nivel é } \\
\text { representado por zero, o segundo nivel por um e assim por } \\
\text { diante. Todo ramo de árvore sucessora, exceto o ramo inicial, } \\
\text { representa um simbolo de entrada ai, com ai } E X \text {, e cada } \\
\text { ramo está associado com um nó, sendo este nó um grupo } A ;\end{array}$ & \\
\hline a-seqüência & $\begin{array}{l}\text { Objetivo: reconhecer todos os estados da } M E F M \text { e todos os } \\
\text { próximos estados de } M \text { após a aplicaçāo de } X \mathrm{X} \text { sobre cada } \\
\text { um dos estados. A a-seqüência é gerada percorrendo-se o } \\
\text { Diagrama-Xd, iniciando num estado origem. Cada estado } \\
\text { alcançado pela a-seqüencia é marcado e quando um estado } \\
S_{i} \text { é alcançado e já foi marcado anteriormente, é incorporado } \\
\text { à a-seqüência uma } T \text {-seqüência que leva } M \text { do estado } S_{i} \text { a um } \\
\text { estado origem, até que todos do Diagrama-Xd tenham sido } \\
\text { marcados. }\end{array}$ & \\
\hline b-seqūência & 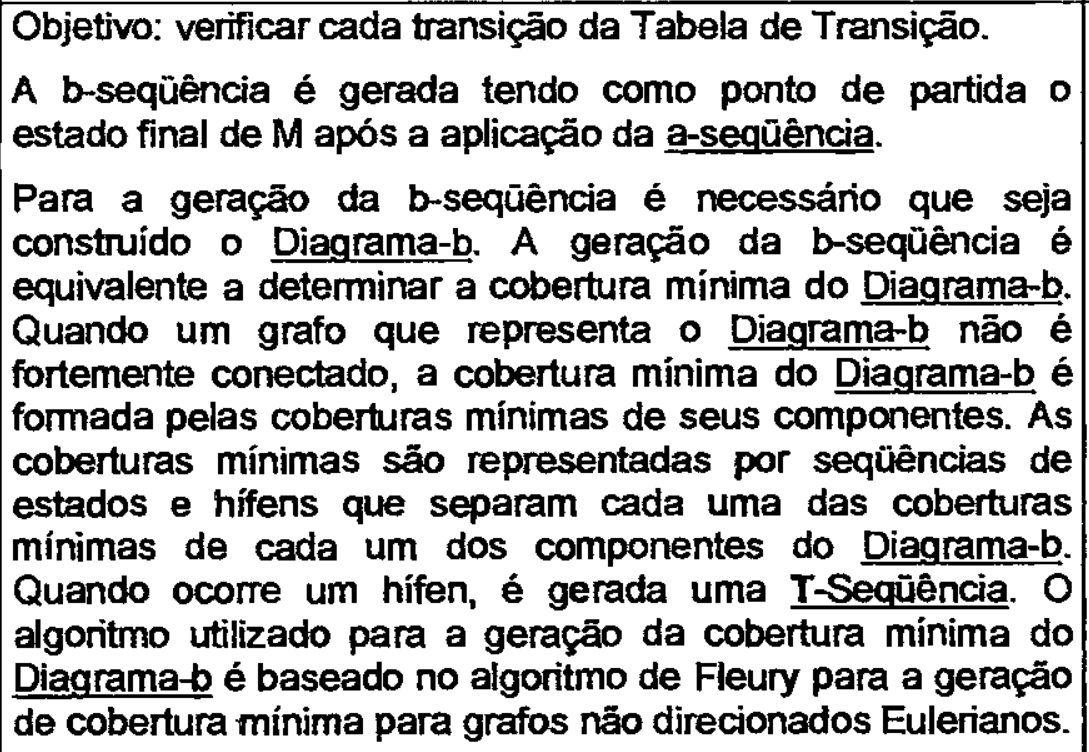 & \\
\hline $\begin{array}{l}\text { Classes de } \\
\text { equivalência }\end{array}$ & $\begin{array}{l}\text { Uma MEF M pode ser dividida em partiçōes de estado que } \\
\text { são classes de equivalência, dentro das quais têm-se os } \\
\text { seguintes critérios: 1) todos os estados que se encontram na } \\
\text { mesma partiçäo devem ser estados k-equivalentes; 2)Todos } \\
\text { os estados que se encontram em partiçöes diferentes devem } \\
\text { ser estados k-distinguiveis. Essas partiçōes säo chamadas de } \\
\text { partiçöes de k-equivalência e denotadas por Pk, podendo ser } \\
\text { representadas pelas Tabelas Pk, com } k>=1 \text {; }\end{array}$ & \\
\hline $\begin{array}{l}\text { Conectividade } \\
\text { Forte }\end{array}$ & $\begin{array}{l}\text { Propriedade da MEF que verifica se para todo par de estados } \\
\text { (Si, sj) da máquina } M \text {, existe uma seqüência de simbolos de } \\
\text { entrada tal que essa seqüência leve a máquina do estado si } \\
\text { para o estado sj; }\end{array}$ & \\
\hline
\end{tabular}


TABELA 6.2 - LÉXICO DO DOMÍNIO DA APLICACAOO-MGASET (CONT.)

\begin{tabular}{|c|c|c|}
\hline Termo & Definição & Sinônimos \\
\hline $\begin{array}{l}\text { Conjunto } \\
\text { admissivel }\end{array}$ & $\begin{array}{l}\text { E um conjunto de estados }\{\text { si } 1, s i 2, \ldots, \operatorname{sim}\} \text { da } \mathrm{MEF} M \text {, } \\
\text { representado por } A(M) \text {, onde os estados são candidatos a } \\
\text { estado inicial de } M \text {; }\end{array}$ & $A(M)$ \\
\hline $\begin{array}{l}\text { Conjunto de } \\
\text { Caracterização } \\
\text { W }\end{array}$ & $\begin{array}{l}\text { E um conjunto de seqüências de identificaçäo \{seq1, } \\
\text { seq2,...,seqd\} tal que os símbolos de saída observados após } \\
\text { a aplicação dessas seqüências (numa ordem fixada) sobre } \\
\text { cada um dos estados säo diferentes. Este conjunto pode ser } \\
\text { obtido através da geraçäo de Tabelas Pk; }\end{array}$ & \\
\hline Conjunto P & $\begin{array}{l}\text { É o conjunto que representa todos os caminhos parciais da } \\
\text { Árvore de Teste do critério } \mathrm{W} \text {. }\end{array}$ & \\
\hline Conjunto Q & $\begin{array}{l}\text { E o conjunto de sequêencias de entrada que levam a MEF M } \\
\text { do estado inicial para todos os outros estados e, por } \\
\text { definição, tem-se que a seqūência nula, que leva M do estado } \\
\text { inicial para o próprio estado inicial, também está incluída em } \\
\text { Q. }\end{array}$ & \\
\hline Conjunto $\mathrm{R}$ & $\begin{array}{l}\text { Formado pelas seqüências que estão no Conjunto P e não se } \\
\text { encontram no conjunto } Q \text {. }\end{array}$ & \\
\hline Conjuntos Wi & $\begin{array}{l}\text { Conjunto de Caracterizaçäo de cada estado } S_{i} \text { da } \mathrm{MEF} M \text {; } \\
\text { dessa forma, estes conjuntos identificam unicamente cada } \\
\text { estado de } M \text { e säo subconjuntos do Conjunto de } \\
\text { Caracterização } W .\end{array}$ & \\
\hline Critério DS & $\begin{array}{l}\text { E um critério de geraçäo de seqüências de teste. Objetivo } \\
\text { inicial: solucionar o problema de teste de um circuito de } \\
\text { chaveamento seqüencial, isto é, o problema de determinar se } \\
\text { o circuito está ou näo operando corretamente de acordo com } \\
\text { uma dada Tabela de Transição. } \\
\text { Para aplicação desse critério, as MEFs devem apresentar as } \\
\text { seguintes propriedades: Conectividade Forte, Minimalidade, } \\
\text { Determinismo, Máquina de Mealy e Especificaçäo Completa; } \\
\text { devem também apresentar as seguintes seqüências básicas: } \\
\text { Seqūência de Sincronizacäo e Seqüência Distinguível; } \\
\text { Há um Procedimento que define o critério DS sobre uma } \\
\text { MEF; }\end{array}$ & \\
\hline Critério UlO & $\begin{array}{l}\text { É um critério de geração de seqüências de teste. Principal } \\
\text { motivaçäo: checagem de conformidade de especificaçöes de } \\
\text { protocolos de comunicaçäo de redes de computadores. } \\
\text { Para aplicaçäo desse critério, as MEFs devem apresentar as } \\
\text { seguintes propriedades: Conectividade Forte, Minimalidade, } \\
\text { Determinismo, Máquina de Mealy; Especificação Completa e } \\
\text { Estado Inicial Fixo; devem também apresentar as seguintes } \\
\text { seqüências básicas: seqüências únicas de entrada/saída para } \\
\text { cada estado de M; } \\
\text { Há um Procedimento que define o critério UlO sobre uma } \\
\text { MEF; }\end{array}$ & \\
\hline
\end{tabular}


TABELA 6.2 - LÉXICO DO DOMÍNO DA APLICACĀO-MGASET (CONT.)

\begin{tabular}{|c|c|c|}
\hline Termo & Definicá & Sinốnimos \\
\hline Critério W & $\begin{array}{l}\text { É um critério de geração de seqüências de teste baseado na } \\
\text { modelagem de projetos de sistema através de MEF. Esse } \\
\text { critério tem as seguintes características: Somente a estrutura } \\
\text { de controle do projeto é checada; Näo existe a exigência de } \\
\text { especificaçäo executável; } \\
\text { Para aplicaçäo desse critério, as MEFs devem apresentar as } \\
\text { seguintes propriedades: Minimalidade, Determinismo, } \\
\text { Máquina de Mealy, Especificaçăo Completa, Estado Inicial } \\
\text { Fixo e Alcançabilidade do Estado Inicial; devem também } \\
\text { apresentar o Conjunto de Caractenização W; } \\
\text { Há um Procedimento que define o critério W sobre uma MEF; }\end{array}$ & \\
\hline Critério Wp & $\begin{array}{l}\text { E um critério de geração de seqüências de teste. Este critério } \\
\text { tem como uma das principais motivaçöes o fato de que } \\
\text { métodos para o desenvolvimento de seqüências de teste têm } \\
\text { recebido muita atenção em relaçäo a testes de conformidade } \\
\text { de protocolos de comunicaçäo de redes de computadores; } \\
\text { Para aplicaçäo desse critério, as MEFs devem apresentar as } \\
\text { seguintes propriedades: Minimalidade, Determinismo, } \\
\text { Máquina de Mealy; Especificaçäo Completa e Estado Inicial } \\
\text { Fixo; Alcançabilidade do Estado Inicial; também devem } \\
\text { apresentar o Conjunto de CaracterizaçäoW; } \\
\text { Há um Procedimento que define o critério Wp sobre uma } \\
\text { MEF; }\end{array}$ & \\
\hline $\begin{array}{l}\text { Critérios de } \\
\text { geraçäo de } \\
\text { seqüências de } \\
\text { teste }\end{array}$ & $\begin{array}{l}\text { Oferecem a possibilidade de se executar atividades de teste e } \\
\text { validaçäo em sistemas modelados de acordo com alguma } \\
\text { técrica de modelagem, de forma sistemática, através de } \\
\text { procedimentos bem definidos para a geraçäo dessas } \\
\text { sequêencias de teste, fazendo com que os produtos se } \\
\text { apresentem de forma mais segura e com maior qualidade; }\end{array}$ & \\
\hline Determinismo & $\begin{array}{l}\text { Propriedade da MEF M que verifica se para cada entrada } \\
\text { existe no máximo uma transição definida em cada estado de } \\
\text { M; }\end{array}$ & \\
\hline Diagrama-Xd & É estabelecido a partir da Tabela Xd. & \\
\hline $\begin{array}{l}\text { Especificação } \\
\text { Completa }\end{array}$ & $\begin{array}{l}\text { Propriedade da MEF que verifica se para cada estado existe } \\
\text { uma transição para cada símbolo de entrada; }\end{array}$ & \\
\hline $\begin{array}{l}\text { Estado Inicial } \\
\text { Fixo }\end{array}$ & $\begin{array}{l}\text { Estado único ao qual a MEF se encontra no inicio da } \\
\text { execuçäo; }\end{array}$ & \\
\hline $\begin{array}{l}\text { Estados } \\
\text { Equivalentes/ } \\
\text { Distinguiveis }\end{array}$ & $\begin{array}{l}\text { O estado } s_{\mathrm{j}} \text { da MEF M1 e o estado } \mathrm{s}_{\mathrm{j}} \text { da } \mathrm{MEF} \text { M2 säo } \\
\text { denominados estados equivalentes se } \mathrm{M} 1 \mid \mathrm{s}_{\mathrm{j}} \text { e } \overline{\mathrm{M}} \mid \mathrm{s}_{\mathrm{j}} \text { quando } \\
\text { exercitados por qualquer seqüência de entrada, produzem } \\
\text { saídas idênticas; caso contrário, säo chamados estados } \\
\text { distinguiveis. M1 e M2 podem representar a mesma máquina; }\end{array}$ & \\
\hline
\end{tabular}


TABELA 6.2-LÉXICO DO DOMÓNIO DA APLICAÇ̃̃O-MGASET (CONT.)

\begin{tabular}{|c|c|c|}
\hline Termo & Beffinição & Sinônimos \\
\hline $\begin{array}{l}\text { Estados k- } \\
\text { equivalentes/ k- } \\
\text { distinguiveis }\end{array}$ & $\begin{array}{l}\text { Dois estados quaisquer da MEF } M, s_{i} \text { e } s_{j} \text { são chamados de } \\
\text { estados } k \text {-equivalentes se quando exercitados por qualquer } \\
\text { seqüência de comprimento } k \text {, produz seqüências de saida } \\
\text { idênticas, caso contráno säo chamados estados } k \text { - } \\
\text { distinguíveis; }\end{array}$ & \\
\hline $\begin{array}{l}\text { Grafos } \\
\text { Direcionados }\end{array}$ & $\begin{array}{l}\text { Grafos que representam o comportamento de MEFs, onde } \\
\text { cada estado é representado por um vértice e cada transiçāo é } \\
\text { representada por uma aresta direcionada, onde cada aresta } \\
\text { possui um rótulo } x_{1} / \mathrm{z}_{\text {, }} \text { com } \mathrm{f}_{\mathrm{z}}=\mathrm{z}_{\mathrm{i}} \text { e o estado destino da aresta } \\
\text { representando } \mathrm{f}_{\mathrm{si}}\end{array}$ & \\
\hline Grupo A & $\begin{array}{l}\text { É um conjunto de incertezas onde } m \text { é o número total de } \\
\text { estados de todas as incertezas incluidas no grupo A para uma } \\
\text { máquina } \mathrm{M} \text { cujo conjunto admissivel tem tamanho m; }\end{array}$ & \\
\hline Grupo A simples & Grupo A onde todas as incertezas são simples; & \\
\hline Incerteza & $\begin{array}{l}\text { Reflete as situaçöes em que não se pode identificar em qual } \\
\text { estado a MEF se encontrava, observando somente o símbolo } \\
\text { de saida gerado. Uma incerteza I de uma MEF M em relaçäo } \\
\text { a um símbolo de entrada xi-antecessores dos estados de I } \\
\text { produzem os mesmos símbolos de saida quando estimulados } \\
\text { por xi; }\end{array}$ & \\
\hline $\begin{array}{l}\text { Incerteza } \\
\text { múltipla }\end{array}$ & Uma incerteza que contém dois ou mais estados idênticos; & \\
\hline $\begin{array}{l}\text { Incerteza } \\
\text { simples }\end{array}$ & Uma incerteza que contém um único estado; & \\
\hline $\begin{array}{l}\text { K-ésimo } \\
\text { sucessor }\end{array}$ & $\begin{array}{l}\text { O estado } s_{i} \text { em que a MEF M1 se encontra, depois de ser } \\
\text { aplicada uma seqüência de entrada de comprimento } k \text { em } M 1 \text {, } \\
\text { é chamado k-ésimo sucessor de } s_{i} \text { em relação a essa } \\
\text { seqüência de entrada; }\end{array}$ & \\
\hline $\begin{array}{l}\text { Máquina de } \\
\text { Estados Finito }\end{array}$ & $\begin{array}{l}\hat{E} \text { uma classe de sistemas com um alfabeto de entrada } X= \\
\left\{x_{1}, x_{2}, x_{3}, \ldots, x_{p}\right\} \text {, um alfabeto de saida } Z=\left\{z_{1}, z_{2}, z_{3}, \ldots, z_{q}\right\} \\
\text { um conjunto de estados } S=\left\{s_{1}, s_{2}, s_{3}, \ldots, s_{n}\right\} \text { e um par de } \\
\text { funçöes de caracterizaçäo } f_{z} \text { e } f_{s} \text { dados por: } \\
\text { (i) } z_{v}=f_{z}\left(s_{v}, x_{v}\right) \text { e (ii) } s_{v}+1=f_{s}\left(s_{v}, x_{v}\right) \text { onde } x_{v}, z_{v} \text { e } s_{v} \text { são, } \\
\text { respectivamente, o símbolo de entrada, o símbolo de saida e } \\
\text { o estado da MEF } M \text { no instante } t_{v} \text { e } s_{v}+1 \text { é } 0 \text { estado no } \\
\text { instante } t_{v}+1 ;\end{array}$ & MEF \\
\hline $\begin{array}{l}\text { Máquina de } \\
\text { Mealy }\end{array}$ & $\begin{array}{l}\text { Propriedade da MEF que verifica se para cada transiçāo } \\
\text { existe uma saida associada; }\end{array}$ & \\
\hline Minimalidade & $\begin{array}{l}\text { Propriedade da MEF que verifica se não existe nenhum par } \\
\text { de estados equivalentes nessa MEF; }\end{array}$ & \\
\hline $\begin{array}{l}\text { Passeio de todas } \\
\text { as arestas }\end{array}$ & Representa a seqüência de teste gerada pelo criténo UIO. & TS \\
\hline
\end{tabular}


TABELA 6.2 - LÉXYCO DO DOMÍNO DA APLICAÇĀO - MGASET (CONT.)

\begin{tabular}{|c|c|c|}
\hline Tetrno & 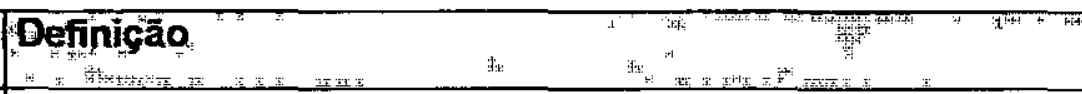 & Siñonimos \\
\hline $\begin{array}{l}\text { Passeios de } \\
\text { aresta }\end{array}$ & $\begin{array}{l}\text { A geração dos passeios de aresta para cada aresta da MEF } \\
\text { M é feita através das seguintes sub-seqüências: } \\
\text { TE(aresta) = } \\
\text { P((Head(aresta))@rótulo(aresta)@UIO(Tail(aresta)) onde: } \\
\text { TE(aresta) é o passeio da aresta } \\
\text { Head(aresta) é o estado origem da aresta } \\
\text { Tail(aresta) é o estado final da aresta } \\
\text { Dessa forma, cada passeio de aresta verifica se cada aresta } \\
\text { tem o estado origem, o estado destino e o rótulo corretos. A } \\
\text { geraçäo do passeio de todas as arestas é realizada da } \\
\text { seguinte forma: TS= \#ri/null@TE(aresta) onde ri/null é uma } \\
\text { operação que leva a MEF M para o estado inicial e não } \\
\text { produz nenhum símbolo de saida e \# é a concatenaçäo de } \\
\text { todas as sub-seqüências ri/mull@TE(aresta), para toda aresta de } \\
\text { M. }\end{array}$ & \\
\hline P-caminhos & $\begin{array}{l}\text { Săo gerados para cada estado de M. Representa calcular os } \\
\text { mais curtos caminhos do estado inicial até cada um desses } \\
\text { estados. O algoritmo usado para a geração dos P-caminhos é } \\
\text { o de Djkstra. }\end{array}$ & \\
\hline $\begin{array}{l}\text { Procedimento do } \\
\text { critério DS }\end{array}$ & $\begin{array}{l}\text { Composto pelos seguintes passos: Geração da Seqūència } \\
\text { Distinquivel, Geração do Diagrama-Xd, Geração das } \\
\text { Seqüências de Sincronizaçăo, Geração da Seqūência Inicial e } \\
\text { Geraçäo da Seqüência de Checagem; }\end{array}$ & \\
\hline $\begin{array}{l}\text { Procedimento do } \\
\text { critério UIO }\end{array}$ & $\begin{array}{l}\text { Composto pelos seguintes passos: Geração da Tabela de } \\
\text { Rótulos, Geraçăo de seqüếncias únicas de entradalsaída } \\
\text { para cada estado M, Geração dos P-caminhos para cada } \\
\text { estado, Geração dos passeios de aresta para cada aresta de } \\
\text { M, Geração do passeio de todas as arestas; }\end{array}$ & \\
\hline $\begin{array}{l}\text { Procedimento do } \\
\text { critério W }\end{array}$ & $\begin{array}{l}\text { Composto pelos seguintes passos: Geração do Conjunto de } \\
\text { Caracterização W, Geraçäo da Árvore de Teste e Geraçäo } \\
\text { das Sequências de Teste; }\end{array}$ & \\
\hline $\begin{array}{l}\text { Procedimento do } \\
\text { critério Wp }\end{array}$ & $\begin{array}{l}\text { Composto pelos seguintes passos: Geraçäo do Conjunto de } \\
\text { Caracterizaçäo W, Geraçäo dos Conjuntos Wi, Geraçäo do } \\
\text { Conjunto Q, Conjunto P e Conjunto R, Geraçäo das } \\
\text { sequências da Fase 1, Geraçäo das seqüências da Fase 2; }\end{array}$ & \\
\hline Propriedade & $\begin{array}{l}\text { Propriedade que a MEF deve apresentar para poder ser } \\
\text { submetida a determinados critérios de geração de seqüencias } \\
\text { de teste; }\end{array}$ & \\
\hline $\begin{array}{l}\text { Seqüência de } \\
\text { Checagem }\end{array}$ & $\begin{array}{l}\text { Formada pela concatenação de duas outras: a a-sequêencia e } \\
\text { a b-seqüência. }\end{array}$ & \\
\hline
\end{tabular}


TABELA 6.2 - LÉXICO DO DOMÍNIO DA APLICACGAO - MGASET (CONT.)

\begin{tabular}{|c|c|c|}
\hline Termo & Definicáo & Sinônimimos \\
\hline $\begin{array}{l}\text { Seqüência de } \\
\text { Diagnose }\end{array}$ & $\begin{array}{l}\text { Uma sequêência de diagnose de dois estados } s_{i} \text { e } s_{j} \text { da MEF } M \\
\text { é uma seqūência de simbolos de entrada que, quando } \\
\text { aplicada em } M \text { no estado } s_{i} \text { e em } M \text { no estado } s_{j} \text {, produzem } \\
\text { duas seqüências de símbolos de saída diferentes; }\end{array}$ & \\
\hline $\begin{array}{l}\text { Seqüência de } \\
\text { Identificação }\end{array}$ & $\begin{array}{l}\text { É uma sequêência de simbolos de entrada que tem como } \\
\text { objetivo identificar, de maneira única, cada um dos estados da } \\
\text { máquina } M \text {; }\end{array}$ & \\
\hline $\begin{array}{l}\text { Seqüência de } \\
\text { Sincronização }\end{array}$ & $\begin{array}{l}\text { Seqüência básica que gera uma seqüência de símbolos de } \\
\text { entrada que leva a máquina } M \text { a um estado final especificado, } \\
\text { independente da saida gerada ou do estado inicial. É descrita } \\
\text { por um caminho na árvore de sincronizaçäo do nó inicial até } \\
\text { um nó formado por um grupo A simples. De acordo com o } \\
\text { algoritmo de geraçäo da árvore de sincronizaçäo, pode-se } \\
\text { estabelecer as seqüências mais curtas de sincronização de } \\
\text { todos os estados da máquina } M \text { uma vez que a ávore de } \\
\text { sincronização de uma máquina pode permitir a identificação } \\
\text { de mais de uma seqüência de sincronização para alguns } \\
\text { estados; }\end{array}$ & SS \\
\hline $\begin{array}{l}\text { Seqüência } \\
\text { distinguível }\end{array}$ & $\begin{array}{l}\text { Seqüência básica que gera uma seqūência de identificacãăo } \\
\text { que produz seqüências de saida diferentes para cada um dos } \\
\text { estados da máquina } M \text {. Uma seqüência distinguivel é descrita } \\
\text { por um caminho da árvore de distinção e que tem como } \\
\text { origem o nó inicial e como destino um nó formado por um } \\
\text { grupo A simples. }\end{array}$ & DS \\
\hline Seqüência Inicial & $\begin{array}{l}\text { É a seqüência de sincronização do estado de partida. } \\
\text { Deve-se, primeiramente, identificar no Diagrama-Xd quais os } \\
\text { estados que não são destino de nenhuma aresta, os } \\
\text { chamados estados origem. Entre os estados origem, o estado } \\
\text { que apresentar a seqüência de sincronizaçäo mais curta será } \\
\text { identificado como estado de partida. }\end{array}$ & \\
\hline $\begin{array}{l}\text { Seqüência } \\
\text { Minimal de } \\
\text { Diagnose }\end{array}$ & $\begin{array}{l}\text { Uma seqüência de diagnose de dois estados } s_{i} \text { e } s_{j} \text { da MEF M } \\
\text { que possui menor número de simbolos de entrada é chamada } \\
\text { de Seqüência Minimal de Diagnose de } s_{i} \text { e } s_{j}\end{array}$ & \\
\hline $\begin{array}{l}\text { Seqüência Única } \\
\text { de } \\
\text { Entrada/Saida } \\
\text { (UIO) }\end{array}$ & $\begin{array}{l}\text { Seqüência básica que gera uma seqüência de identificacãa } \\
\text { que relaciona um símbolo de entrada e um símbolo de sajda, } \\
\text { e que é única para cada um dos estados da máquina; }\end{array}$ & UIO \\
\hline
\end{tabular}


TABELA 6.2-LÉXICO DO DOMINIO DA APLICACÃ̃O-MGASET (CONT.)

\begin{tabular}{|c|c|c|}
\hline Temio & Definiça & Sinónimos \\
\hline $\begin{array}{l}\text { Seqüèncias } \\
\text { básicas }\end{array}$ & 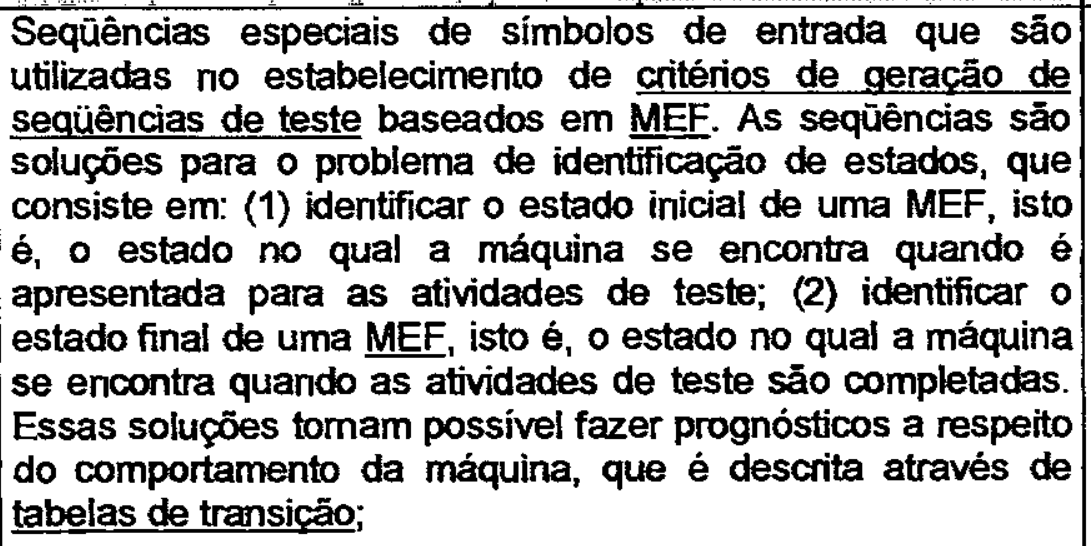 & \\
\hline $\begin{array}{l}\text { Seqüências da } \\
\text { Fase } 1\end{array}$ & $\begin{array}{l}\text { Tem como objetivo verificar se todos os estados definidos } \\
\text { pela especificação sảo identificáveis rla implementaçäo e ao } \\
\text { mesmo tempo verificar se as tranıiçōes que levam M do } \\
\text { estado inicial para esses estados apreseritam as saídas e o } \\
\text { próximo estado corretos. }\end{array}$ & \\
\hline $\begin{array}{l}\text { Seqüências da } \\
\text { Fase } 2\end{array}$ & $\begin{array}{l}\text { Verifica todas as trarısiçōes definidas pela Tabela de } \\
\text { Transiçäo, mas que não foram checadas na Fase } 1 \\
\text { (seqüências da Fase 1). }\end{array}$ & \\
\hline $\begin{array}{l}\text { Seqüências de } \\
\text { teste }\end{array}$ & $\begin{array}{l}\text { Sequêtências de símbolos de entrada e saida que servem para } \\
\text { averiguar se os símbolos gerados são idênticos aos das } \\
\text { saídas esperadas; }\end{array}$ & \\
\hline $\begin{array}{l}\text { Tabela de } \\
\text { Rótulos }\end{array}$ & $\begin{array}{l}\text { É gerada a partir da identificação de todos os rótulos } \\
\text { apresentados por } M \text { e para cada rótulo é apresentada uma } \\
\text { lista de transiçöes onde cada elemento da lista, } O_{j} d_{5}, \\
\text { representa o vértice origem } O_{1} \text { e o vértice destino } d_{3} \text { de cada } \\
\text { aresta que possui este rótulo. }\end{array}$ & \\
\hline $\begin{array}{l}\text { Tabela de } \\
\text { transiçäo }\end{array}$ & $\begin{array}{l}\text { Trata-se da estrutura básica a partir da qual todas as } \\
\text { informaçöes sobre a MEF são elaboradas. } \\
\text { É a tabela de descriçäo da MEF através das funçōes de } \\
\text { caracterização } f_{z} \text { e } f_{z} \text { que representam os simbolos de saida } \\
\text { e o próximo estado da MEF em relação aos símbolos de } \\
\text { ertrada. }\end{array}$ & \\
\hline
\end{tabular}


TABELA 6.2 - LÉXICO DO DOMÍNIO DA APLICACAAO - MGASET (CONT.)

\begin{tabular}{|c|c|c|}
\hline Termo & Defiñicäo & Sinônimos \\
\hline Tabela Pk & 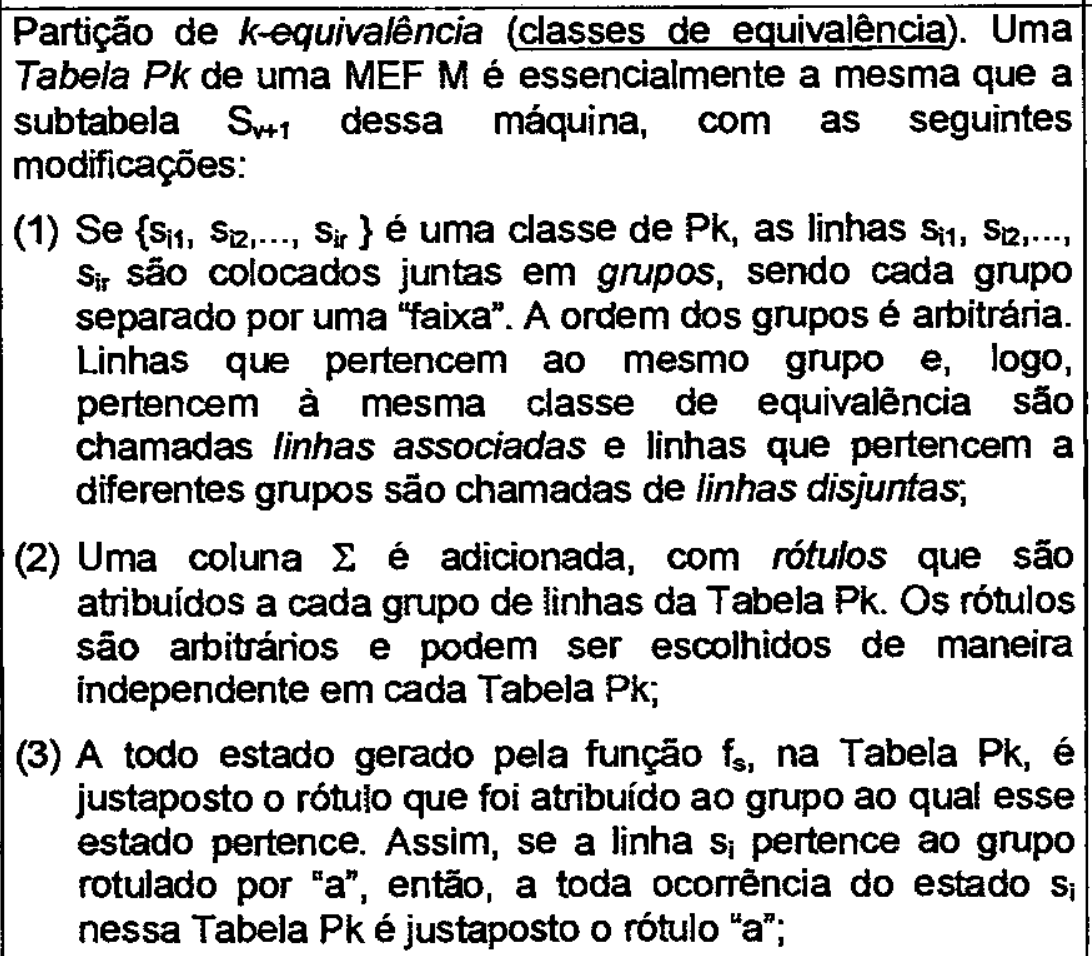 & \\
\hline Tabela Xd & $\begin{array}{l}\text { Apresenta para todo estado } S_{i} \text { de } M \text {, a seqüência de saida } \\
\text { gerada e o estado destino após a aplicaçäo de Xd no estado } \\
S_{i} \text {. }\end{array}$ & \\
\hline T-Seqüência & $\begin{array}{l}\text { Leva uma MEF M do à esquerda do hífen para o estado à } \\
\text { direita do hífen. A T-seqüência também é incorporada à b- } \\
\text { seqüência. }\end{array}$ & \\
\hline$X d$ & A mais curta seqüência distinguível. & \\
\hline
\end{tabular}

A Figura 6.3 mostra o Diagrama do Dominio da Aplicação da ferramenta MGASET. 


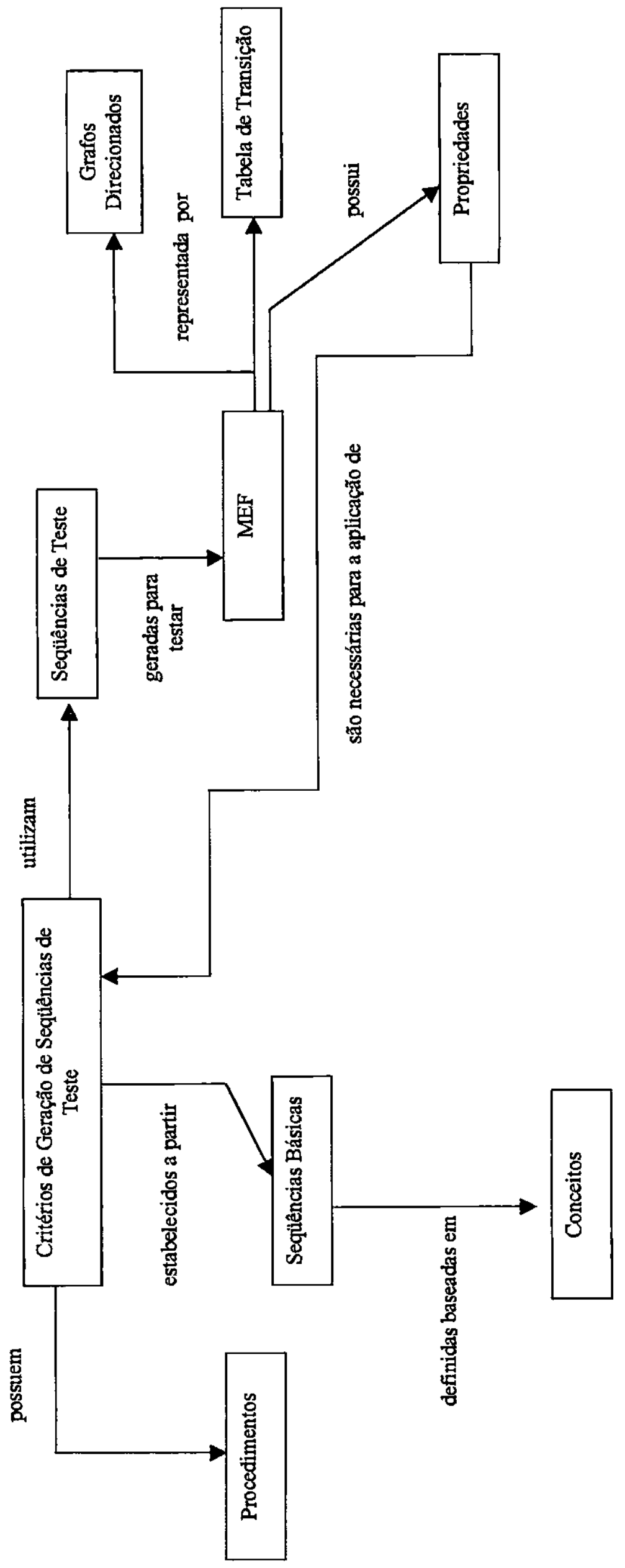

 


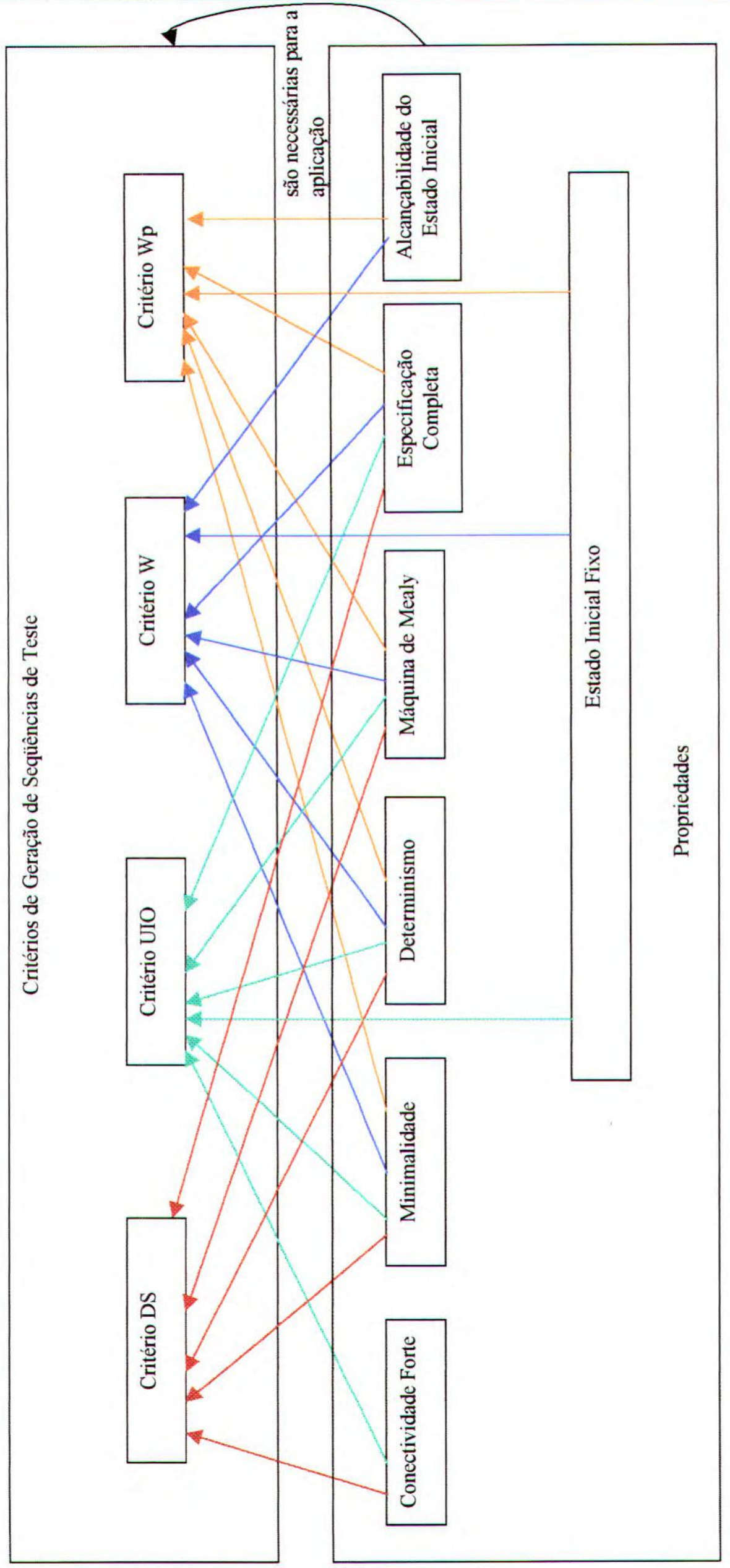

है 


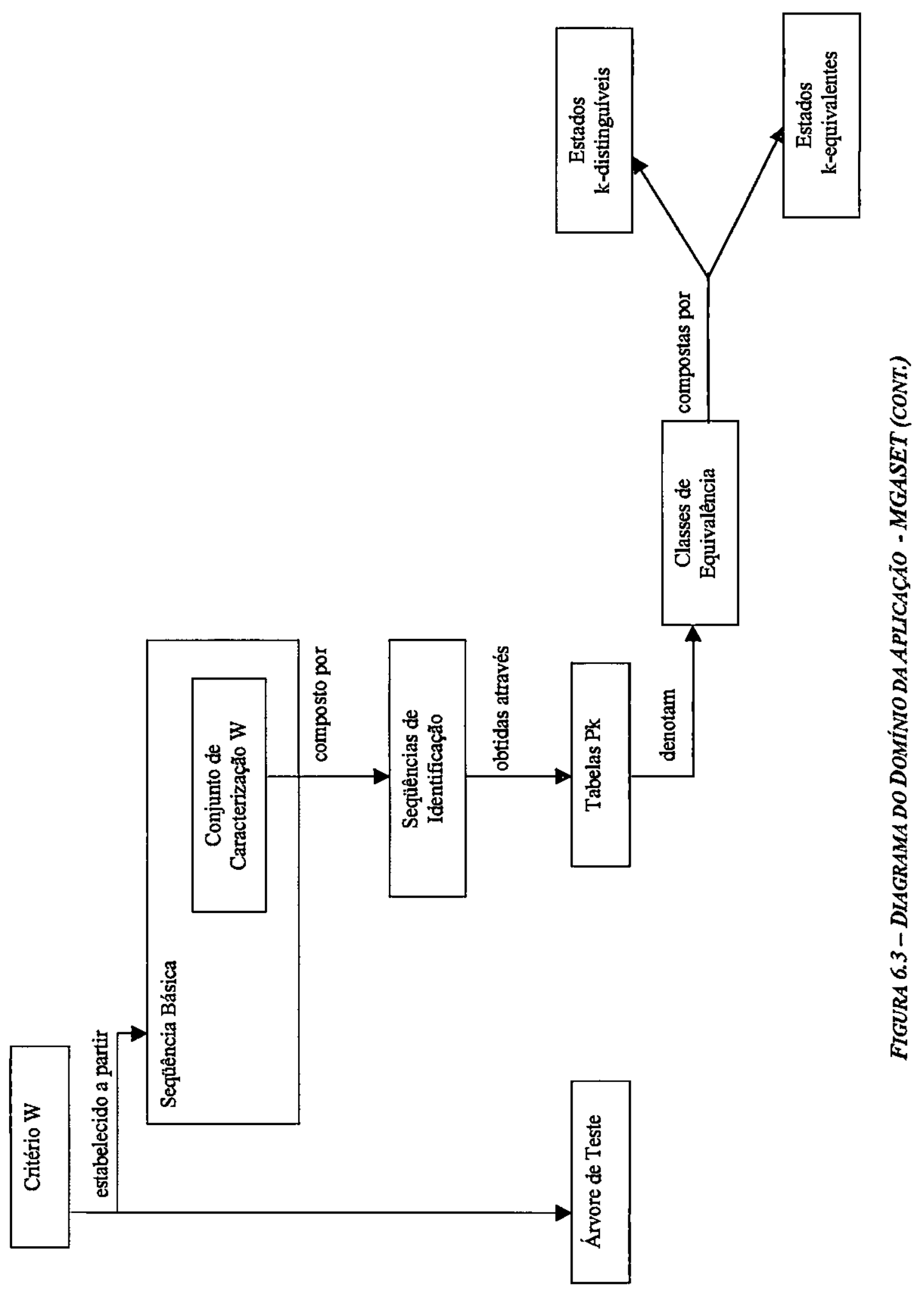




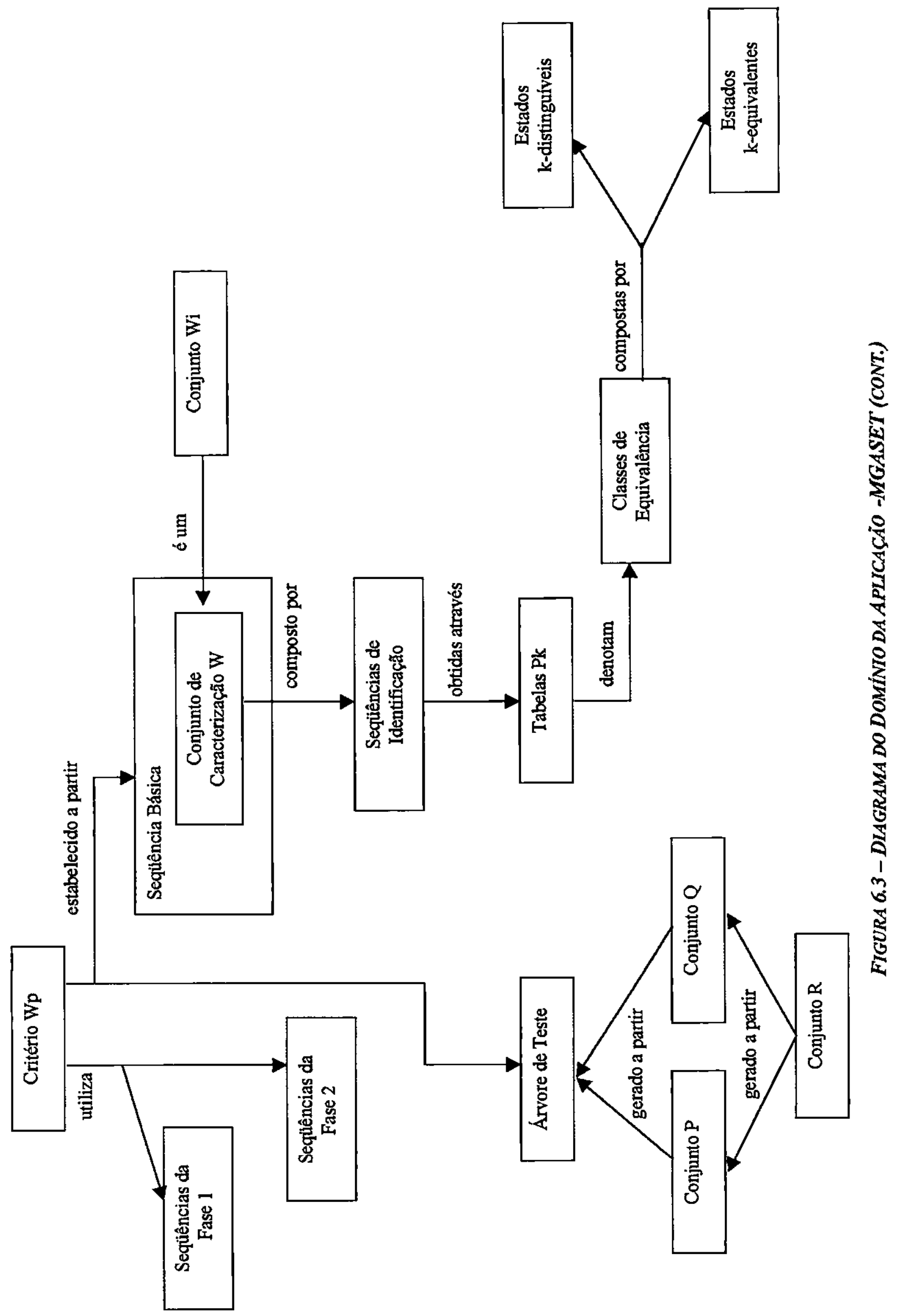




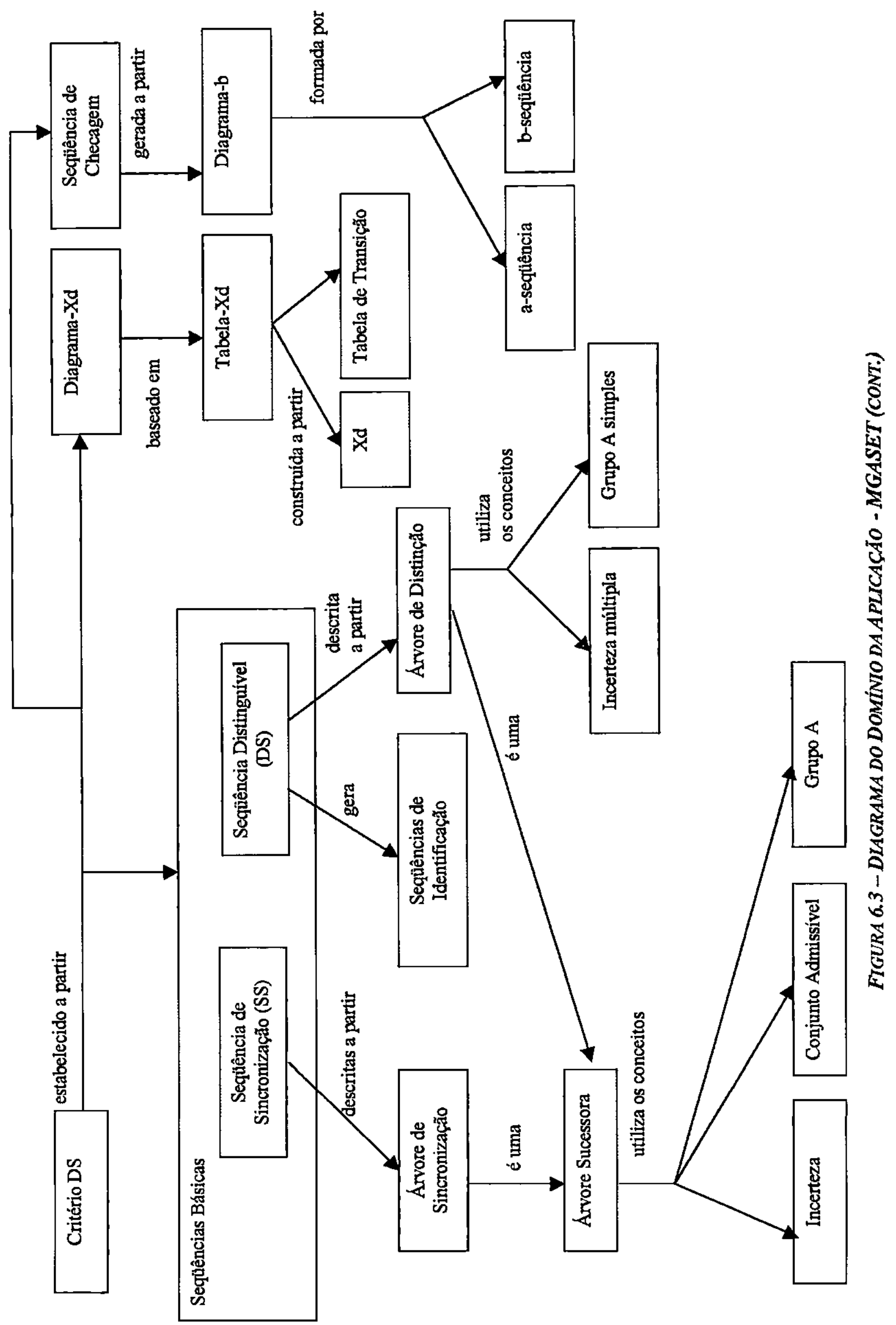




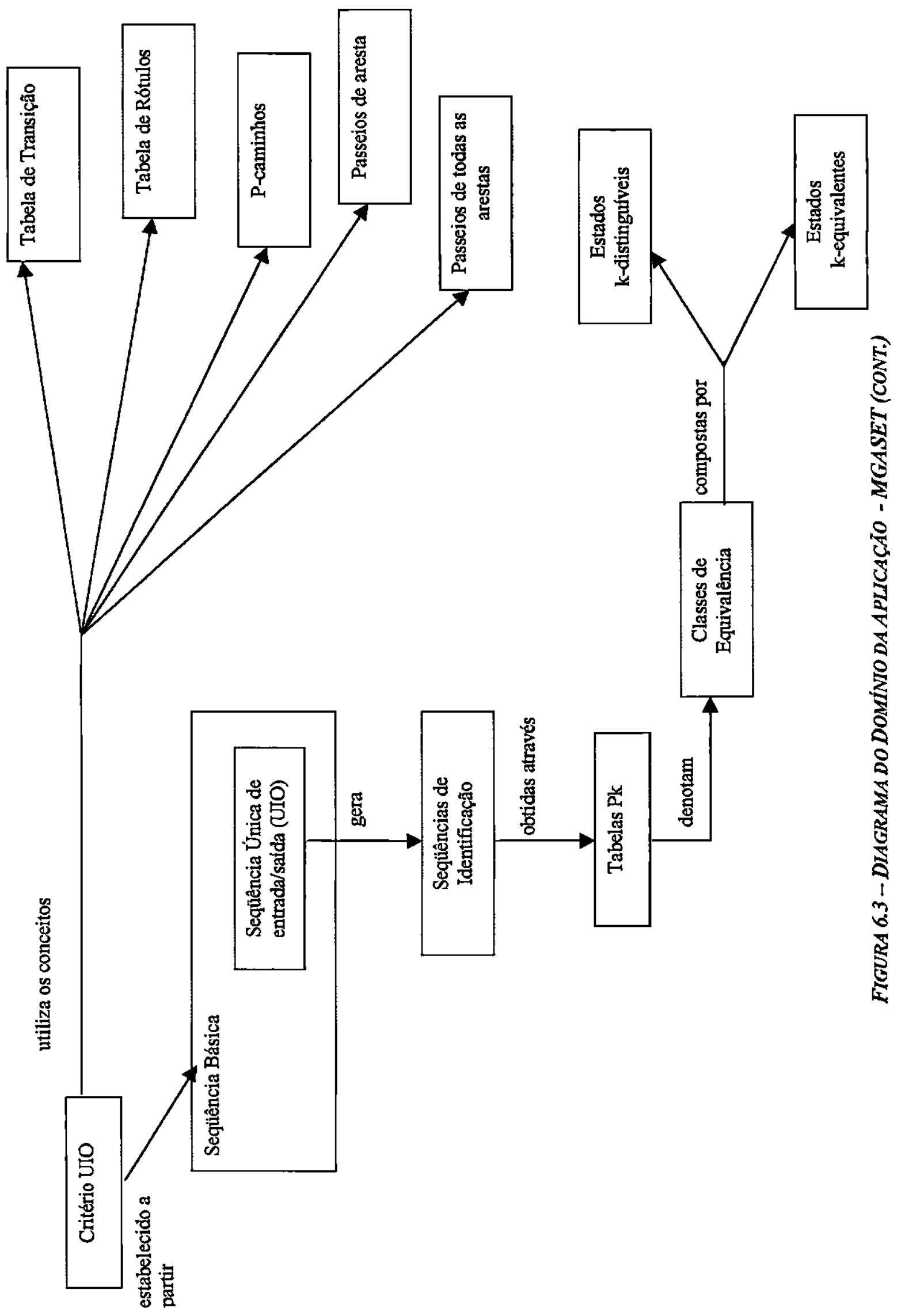


O Quadro 6.7 mostra a descrição das principais funçōes do dominio referente ao contexto de especificação e validaçāo de sistemas baseadas na técrica máquina de estados finito.

QUADRO 6.7-QUADRO DE DESCRICAOO DAS PRINCIPATS FUNÇÓES - MGASET

\begin{tabular}{|c|c|}
\hline Função & Objetivo \\
\hline $\begin{array}{l}\text { Editar o Grafo da } \\
\text { MEF ou a Tabela } \\
\text { de Transiçāo }\end{array}$ & $\begin{array}{l}\text { Entrar com o grafo ou a tabela de transiçāo que representa a } \\
\text { especificaçāo da MEF. }\end{array}$ \\
\hline $\begin{array}{l}\text { Abrir o Grafo da } \\
\text { MEF ou Tabela de } \\
\text { Transição }\end{array}$ & Utilizar um grafo ou uma tabela de transição já existente. \\
\hline $\begin{array}{l}\text { Verificar } \\
\text { propriedades }\end{array}$ & $\begin{array}{l}\text { Verificar se a MEF tem certas propriedades: Minimalidade, } \\
\text { Especificaçāo Completa, Determinismo, Alcançabilidade do Estado } \\
\text { Inicial, Conectividade Forte e Máquina de Mealy dependendo do critério } \\
\text { selecionado. }\end{array}$ \\
\hline $\begin{array}{l}\text { Gerar Seqüências } \\
\text { Básicas }\end{array}$ & $\begin{array}{l}\text { Gerar as seqūências básicas (Seqūència de Sincronização, Seqüência } \\
\text { Distinguivel, Seqüência Única de Entrada/Saida e Conjunto de } \\
\text { Caracterizaçäo) de acordo com o critério selecionado. }\end{array}$ \\
\hline $\begin{array}{l}\text { Gerar Sequêencias } \\
\text { de Teste }\end{array}$ & $\begin{array}{l}\text { Gerar as seqüếncias de teste de acordo com o critério W, DS, UIO ou } \\
\text { Wp. }\end{array}$ \\
\hline $\begin{array}{l}\text { Executar as } \\
\text { Seqüências de } \\
\text { Teste }\end{array}$ & $\begin{array}{l}\text { Executar as seqüēencias de teste geradas por cada um dos critérios: } W \text {, } \\
\text { DS, UIO e Wp. }\end{array}$ \\
\hline
\end{tabular}

Foram selecionados dois membros para participarem das sessōes de aquisição de conhecimento. Esses membros fizeram tanto o papel de especialista do domínio quanto o de usuário do sistema. Um relato inicial foi realizado comentando-se sobre aquisição de conhecimento, sua importância para a organização e os principais conceitos relacionados.

\subsection{2 - Ciclo Brainstorming do Processo IPAIA Instanciado para o Dominio de}

\section{Engenharia Reversa}

Nesse ciclo foi obtido conhecimento de âmbito geral sobre o dominio da ferramenta, a partir de dois especialistas do domínio, incluindo as principais funcionalidades que uma ferramenta inserida no contexto de geraçāo de seqüências de teste em máquinas de estado finito deveria ter.

CICLO BRAINSTORMING - Preparação da Sessão de Brainstorming. nessa fase foram selecionados os dois membros da equipe de aquisição de conhecimento para participarem da 
sessão de brainstorming e também, foi elaborado um plano para auxiliar na condução da sessão de brainstorming. Esse plano foi entregue a cada um dos participantes, com dois dias de antecedência da sessão, para que esses pudessem se preparar melhor (Quadro 6.8).

\section{QUADRO 6.8 - PLANO PARA A SESSÃO DE BRAINSTORMING - MGASET}

\section{PLANO PARA A SESSÃO DE BRAINSTORMING}

1 Introduçäo: o objetivo deste plano é orientar o engenheiro de conhecimento na condução da sessão de brainstorming (técnica utilizada para adquirir informaçōes de um grupo de pessoas sobre determinado assunto).

\section{Gerenciamento:}

Local da Sessăo: Sala Profa Rosely Sanches

Date da Sessão: 28/10/1999 Horário: 08:30 hs

Engenheiro de Conhecimento: Andrea Padovan Jubileu

Anotodores/Assistentes: não será utilizado

Tempo Total: aproximadamente 40 minutos

Especialistas do Domínio/Fonté de Conhecimento: Adenilso da Silva Simão

Tatiana Sugeta

Meta da Sessão; obter iñfortnaçōes gerais sobre os temos (e os relacionamentos entre esses termos) do domínio de Geração de sequências de Teste para sistemas baseados na técnioa de Máquinas de Estado Finito, e sobre as principais funcionalidades que uma ferramenta inserida nessel contexto deveria ter, além de comentários a respeito de openações, itens de entrada e de saída que a ferramenta não implementa, mas foram previstos para uma futura versão da mesma.

\section{Tarefos:}

3.1 Iniciação: $O$ objetivo pelo qual faremos essa sessão de brainstorming é enfocado na obtenção de informações a respeito do contexto Máquina de Estadas Finito (MEF) e Geraçáo de Sequiencias de Teste para sistemas baseodos nessa técnica, sendo assim, é de suma importância a sua participação. As informações obtidas serviräo de base para a elaboração de representaçöes do conhecimento obtido que farão parte da documientação da ferramenta que está sendo analisada - MGASET.

3.2 Haverí um tempo disponivel para que cada participante exponha o que conhece a respeito dos termos, relacionamentos entre os termos e funcionalidades relacionados ao contexto MEF e Geração de Seqüéncias de Teste para sistemas baseados em MEF. Se no momento da exposição você se lembrar de algo a respeito do que está sendo relatado, anote $e$, após o término do pronumciamento a respeito dessa funcionalidade, voce poderd fazer um adendo ao que foi relatado.

3.3 A seguir, cado uño das funcionalidades que a ferramenta deveria ter será levantada e cada um dos participantes da sessäo terí um tempo para comentar a respeito dessa funcionalidade, expondo quais seriam os itens de entrada recessários para a sua execução e quais seriam os itens de saída.

3.4 Depois de cada especialista ter exposto seu conhecimento, aqueles que quiserem complementar algo, poderũo fazê-lo.

\section{Cronograma:}

\begin{tabular}{|c|c|c|c|c|c|c|c|c|}
\hline Tarefas & $\begin{array}{c}5 \\
\text { minutos }\end{array}$ & $\begin{array}{c}10 \\
\text { minutos }\end{array}$ & $\begin{array}{c}15 \\
\text { minutos }\end{array}$ & $\begin{array}{c}20 \\
\text { minutos }\end{array}$ & $\begin{array}{c}25 \\
\text { minutos }\end{array}$ & $\begin{array}{c}30 \\
\text { minutos }\end{array}$ & $\begin{array}{c}35 \\
\text { minutos }\end{array}$ & $\begin{array}{c}40 \\
\text { minutos }\end{array}$ \\
\hline 3.1 & 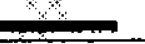 & & & & & & & \\
\hline 3.2 & $=$ & & & & 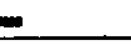 & & & \\
\hline 3.3 & & & & & & & 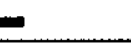 & \\
\hline 3.4 & & & & & & & & \\
\hline
\end{tabular}

5 Recursos: cada participante terá papel e caneta para anotações, caso seja necessário. 
GICLO BRAINSTORMING - Aquisiçäo de Conhecimento: nessa fase o plano elaborado anteriormente foi colocado em prática. O engenheiro de conhecimento fez o papel de moderador na sessão quando foi aplicado o brainstorming desestruturado, de modo que quando um estivesse se prorunciando e outro se lembrasse de algo para complementar, existisse ponderação e bom senso para dar a palavra a outro.

CICLO BRAINSTORMING - Implementação do Conhecimento: nessa fase foram transcritas as anotaçöes feitas pelo engenhejro de conhecimento. O Léxico do Domínio da Aplicação, o Diagrama do Dominio da Aplicação e o Quadro de Descriçöes das Principais Funçóes foram complementados e confirmados. Foi elaborado um Quadro Consensual composto pelas operaçōes que a ferramenta deveria ter $\theta$ pelos respectivos litens de entrada $\theta$ de saida dessas operações, além de comentánios a respeito das operações, itens de entrada e de saida que não estão implementados na ferramenta, mas foram previstos para uma futura versão da mesma (Quadro 6.9).

QUADRO 6.9-QUADRO CONSENSUAL - MGASET

\begin{tabular}{|c|c|c|}
\hline Operaçöes & ttens de Entrada & Itens de Saida \\
\hline Editar MEF & $\begin{array}{l}\text { Grafo direcionado ou Tabela de } \\
\text { Transição } \\
\text { Diretório onde será gravado o grafo } \\
\text { ou tabela e nome do arquivo }\end{array}$ & msg "Deseja salvar?" \\
\hline Abrir MEF & $\begin{array}{l}\text { Diretónio e nome do arquivo que } \\
\text { contém o grafo ou tabela }\end{array}$ & \\
\hline $\begin{array}{l}\text { Selecionar critério } \\
\text { para gerar as } \\
\text { seqüências de } \\
\text { teste }\end{array}$ & $\begin{array}{l}\text { Critério (DS, UIO, W, Wp) } \\
\text { \{está implementado somente o } \\
\text { critérios W- objetivo dessa versão } \\
\text { da MGASET, mas foram previstas } \\
\text { possibilidades para implementação } \\
\text { futura dos critérios DS, UNO e Wp\} }\end{array}$ & $\begin{array}{l}\text { Propriedades que aquela MEF } \\
\text { possui } \\
\text { Propriedades que a MEF deveria } \\
\text { atender, mas não atende } \\
\text { Seqūências básicas que são } \\
\text { geradas } \\
\text { Seqüencias básicas que a } \\
\text { ferramenta deveria gerar para a } \\
\text { MEF, mas não gera } \\
\text { Seqüências de teste geradas se, } \\
\text { dependendo do critério, atendidas } \\
\text { certas propriedades e geradas } \\
\text { certas seqüências básicas }\end{array}$ \\
\hline $\begin{array}{l}\text { Executar } \\
\text { seqüências de } \\
\text { teste }\end{array}$ & $\begin{array}{l}\text { MEF que atende a certas } \\
\text { propriedades e possui certas } \\
\text { seqüências básicas referentes ao } \\
\text { critério selecionado }\end{array}$ & $\begin{array}{l}\text { Saidas obtidas quando executadas } \\
\text { as seqüências básicas }\end{array}$ \\
\hline Alterar a MEF & $\begin{array}{l}\text { Grafo direcionado ou Tabela de } \\
\text { Transição }\end{array}$ & msg "Confirma alteração?" \\
\hline
\end{tabular}


CICLO BRAINSTORMING - Avaliaçäo do Conhecimento: nessa fase o conhecimento adquirido foi validado junto aos especialistas do domínio participantes da sessāo de brainstorming. Para isso, foi realizada uma inspeção onde foi averiguada tanto a consistência quanto a completitude do conhecimento conceitual do dominio adquirido. Depois de realizada a inspeção notou-se que não haveria necessidade de ser realizado outro ciclo brainstoming; desse modo, o seguinte ciclo (ciclo rastreamento de processo) foi realizado visando a obtenção do conhecimento especifico da ferramenta MGASET.

\subsection{3 - Ciclo Rastreamento de Processo do Processo IPAIA Instanciado para o Dominio de Engenharia Reversa}

Nesse ciclo o conhecimento foi obtido de um usuário do sistema por meio da observação, por parte do engenheiro do conhecimento, dos procedimentos tomados pelo usuário ao utilizar a ferramenta MGASET.

CIClo RASTREAMENTO DE PROCESSO - Preparação da Sessão de Rastreamento de Processo: nessa fase foi selecionado um usuário do sistema para dele adquirir conhecimento, e foi elaborado um plano (Quadro 6.10) para conduzir a sessão de rastreamento de processo, - qual foi entregue ao usuário com dois dias de antecedência.

CIClo RASTREAMENTO DE PROCESSO - Aquisiçăo do Conhecimento: nessa fase o plano elaborado anteriormente foi colocado em prática para se adquirir conhecimento específico referente às operaçōes do sistema, seus respectivos itens de entrada e de saída, a seqüência de execução das operaçōes e a seqüência dos itens de cada operação. O papel do engenheiro de conhecimento, nessa fase, foi o de somente observar o usuário que "pensou alto" enquanto utilizava o sistema.

CICLO RASTREAMENTO OE PROCESSO - Implementação do Conhecimento: nessa fase o que foi registrado durante a sessäo foi transcrito no Quadro Consensual Específico do Sistema Analisado (Quadro 6.11) e no Diagrama de Seqüência de Operações (Figura 6.4). 


\section{PLANO PARA AS SESSÖES DERASTREAMENTO DE PROCESSO.}

1 Introduçaos o objetivo deste plano é orientar o Engenheiro de Conhecimento a conduzir a sessão de nastreanento de processo (técnica intilizada parta adquirit informaçós ao observar o desenvolvimento de determinada tarefa por alguéti).

\section{Gerenciamento:}

Engenheiro de Conhecimento: Andrea Padovan Jubileu

Meta da Sessão: obfer conhecinento a respeito das funcionalidades da ferramenta, dos itens de entrada $e$ saida de cada operação, da sequéncia das operaçōes ê da sequiência dós sitents de cadaoperação, observandoo ao utilizar a ferramenta MGASET, ém um cáso hipofético ou real:

\begin{tabular}{|c|c|c|c|c|}
\hline 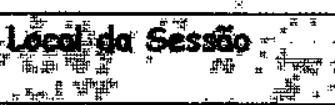 & Dente fda & 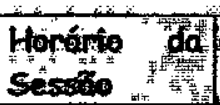 & Forpo & W \\
\hline $\begin{array}{l}\text { Laboratório de } \\
\text { Engentaria } \\
\text { Software }\end{array}$ & $12 / 11 / 1999$ & $08: 30$ hs & Thora & Adenilso da silva Simäo \\
\hline
\end{tabular}

\section{Tarefas:}

3.1 Inicioção durante essa sessäo vocế sérá observado enquanto untiliza a fertamenta MGASET, por "isso, utilize-a imaginando que um novo tisiúrio que nada conhece sobre a ferratnento o está observando:

3.2 Dunânte a útilizagäo da ferramenta, em um coso hipotético ou real, vocé deve pensar al to", ou seja, relatar verbalmente todos as passos tomadios - nä́o esquecendo que um noyo usuário da ferramenta 0 está observando - procure falar pausadatiente a respeito de cada posso tomado:

3.3 Todos os pássos do procedimento que vocé executar â utilizor a ferramenta serũo observados e registrados. Serëio observados:

- As operaçōes efétuadás e a descriçōo informal de cada ûma delas.

- As précondiçóes para que cada operoçáo possa ser executado.

- Os itens de entrada para a execucáo de cada operagáo, identificando entre esses itens de entrada quais são ós całpos chaves (parametros da operaço, aqueles os quais outros campos dependem):

- Os itens de saida decorrentes da execuçấo de cadi operaçố:

- A séqiência de ocor tênció das operações:

- A sequência de ocorrencia dós ítens de entrada e saída em cada operaçấo:

- As opções dos menus do sistemia:

\section{Cronograma:}

\begin{tabular}{|c|c|c|c|c|c|c|}
\hline Tarefas & 10 minutos & 20 minutos & $30 \mathrm{minutos}$ & 40 miliutos & 50 minutos & 60 minutos \\
\hline $3: 1$ e 3.2 & $m=1$ & & & & & \\
\hline 3.3 & & & & & & \\
\hline & & & & & & \\
\hline
\end{tabular}

5 Recursos: no laboratório de Engenharia de Software deve haver uma estacão disponivel com a ferramenta instalada e cón todoss os periféricos necessários para a simulaçóo de un caso hipotético ou real. 
QUADRO 6.11-QUADRO CONSENSUAL ESPECÍFICO DO SISTEMA - MGASET

\begin{tabular}{|c|c|c|c|}
\hline Operaçōes & Iteṇs de Entrada & Itens de Saída & Pré-Condiçōes \\
\hline $\begin{array}{l}\text { Abrir MEF } \\
\text { (Abre um arquivo } \\
\text { que contém uma } \\
\text { MEF representada } \\
\text { por uma Tabela } \\
\text { de Transição) }\end{array}$ & $\frac{\text { Diretório, nome arquivo (.mef), }}{1,2}$ & $\begin{array}{l}\text { 1. Msg "Arquivo não } \\
\text { existe" (opcional) } \\
\text { 2. Nome do arquivo } \\
\text { na barra de status, } \\
\text { Tabelas Pk da MEF }\end{array}$ & Que a MEF exista \\
\hline $\begin{array}{l}\text { Editar MEF } \\
\text { (Possibilita a } \\
\text { edição de uma } \\
\text { MEF através de } \\
\text { uma tabela de } \\
\text { transição) }\end{array}$ & $\begin{array}{l}\text { No de símbolos de entrada, } \underline{n}^{\circ} \\
\text { de estados } \\
\text { festa opçāo não funciona } \\
\text { corretamente, sendo assim, } \\
\text { para entrar com a MEF deve-se } \\
\text { criar um arquivo com apenas } \\
\text { uma linha onde constará } n^{\circ} \text { de } \\
\text { estados, } n^{\circ} \text { de entradas, } n^{\circ} \text { de } \\
\text { saídas, o os próximos estados, } \\
\text { nessa ordem\} }\end{array}$ & & \\
\hline $\begin{array}{l}\text { Verificar as } \\
\text { propriedades } \\
\text { (Verifica se a MEF } \\
\text { tem certas } \\
\text { propriedades que } \\
\text { podem ser } \\
\text { selecionadas pelo } \\
\text { usuánio) }\end{array}$ & $\begin{array}{l}\text { Propriedades (Minimalidade, } \\
\text { Especificação Completa, } \\
\text { Determinismo, Alcançabilidade } \\
\text { do estado inicial, Conectividade } \\
\text { forte e Máquina de Mealy) } \\
\text { \{(1)as propriedades } \\
\text { Alcançabilidade do estado } \\
\text { inicial e Conectividade Forte } \\
\text { não estão implementadas } \\
\text { corretamente; (2)não há como } \\
\text { entrar com uma MEF que nāo } \\
\text { seja deterministica e que não } \\
\text { seja de Mealy - o formato de } \\
\text { dados nāo permite\} }\end{array}$ & $\begin{array}{l}\text { Propriedades que a } \\
\text { MEF possui }\end{array}$ & $\begin{array}{l}\text { Que exista uma } \\
\text { MEF } \\
\text { \{não há } \\
\text { tratamento. Se } \\
\text { tentar verificar } \\
\text { propriedades sem } \\
\text { ter selecionado } \\
\text { uma MEF a } \\
\text { ferramenta será } \\
\text { abortada\} }\end{array}$ \\
\hline $\begin{array}{l}\text { Gerar as } \\
\text { seqüências } \\
\text { básicas } \\
\text { (Gera as } \\
\text { seqüências } \\
\text { básicas } \\
\text { selecionadas pelo } \\
\text { usuário) }\end{array}$ & \begin{tabular}{|l|} 
Seqüências básicas \\
(Seqüência de Sincronização, \\
Seqüência Distinguivel, \\
Seqüência Única de Entrada e \\
Saida e Conjunto de \\
Caracterização) \\
\{a Seqũência Única de Entrada \\
e Saída não está \\
implementada; a Seqüência de \\
Sincronizaçäo e a Seqüência \\
Distinguível näo estäo \\
implementadas corretamente\}
\end{tabular} & $\begin{array}{l}\text { Sequiências básicas } \\
\text { que a ferramenta } \\
\text { gera a partir da } \\
\text { MEF }\end{array}$ & $\begin{array}{l}\text { Que exista uma } \\
\text { MEF } \\
\text { \{não há } \\
\text { tratamento. Se } \\
\text { tentar gerar as } \\
\text { seqüências } \\
\text { básicas sem ter } \\
\text { selecionado uma } \\
\text { MEF a ferramenta } \\
\text { será abortada\} }\end{array}$ \\
\hline
\end{tabular}


QUADRO 6.11 - QUADRO CONSENSUAL ESPECIFICO DO SISTEMA - MGASET (CONT.)

\begin{tabular}{|c|c|c|c|}
\hline Operaçoes & Itens defEntrada & Itenș de Saida & Prêngondicóes \\
\hline $\begin{array}{l}\text { Gerar seqüências } \\
\text { de teste } \\
\text { (Gera as } \\
\text { seqüencias de } \\
\text { teste do critério } \\
\text { selecionado) }\end{array}$ & $\begin{array}{l}\text { Critério } \\
\text { \{critérios DS, UIO, W, Wp, mas } \\
\text { só está implementado o critério } \\
\text { W\} }\end{array}$ & $\begin{array}{l}\text { Seqüências de } \\
\text { teste }\end{array}$ & $\begin{array}{l}\text { Que exista uma } \\
\text { MEF que atenda a } \\
\text { certas } \\
\text { propriedades e } \\
\text { possua certas } \\
\text { seqüéncias } \\
\text { básicas, } \\
\text { dependendo do } \\
\text { critério } \\
\text { selecionado }\end{array}$ \\
\hline $\begin{array}{l}\text { Executar } \\
\text { Seqüencias de } \\
\text { Teste } \\
\text { (Executa as } \\
\text { seqüencias de } \\
\text { teste fomecendo } \\
\text { as saidas que a } \\
\text { MEF fomece) }\end{array}$ & $\begin{array}{l}\text { Critério } \\
\text { \{critérios DS, UIO, W, Wp, mas } \\
\text { não está implementado } \\
\text { nenhum critério\} }\end{array}$ & $\begin{array}{l}\text { Saidas obtidas } \\
\text { quando executadas } \\
\text { as seqüèncias } \\
\text { básicas }\end{array}$ & $\begin{array}{l}\text { Que exista uma } \\
\text { MEF que atenda a } \\
\text { certas } \\
\text { propriedades e } \\
\text { possua certas } \\
\text { seqüencias } \\
\text { básicas, } \\
\text { dependendo do } \\
\text { critério } \\
\text { selecionado }\end{array}$ \\
\hline
\end{tabular}

A Figura 6.4 mostra a seqüência de operaçöes permitidas na ferramenta MGASET.

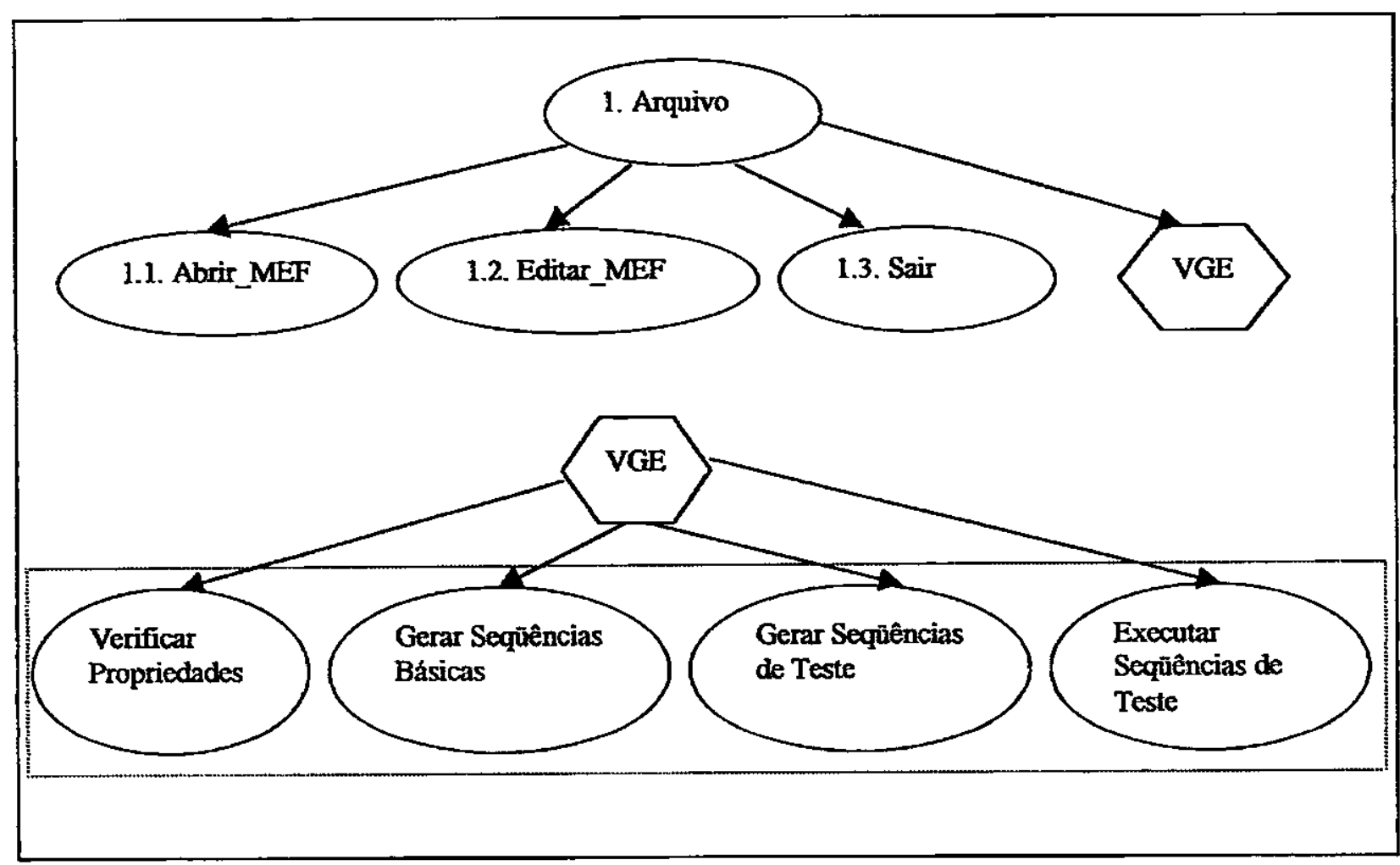

FIGURA 64-DLAGAMA DESEQÜÊNCLA DE OPERAÇŌES-MGASET 
CTCLO RASTREAMENTO DE PROCEsSO - Avaliação do Conhecimento: nessa fase o conhecimento adquirido foi verificado, pelo engenheiro de conhecimento, quanto à corretitude sintática e semåntica do Quadro Consensual Específico do Sistema Analisado (QCESA) ө do Diagrama de Seqüência de Operaçōes (DSO). Foi também validado por meio da utilização do sistema pelo engenheiro de conhecimento que averiguou se o QCESA e o DSO estavam realmente consistentes. Devido à simplicidade do sistema, com somente um ciclo rastreamento de processo foi possivel adquirir o conhecimento necessário. As dúvidas em relação ao Quadro Consensual e o Quadro Consensual Especifico do Sistema Analisado foram anotadas para serem questionadas na próxima sessão de aquisição de conhecimento.

\subsection{4 - Ciclo Entrevista Estruturada do Processo IPAlA Instanciado para o Domínio de Engenharia Reversa}

Nesse ciclo o conhecimento foi obtido do mesmo usuário que participou da sessão anterior com 0 intuito obter conhecimento mais detalhado a respeito das operações da ferramenta MGASET, principalmente, da seqüência das operaçōes e dos itens de entrada e saída de cada operação, a fim de esclarecer as dúvidas em relação ao conhecimento já adquirido.

CICLO ENTREVISTA ESTRUTURADA - Preparação da Sessāo de Entrevista Estruturada: nessa fase 0 usuário participante da sessão de rastreamento de processo foi o selecionado para ser entrevistado, o engenheiro de conhecimento fez o papel de entrevistador e anotador, e foi elaborado um plano (Quadro 6.12) para auxiliar na condução da sessão de entrevista estruturada.

CICLO ENTREVISTA ESTRUTURADA - Aquisição de Conhecimento: nessa fase o plano elaborado anteriormente foi colocado em prática a fim de conhecer mais detalhes sobre as operaçōes do sistema como seqüências de operações, itens de entrada e saida, seqüencia dos itens de entrada e saída em cada operação e, também, para esclarecer as dúvidas existentes relacionadas ao conhecimento já adquirido.

CTCLO ENTREVISTA ESTRUTURADA - Implementação do Conhecimento: com as dúvidas esclarecidas, o conhecimento obtido foi complementado no Quadro Consensual Específico do Sistema Analisado (Quadro 6.11). 


\section{PLANO PARA A SESSÁO DE ENTREVISTYA ESTRUTURADA}

1 Introdução: o objetivo déste pláno é orientar o engentieino de conhecimentio na conduçáo da sessão de entrevista estrethurada.

\section{Gerenciantiento:}

Engenheiro de Conhecinento: Andrea Padovan Jubileu

Meta da Séssäo: questionar sobre a sequência das operocốes, sobrue a sequência dos itens de entrada $e$ saida de cada operacắo e sobre outros detailhes das funcionalidades do sistema, a fim de eliminar as dívidas existentes.

\begin{tabular}{|c|c|c|c|c|}
\hline Loced la Sesseo & $\begin{array}{l}\text { Data } \\
\text { Sessicéc| }\end{array}$ & 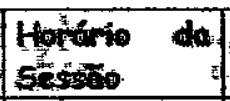 & $\begin{array}{l}\text { Thitpo } \\
\text { Toted }\end{array}$ & W \\
\hline $\begin{array}{l}\text { Laboratório de Eng. } \\
\text { de Software }\end{array}$ & $15 / 11 / 1999$ & $09.00 \mathrm{hs}$ & 30 minutos & Adenilso do silvo sinăo \\
\hline
\end{tabular}

\section{Tarefas:}

3.1 Iniciaçäo: $Q$ motivo pelo qual essa sessôn de entrevista estrïturoda será realizada $E$ enfocado na obtenção de informagöes da ferramenta MGASET a fim de esclorecer os dúvidás em relação ao conhecimento. já obtido, e obter informacóes mais de tallados dos funçöes da ferramenta.

3.2 Das questóes a seguir deseja-se saber a razäo de, oparentemente, olguns itens não existirem no sistema. As possiveis razóes podem ser: (1) devido oo esquecimento de alguma funcionalidade ou (2) devido ao fáto da funcionalidade estar embutida eln alguma fünça thaior ou ainda (3) devido ap fato do sistema răo estar completo?

Questões:

- Para gerar sequéncias de teste, a partir de determinado tritério, é necessário que a MEF gere centas sequênciós bósicas e possua certas propriédádes. Por que estão disponiveis as opçōes "verificar propriedades" e "genar sequiências básicas", anibas com alternativa de múltipla escolho, no menu da ferrametita? A verificação de propriedades para gerar certas

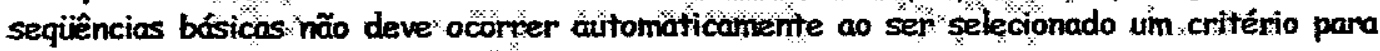
gerar as sequiências de teste da máquitina?

- NGio há como olferar uma MEF ja editada se necessárior.

3.3 As questões a seguir seräo feitas a efeito de confirmar e/oú completar o conhecinento já existente a respeito das operaçöes do sistema de charnadas técnicas.

- Quals sấo as operoçốs disponiveis na ferránento MGASET? E qual É a sequîncia de execução dessas operagôes?

- Quais são os itens de entrada de cada uma das operacóes apontadas anteriómente, e quais são os respectivos itents de saída (possiveis respostas do sistema cos ittens de entrada)?

- Quais sấo os campos chaves de cada operasão?

- Qual a sequiência de ocomencia dos itens de entrada e saida em cada operacão?

- Serño questionadas oưtros dívidas particulares, coso neceśstripi...

\section{Cronograna:}

\begin{tabular}{|l|c|c|c|}
\hline Tarefas & 10 minutos & 20 minutos & 30 minutos \\
\hline 3.1 & & & \\
\hline 3.2 & & & \\
\hline 3.3, & & & \\
\hline
\end{tabular}

5 Recursos: o local selecionado para a entrevista deve ser isolado de quaisquer outras pessoas que não façam parte da sessão, para que não haja enterferência na lógica de seu raciocíniô. Se você sentir mais firmeza em suas respostas utilizando o sistema, faça-o dessa forma. Sendo assim, é importante ter todo a equipamento disponivel. 
CICLO ENTREVISTA ESTRUTURADA - Avaliação do Conhecimento: nessa fase o conhecimento representado foi verificado tanto no Quadro Consensual Específico do Sistema Analisado quanto no Diagrama de Sequência de Operações pelo engenheiro de conhecimento.

CHECKPOINT. Como o objetivo do estudo de caso era o de aplicar tanto o Processo de Aquisição de Conhecimento IPAIA, instanciado para o domínio de engenharia reversa, quanto as diretrizes, não foi questionado, nesse ponto, a elaboração ou não dos modelos funcionais Fusion.

\subsection{5 -Modelo de Ciclo de Vida da Ferramenta MGASET}

A partir do Diagrama de Seqüência de Operaçōes, obtido depois de realizadas as sessões de Aquisição de Conhecimento, elabora-se os níveis do modelo de ciclo de vida até ser atingido o nível anterior ao nível de detalhamento das operações (Figura 6.5).

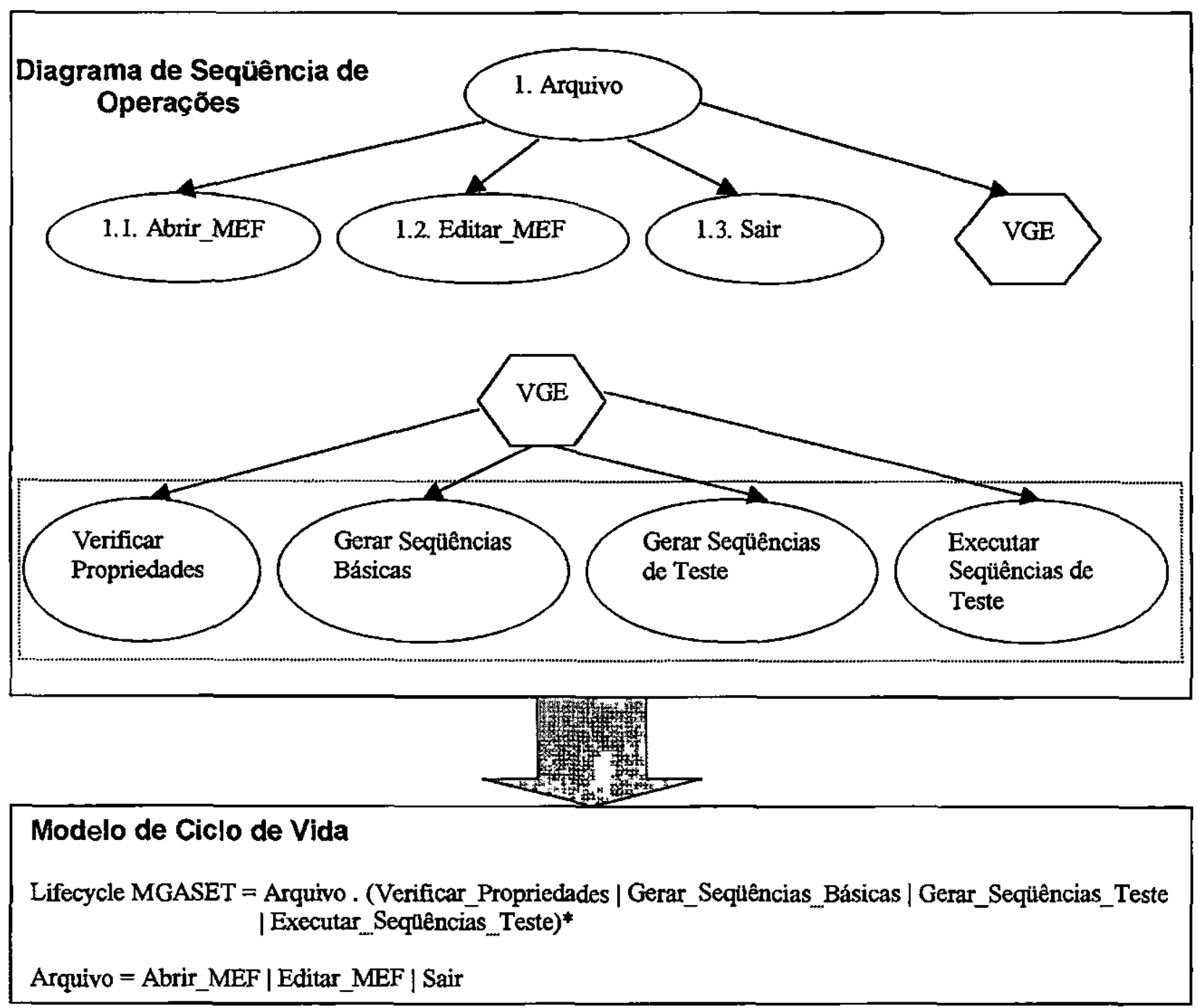

FIGURA 6.5 - TRANSIÇÃO DO DLAGRAMA DE OPERAÇOEES PARA O MODELO DE CICLO DE VIDA (MGASET) 
O complemento do modelo de ciclo de vida é obtido a partir do Quadro Consensual Específico do Sistema Analisado (Quadro 6.11). A seguir, será mostrada a expressão do ciclo de vida de cada operação pertencente ao Quadro Consensual Especifico do Sistema Analisado (Figura 6.6, 6.7, 6.8, 6.9, 6.10 e 6.11).

\begin{tabular}{|l|l|l|l|}
\hline Operacões & Itens de Enitrada & Itens de Sáida & Pré-Condições \\
\hline $\begin{array}{l}\text { Abrir_MEF } \\
\begin{array}{l}\text { (Abre um arquivo que } \\
\text { contém uma MEF } \\
\text { representada por uma } \\
\text { Tabela de Transição) }\end{array}\end{array}$ & Diretório, nome arquivo (mef), 1,2 & $\begin{array}{l}\text { 1. Msg “Arquivo não } \\
\text { existe” (opcional) } \\
\text { 2. Nome do arquivo na } \\
\text { barra de status, Tabelas } \\
\text { Pk da MEF }\end{array}$ & Que a MEF exista \\
\hline
\end{tabular}

Abrir_MEF = diretório . nome_arquivo . [\#msg_arquivo_não_existe] . nome_arquivo_barra_status . Tabelas_Pk

\section{FIGURA 6.6 - TRANSIÇÃO DO QUADRO CONSENSUAL ESPECÍFTCO DO SISTEMA ANALISADO PARA A EXPRESSATO DE CICLO DE VIDA CORRESPONDENTE Aं OPERACÄO ABRIR}

\begin{tabular}{|c|c|c|c|}
\hline Operacōes & Itens de Entrada & Itens de-Saída & Pré-Condiçőes \\
\hline $\begin{array}{l}\text { Editar_MEF } \\
\text { (Possibilita a edição } \\
\text { de uma MEF através } \\
\text { de uma tabela de } \\
\text { transição) }\end{array}$ & $\begin{array}{l}\mathrm{N}^{\circ} \text { de símbolos de entrada, } \mathrm{n}^{\circ} \text { de } \\
\text { estados } \\
\text { \{esta opção não funciona } \\
\text { corretamente, sendo assim, para entrar } \\
\text { com a MEF deve-se criar um arquivo } \\
\text { com apenas uma linha onde constará } \\
n^{\circ} \text { de estados, } \mathrm{n}^{\circ} \text { de entradas, } \mathrm{n}^{\circ} \text { de } \\
\text { saídas, as saídas e os próximos } \\
\text { estados, nessa ordem\} }\end{array}$ & & \\
\hline
\end{tabular}




\begin{tabular}{|c|c|c|c|}
\hline Opcracões & Itens.de Entrada & Itens de Saida & Pré-Condições \\
\hline $\begin{array}{l}\text { Verificar as } \\
\text { propriedades } \\
\text { (Verifica se a MEF } \\
\text { tem certas } \\
\text { propriedades que } \\
\text { podem ser } \\
\text { selecionadas pelo } \\
\text { usuário) }\end{array}$ & $\begin{array}{l}\text { Propriedades (Minimalidade, } \\
\text { Especificação Completa, } \\
\text { Determinismo, Alcançabilidade do } \\
\text { estado inicial, Conectividade forte e } \\
\text { Máquina de Mealy) } \\
\text { \{(1)as propriedades Alcançabilidade } \\
\text { do estado inicial e Conectividade } \\
\text { Forte não estão implementadas } \\
\text { corretamente; (2)não há como entrar } \\
\text { com uma MEF que não seja } \\
\text { deterministica e que não seja de Mealy } \\
\text { - o formato de dados não permite\} }\end{array}$ & $\begin{array}{l}\text { Propriedades que a MEF } \\
\text { possui }\end{array}$ & $\begin{array}{l}\text { Que exista uma MEF } \\
\text { \{não há tratamento. Se } \\
\text { tentar verificar } \\
\text { propriedades sem ter } \\
\text { selecionado uma MEF } \\
\text { a ferramenta será } \\
\text { abortada\} }\end{array}$ \\
\hline \multicolumn{4}{|c|}{ 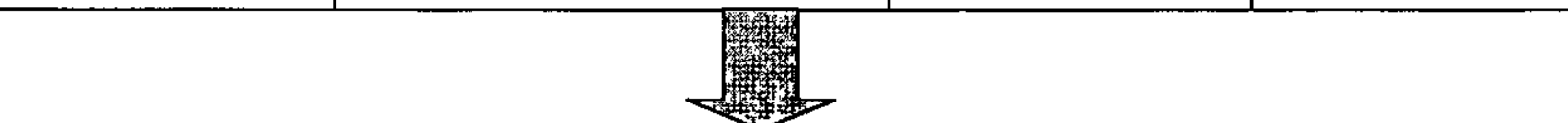 } \\
\hline & $\begin{aligned} &= \text { Minimalidade] } \text { [Especificação } \\
& \text { [Alcançabilidade_Estado_inicial] } \\
& \text { \#propriedades_MEF_possui }\end{aligned}$ & 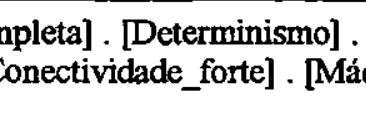 & Iina_Mealy] . \\
\hline
\end{tabular}

FIGURA 6.8 - TRANSIÇAOO DO QUADRO CONSENSUAL ESPECÍFICO DO SISTEMA ANALISADO PARA A EXPRESSÃO DE CICLO DE VIDA CORRESPONDENTE À OPERAÇÄO VERIFICAR AS PROPRIEDADES

\begin{tabular}{|c|c|c|c|}
\hline Operaçóes & Itens de Entrada & Itens de Saída & Pré-Condições \\
\hline $\begin{array}{l}\text { Gerar as seqüências } \\
\text { básicas } \\
\text { (Gera as seqüências } \\
\text { básicas selecionadas } \\
\text { pelo usuário) }\end{array}$ & $\begin{array}{l}\text { Seqüências básicas (Seqüûncia de } \\
\text { Sincronização, Sequêência } \\
\text { Distinguível, Seqüência Única de } \\
\text { Entrada e Saída e Conjunto de } \\
\text { Caracterização) } \\
\text { \{a Seqüuência Única de Entrada e } \\
\text { Saída não está implementada; a } \\
\text { Sequêência de Sincronização e a } \\
\text { Seqüência Distinguível não estão } \\
\text { implementadas corretamente\} }\end{array}$ & $\begin{array}{l}\text { Sequiências básicas que } \\
\text { a MEF gera }\end{array}$ & $\begin{array}{l}\text { Que exista uma MEF } \\
\text { \{não há tratamento. Se } \\
\text { tentar gerar as } \\
\text { sequiências básicas } \\
\text { sem ter selecionado } \\
\text { uma MEF a } \\
\text { ferramenta será } \\
\text { abortada\} }\end{array}$ \\
\hline \multicolumn{4}{|c|}{ 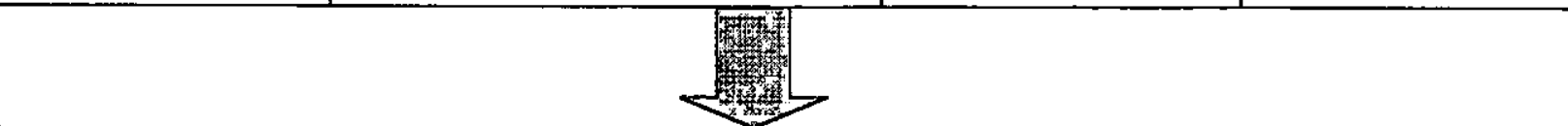 } \\
\hline \multicolumn{4}{|c|}{$\begin{aligned} \text { Gerar_seqüências_básicas }= & {[\text { Sequiência_Sincronização] } . \text { [Sequêência_Distinguivel] } .} \\
& \text { [Sequêencia_Única_Entrada_Saída] } .[\text { Conjunto_Caracterização] } . \\
& \text { \#seqüências_básicas_MEF_gera }\end{aligned}$} \\
\hline
\end{tabular}

FIGURA 6.9 - TRANSIÇAO DO QUADRO CONSENSUAL ESPECÍFICO DO SISTEMA ANALISADO PARA A EXPRESSÄO DE CICLO DE VIDA CORRESPONDENTE À OPERAÇÄO GERAR SEQÜENACIAS BÁSICAS 


\begin{tabular}{|c|c|c|c|}
\hline Operacōos & Tttens déntrada & Ttens de Salda & Pre-Condiçoes \\
\hline $\begin{array}{l}\text { Gerar sequiências de } \\
\text { teste } \\
\text { (Gera as sequiências de } \\
\text { teste do critério } \\
\text { selecionado) }\end{array}$ & $\begin{array}{l}\text { Critério } \\
\text { \{critérios DS, UIO, W, Wp, mas só } \\
\text { está implementado o critério W\} }\end{array}$ & Seqüências de teste & $\begin{array}{l}\text { Que exista uma MEF } \\
\text { que atenda a certas } \\
\text { propriedades e possua } \\
\text { certas seqüèncias } \\
\text { básicas, dependendo } \\
\text { do critério selecionado }\end{array}$ \\
\hline
\end{tabular}

Gerar_seqüências_teste $=$ critério . \#seqüências_teste_geradas

FIGURA 6.10 - TRANSIÇÃO DO QUADRO CONSENSUAL ESPECÍFICO DO SISTEMA ANALISADO PARA A EXPRESSÃO DE CICLO DE VIDA CORRESPONDENTE A OPERAÇÄO GERAR SEQÜÊNCLAS DE TESTE

\begin{tabular}{|c|c|c|c|}
\hline Operacöes & Itens de Entrada & Itens de Sáída & Pré-Condiçōes \\
\hline $\begin{array}{l}\text { Executar Sequiências } \\
\text { de Teste } \\
\text { (Executa as seqüências } \\
\text { de teste fornecendo as } \\
\text { saídas que a MEF } \\
\text { fornece) }\end{array}$ & $\begin{array}{l}\text { Critério } \\
\text { \{critérios DS, UIO, W, Wp, mas não } \\
\text { está implementado nenhum critério\} }\end{array}$ & $\begin{array}{l}\text { Saídas obtidas quando } \\
\text { executadas as } \\
\text { seqüências básicas }\end{array}$ & $\begin{array}{l}\text { Que exista uma MEF } \\
\text { que atenda a certas } \\
\text { propriedades e possua } \\
\text { certas seqüências } \\
\text { básicas, dependendo } \\
\text { do critério selecionado }\end{array}$ \\
\hline
\end{tabular}

Executar_seqüências_teste $=$ critério . \#saídas_obtidas

FIGURA 6.11 - TRANSIÇÃO DO QUADRO CONSENSUAL ESPECÍFICO DO SISTEMA ANALISADO PARA A EXPRESSÁO DE CICLO DE VIDA CORRESPONDENTE À OPERACÃO EXECUTAR SEQÜENACLAS DE TESTE

\subsection{6 - Modelo de Operações da Ferramenta MGASET}

A partir do Quadro Consensual Especifico do Sistema Analisado (Quadro 6.11), obtido depois de realizadas as sessões de aquisição de conhecimento, são elaborados os esquemas do modelo de operações (Quadro 6.13,6.14, 6.15, 6.16, 6.17,6.18) mostrados a seguir. 


\section{QUADRO 6.13 - ESQUEMA DA OPERAÇÄO ABRIR MEF}

\begin{tabular}{|c|c|}
\hline Operaçäo & $A b^{3}+M E F$ \\
\hline Descriçäo & Abre um arquivo que contém uma MEF representada por uma Tabela de Transição \\
\hline LÂ & supplied diretório; supplied nome_arquivo \\
\hline Altera & \\
\hline Envia & $\begin{array}{l}\text { agente externo: \{msg_arquivo_não_existe\}, agente externo: \{nome_arquivo_barra_status\}, } \\
\text { agente externo: }\{\text { Tabelas_Pk\} }\end{array}$ \\
\hline Assume & Que a MEF exista \\
\hline Resultado & $\begin{array}{l}\text { Se a operação_Abrit_MEF é confirmada } \\
\text { então o nome_arquivo aparece na barra de status da ferramenta e } \\
\text { Tabelas Pk da MEF são mostradas }\end{array}$ \\
\hline
\end{tabular}

\section{QUADRO 6.14 - ESQUEMA DA OPERAÇAOO EDITAR MEF}

\begin{tabular}{|c|c|}
\hline Operação & Editar MEF \\
\hline Descrição & Possibilita a edição de uma MEF através de uma tabela de transição \\
\hline $\mathbf{L} \hat{\mathbf{e}}$ & supplied $n^{\circ}$ símbolos_entrada; supplied n ${ }^{\circ}$ estados \\
\hline Altera & new arquivo.mef \\
\hline \multicolumn{2}{|l|}{ Envia } \\
\hline \multicolumn{2}{|l|}{ Assume } \\
\hline Resultado & \{não funciona\} \\
\hline
\end{tabular}

\section{QUADRO 6.15 - ESQUEMA DA OPERAÇATO VERIFICAR PROPRIEDADES}

\begin{tabular}{|l|l|}
\hline Operação & Verificar__propriedades \\
\hline Descrição & Verifica se a MEF tem certas propriedades que podem ser selecionadas pelo usuário \\
\hline Lê & $\begin{array}{l}\text { supplied propriedades (minimalidade; especificação_completa; determinismo; } \\
\text { alcançabilidade_estado_imicial; conectividade_forte; máquina_mealy) }\end{array}$ \\
\hline Altera & \\
\hline Envia & agente externo: \{propriedades_MEF_possui\} \\
\hline Assume & Que exista uma MEF \\
\hline Resultado & Verifica se a MEF possui as propriedades selecionadas \\
\hline
\end{tabular}


QUADRO 6.16-ESQUEMA DA OPERAÇAOO GERAR SEQÜÊNCIAS BÁSICAS

\begin{tabular}{|c|c|}
\hline Operaçäo & Gerar sequências básicastion \\
\hline Descriçăo & Gera as seqüências básicas selecionadas pelo usuário \\
\hline $\mathbf{L e}$ & $\begin{array}{l}\text { supplied seqüências_básicas (seqüûência_sincronização; sequiência_distinguível; } \\
\text { seqüência_única_entrada_saida; conjunto_caracterização) }\end{array}$ \\
\hline \multicolumn{2}{|l|}{ Alfera } \\
\hline Envia & agente externo: \{sequiências_básicas_MEF_gera\} \\
\hline Assinime & Que exista uma MEF \\
\hline Resultado & São geradas as sequências básicas selecionadas se a MEF possuir propriedades para tal. \\
\hline
\end{tabular}

\section{QUADRO 6.17 - ESQUEMA DA OPERAÇÃO GERAR SEQÜÊNCIAS DE TESTE}

\begin{tabular}{|c|c|}
\hline Operação & Gerar_sequiteñctas feste \\
\hline Deș̉ição & Gera as sequências de teste do critério selecionado \\
\hline$\overline{\mathbf{L e}}$ & supplied critério (DS ou UIO ou W ou Wp) \\
\hline \multicolumn{2}{|l|}{ Altera } \\
\hline Efivia & agente externo: \{seqüências_teste_geradas\} \\
\hline Assume & $\begin{array}{l}\text { Que exista uma MEF que atenda a certas propriedades e gere certas sequiências básicas, } \\
\text { dependendo do critério selecionado }\end{array}$ \\
\hline Resultado & São geradas as sequências de teste segundo o critério selecionado \\
\hline
\end{tabular}

\section{QUADRO 6.18 - ESQUEMA DA OPERAÇATO EXECUTARSEQUUENCLAS DE TESTE}

\begin{tabular}{|c|c|}
\hline Operaçăo & Executar_seqüüencias teste \\
\hline Descrição & Executa as sequêtncias de teste fornecendo as saidas que a MEF fornece \\
\hline $\mathbf{L} \hat{\mathbf{e}}$ & supplied critério (DS ou UIO ou W ou Wp) \\
\hline \multicolumn{2}{|l|}{ Alteira } \\
\hline Envia & agente externo: \{saidas_obtidas\} \\
\hline Assivime & $\begin{array}{l}\text { Que exista uma MEF que atenda a certas propriedades e gere certas seqüências básicas, } \\
\text { dependendo do critério selecionado }\end{array}$ \\
\hline Resitutadò & São geradas as saidas da MEF se executadas as sequiências de teste \\
\hline
\end{tabular}

\section{4-Considerações Finais}

Neste capitulo foram apresentados dois estudos de caso do Processo de Aquisição de Conhecimento IPAIA, instanciado para o domínio de engenharia reversa. 
O estudo de caso referente ao Sistema de Chamadas Técnicas foi útil a efeito de melhorar algumas atividades do processo, como a inserção de um patrocinador e a inserção de uma palestra Inicial que coloca todos os possíveis participantes da sessão cientes dos termos técnicos utilizados e da importância de sua participação nas sessões de aquisição de conhecimento.

Já com o estudo de caso referente à ferramenta MGASET foj observado que tanto o processo quanto as diretrizes elaboradas podem ser cada vez mais úteis, conforme aumente a complexidade do sistema submetido à engenharia reversa.

No capítulo a seguir são apresentadas as conclusões deste trabalho, bem como futuros desenvolvimentos que podem advir do mesmo. 


\section{CAPÍTULO 7 - CONCLUSÕES E}

TRABALHOS FUTUROS

\section{1 - Conclusōes}

O método de engenharia reversa FUSION-RE/I foi desenvolvido por Costa (1997) com o intuito de auxiliar a atividade de manutenção de software. Nesse método são recuperadas tanto visöes funcionais quanto visões estruturais do sistema - método Fusion (Coieman et al., 1994). As visões funcionais são recuperadas a partir de aspectos operacionais e dados disponíveis via interface; as visões estruturais são recuperadas a partir do código fonte e das visões funcionais obtidas.

O primeiro passo desse método - obter informaçőes sobre o sistema - é muito importante, pois o processo de engenharia reversa depende, totalmente, de informações existentes sobre o sistema. Esse passo, no entanto não está formalmente descrito e sendo assim, neste trabalho foi desenvolvido um processo para a criação de uma base de conhecimento e diretrizes de utilização dessa base para elaboração dos modelos funcionais Fusion.

O processo elaborado para adquirir conhecimento a ser armazenado na base foi o IPAIA, instanciado para o domínio de engenharia reversa. Em se tratando de uma instância, foram definidos três tipos de ciclos de conhecimento: ciclo brainstorming, ciclo rastreamento de processo e ciclo entrevista estruturada os quais se repetem até que os conhecimentos relacionados à interface e ao ambiente do sistema estejam representados na base de conhecimento. 
$\mathrm{Na}$ base de conhecimento são armazenadas estruturas de representação do conhecimento relacionadas ao ambiente e à interface. Essas estruturas compreendem o Léxico do Domínio da Aplicação, o Diagrama do Domínio da Aplicaçăo, o Quadro de Descriçăo das Principais Funções, o Quadro Consensual, o Quadro Consensual Específico do Sistema Analisado e o Diagrama de Seqüência de Operações.

As diretrizes desenvolvidas orientam como utilizar o conhecimento armazenado na base para elaborar as visőes funcionais do sistema.

O procedimento desenvolvido neste trabalho foi aplicado em dois estudos de caso. Esses estudos de caso mostraram que, tanto o Processo de Aquisição de Conhecimento $I P A I A$, instanciado para o domínio de engenharia reversa, quanto as diretrizes elaboradas podem ser úteis para o método FUSION-RE/I, pois formalizam um procedimento, atè então, não sistematizado. O primeiro estudo de caso (Sistema de Chamadas Técnicas) foi útil, pois notou-se a importância da inclusão de um patrocinador no processo, além de uma palestra inicial que conscientiza os possiveis participantes da sessão sobre os termos técnicos utilizados e sobre a sua participação nas sessões de aquisição de conhecimento. Já a partir do estudo de caso da ferramenta MGASET, verificou-se que a utilização do procedimento formalizado (processo e diretrizes) pode ser cada vez mais útil conforme aumente a complexidade do sistema submetido à engenharia reversa.

Outra contribuição deste trabalho é que o conhecimento armazenado na base pode não apenas ser utilizado para a engenhana reversa, através da aplicação das diretrizes, mas também para a reconstrução de um novo sistema, visto que o Quadro Consensual existente na base de conhecimento pode ser aproveitado na elaboração do documento de requisitos.

Deve-se observar que um dos objetivos inicialmente proposto neste trabalho não pode ser realizado. Em princípio, as estruturas de conhecimento contidas na base seriam utilizadas para a construção do modelo de ciclo de vida, do modelo de operações e também do modelo de objetos. No entanto, como citado no capítulo 5, verificou-se que a utilização de informações obtidas apenas da interface e do ambiente produziriam um modelo de objetos idealizado e não o realmente implementado. Assim, procurou-se obter o modelo de objetos a partir do modelo lógico da base de dados do sistema. Para isso, foi utilizada uma técnica de aquisição de conhecimento implicito denominada data mining.

Data Mining é considerada a parte central de um processo de Extração de Conhecimento em Bases de Dados (Knowledge Discovery in Databases - KDD). Envolve a aplicaçăo de algoritmos de aprendizado de máquina para encontrar padrões nos dados analisados (Capítulo 3).

MineSet (Silicon, 1999) é uma ferramenta baseada na técnica data mining e através dessa pode-se descobrir relacionamentos entre os elementos de dados, até então desconhecidos pelo usuário. A MineSet é composta por vánas ferramentas, entre elas a Rules Visualizer que fomece dados importantes por intermédio da construção, verificação e representação gráfica de modelos de padrōes em grandes bases de dados. Esses padröes são 
expressos via associação de regras as quais indicam a freqüência de itens ocorrerem juntos na base de dados.

Procurou-se, entāo, utilizar a ferramenta MineSet com o propósito de obter diretrizes a respeito dos relacionamentos entre os atributos de uma base de dados, a partir de análises obtidas através da visualização das regras de associação com a ferramenta Rules Visualizer, que pudessem direcionar um modelo de objetos de uma base de dados.

No teste realizado foi utilizada uma pequena base de dados de um sistema exemplo - o Northwind do Microsoft Access. A ferramenta MineSet aceita tanto arquivos textos quanto base de dados como Informix, Sybase e Oracle. Mas, para trabalhar com as bases de dados, é necessária a conexão com os respectivos servidores. No caso, devido à falta de conexăo com o servidor, as tabelas do sistema exemplo foram agrupadas em um arquivo texto para poder ser realizado o teste. No entanto, verificou-se que a malha de dados produzida é demasiadamente grande (anexo A) e apesar da ferramenta Rules Visualizer oferecer opções de filtragens para visualizar as regras, notou-se a necessidade de uma ferramenta de análise que oferecesse resultados mais claros para se encontrar relações entre os atributos. Mesmo assim, percebeu-se que existem alguns obstáculos para obter o projeto lógico a partir, somente, dos dados existentes na base (Navathe \& Elmasni, 1989). Por exemplo:

1. As tabelas podem não estar normalizadas existindo "erros" na representação física dos dados como valores redundantes nas tuplas e valores nulos;

2. A semántica representa como se pode interpretar os valores dos atributos relacionados aos outros atributos. O valor semântico dos atributos é relativo; não se consegue enxergá-lo a partir das instâncias, mas sim do esquema (especificação). Por exemplo, nāo há diferença na representação de dados multivalorados e de relacionamentos $1: \mathrm{N}$;

Portanto, a tentativa de utilizar a ferramenta Rules Visualizer para obter indicios a serem utilizados na elaboração do modelo de objetos não produziu os resultados esperados.

Ainda, durante o estudo das possiveis estruturas de representação do conhecimento na base de conhecimento, também foi questionada a utilização do diagrama abstrato detalhado (DAD) - diagrama pertencente ao método ERACE (Caldas, 1998).

ERACE é um método que propõe a elicitação e modelagem de requisitos por intermédio de cenários. Cada DAD é composto por uma seqüência de estados e um conjunto de transições. Os diagramas visam a identificação com detalhes das várias operações realizadas durante o desenrolar de uma cena. Uma cena é composta por estados que representam ações realizadas pelo sistema e um conjunto de transições (eventos) que representam estimulos, interações e mensagens em nivel de interface.

No entanto, a utilização dos DADs como estrutura de representação de conhecimento para ser utilizado no processo de engenharia reversa não se mostrou interessante, pois o nivel de abstração desses diagramas é mais alto do que o necessário. Para representar o conhecimento a ser utilizado na engenharia reversa do sistema utilizando DADs, cada estado deveria referir-se a cada atributo lido tornando o diagrama demasiadamente grande e de difícil 
interpretação. Essa tentativa foi realizada com o Sistema de Chamadas Técnicas (um dos estudos de caso existente no capítulo 6) e é apresentada no anexo B.

\section{2 - Trabalhos Futuros}

As possíveis linhas de pesquisa que podem dar continuidade a este trabalho são:

- Outros estudos de casos a serem realizados para aprimorar as diretrizes elaboradas e verificar a eficiência da utilização do Processo de Aquisição de Conhecimento IPAIA, instanciado para o domínio de engenharia reversa;

- Adicionar ao Processo de aquisiçăo de conhecimento IPAIA, instanciado para o domínio de engenharia reversa, uma forma de adquirir e representar o conhecimento referente ao código fonte, para elaborar as visões estruturais do sistema;

- Criar diretrizes para serem utilizadas na transição das estruturas de representação do conhecimento, referente ao código fonte, para os quadros de procedimentos, de indice $\theta$ das operaçöes/procedimentos de implementaçăo;

- Aprofundar o estudo da utilização da técnica de data mining para a confirmação ou não de seu uso na elaboração do modelo de objetos a partir da base de dados;

- Elaborar uma ferramenta que automatize, na medida do possível, o uso da base de conhecimento na elaboração tanto das visões funcionais quanto das visőes estruturais do sistema. 


\section{REFERÊNCIAS BIBLIOGRÁFICAS}

(Andert, 1999)

(Benedusi et al., 1992)

(Bennet, 1991)

(Bennet, 1995)

(Biggerstaff, 1989)
ANDERT, Ed. P. Jr. Expert System Soffware Verification, Validation and Test. Published in: ASQC Proceedings of the Second International Conference on Software Quality, 1992, in: http://www.consvs.com/publications/w test.html, [acessado em 10/03/1999].

BENEDUSI, P.; CIMITILE, A.; CARLINI, U. Reverse Engineering Processes, Design Document Production, and Structure Charts. Journal of Systems and Software, v. 19, p. 225-45, 1992.

BENNET, K. H. Automated Support of Software Maintenance. Information and Software Technology, v. 33, n. 1, p. 74-85, 1991.

BENNET, K. H. Legacy Systems. IEEE Software, v. 12, n. 1, p. 19 23, 1995.

BIGGERSTAFF, T. J. Design Recovery for Maintenance and Reuse. IEEE Computer, v. 22, n. 7, p. 36-49, 1989. 
(Biggerstaff et al., 1994) BIGGERSTAFF, T. J. et al. Program Understanding and the Concept Assignment Problem. Communications of the ACM, v. 37, n. 5, p. 72-82, may, 1994.

(Bouchard, 1999)

BOUCHARD, T. J. "Whatever Happened to Brainstorming?" In Guide to Creative Action, 1977, http://www.rla.unc.edu/lessons/brain_rules.htm, [acessado em 19/05/1999].

(Caine \& Gordon, 1975) CAINE, S; GORDON K. PDL - A Tool for Software Design. In: Proc. National Computer Conference. AFIPS Press, p. 271-276, 1975.

(Caldas, 1998)

CALDAS, J. Jr. Uma Ferramenta Baseada em Cenánios para Elicitação e Modelagem de Requisitos. Dissertação apresentada ao Instituto de Ciências Matemáticas de São Carlos - USP, como parte de requisitos para obtençăo do título de Mestre, abril de 1998.

(Chikofsky \& Cross II, CHIKOFSKY, E.J.; CROSS II, J.H. Reverse Engineering and 1990)

(Choi \& Scacchi, 1990) CHOI, S.C.; SCACCHI, W. Extracting and Reestructuring the Design of Systems. IEEE Software, v.7, n.1, p.66-71, 1990.

(Cleveland, 1989)

CLEVELAND, L. A Program Understanding Support Environment. IBM Systems Journal, v. 28, n. 2, p.324-344, 1989.

(Coleman et al., 1994) COLEMAN, D. et al. Object-Oriented Development - The FUSION Method. Englewood Cliffs, New Jersey, Prentice Hall, 1994.

(Cooke, 1994)

COOKE, N. J. Varieties of knowledge elicitation techniques. International Journal of Human-Computer Studies, v. 41, n. 6, p. 801-849, 1994.

(Costa, 1997)

COSTA, R.M; FUSION-REII - Um Método de Engenharia Reversa para Auxiliar a Manutenção de Software. Dissertação apresentada ao Instituto de Ciências Matemáticas de São Carlos - USP, como parte de requisitos para obtenção do título de Mestre, maio de 1997.

(Cross II 1990)

CROSS II, J.H. Grasp/Ada Uses Control Structure. IEEE Software, v. 7, n. 3, p. 62, 1990. 
(DeMarco \& Sarson, 1979)

(Fayyad et al., 1996)

(Giarratano, 1994)

(Gootinalake \&

Khebbal, 1995)

(Gremba \& Myers, 1998)

(Harandi \& Ning, 1990)

(Herbane, 1997)

(Johnson, 1990)

(Jonathan et al., 1993)

(Jubileu et al., 1998)

(Khabaza, 1989)

(Kci, 1999)
DeMARCO, T. SARSON, C. Structured Analysis and Systems Specification. Prentice-Hall, 1979.

FAYYAD, U. M. et al. Advanced in Knowledge and Data Mining. AAAI/MIT Press, 1996.

GIARRATANO, Riley. Expert System - Principles and Programming. PWS Publishing Company, 1994.

GOONATILAKE, S. KHEBBAL, S. Intelligent Hybrid Systems: Issues, Classifications and Future Directions (Chapter 1). Intelligent Hybrid Systems, Edited by S. Goonatilake and S. Khebbal, John Wiley \& Sons Ltd, 1995.

GREMBA, J.; MYERS, C. The IDEAL Process Model: A Practical Guide for Improvement, in: http://www.sei.cmu.edu/activitics/ideal/ideal.bridge.htmnl, [acessado em 25/08/1998].

HARANDI, M.T.; NING, J.Q. Knowledge-Based Program Analysis. IEEE Software, v. 7, n. 1, p. 74-81, 1990.

HERBANE, C. Knowledge Acquisition: Techniques in and barries to Knowledge Acquisition, http://osiris.sund.ac.uk/-cs0che/chweb/paper2.htm, [acessado em 20/11/1997].

JOHNSON, W.L. Understanding and Debugging Novice Programs. Artificial Intelligent, v. 42, n. 1, p. 51-97, 1990.

JONATHAN, B.; BREUER, P.; LANO, K. A Compendium of Formal Techniques for Software Maintenance. Software Engineering Journal, v. 8, n. 5, p. 253-262, 1993.

JUBILEU, A. P.; PUGLIESI, J. B.; REZENDE, S. O.; SANCHES, R. Proposta de um Processo para a Aquisiçăo de Conhecimento Explícito. Relatórios Técnicos - Instituto de Ciências Matemáticas de São Carlos, $n^{\circ} 77$, agosto de 1998.

KHABAZA, I. Maintenance, Validation, and Documention of software Systems: 'REDO'-ESPRIT P2487. In CASE '89: Proc. of the Third International Workshop on Computer-Aided Software Engineering, British Computer Society, p. 221-222, 1989.

$\mathrm{KCl}$ - Kanten Communications International. The Basic Rules of Brainstorming, http://www.kanten.com/RBWV/bsrules.html, [acessado em 19/05/1999]. 
(Kidd, 1987)

(Leite, 1997)

(Letovsky, 1987)

(Littman et al., 1987)

(Mayrhauser, 1995)

(Mayrhauser, 1996)

(McGraw \& Briggs, 1989)

(Nakazato, 1994a)

(Nakazato, 1994b)

(Nakazato, 1994c)
KIDD, A.L. Knowledge Acquisition for Expert Systems. Plenum Press - New York and London, 1987.

LEITE, J. C. S. P. Tutonial: Utilizando Cenánios para o Desenvolvimento de Sistema Orientado a Objetos. In: XI SBES Simpósio Brasileiro de Engenharia de Software, Fortaleza/CE, 14 outubro 1997.

LETOVSKY, S. Cognitive Processes in Program Comprehension. The Joumal of Systems and Software, v. 7, p. 325-339, 1987.

LITTMAN, D.C. et al. Mental Models and Software Maintenance. The Joumal of Systems and Software, vol 7, p. 341-355, 1987.

MAYRHAUSER, A.V. Program Comprehension During Software Maintenance and Evolution. IEEE Computer, v. 28, n. 8, p. 44-55, august, 1995.

MAYRHAUSER, A.V. Identification of Dynamic Comprehension Processes During Large Scale Maintenance. IEEE Transactions on Software Engineering, v. 22, n. 6, p. 424-437, june, 1996.

McGRAW, K.L.; BRIGGS, K.H. Knowledge Acquisition - Principles and Guidelines. Prentice-Hall, 1989.

NAKAZATO, K.; MALDONADO, J. C.; FABBRI, S. C. P. F; MASIERO, P. C. Aspectos teóricos e de implementação de critérios de geração de sequências de teste baseados em máquinas de estado finito. Relatórios Técnicos - Instituto de Ciências Matemáticas de São Carlos (USP), n² 25, outubro 1994.

NAKAZATO, K.; MALDONADO, J. C.; FABBRI, S. C. P. F.; MASIERO, P. C. Propriedades de máquinas de estado finito relevantes para critérios de geração de seqüências de teste. Relatónios Técnicos - Instituto de Ciências Matemáticas de São Carlos (USP), $n^{\circ} 27$, outubro 1994.

NAKAZATO, K.; MALDONADO, J. C.; FABBRI, S. C. P. F.; MASIERO, P. C. Sequências básicas de máquinas de estado finito: aspectos teóricos e de implementação. Relatónios Técnicos Instituto de Ciências Matemáticas de São Cartos (USP), $n^{\circ} 28$, outubro 1994. 
(Nakazato, 1995)

NAKAZATO, K. K. Módulo de Geração de Seqüências de Teste baseada em Máquinas de Estado Finito. Dissertação apresentada ao Instituto de Ciências Matemáticas de São Carlos - USP, como parte de requisitos para obtenção do título de Mestre, 1995.

(Navathe \& Elmasri, 1989)

(Oman et al., 1990)

(Osbome, 1999)

(Ourston, 1989)

(Oxford, 1986)

(Penteado, 1996)

(Penteado et al., 1996)

(Pressman, 1995)

(Quinaia, 1998)

(Rekoff, 1985)

(Rezende \& Pugliesi, 1998)
NAVATHE, S. B.; ELMASRI, R. Fundamentals od Database Systems. Benjamim/Cummings Publishing Company, Inc, 1989.

OMAN, P.W.; et al. The Book Paradigm for Improved Maintenance. IEEE Software, v. 7, n. 1, p. 39-45, january, 1990.

OSBORNE. Generic Brainstoming Rules, Henley Management College, http://www.henlevmc.ac.uk/rcsearch/creat01.him, [acessado em 19/05/1999].

OURSTON, D. Program Recognition. IEEE Expert, v. 4, n. 4, p. 36$49,1989$.

Dictionary of Computing Oxford University Press, 1986.

PENTEADO, R. D. Um método para Engenharia Reversa Orientada a Objetos. Tese de Doutorado, Instituto de Física de São Carlos, Universidade de São Paulo, Săo Carlos, 1996.

PENTEADO, R. D.; GERMANO, F.; MASIERO, P. C. Melhoria da Manutenibilidade de Software Legado com Base em Engenharia Reversa. In: VII CITS - Conferência Intemacional de Tecnologia de Software: Qualidade de Software, Curitiba-PR, p. 155-169, junho, 1996.

PRESSMAN, R.S. Engenharia de Software. Traduçäo José Carlos Barbosa dos Santos; revisão técnica José Carlos Maldonado, Paulo Cesar Masiero, Rosely Sanches - Săo Paulo: Makron Books, 1995.

QUINAIA, M. A. Diretrizes para Reengenharia de Sofware com características de software legado. Dissertação apresentada ao instituto de Ciencias Matemáticas de Săo Carlos - USP, como parte de requisitos para obtenção do titulo de Mestre, junho de 1998.

REKOFF, M.G. On Reverse Engineering. IEEE Transactions on Systems, Man, and Cybemetics, v. 15, n. 2, 1985.

REZENDE, S. O; PUGLIESI, J. B. Aquisiçăo de Conhecimento Explícito ou Manual. Notas do ICMSC, n. 37, março, 1998. 
(Rich \& Knigth, 1993) $\quad$ RICH, E; KNIGTH, K. Inteligência Artificial. Makron Books, $2^{\mathrm{a}}$ ed.; 1993.

(Robson et al., 1991) ROBSON, D. J.; BENNETT, K. H.; CORNELIUS, B. J.; MUNRO, M. Approaches to Program Comprehension. The Journal of Systems and Software, v. 14, n. 2, p 79-84, february, 1991.

(Ross, 1988)

(Sage, 1995)

ROSS, R.G. Entity Modeling: Techniques and Application. Data Research Group, 1988.

SAGE, A. P. Systems Engineering and Systems Management for Reengineering. Journal Systems and Software, v. 30, $n^{\circ} 1, p$ 13750, 1995.

(Scott et al., 1991)

SCOTT, A. C.; CLAYTON, J. E.; GIBSON, E. L. A Practical Guide to Knowledge Acquisition. Addison-Wesley, 1991.

(Seviora, 1987)

(Silicon, 1999)

(Spivey, 1988)

(Stephen \& Lynn, 1995) STEPHEN, R. M.; LYNN, M. M. Software Migration and Reengineering: A Pilot Project in Reengineering. Joumal Systems and Software, v. 30, n० 1, p 137-50, 1995.

(Turine \& Masiero)

TURINE, M. A. S; MASIERO, P. C. Especificaçăo de Requisitos: uma introdução. Relatónios Técnicos - Instituto de Ciências Matemáticas de São Carlos - USP, nº 39, 1996.

(Tuthill, 1990)

TUTHILL, G. S. Knowledge Engineering: Concepts and Practices for Knowledge-Based System. TAB - Books Inc., 1990.

Waters \& Chikofsky, 1994)

(Wilson, 1999)

(Wong et al., 1995)

WATERS, R. C.; CHIKOFSKY, E. J. Reverse Engineening: Progress Along Many Dimensions. Communications of the ACM, $v$. 37, n. 5, p. 23-4, 1994.

WILSON, Michael. Knowledge Acquisition: The current position. Science and Engineering Research Council. Rutherford Appleton Laboratory, in: http://www.dci.clrc.ac.uk/AclivityPublications/92, [acessado em 14/01/1999].

WONG, K. et al. Structural Redocumentation: A Case Study. IEEE Software, v. 12, n. 1, p. 46-54, 1995. 
(Yägiz, 1999)

YÄGIZ, Ömer. Certificate Program in Advanced Management Studies. Brainstorming - A Planning and Problem Solvind Technique. Department of Management METU, http://www.man.metu.edu.tr/yagiz/sertifika/slides/brainsto/sld00l.htm, [acessado em 19/05/1999]. 


\section{ANEXO A}

Malha de Dados Resultante do Exemplo Northwind Ferramenta Rules Visualizer 

selection
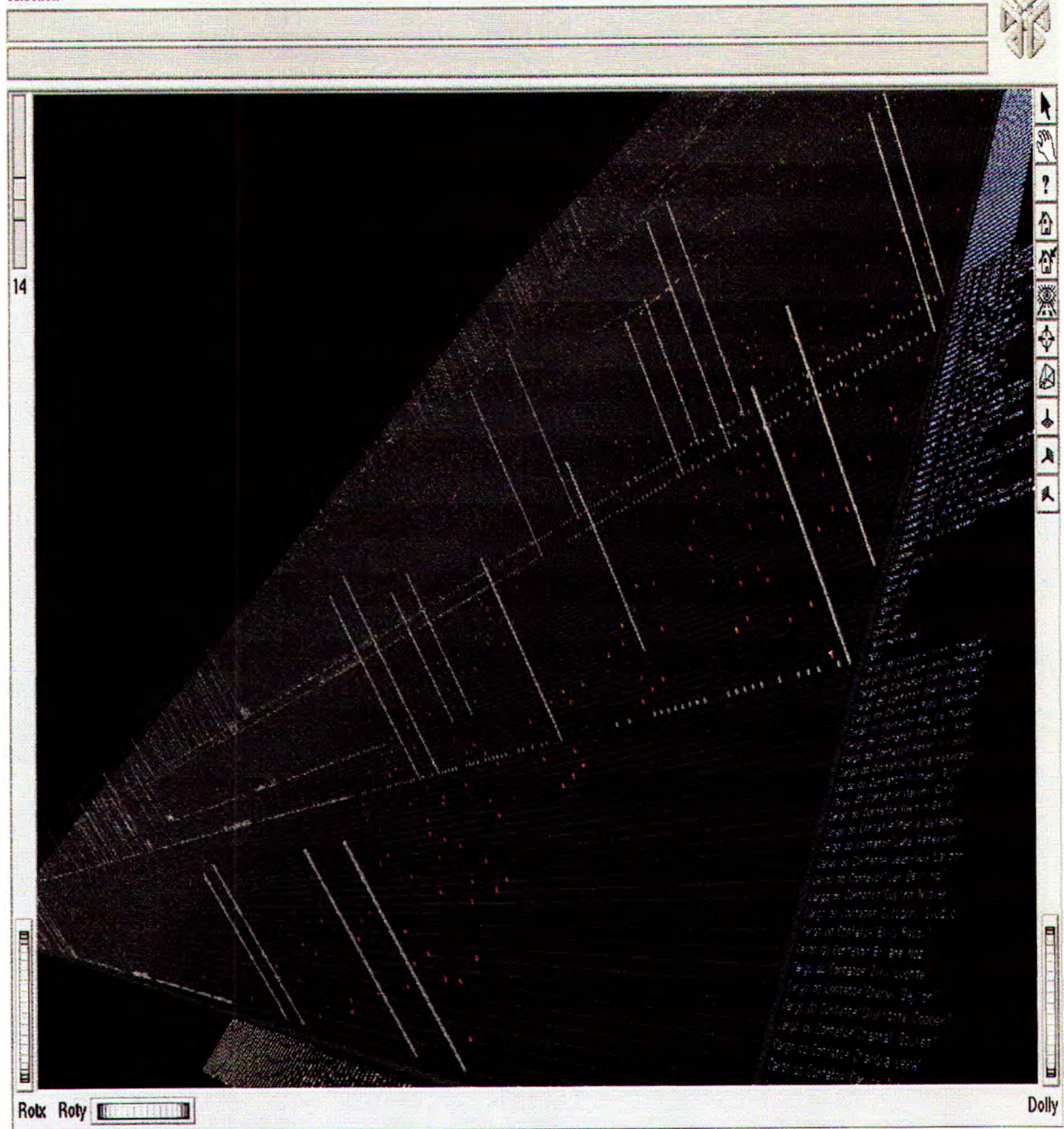

Disk Height: expected confidence

Disk Color: confidence 0.00100 .0

Bar Height: support

Bar Color: litt 1.0020 .0039 .0077 .00 


\section{ANEXO B}

DAD da Operação "Inserção de Chamadas Técnicas" e DAD da Operação "Alteração/Exclusão de Chamadas Técnicas" 



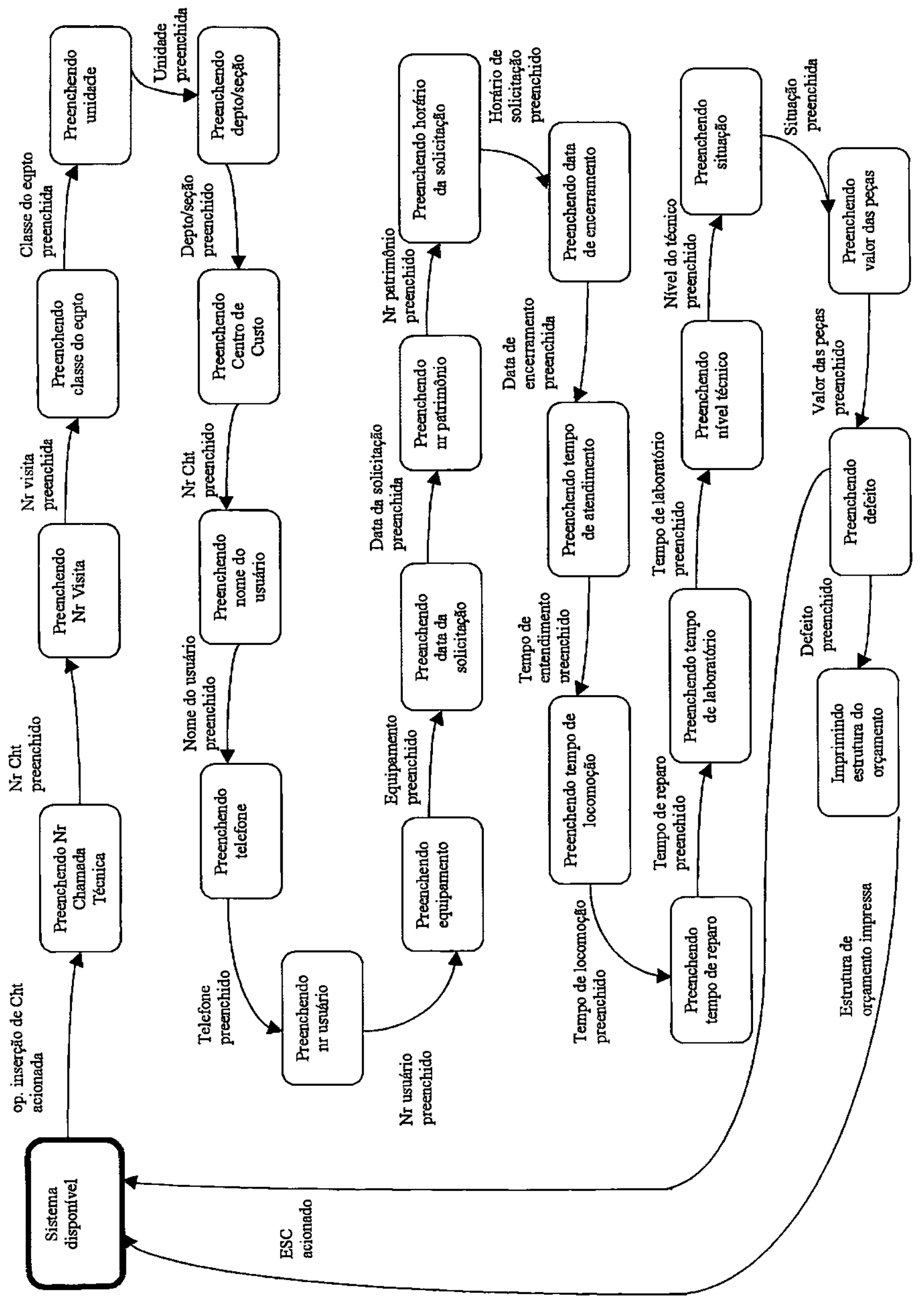




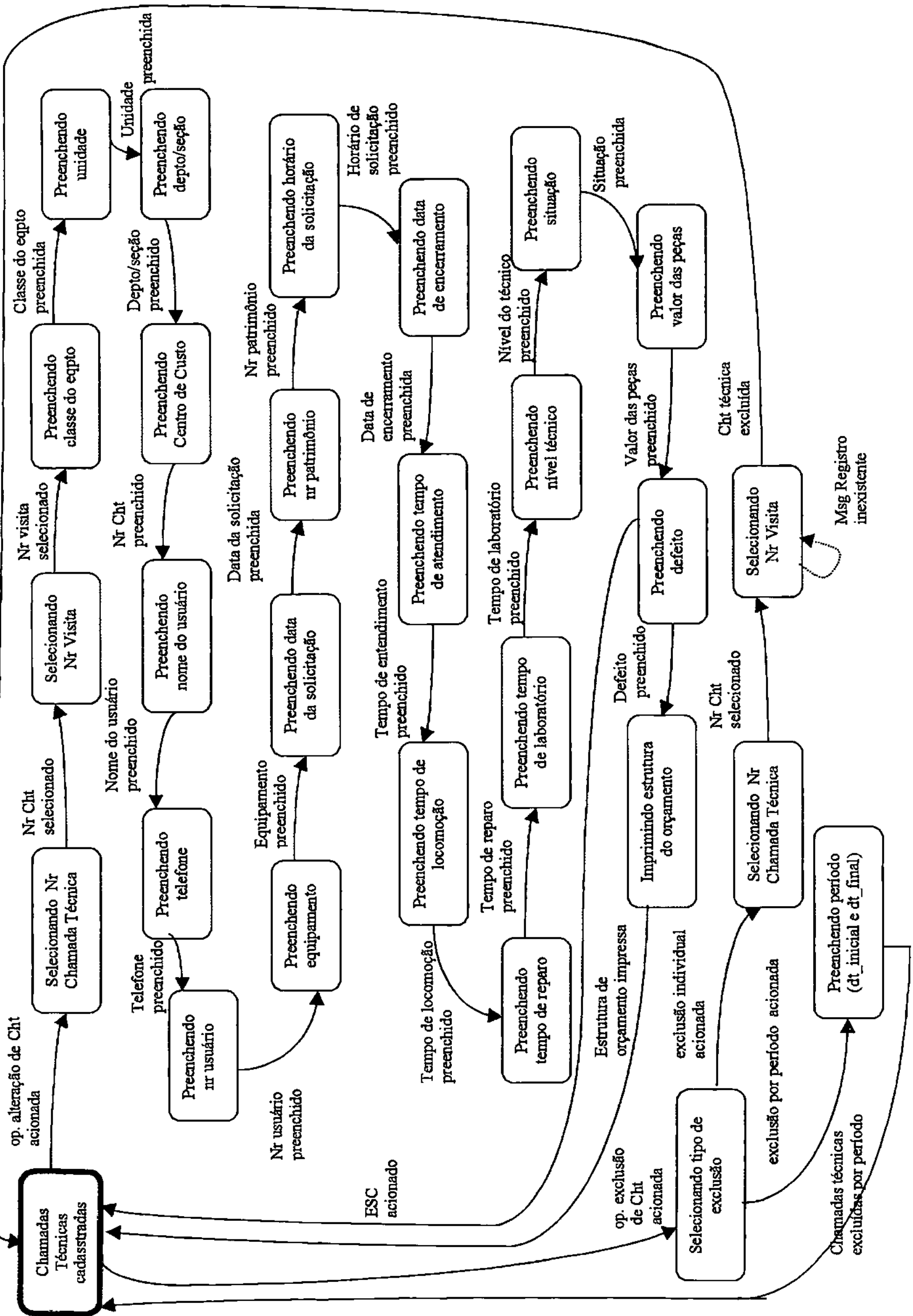

